\title{
Agronomy and photosynthesis physiology of hemp (Cannabis sativa L.)
}

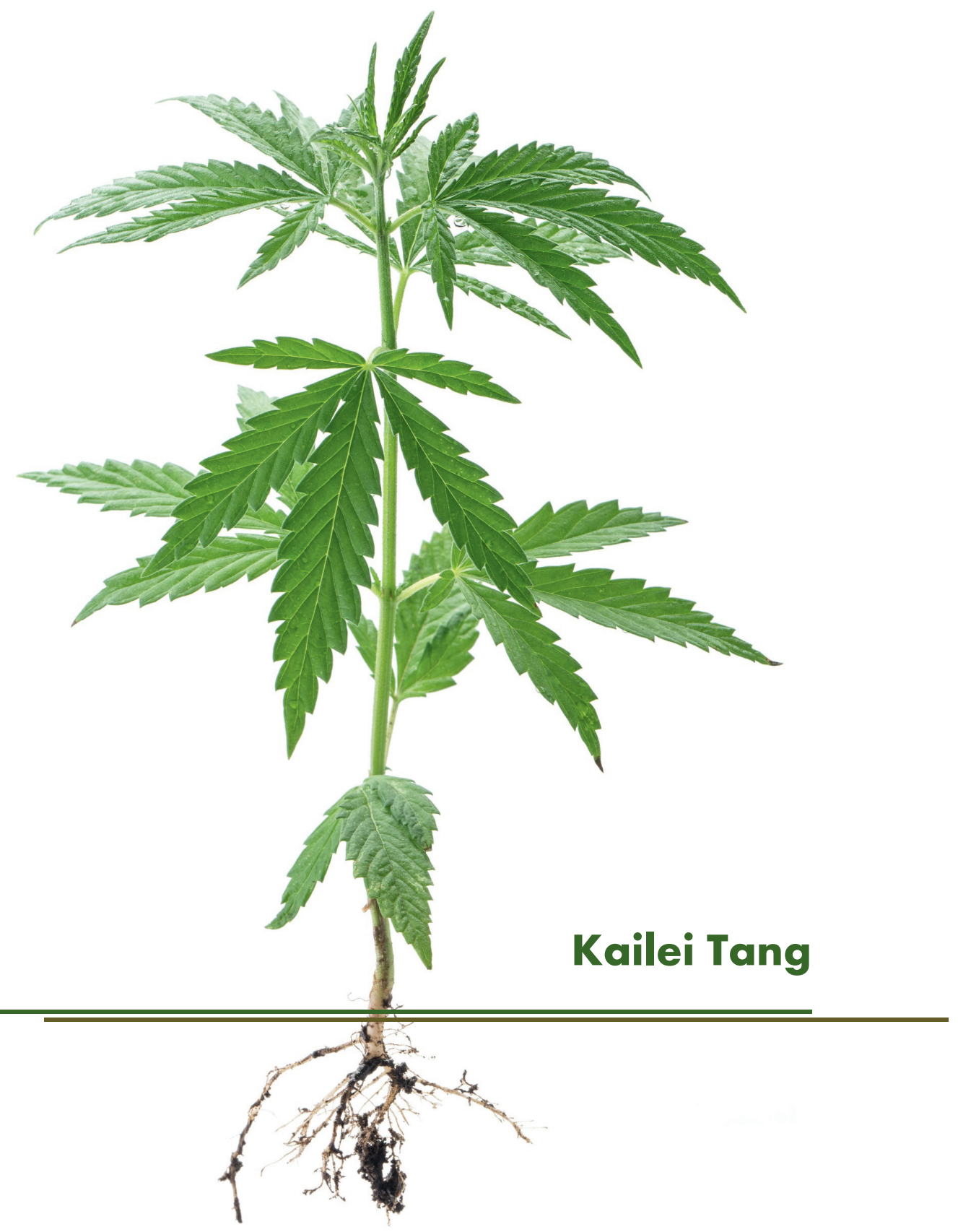




\section{Propositions}

1. Hemp has a great potential for the bio-economy.

(this thesis)

2. Growing hemp is easy but only if the farmer chooses the right cultivar.

(this thesis)

3. Bio-economically sustainable industrial crops coupled with advanced agronomy could help to alleviate poverty in rural China.

4. Agronomic management should aim to reduce the use of agrochemicals, especially herbicides.

5. Working long hours does not help writing a $\mathrm{PhD}$ thesis.

6. Advancement of society requires the orchestrated efforts of several generations.

7. Smart devices make smart man smarter while they make dumb man dumber.

Propositions belonging to the thesis of Kailei Tang, entitled:

'Agronomy and photosynthesis physiology of hemp (Cannabis sativa L.)'.

Wageningen, March 23, 2018 
Agronomy and photosynthesis physiology

of hemp (Cannabis sativa $\mathrm{L}$. )

Kailei Tang 


\section{Thesis committee}

\section{Promotor}

Prof. Dr P.C. Struik

Professor of Crop Physiology

Wageningen University \& Research

\section{Co-promotors}

Dr X. Yin

Senior scientist, Centre for Crop Systems Analysis

Wageningen University \& Research

Dr S. Amaducci

Associate professor, Department of Sustainable Crop Production

Università Cattolica del Sacro Cuore, Italy

\section{Other members}

Prof. Dr K.E. Giller, Wageningen University \& Research

Prof. Dr S.L. Cosentino, University of Catania, Italy

Dr L.M. Trindade, Wageningen University \& Research

Dr E. Heuvelink, Wageningen University \& Research

This research was conducted under the auspices of the C.T. de Wit Graduate School for Production Ecology and Resource Conservation 


\title{
Agronomy and photosynthesis physiology of hemp (Cannabis sativa $L$.)
}

\author{
Kailei Tang
}

\section{Thesis}

submitted in fulfilment of the requirements for the degree of doctor at Wageningen University

by the authority of the Rector Magnificus,

Prof. Dr A.P.J. Mol,

in the presence of the

Thesis Committee appointed by the Academic Board

to be defended in public

on Friday 23 March 2018

at 4 p.m. in the Aula. 
Kailei Tang

Agronomy and photosynthesis physiology of hemp (Cannabis sativa L.), 174 pages.

$\mathrm{PhD}$ thesis, Wageningen University, Wageningen, the Netherlands (2018) With references, with summary in English

ISBN: 978-94-6343-884-1

DOI: https://doi.org/10.18174/434837 


\begin{abstract}
Kailei Tang, 2018. Agronomy and photosynthesis physiology of hemp (Cannabis sativa L.). PhD thesis, Wageningen University, Wageningen, the Netherlands, 174 pp.

Hemp (Cannabis sativa L.) is a sustainable high-yielding crop that delivers valuable fibres, seeds and psychoactive substances. However, there is a lack of field experimental data on the cultivation of hemp because its production was largely abandoned in the last century. Hemp is now considered as an ideal crop to produce innovative biomaterials, and in particular, the dualpurpose hemp production (fibre + seed) is now the norm in European countries, driven by the shift of a rapidly expanding market for hemp seeds coupled with lower quality fibre requirements for innovative biomaterials. This study brought new information on the agronomy and photosynthesis physiology for the resurging production of hemp, particularly for dualpurpose production in Europe.
\end{abstract}

The effects of important agronomic factors, i.e. cultivar, planting density, and nitrogen fertilization, on the performance of the hemp crop were investigated under contrasting European environments. Based on the experimental data, for dual-purpose hemp production, a planting density of $90-150$ plants $\mathrm{m}^{-2}$ is recommended for a monoecious cultivar that gives a long vegetative phase while leaving enough time for seed growth. A nitrogen fertilization rate of $60 \mathrm{~kg} \mathrm{~N} \mathrm{ha}^{-1}$ was generally sufficient in the tested environments whereas further optimization of nitrogen fertilization requires accurate and precise assessment of plant nutritional status. To facilitate assessing plant nutritional status, a critical nitrogen dilution curve was determined for hemp.

The responses of leaf photosynthesis to nitrogen content and temperature were quantified using a biochemical model of $\mathrm{C}_{3}$ leaf photosynthesis, based on a complete set of photosynthetic measurements for hemp leaves. Then, by combining measurements and modelling, an upscaling was made from the leaf to the canopy level to analyse hemp's photosynthetic nitrogen-use efficiency $(N U E)$ and water-use efficiency $(W U E)$ in response to water and nitrogen supply. The effect of nitrogen supply level on hemp's $N U E$ and $W U E$ was largely determined by its effect on canopy size or leaf area index $(L A I)$. The effect of short-term water stress on $W U E$ and $N U E$ was reflected in the stomatal regulation, whereas long-term water stress enhanced leaf senescence, reduced $L A I$ but retained total canopy nitrogen content, and thus resulted in a further increase in $W U E$. 
Findings in this thesis provided an improved understanding of the agronomy and photosynthesis physiology of hemp, particularly in relation to the dual-purpose production of hemp in Europe. Such understanding not only provides additional evidence that hemp can be grown as a sustainable crop over a wide range of climatic and agronomic conditions, but also provides essential information for parameterizing crop growth models. Prospects for further research were discussed in view of using the findings in this thesis in combination with a crop growth model to develop strategies for optimization of hemp cultivation and breeding.

Keywords: canopy; critical dilution curve; cultivar; density; fibre; hemp (Cannabis sativa L.); leaf; modelling; nitrogen; nitrogen use efficiency; phenology; photosynthesis; seed; stem; temperature; water; water use efficiency. 


\section{Contents}

Chapter 1 General introduction 1

Chapter 2 Comparing hemp (Cannabis sativa L.) cultivars for dual-purpose 15 production under contrasting environments

Chapter 3 A comprehensive study of planting density and nitrogen fertilization 47 effect on dual-purpose hemp (Cannabis sativa L.) cultivation

Chapter 4 Hemp (Cannabis sativa L.) leaf photosynthesis in relation to nitrogen 83 content and temperature: implications for hemp as a bio-economically sustainable crop

Chapter 5 Water- and nitrogen-use efficiencies of hemp (Cannabis sativa L.) based 115 on whole-canopy measurements and modelling

Chapter 6 General discussion 149

$\begin{array}{ll}\text { Summary } & 165\end{array}$

$\begin{array}{ll}\text { Acknowledgements } & 169\end{array}$

$\begin{array}{ll}\text { PE\&RC Training and Education Statement } & 171\end{array}$

$\begin{array}{ll}\text { Curriculum vitae } & 173\end{array}$

$\begin{array}{ll}\text { Funding } & 174\end{array}$ 



\section{Chapter 1}

General introduction 
Chapter 1

\begin{abstract}
This chapter first provides a brief introduction to the hemp (Cannabis sativa L.) plant and the state of knowledge on hemp agronomy and crop physiology. Subsequently, the aim of the thesis, the methodological framework and an overall thesis structure are outlined.
\end{abstract}




\subsection{Hemp plant}

Hemp (Cannabis sativa L.) is an annual dicotyledonous angiosperm plant belonging to the Cannabaceae family and the Cannabis genus. Hemp seedlings have two sessile seed leaves but all true leaves have a $1-3 \mathrm{~cm}$ petiole. The first pair of true leaves have a single narrowly elliptic blade with serrate margins. A leaf from the second pair has $3-13 \mathrm{~cm}$ palmately composed serrate leaflets. Each leaflet has a length of 5-15 cm and a width of 1-2 cm. In young hemp plants the number of leaflets per compound leaf increases progressively and the phyllotaxis is opposite, but as flowering begins, the number of leaf leaflets per compound leaf declines and phyllotaxis changes from opposite to alternate.

The stem of the hemp plant is hollow. Its size at maturity is very variable. At high planting densities hemp plants develop thinner stems with fewer branches whereas at low density the plants are highly branched with much thicker stems. Technically hemp stems can be separated into two components: the stem tissues outside the vascular cambium (bark) and the stem tissues inside the vascular cambium (core). The bark, accounting for $24-47 \%$ of whole stem weight (De Meijer, 1994), consists of the epidermis, the cortex and the phloem. In the phloem are sieve tubes and primary bast fibres, arising from the prodesmogen. The primary fibres have a length ranging between $3 \mathrm{~mm}$ and $55 \mathrm{~mm}$ with a mean of 20-28 $\mathrm{mm}$ (Amaducci et al., 2005). In old hemp plants, the phloem may contain secondary bast fibres arising from the cambium. The mean length of secondary bast fibres is about $2 \mathrm{~mm}$ (Amaducci et al., 2005). Wood core mainly consists of short fibres with length of about $5 \mathrm{~mm}$ (Li et al., 2013).

Naturally hemp is dioecious, meaning that male and female flowers develop on separate plants. The two sexes are morphologically indistinguishable before the development of inflorescences, but in the generative phase sexual dimorphism is extremely pronounced. Male plants have a loose and branched inflorescence in the top of the plant, with few or no leaves. Each male flower has five white to yellowish-green petals about $5 \mathrm{~mm}$ long, and five stamens which at maturity release abundant yellow pollen for wind-pollination. The male plants die after flowering. Female plants have a compacted and leafy inflorescence in the top of the plant. Female flowers, that are surrounded by green bracts, are only recognizable after the emission of stigmas that are only a few millimetres long. In modern times, monoecious varieties, meaning that male and female flowers develop on the same plant, have been selected and cultivated (Salentijn et al., 2015).

The seed of commerce is an achene with a hard shell, tightly covered by the thin wall of the 
ovary. The seed is ellipsoid, slightly compressed, smooth, 2-6 mm in length and 2-4 $\mathrm{mm}$ in diameter. It is light brown to dark grey, in some cases mottled, containing about $28 \%$ oil and $26 \%$ crude protein (Vonapartis et al., 2015).

It should be mentioned that industrial hemp generally contains a low percentage of $\Delta^{9}$ tetrahydrocannabinol (THC, the principal intoxicant cannabinoid found in marijuana). Current laws in many countries constrain cultivation of hemp cultivars bearing THC above a (low) threshold. The threshold is arbitrarily set at $0.3 \%$ in China and Canada, although a THC level of $1 \%$ is considered a minimum value to elicit an intoxicating effect (Grotenhermen \& Karus, 1998). In the European Union (EU), the THC threshold is even down to $0.2 \%$ in the interest of safety. However, there is an appeal to bring the European threshold up to $0.3 \%$ (Carus et al., 2017).

\subsection{Growing interest for multi-purpose hemp cultivation}

In recent years, the pressing need for renewable resources and sustainable materials has fuelled a renewed interest in natural plant fibres. Actual markets of natural plant fibres are dominated by cotton that, on average, accounts for over $70 \%$ of the global natural fibre production (20102014) (FAOSTAT, 2017). However, cotton poses particular concerns with regard to sustainability as it has one of the worst environmental footprints of any crop, with particularly high demands for irrigation and agricultural chemicals (Pfister et al., 2011). An increasing concern on sustainable development of agricultural bio-economy appeals for cultivation of profitable fibre crops with positive environment effects.

Hemp has potential to produce up to $25 \mathrm{Mg} \mathrm{ha}^{-1}$ biomass yield at relatively low inputs (Struik et al., 2000) and it was said to improve soil structure, suppress weeds effectively, and to be virtually free from disease or pests (Desanlis et al., 2013). Moreover, traditionally cultivated mainly for the production of textiles and ropes, hemp is now considered as an ideal crop to produce innovative biomaterials. Its stems contain high-quality cellulose (De Meijer \& van der Werf, 1994); its seeds contain healthy oil (Leizer et al., 2000); high added-value compounds can be recovered from the female inflorescence and from threshing residues after harvesting seeds (Calzolari et al., 2017; Bertoli et al., 2010). Examples of actual and potential innovative uses of hemp plant are numerous (Carus et al., 2013). Hemp stem can be used as raw materials for making paper (Van der Werf et al., 1994a); hemp fibre can be used as reinforcement in composites materials, to produce insulation mats (Grohe, 2004) and car interior panels (Holbery \& Houston, 2006); hemp shives alone (Jarabo et al., 2012) or shives together with bast fibre 
(de Bruijn et al., 2009) mixed with a binder (lime, clay, plaster, etc.) are used to form hemp concrete; hemp seeds can be used as food, feed (Callaway, 2004) and to make cosmetics (Sapino et al., 2005). A summary of the many applications of hemp in Europe is presented in Figure 1.1.

Hemp is one of the oldest crops known to man that is estimated to have begun with a first harvest around 8500 years ago (Fike, 2016). As one of the most important fibre crops, hemp cultivation peaked between the $16^{\text {th }}$ and the $18^{\text {th }}$ century. Its cultivation declined in the last

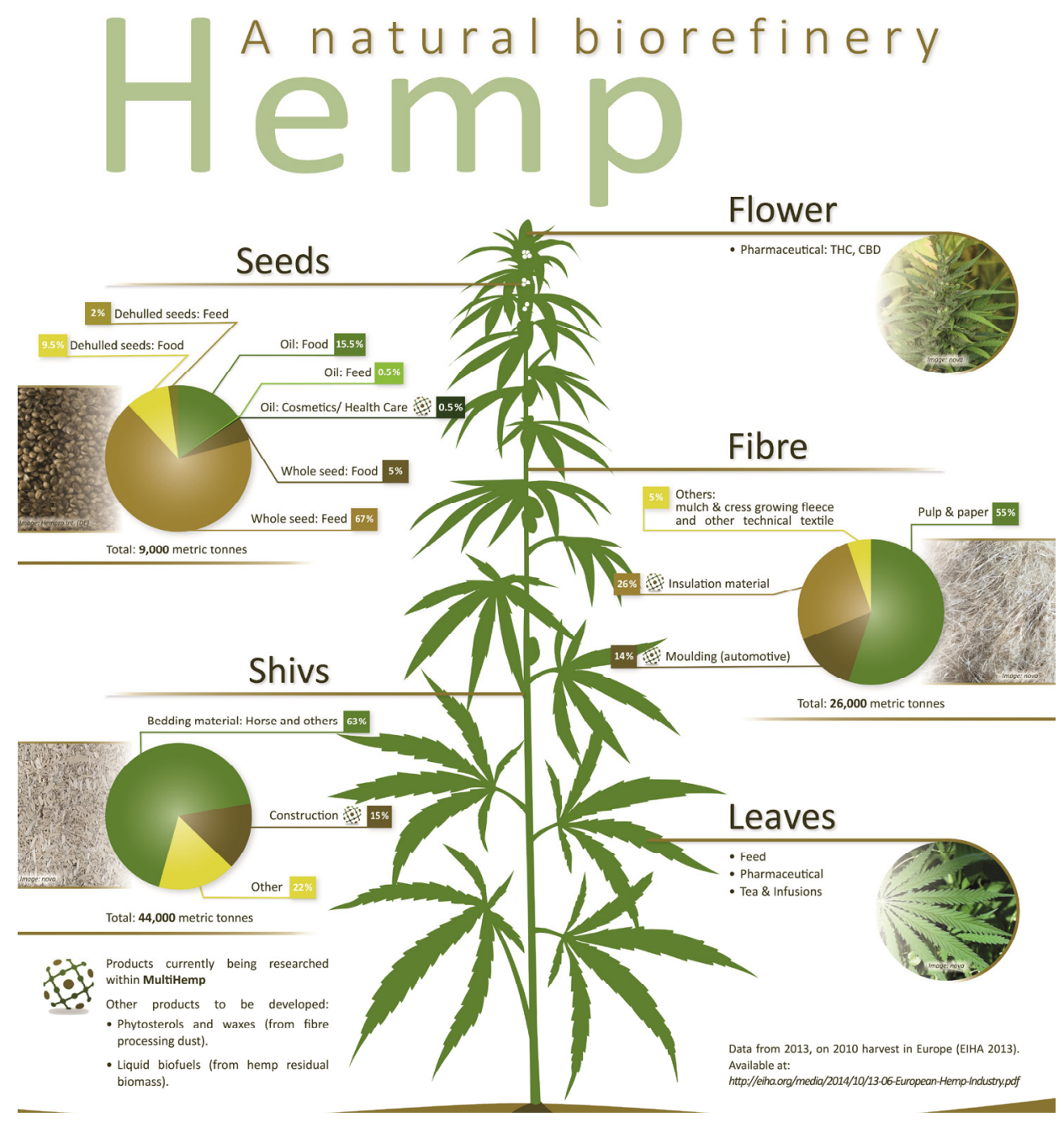

Figure 1.1 Hemp: a natural bio-refinery. Reprinted from a poster produced during EC funded Multihemp project (www.multihemp.eu). 
century and was displaced largely by cotton and synthetic fibres (Allegret, 2013). This decline was hastened by concerns over the use of its illegal narcotics.

According to FAOSTAT, there was about 70,000 ha year ${ }^{-1}$ of hemp cultivated worldwide (excluding the acreage in Canada) in the last decade (2004-2014). The main cultivation areas of hemp were North Korea, China, Canada and the EU. The area of hemp in North Korea was estimated at about 20,000 ha year ${ }^{-1}$ mainly for the purpose of fibre production. In China, hemp was cultivated on about 18,000 ha year-1, with about half of the area for the production of textile fibre in the North-eastern, Central-eastern and South-western parts while another half of the area for seed production, mainly in Northern China.

In recent years, the innovative uses of hemp materials and the increasing concern on sustainable development of the agricultural bio-economy have encouraged and sustained a development of the hemp industry that supports the cultivation, processing and use of hemp and its products, particularly in Canada and Europe (www.eiha.org). The cultivation of hemp in Canada and in the EU was reauthorized in the 1990s. Canadian hemp production has been steadily increasing since 2008 after some market adjustments during the early years. At present, licensed hemp cultivation in Canada reaches more than 20,000 ha year ${ }^{-1}$, almost exclusively for the production of seeds (Cherney \& Small, 2016). A fast growth of hemp cultivation was also seen in Europe, where hemp acreage increased from 8,000 ha in 2011 to more than 33,000 ha in 2016 (Carus \& Sarmento, 2016). In Europe, the main cultivation areas are in France, the Netherlands, the Baltic Countries and in Romania. However, many other European countries started or expanded their hemp cultivation, mainly for dual-purpose hemp production: for the seeds and for the fibre. The dual-purpose hemp production in Europe is driven by the shift of a fast expanding market for hemp seeds coupled with lower quality fibre requirements for innovative biomaterials (Amaducci et al., 2015).

\subsection{Rapidly improved hemp production}

Despite the renewed interest in hemp's obvious potential as a biorefinery crop, hemp remains poorly developed (Wirtshafter, 2004), as a consequence of the declination of its production in the last century when intensive breeding and agronomic programmes have driven great improvements in major crops. Since 2012, a comprehensive 4-year study, the European project Multihemp (http://multihemp.eu/), covered the levels from molecular genetics through to end product demonstration, with the aims to have significant impacts from both scientific and economic aspects by building on fundamental scientific understanding in the development of 
hemp raw materials through to providing the basis for innovations in the areas of crop breeding, agronomy and harvesting, and biorefining. The ambition of Multihemp was to develop an integrated hemp-based biorefinery in which improved feedstock is subjected to efficient and modular processing steps to provide fibre, oil, construction materials, fine chemicals and biofuels using all components of the harvested biomass, and to generate new opportunities within the developing knowledge based bio-economy. This thesis reports on a major part of the research activities on the agronomy and photosynthesis physiology of hemp carried out within the Multihemp framework, paying particular attention to the effects of genotype, environment and management on dual-purpose hemp production (fibre + seed). It also investigates the physiological basis of hemp's high resource-use efficiencies (RUE). Such understanding will help to parameterize a generic crop growth model for hemp to develop strategies for optimization of cultivation and breeding in hemp.

\subsubsection{Understandings of the effects of genotype, environment and management on dual- purpose hemp production}

Knowledge of genotype, environment and management effects on hemp production is of paramount importance for developing strategies to optimize cultivation and breeding in hemp.

The number of registered cultivars has risen rapidly since the 1990s when hemp cultivation was progressively authorized throughout the EU. In 2016, there were more than 60 hemp cultivars registered in the common catalogue of varieties of agricultural plant species (https://ec.europa.eu/). These cultivars differ not only in many characters, such as stem fibre content and sex type (Höppner \& Menge-Hartmann, 2007), but also in their response to the growing environment (Legros et al., 2013). Cultivars bred at low latitudes show a very long vegetative phase or even fail to reach flowering when cultivated at higher latitudes, which not only results in low seed yield but also in frequent frost damage affecting the fibre quality. In contrast, cultivars bred at high latitudes have very short vegetative phases and limited biomass production when cultivated in southern environments (Amaducci et al., 2015). Therefore, there is a need to characterize currently available cultivars or potential breeding lines to identify their suitability for specific environments and end-use destinations.

In the absence of water limitation, management factors that have a major influence on hemp cultivation, in terms of quality and/or quantity of products, are planting density and nitrogen fertilization. While the effects of these factors on hemp cultivation have been subjected to a number of research studies (Finnan \& Burke, 2013, Westerhuis et al., 2009; Amaducci et al., 
2002; Struik et al., 2000), their effects on both stem and seed yields have not been properly addressed so far, and important agronomic information such as optimal planting and crop nitrogen demand has not been made available for growing hemp as a dual-purpose crop.

\subsubsection{Understandings of hemp's resource-use efficiency}

Besides a high yield potential, an important characteristic for an industrial crop, adapted to modern sustainable production systems, is the ability to use resources efficiently. The higher is the RUE of a crop, the higher is the yield for a given level of the resource and the lower is the impact on the environment.

Hemp RUE depends on growth environment and plant physiological state (Amaducci et al., 2015). The most important physiological process determining RUE is photosynthesis, at both leaf and canopy levels. Leaf photosynthetic capacity is strongly related to leaf nitrogen content (Sinclair \& Horie, 1989). Studies of hemp photosynthesis in response to nutritional status are generally scarce although increased hemp leaf nitrogen content (Marija et al., 2011; Ivanyi \& Izsaki, 2009) and biomass yield (Finnan \& Burke, 2013) were reported when nitrogen was applied. Moreover, hemp RUE was widely reported to decrease after flowering (Struik et al., 2000, Van der Werf et al., 1994b) and this decrease was proposed to be a result of leaf senescence (Van der Werf et al., 1996). In senescent leaves, chlorophyll is degraded and photosynthesis related enzymes and other proteins are broken down into amino acids (Chiba et al., 2003) that are exported as a source of nitrogen transfer to seeds. Literature evidence that the photosynthetic rate of hemp decreases as a result of nitrogen loss resulting in lower RUE is lacking for hemp. On the other hand, leaf photosynthesis has been studied in detail for major crops (Sinclair \& Horie, 1989; Yin et al., 2009), and a biochemical leaf photosynthesis model has been developed (Farquhar et al., 1980). The experimental protocols for parameterizing this model have also been standardised (Yin et al., 2009; Sharkey et al., 2007). Therefore, there is an excellent opportunity to fully understand hemp leaf photosynthesis and its variation in response to growth environment, developmental stage and nutritional status at leaf level.

RUE at leaf level may not represent that at canopy level (Tomás et al., 2012) because the latter also depends on canopy size and the distributions of light intensity and leaf nitrogen concentration within canopy. On the basis of a thorough understanding of the underlying mechanisms of leaf and canopy photosynthesis, models have been developed to quantify the response of canopy photosynthesis to varying micro-environments under different physiological conditions (Hikosaka et al., 2016). Such canopy models are capable of simulating 
instantaneous canopy gas exchange measurements by micro-meteorological techniques (Wright et al., 2013; Leuning et al., 1998) and in canopy chambers (Müller et al., 2005). In this context, the RUE of hemp at canopy level could be quantitatively assessed using a well-defined canopy model.

\subsection{Objectives of the present study}

The overall objective of this study is to obtain an enhanced understanding of the agronomy and photosynthesis physiology for dual-purpose production of hemp (fibre + seed) in Europe. To this end, studies are defined to assess the effects of genotype, environment and management on the functioning of hemp crops, and to elucidate the physiological basis of hemp resource-use efficiencies. The specific objectives are:

1) to compare hemp cultivars for dual-purpose production under contrasting environments;

2) to assess the effects of planting density and nitrogen fertilization on hemp production, and to quantify the optimal planting density and nitrogen demand of hemp as a dual-purpose crop;

3) to quantitatively analyse the photosynthetic capacities of hemp leaf under varying physiological and environmental conditions;

4) to upscale hemp photosynthesis from leaf level to canopy and to assess water- and nitrogen-use efficiencies of hemp crop;

5) to discuss potential strategies to develop cultivars and cropping practices for dual-purpose hemp production.

\subsection{Structure of this thesis}

This thesis consists of six chapters. Chapter 1 (this chapter) provides a brief introduction to the hemp plant and the state of knowledge on hemp agronomy and photosynthesis physiology. Knowledge gaps on the effects of genotype, environment and management on hemp production and on hemp's RUE are identified, and a list of objectives is presented. Chapter 2 evaluates the genotypic variation of hemp productivity over a wide range of environments, and potential strategies to develop cropping practices and new cultivars for dual-purpose hemp production are discussed thereof. Chapter 3 assesses the effects of planting density and nitrogen fertilization on hemp stem and seed productivities. Specific effort is dedicated to the determination of optimal planting density for dual-purpose hemp production and nitrogen demand of hemp crops during the growing season. Chapters 4 and 5 aim to understand the 
physiological basis of hemp's high RUE by analysing leaf and canopy photosynthesis, respectively, of hemp grown under varying physiological and environmental conditions. Chapter 6 provides a synthesis of the main findings and discusses the potential role of hemp in sustainable development of agricultural bio-economy. Finally, the current state and prospects of hemp research are discussed.

\section{References}

Allegret, S. (2013) The history of hemp. In: Hemp: industrial production and uses (eds Allegret, S., Bouloc, P. and Arnaud, L.), pp. 4-26. CPi Group (UK) Ltd, Croydon, UK.

Amaducci, S., Errani, M. and Venturi, G. (2002) Response of hemp to plant population and nitrogen fertilisation. Italian Journal of Agronomy, 6, 103-111.

Amaducci, S., Pelatti, F. and Bonatti, P.M. (2005) Fibre development in hemp (Cannabis sativa L.) as affected by agrotechnique: preliminary results of a microscopic study. Journal of Industrial Hemp, 10, 31-48.

Amaducci, S., Scordia, D., Liu, F. et al. (2015) Key cultivation techniques for hemp in Europe and China. Industrial Crops and Products, 68, 2-16.

Bertoli, A., Tozzi, S., Pistelli, L. et al. (2010) Fibre hemp inflorescences: From crop-residues to essential oil production. Industrial Crops and Products, 32, 329-337.

Callaway, J.C. (2004) Hempseed as a nutritional resource: An overview. Euphytica, 140, 6572 .

Calzolari, D., Magagnini, G., Lucini, L. et al. (2017) High added-value compounds from Cannabis threshing residues. Industrial Crops and Products, 108, 558-563.

Carus, M., Karst, S., Kauffmann, A. et al. (2013) The European hemp industry: cultivation, processing and applications for fibres, shivs and seeds. European Industrial Hemp Association (EIHA), Hürth, Germany, European. Available at (2017, November 29): http://eiha.org/media/2014/10/13-06-European-Hemp-Industry.pdf

Carus, M. and Sarmento, L. (2016) The European hemp industry: cultivation, processing and applications for fibres, shivs and seeds. European Industrial Hemp Association (EIHA), Hürth, Germany, European. Available at (2017, November 29): http://eiha.org/media/2016/05/16-05-17-European-Hemp-Industry-2013.pdf

Carus, M., Reinders, M., Baňas, B. et al. (2017) The Cologne declaration on industrial hemp. European Industrial Hemp Association (EIHA), Hürth, Germany, European. Available at (2017, November 29): http://eiha.org/media/2017/07/17-06-06\%20EIHA\%20Colog ne\%20Declaration_final.pdf

Cherney, J. and Small, E. (2016) Industrial hemp in North America: production, politics and potential. Agronomy, 6, 58-82.

Chiba, A., Ishida, H., Nishizawa, N.K. et al. (2003) Exclusion of ribulose-1,5-bisphosphate carboxylase/oxygenase from chloroplasts by specific bodies in naturally senescing leaves of wheat. Plant Cell Physiology, 44, 914-921.

De Bruijn, P.B., Jeppsson, K-H, Sandin, K. et al. (2009) Mechanical properties of lime-hemp 
concrete containing shives and fibres. Biosystems Engineering, 103, 474-479.

De Meijer, E.P.M. (1994) Variation of Cannabis with reference to stem quality for paper pulp production. Industrial Crops and Products, 3, 201-211.

De Meijer, E.P.M. and Van der Werf, H.M.G. (1994) Evaluation of current methods to estimate pulp yield of hemp. Industrial Crops and Products, 2, 111-120.

Desanlis, F., Cerruti, N., Warner, P. et al. (2013) Hemp agronomics and cultivation. In Hemp: industrial production and uses (eds Allegret, S., Bouloc, P. and Arnaud, L.), pp. 98-124. CPi Group (UK) Ltd, Croydon, UK.

Farquhar, G.D., Von Caemmerer, S. and Berry, J.A. (1980) A biochemical model of photosynthetic $\mathrm{CO}_{2}$ assimilation in leaves of $\mathrm{C}_{3}$ species. Planta, 149, 78-90.

Fike, J. (2016) Industrial hemp: renewed opportunities for an ancient crop. Critical Reviews in Plant Sciences, 35, 406-424.

Finnan, J. and Burke, B. (2013) Nitrogen fertilization to optimize the greenhouse gas balance of hemp crops grown for biomass. GCB Bioenergy, 5, 701-712.

Grohe, B. (2004) Heat conductivities of insulation mats based on water glass bonded non-textile hemp or flax fibres. European Journal of Wood and Wood Products, 62, 352-357.

Grotenhermen, F. and Karus, M. (1998) Industrial hemp is not marijuana: Comments on the drug potential of fiber Cannabis. Journal of the International Hemp Association, 5, 96101 .

Hikosaka, K., Kumagai, T.O. and Ito, A. (2016) Modeling canopy photosynthesis. In: Canopy Photosynthesis: From Basics to Applications. (eds Hikosaka, K., Niinemets, Ü. and Anten, N.P.R.), pp. 239-268. Springer, Dordrecht, Netherlands.

Holbery, J.D. and Houston, D.Q. (2006) Natural-fiber-reinforced polymer composites in automotive applications. JOM, 58, 80-86.

Höppner, F. and Menge-Hartmann, U. (2007) Yield and quality of fibre and oil of fourteen hemp cultivars in Northern Germany at two harvest dates. Landbauforschung Volkenrode, 57, 219-232.

Ivanyi, I. and Izsaki, Z. (2009) Effect of nitrogen, phosphorus, and potassium fertilization on nutrional status of fiber hemp. Communications in Soil Science and Plant Analysis, 40, 974-986.

Jarabo, R., Fuente, E., Monte, M.C. et al. (2012) Use of cellulose fibers from hemp core in fiber-cement production. Effect on flocculation, retention, drainage and product properties. Industrial Crops and Products, 39, 89-96.

Legros, S., Picault, S. and Cerruti, N. (2013) Factors affecting the yield of industrial hemp experimental results from France. In: Hemp: industrial production and uses (eds Allegret, S., Bouloc, P. and Arnaud, L.), pp. 72-97. CPi Group (UK) Ltd, Croydon, UK.

Leizer, C., Ribnicky, D., Poulev, A. et al. (2000) The composition of femp seed oil and its potential as an important source of nutrition. Journal of Nutraceuticals, Functional \& Medical Foods, 2, 35-53.

Leuning, R., Dunin, F. and Wang, Y-P (1998) A two-leaf model for canopy conductance, photosynthesis and partitioning of available energy. II. Comparison with measurements. 
Agricultural and Forest Meteorology, 91, 113-125.

Li, X., Wang, S., Du, G. et al. (2013) Variation in physical and mechanical properties of hemp stalk fibers along height of stem. Industrial Crops and Products, 42, 344-348.

Marija, M., Māra, V. and Veneranda, S. (2011) Changes of photosynthesis-related parameters and productivity of Cannabis sativa under different nitrogen supply. Environmental and Experimental Biology, 9, 61-69.

Pfister, S., Bayer, P., Koehler, A. et al. (2011) Environmental impacts of water use in global crop production: hotspots and trade-offs with land use. Environmental Science \& Technology, 45, 5761-5768.

Salentijn, E.M.J., Zhang, Q., Amaducci, S. et al. (2015) New developments in fiber hemp (Cannabis sativa L.) breeding. Industrial Crops and Products, 68, 32-41.

Sapino, S., Carlotti, M.E., Peira, E. et al. (2005) Hemp-seed and olive oils: Their stability against oxidation and use in $\mathrm{O} / \mathrm{W}$ emulsions. International Journal of Cosmetic Science, 27, 355-355.

Sharkey, T.D., Bernacchi, C.J., Farquhar, G.D. et al. (2007) Fitting photosynthetic carbon dioxide response curves for $\mathrm{C}_{3}$ leaves. Plant, Cell \& Environment, 30, 1035-1040.

Sinclair, T.R. and Horie, T. (1989) Leaf nitrogen, photosynthesis, and crop radiation use efficiency: a review. Crop Science, 29, 90-98.

Struik, P.C., Amaducci, S., Bullard, M.J. et al. (2000) Agronomy of fibre hemp (Cannabis sativa L.) in Europe. Industrial Crops and Products, 11, 107-118.

Tomás, M., Medrano, H., Pou, A. et al. (2012) Water-use efficiency in grapevine cultivars grown under controlled conditions: effects of water stress at the leaf and whole-plant level. Australian Journal of Grape and Wine Research, 18, 164-172.

Van der Werf, H.M.G., Harsveld Van der Veen, J.E., Bouma, A.T.M. et al. (1994a) Quality of hemp (Cannabis sativa L.) stems as a raw material for paper. Industrial Crops and Products, 2, 219-227.

Van der Werf, H.M.G, Haasken, H.J. and Wijlhuizen, M. (1994b) The effect of daylength on yield and quality of fibre hemp (Cannabis sativa L.). European Journal of Agronomy, 3, $117-123$.

Van der Werf, H.M.G., Mathijssen, E.W.J.M. and Haverkort, A.J. (1996) The potential of hemp (Cannabis sativa L.) for sustainable fibre production: A crop physiological appraisal. Annals of Applied Biology, 129, 109-123.

Vonapartis, E., Aubin, M-P, Seguin, P. et al. (2015) Seed composition of ten industrial hemp cultivars approved for production in Canada. Journal of Food Composition and Analysis, 39, $8-12$.

Westerhuis, W., Amaducci, S., Struik, P.C. et al. (2009) Sowing density and harvest time affect fibre content in hemp (Cannabis sativa L.) through their effects on stem weight. Annals of Applied Biology, 155, 225-244.

Wright, J., Williams, M., Starr, G. et al. (2013) Measured and modelled leaf and stand-scale productivity across a soil moisture gradient and a severe drought. Plant, Cell \& Environment, 36, 467-483. 
Yin, X., Struik, P. C., Romero, P. et al. (2009) Using combined measurements of gas exchange and chlorophyll fluorescence to estimate parameters of a biochemical $\mathrm{C}_{3}$ photosynthesis model: A critical appraisal and a new integrated approach applied to leaves in a wheat (Triticum aestivum) canopy. Plant Cell \& Environment, 32, 448-464. 



\section{Chapter 2}

\section{Comparing hemp (Cannabis sativa L.) cultivars for dual-purpose production under contrasting environments}

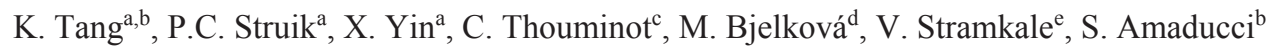

${ }^{a}$ Centre for Crop Systems Analysis, Department of Plant Sciences, Wageningen University \& Research, Droevendaalsesteeg 1, Wageningen, The Netherlands

${ }^{b}$ Department of Sustainable Crop Production, Università Cattolica del Sacro Cuore, via Emilia Parmense, 84, Piacenza, Italy

${ }^{c}$ Federation Nationale des Producteurs de Chanvre, 20, rue Paul Ligneul, Le Mans, France

${ }^{d}$ Department of Industrial Crops, AGRITEC Plant Research Ltd., Zemedělská 16, Šumperk, Czech Republic

${ }^{e}$ Latgale Agriculture Research Centre, Kulturas Laukums 1a, Vilani, Latvia

This Chapter is published in Industrial Crops and Products 87 (2016), 33-44. 


\title{
Chapter 2
}

\begin{abstract}
Interest in hemp as a multi-purpose crop is growing worldwide and for the first time in 2015 it was cultivated in Europe on more than 20,000 ha as a dual-purpose crop, for the seeds and for the fibre. In the present study, fibre and seed productivity of 14 commercial cultivars were tested in four contrasting European environments (Latvia, the Czech Republic, France, Italy). At full flowering, the stem yield ranged from 3.7 $\mathrm{Mg} \mathrm{ha}^{-1}$ to $22.7 \mathrm{Mg} \mathrm{ha}^{-1}$, the bast fibre content ranged from $21 \%$ to $43 \%$, and the bast fibre yield ranged from $1.3 \mathrm{Mg} \mathrm{ha}^{-1}$ to $7.4 \mathrm{Mg} \mathrm{ha}^{-1}$. When harvesting was postponed from full flowering until seed maturity, the stem yield of monoecious cultivars significantly increased but in dioecious cultivars it decreased at all tested sites, except for Italy. The seed yield ranged from $0.3 \mathrm{Mg} \mathrm{ha}^{-1}$ to 2.4 $\mathrm{Mg} \mathrm{ha}^{-1}$ in Italy, France and the Czech Republic. Only the early cultivars Fedora 17 and Markant produced seed in the most northern location Latvia.The cultivar effect on stem and seed yield was mainly determined by the genetic variation in time of flowering. Stem yield at full flowering was strictly related to the duration of the vegetative phase while seed yield was lowest in the late flowering cultivar. The late cultivar CS is suitable for stem and fibre production as it had the highest stem yield at full flowering in all locations. Both Fedora 17 and Futura 75 are candidate cultivars for dual-purpose production in Italy, France and the Czech Republic, with Fedora 17 being more suitable for seed production and Futura 75 for fibre production.
\end{abstract}

The application of modelling to design production strategies for dual-purpose hemp is promising. However, accurate parameterisation is needed based on large data sets and diverse genetic background.

Key words: hemp (Cannabis sativa L.); cultivar; phenology; modelling; seed; fibre. 


\subsection{Introduction}

Hemp is a high-yielding crop (Struik et al., 2000) that requires little technical inputs (Amaducci et al., 2015) and has a positive impact on the environment (Barth \& Carus, 2015; Bouloc \& Werf, 2013). Its stem contains high-quality cellulose (De Meijer, 1994), the seed contains highquality oil (Callaway, 2004) and the inflorescence contains valuable resins (Bertoli et al., 2010). From speciality pulp and paper to nutritional food, medicine and cosmetics, a wide variety of products can be derived from hemp stem, seed and inflorescence (Carus et al., 2013). However, once an important non-food crop for the production of textiles and ropes, hemp cultivation progressively declined during the $20^{\text {th }}$ century due to the competition from other feedstocks such as cotton and synthetic fibres (Allegret et al., 2013). Recent research (Amaducci, 2005) and entrepreneurial attempt (Amaducci, 2003) to develop a hemp production chain for high quality fibre have not been successful. Consequently, hemp has not been subjected to the intensive agronomic and breeding research and development that have driven great improvements in major crops in the last 50 years (Amaducci et al., 2015; Salentijn et al., 2015). A renewed interest in hemp cultivation for multi-purpose production is apparent, and particularly for the combination of fibre and seeds, a profitable practice that is now the norm in European countries (Carus et al., 2013). However, agronomic information to support dualpurpose hemp cultivation is scarce.

Genotype and environment have large effects on both fibre and seed production (Legros et al., 2013). Since the 1990s, when hemp cultivation was progressively authorized throughout the European Union (Wirtshafter, 2004), the number of registered cultivars has risen rapidly, from 12 cultivars in 1995 to 45 in 2008 and 51 in 2013 (Salentijn et al., 2015). Given the large variation in environmental conditions throughout Europe and the limited information available on hemp genotypes, it is a challenge for the farmers to choose suitable cultivars that maximize the economic returns. This study aims to assess the fibre and seed productivity of commercial hemp cultivars for dual-purpose production.

It has been reported that hemp stem yield increases proportionally with the length of vegetative phase (Faux et al., 2013); thus, high stem yields are obtained with late flowering cultivars (Amaducci \& Gusovius, 2010; Höppner \& Menge-Hartmann, 2007). These are preferred when maximization of stem biomass is a priority, as in biomass production for bioenergy (Finnan \& Styles, 2013; Prade et al., 2011). In addition to high stem yield, a cultivar with high bast content is desirable because it contains high-cellulose, low-lignified long fibre 


\section{Chapter 2}

that is generally considered of higher value than the woody core. Fibre content was found stable across environments, but varied largely among genotypes, from $25 \%$ to $47 \%$ in cultivars bred during the $20^{\text {th }}$ century (Amaducci \& Gusovius, 2010; Westerhuis et al., 2009b; De Meijer, 1994).

Late-flowering cultivars have high stem yield but low seed yield (Höppner \& MengeHartmann, 2007) which was not a problem in traditional hemp for fibre production, for which harvesting was carried out at full flowering when bark yield reaches its maximum and fibre quality is high (Amaducci et al., 2008a; Mediavilla et al., 2001). Postponed harvesting time until seed maturity could increase stem yield as a consequence of continuous accumulation of secondary fibre and xylem (Amaducci et al., 2005; Keller et al., 2001) or decrease it due to senescence (Mediavilla et al., 2001). The effect of delayed harvesting on bast fibre content and yield are modest (Höppner \& Menge-Hartmann, 2007), but an increase of lignified fibre was observed (Westerhuis et al., 2009a; Amaducci et al., 2005), which is undesirable for applications such as textile and specialty pulp (De Meijer \& van der Werf, 1994). In traditional hemp cultivation, seed production was further complicated by the use of dioecious cultivars that produced high stem yield with a large proportion of male plants that were considered of superior quality for textile applications (Berenji et al., 2013). However, the male plants start their senescence soon after flowering which results in biomass loss and an increase in fibre heterogeneity. The shift of modern hemp cultivation to lower quality fibre coupled to seed production has led hemp breeding to focus on the development of monoecious cultivars that are considered suitable for producing stem and seed simultaneously (Salentijn et al., 2015; Berenji et al., 2013).

The large influence of flowering time on biomass production and seed set has stimulated numerous studies on the influence of genotype by environment interactions on hemp flowering (Hall et al., 2012). Hemp is a quantitative short-day plant with temperature and photoperiod having strong effects on hemp development. The development rate increases with increasing temperature between a base and a cut-off temperature and with decreasing day-length during the photoperiod-sensitive phase (Amaducci et al., 2008b; Lisson et al., 2000a). Few studies are aimed at predicting hemp flowering as affected by temperature and photoperiod (Cosentino et al., 2012; Amaducci et al., 2008b; Lisson et al., 2000a). Amaducci et al. (2008b, 2012) successfully modelled the flowering time of several cultivars across diverse environments in Europe on the basis of temperature and photoperiod. Such model could facilitate developing strategies for dual-purpose hemp production in different environments by simulating hemp 
flowering time and hemp flowering duration, that in particular conditions can be longer than 2 months (Amaducci et al., 2008c).

Relatively few studies have compared the stem and seed yield potential of a large selection of commercial hemp cultivars (Faux et al., 2013; Höppner \& Menge-Hartmann, 2007) and no information is available on the productivity of hemp cultivars in a wide range of European environments. In this study, stem and seed productivity of diverse commercial cultivars were compared in contrasting European environments, with the aim of providing novel information to support dual-purpose cultivation of hemp in Europe. In particular, we aim: 1) to investigate the effects of genotype and environment on hemp stem and seed productions; and 2) to discuss potential strategies to develop cultivars and cropping practices for dual-purpose hemp production.

\subsection{Materials and methods}

\subsubsection{Environmental conditions, plant materials and trial arrangement}

Field trials were carried out in four contrasting locations (Latvia, the Czech Republic, France, Italy) in 2013, to compare 14 commercial hemp cultivars (Tables 2.1, 2.2). The southern location (Italy; IT) had a hot and dry summer while the other three environments were cool and humid. The average temperature between May and October (during the hemp season) ranged from $16.0{ }^{\circ} \mathrm{C}$ (the Czech Republic; $\mathrm{CZ}$ ) to $21.6^{\circ} \mathrm{C}$ (IT), the total precipitation ranged from 227 $\mathrm{mm}$ (IT) to $419 \mathrm{~mm}$ (Latvia; LV). The latitude difference between the most northern (LV) and most southern (IT) location is $12^{\circ}$ which corresponds to $2 \mathrm{~h}$ of maximum day-length (Figure 2.1).

Ten monoecious and four dioecious commercial cultivars were sown in a randomized complete block design with four replicates. Single plot size was $40 \mathrm{~m}^{2}$. Sowing was carried out between the end of April and the middle of May according to local conditions. In IT, sowing was delayed until the middle of May due to unfavourable weather conditions. A total of 240 germinable seeds $\mathrm{m}^{-2}$ were drilled at 3-4 $\mathrm{cm}$ depth using experimental-plot sowing machines. The distance between rows varied between $15 \mathrm{~cm}$ and $25 \mathrm{~cm}$, depending on the sowing machine used at each location. Nitrogen fertilization was carried out at sowing (Table 2.2), with the exception of IT where fertilisation was carried out after emergence. Irrigation was only applied in IT (120 mm in total), due to the late sowing and an exceptionally dry summer. Herbicide 
Chapter 2

(Afalon, active ingredient: $37.6 \% \mathrm{w} / \mathrm{w}$ linuron) was only applied in $\mathrm{CZ}$ to control dicotyledonous weeds after sowing.

Table 2.1 List of origin and sexual type of tested cultivars.

\begin{tabular}{llll}
\hline Cultivar & Abbreviation & Origin & Sexual type \\
\hline Beniko & BEN & Poland & Monoecious \\
Bialobrzeskie & BIA & Poland & Monoecious \\
Epsilon 68 & EPS & France & Monoecious \\
Fedora 17 & FED & France & Monoecious \\
Felina 32 & FEL & France & Monoecious \\
Férimon & FER & France & Monoecious \\
Futura 75 & FUT & France & Monoecious \\
Markant & MAR & Netherlands & Monoecious \\
Monoica & MON & Hungary & Monoecious \\
Tygra & TYG & Poland & Monoecious \\
CS & CS & Italy & Dioecious \\
KC Dora & KC & Hungary & Dioecious \\
Tiborszallasi & TIB & Hungary & Dioecious \\
Tisza & TIS & Hungary & Dioecious \\
\hline
\end{tabular}
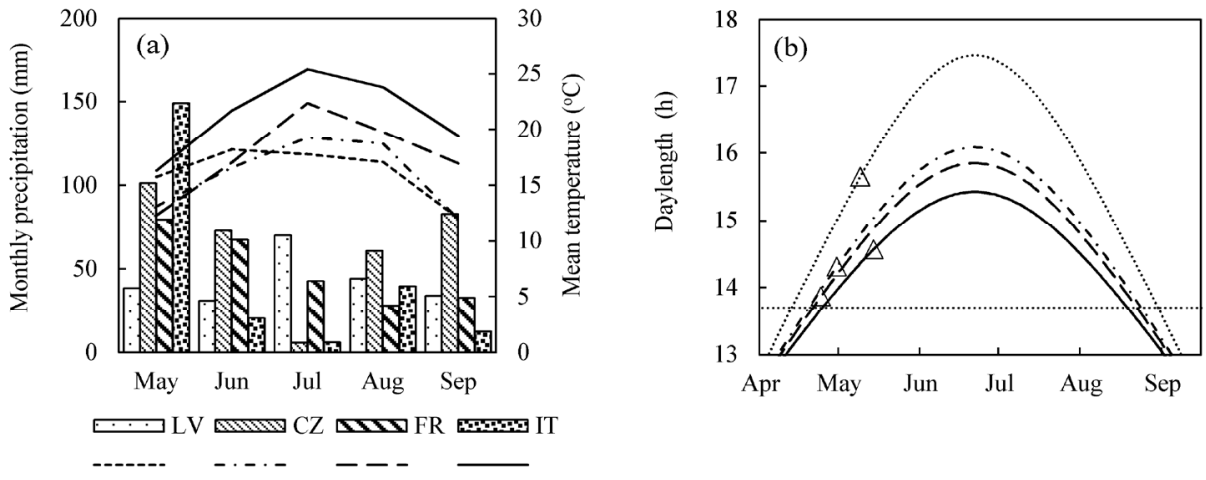

Figure 2.1 The meteorological parameters during the growing season of hemp. Panel a: the time course of mean temperature (line) and precipitation (bar); Panel b: the time course of photoperiod, the critical photoperiod for hemp (13.7 h) reported by Amaducci et al. (2012) is presented with a horizontal dashed line. Sowing dates are presented with an open triangle. The locations name are abbreviated as: LV (Latvia); CZ (the Czech Republic); FR (France); IT (Italy). 


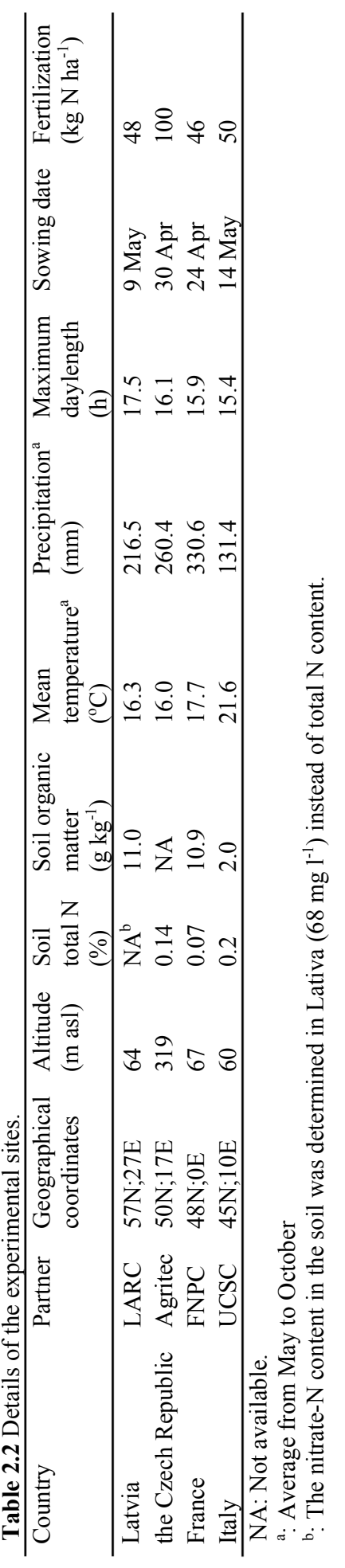




\section{Chapter 2}

\subsubsection{Determination of development and yield}

The number of emerged plants in each plot was counted in one row on a length of $1 \mathrm{~m}$ or in two rows on a length of $50 \mathrm{~cm}$, every two days from the appearance of the first plant until full emergence. The emergence date for each cultivar was set as the date when $50 \%$ of seedlings had appeared. On 10 representative plants that were selected and marked before flowering, flowering state (i.e. onset of flowering, full flowering and end of flowering) was recorded weekly. To capture the full flowering date precisely, the observation was conducted twice a week when the full flowering stage was approaching. For each cultivar it was considered that a specific phenological stage was reached when $50 \%$ of the observed plants had reached that stage.

Harvesting was carried out in each plot twice: at full flowering (H1) and seed maturity $(\mathrm{H} 2)$ (see Supplementary Material Table S2.1). The first harvest was carried out within $10 \mathrm{~d}$ from full flowering in IT, CZ and LV, while in France (FR) it was carried out with a certain delay (from $11 \mathrm{~d}$ to $25 \mathrm{~d}$ to full flowering depending on cultivars). The second harvesting was conducted for both stem and seed production at $46 \mathrm{~d}$ (from $40 \mathrm{~d}$ to $52 \mathrm{~d}$ ), $37 \mathrm{~d}$ (from $26 \mathrm{~d}$ to 52 d), $38 \mathrm{~d}$ (from $26 \mathrm{~d}$ to $51 \mathrm{~d}$ ) and $27 \mathrm{~d}$ (from $18 \mathrm{~d}$ to $35 \mathrm{~d}$ ) after full flowering in IT, FR, CZ and $\mathrm{LV}$, respectively. With the exception of the two early-flowering cultivars, Fedora 17 (FED) and Markant (MAR), the second harvesting in LV was conducted at the beginning of October after a killing frost. At that time, seeds were still immature, therefore, seed yield in LV was only determined for FED and MAR.

At each harvesting time, all plants in a 4- $\mathrm{m}^{2}$ area were cut above soil surface and fresh weight was immediately measured. Ten representative plants were then subsampled, and their fresh weight was measured. Subsequently, their dry weight was measured after oven drying at 105 ${ }^{\circ} \mathrm{C}$ until constant weight. Dry matter content was calculated as the ratio of dry weight: fresh weight. The proportion of stem, leaf and seed (H2) in the total biomass was determined from another subsample of ten representative plants after oven drying. Plant density at harvesting was calculated by counting all the plants in the first harvested $1 \mathrm{~m}^{2}$. Stem diameter at $10 \mathrm{~cm}$ from the stem base and whole stem length were measured on 25 representative plants in each plot.

After harvesting stems were air-dried in a ventilated place. Bast content in the stem was then determined on ten representative stems by mechanically separating bark and woody core. The dried stems were pressed to break by passing them through a laboratory decorticator and, 
subsequently, remaining shives were removed manually from the bast. The decorticator in IT and LV had four pairs of rollers while in FR it had six pairs of rollers. Decortication was conducted with a UTR-scutching machine in CZ. The entire stem was decorticated in FR while in IT, LV and CZ the base $20 \mathrm{~cm}$ containing coarse fibre was removed and the next $1 \mathrm{~m}$ of stem was decorticated. The bast content of the selected stem section was considered representative for the whole stem (Van der Werf et al., 1994). Stems harvested at full flowering were decorticated at all four locations while stems harvested at seed maturity were only processed in IT and CZ. Bast yield (in $\mathrm{Mg} \mathrm{ha}^{-1}$ ) was estimated by multiplying stem yield (in $\mathrm{Mg} \mathrm{ha}^{-1}$ ) by bast content in the stem (in percentage).

\subsubsection{Calculating parameters of a phenological model}

To characterise the phenology of the tested cultivars, flowering data was used to calibrate the phenological model developed by Amaducci et al. (2008b). The model divides post-emergence hemp phenology into three phases: the basic vegetative phase (BVP), the photoperiod induction phase (PIP), and the flower development phase (FDP). The latter ends when $50 \%$ of plants in a stand have visible flowers. Among the 13 parameters of the model, the days needed to complete BVP under the optimal condition (DI) and the steepness of the photoperiod response curve during PIP $(n)$ were considered to depend on genotype while the other ones were considered constant (Amaducci et al., 2012). Therefore, only Dl and $n$ were estimated in the present study by minimizing the difference between observed and predicted flowering time. The other parameters calculated by Amaducci et al. (2012) were used as default value in our calculations. Evaluation of fitting was performed via the performance indices relative root mean square error $(R R M S E, \%)$ and modelling efficiency $(E F)$ :

$$
\begin{aligned}
& R R M S E=\frac{100}{\bar{O}} \sqrt{\frac{\sum_{\mathrm{i}=1}^{N}\left(E_{\mathrm{i}}-O_{\mathrm{i}}\right)^{2}}{N}} \\
& E F=1-\frac{\sum_{\mathrm{i}=1}^{N}\left(E_{\mathrm{i}}-O_{\mathrm{i}}\right)^{2}}{\sum_{\mathrm{i}=1}^{N}\left(O_{\mathrm{i}}-\bar{O}\right)^{2}}
\end{aligned}
$$

where $E$ is the estimated value, $O$ the observed value, $\bar{O}$ the mean of the observed values, $\mathrm{i}$ the ith $E / O$ pair, and $N$ is the number of $E / O$ pairs. $R R M S E$ varies from 0 (best) to positive infinity. $E F$ can give either positive or negative values, 1 being the upper limited, while negative infinity is the theoretical lower boundary. Negative values of $E F$ indicate that the model introduces more ambiguity than that introduced by simply using the mean value of the observations as an estimator. 
Chapter 2

\subsubsection{Statistical analysis}

Statistical analyses were performed to assess the effects of cultivar and location on phenophases, biometric traits and yield components using SPSS statistics 22.0 (SPSS, Chicago, IL, USA). Data was subjected to a two-way ANOVA to assess the effect of cultivar $\times$ location. The "block" was considered to be discrete and random. The effect of harvest on biometric traits and yield components were analysed in each sexual type, i.e. dioecious and monoecious. The duration of the phenophases was expressed in days and degree-days when the rate of development was correlated to the temperature. The degree-days was calculated as the time integral of $T_{\mathrm{ave}}-T_{\mathrm{b}}$, with $T_{\text {ave }}$ being the daily average temperature and $T_{\mathrm{b}}=1{ }^{\circ} \mathrm{C}$, the base temperature for hemp development (Lisson et al., 2000b; Van der Werf et al., 1995).

\subsection{Results}

\subsubsection{Development}

Of the seedlings, 50\% appeared between 6 to 12 days after sowing, depending on locations and cultivars (Tables 2.3, 2.4). A significant effect of genotype on emergence was observed in IT, FR and LV, where MAR emerged significantly earlier than Tisza (TIS). The degree-days

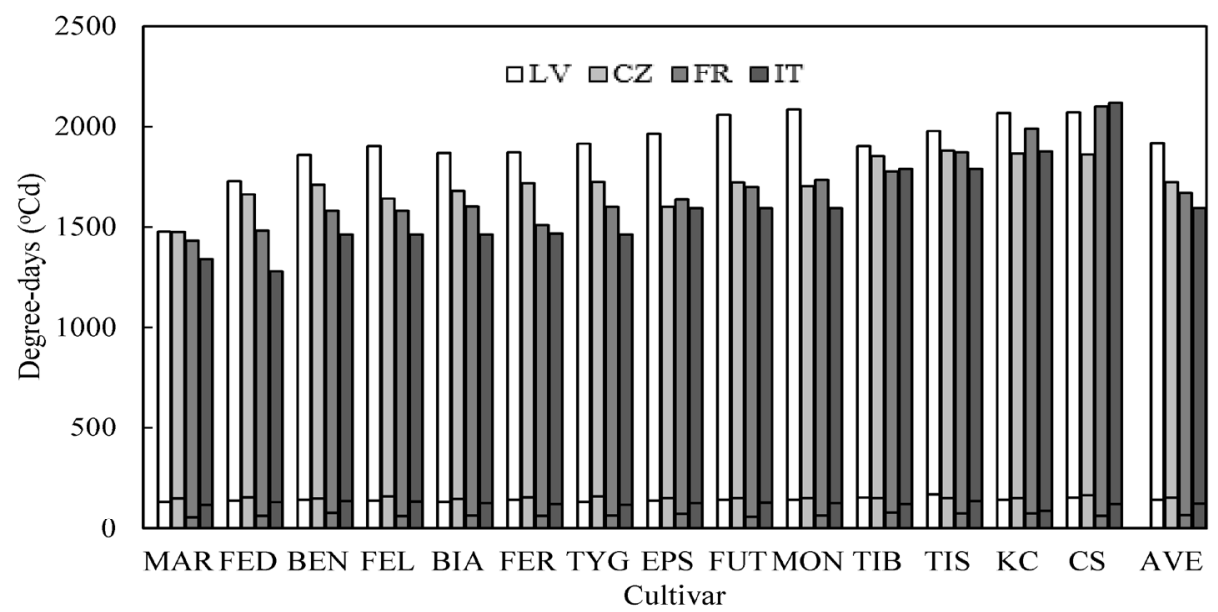

Figure 2.2 Degree-days required to complete phenological stages of tested varieties in different locations. The line in the bar indicates emergence time. The average of 14 varieties at each location is indicated as AVE. The LSD (0.05) for the emergence and vegetative growth periods were $17.3{ }^{\circ} \mathrm{Cd}$ and $54.1{ }^{\circ} \mathrm{Cd}$, respectively. The locations name are abbreviated as: LV (Latvia); $\mathrm{CZ}$ (the Czech Republic); FR (France); IT (Italy). The cultivars name are abbreviated as: BEN (Beniko); BIA (Bialobrzeskie); EPS (Epsilon 68); FED (Fedora 17); FEL (Felina 32); FER (Férimon); FUT (Futura 75); MAR (Markant); MON (Monoica); TYG (Tygra); CS (CS); KC (KC Dora); TIB (Tiborszallasi); TIS (Tisza). 


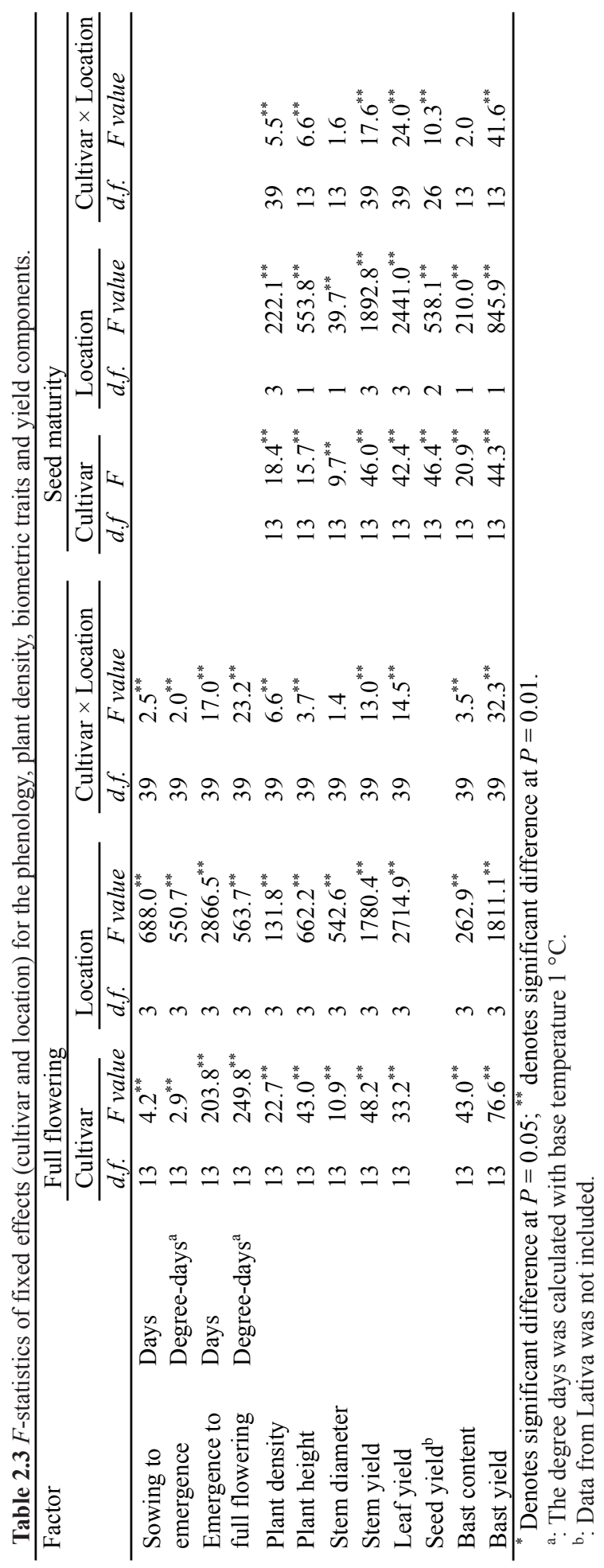




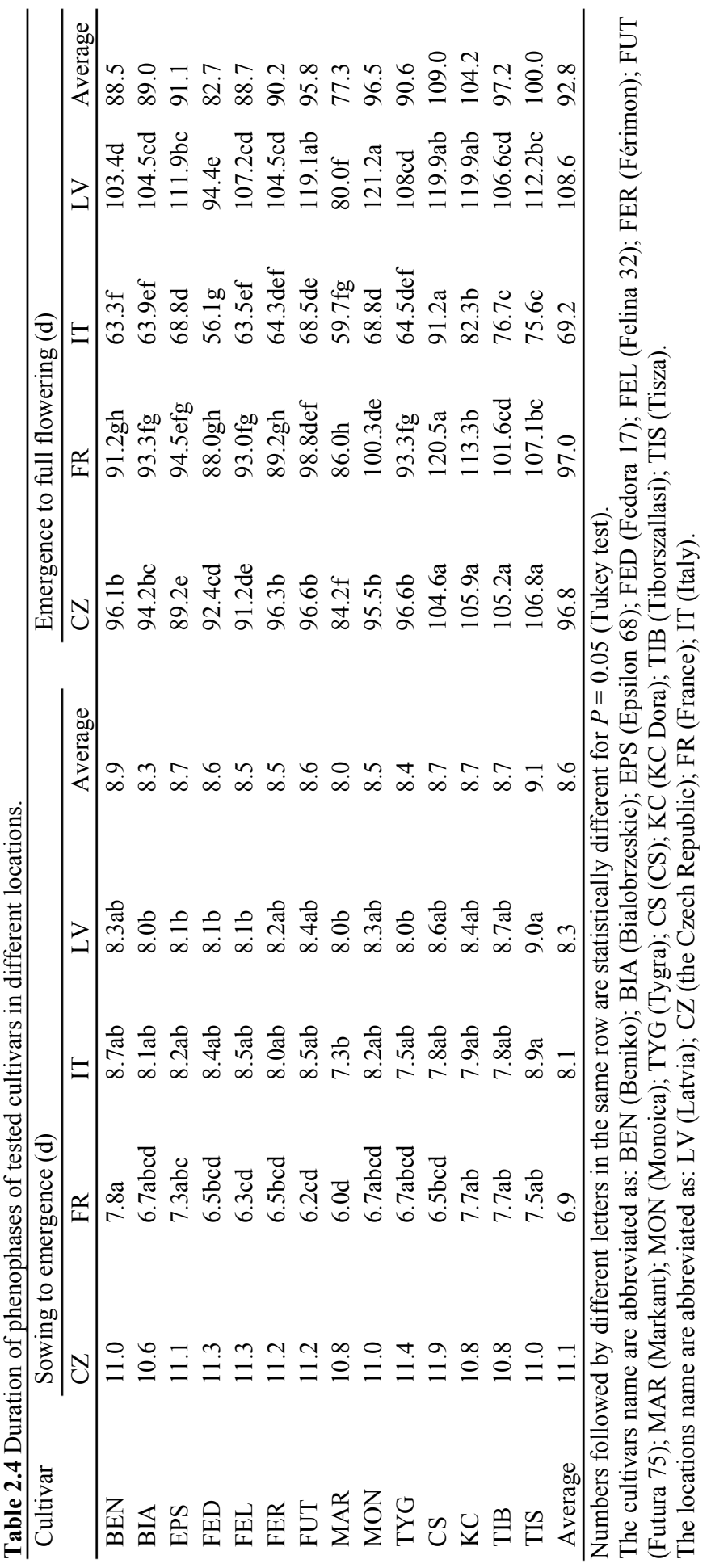


required for emergence varied significantly among locations, with $69^{\circ} \mathrm{Cd}, 125^{\circ} \mathrm{Cd}, 144{ }^{\circ} \mathrm{Cd}$, and $154^{\circ} \mathrm{Cd}$ required in FR, IT, LV and CZ, respectively (Figure 2.2).

Flowering was observed from the beginning of July until the end of September. The duration of the vegetative phase, from emergence until full flowering, ranged from a minimum of $56 \mathrm{~d}$ (FED in IT) to a maximum of $121 \mathrm{~d}$ (Monoica and MON in LV) (Table 2.4). The vegetative phase, which was generally shorter in IT and was longer at higher latitudes, varied significantly among cultivars. As an example, the vegetative phase of MAR was $26 \mathrm{~d}$ shorter in IT than in LV while that of MON was $52 \mathrm{~d}$ shorter in IT than in LV. The variation among locations was smaller when expressed in degree-days than when expressed in days (Table 2.3). The degreedays required to complete the vegetative phase was positively correlated with the latitude for the cultivars Beniko (BEN), Bialobrzeskie (BIA), Felina 32 (FEL), Ferimon (FER), Tygra (TYG), Futura 75 (FUT) and Tiborszallasi (TIB) $(P<0.05)$ while the trend was not significant for the other cultivars $(P>0.05)$ (Table 2.5$)$.

The duration of the vegetative phase was significantly different among cultivars (Table 2.4). On average the dioecious cultivars reached flowering later than the monoecious ones, with the exception of the dioecious cultivar TIB which was significantly earlier (107 d) in LV than the monoecious cultivars MON (121 d) and FUT (119 d). CS was the latest among all the cultivars while FUT was the latest among the 8 monoecious cultivars. Cultivars MAR and FED were the earliest ones in IT (60 d and $56 \mathrm{~d}$ ), FR ( $86 \mathrm{~d}$ and $83 \mathrm{~d}$ ) and LV (80 d and $94 \mathrm{~d}$ ), whereas the flowering time of Epsilon 68 (EPS; $89 \mathrm{~d}$ ) was significantly earlier than that of FED (92 d, $P<$ $0.05)$ in $\mathrm{CZ}$.

Table 2.5 The correlation between degree-days from emergence to full flowering and latitude.

\begin{tabular}{llllll}
\hline Cultivar & $r$ & $P$ & Cultivar & $r$ & $P$ \\
\hline BEN & $\mathbf{0 . 9 7}$ & $\mathbf{0 . 0 3 3}$ & MAR & 0.54 & 0.456 \\
BIA & $\mathbf{0 . 9 3}$ & $\mathbf{0 . 0 3 8}$ & MON & 0.92 & 0.077 \\
EPS & 0.87 & 0.128 & TYG & $\mathbf{0 . 9 8}$ & $\mathbf{0 . 0 2 0}$ \\
FED & 0.87 & 0.133 & CS & -0.27 & 0.728 \\
FEL & $\mathbf{0 . 9 7}$ & $\mathbf{0 . 0 3 2}$ & KC & 0.45 & 0.553 \\
FER & $\mathbf{0 . 9 9}$ & $\mathbf{0 . 0 1 4}$ & TIB & $\mathbf{0 . 9 9}$ & $\mathbf{0 . 0 0 4}$ \\
FUT & $\mathbf{0 . 9 5}$ & $\mathbf{0 . 0 4 8}$ & TIS & 0.73 & 0.265 \\
& & & Average & 0.94 & 0.057 \\
\hline
\end{tabular}

Numbers in bold are significant at $P=0.05$ (2-tailed).

The cultivars name are abbreviated as: BEN (Beniko); BIA (Bialobrzeskie); EPS (Epsilon 68); FED (Fedora 17); FEL (Felina 32); FER (Férimon); FUT (Futura 75); MAR (Markant); MON (Monoica); TYG (Tygra); CS (CS); KC (KC Dora); TIB (Tiborszallasi); TIS (Tisza). 


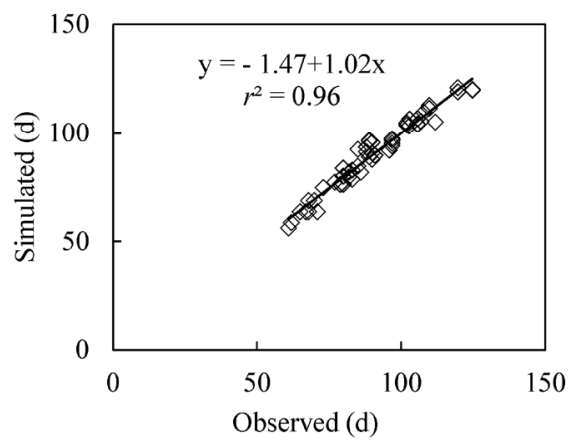

Figure 2.3 Predicted and observed duration between emergence and full flowering. Observed phenological data was fitted to the phenological model developed by Amaducci et al. (2008b).

The flowering time was simulated using the model developed by Amaducci et al. (2008b) on the basis of daily average temperature and photoperiod (Figure 2.3). The maximum difference between observed and simulated flowering time was 8 days. The relative root mean square error (RRMSE) was between $1.2 \%$ and $5.8 \%$, model efficiency $(E F)$ was between 0.85 and 1.0 (Table 2.6). Comparing with the parameters calculated by Amaducci et al. (2012) and Amaducci et al. (2008b) for the three cultivars that are common to our study (FEL, FUT and TIB), the values calculated with our observations were higher for D1 (the days needed to complete basic vegetative phase under optimal conditions) but lower for $n$ (the steepness parameter of the photo-inductive phase). The parameter values reported in Amaducci et al. (2012) enabled a relatively accurate estimation of flowering time for FEL and FUT but the $E F$ of TIB was low (0.19). The parameter values reported in Amaducci et al. (2008b) provided an acceptable estimation of flowering time for FUT, but the EF of FEL and TIB was low.

\subsubsection{Biomass yield}

The average plant density at full flowering was 106 plants $\mathrm{m}^{-2}$ in CZ, 134 plants $\mathrm{m}^{-2}$ in both IT and FR, and 169 plants $\mathrm{m}^{-2}$ in LV (see Supplementary Material Table S2.2), at seed maturity plant density remained constant in FR and LV, while it decreased significantly in IT and CZ for both monoecious and dioecious cultivars (Table 2.7).

Stem dry matter yield at full flowering ranged from $3.7 \mathrm{Mg} \mathrm{ha}^{-1}$ to $9.5 \mathrm{Mg} \mathrm{ha}^{-1}$ in IT, from 3.8 $\mathrm{Mg} \mathrm{ha}^{-1}$ to $10.2 \mathrm{Mg} \mathrm{ha}^{-1}$ in FR, from 10.2 $\mathrm{Mg} \mathrm{ha}^{-1}$ to $17.9 \mathrm{Mg} \mathrm{ha}^{-1}$ in $\mathrm{CZ}$ and from $8.8 \mathrm{Mg}$ $\mathrm{ha}^{-1}$ to $22.7 \mathrm{Mg} \mathrm{ha}^{-1}$ in LV (Table 2.8). The average plant height and stem diameter ranged respectively from $122 \mathrm{~cm}$ (BEN in IT) to $309 \mathrm{~cm}(\mathrm{CS}$ in $\mathrm{CZ})$ and from $3.8 \mathrm{~mm}$ (BEN in IT) to $10.4 \mathrm{~mm}$ (CS at CZ) (see Supplementary Material Table S2.2). The effects of genotype on stem 
Table 2.6 The calculated parameter values for the phenological model developed by Amaducci et al. (2008b) when the difference between observed and predicted flowering date were minimized. D1: the days needed to complete the basic vegetative phase (BVP) under optimal conditions; $n$ : steepness parameter of the photo-inductive phase. The other model parameters were set according to Amaducci et al. (2012); RRMSE: relative root mean square error; $E F$ : modelling efficiency.

\begin{tabular}{lllll}
\hline Cultivar & $D 1$ & $n$ & $R R M S E$ & $E F$ \\
\hline BEN & 50.2 & 21.7 & 5.8 & 0.89 \\
BIA & 43.7 & 23.9 & 3.9 & 0.95 \\
EPS & 43.9 & 25.8 & 1.3 & 0.99 \\
FED & 37.2 & 21.4 & 5.8 & 0.91 \\
FEL & 39.1 & 25.2 & 2.2 & 0.98 \\
FEL $(2012)^{\mathrm{a}}$ & 11.1 & 33.4 & 9.3 & 0.74 \\
FEL $(2008)^{\mathrm{a}}$ & 13.2 & 47.0 & 13.0 & -0.29 \\
FER & 44.8 & 24.3 & 5.6 & 0.91 \\
FUT & 25.1 & 33.6 & 1.2 & 1.00 \\
FUT $(2012)^{\mathrm{a}}$ & 14.7 & 39.6 & 5.6 & 0.92 \\
FUT $(2008)^{\mathrm{a}}$ & 19.7 & 52.1 & 2.2 & 0.99 \\
MAR & 41.9 & 12.6 & 3.9 & 0.91 \\
MON & 26.8 & 34.0 & 1.4 & 1.00 \\
TYG & 42.0 & 25.5 & 5.0 & 0.93 \\
CS & 51.6 & 77.4 & 3.9 & 0.85 \\
KC & 32.5 & 50.9 & 2.6 & 0.97 \\
TIB & 60.9 & 14.1 & 2.9 & 0.95 \\
TIB $(2012)^{\mathrm{a}}$ & 20.6 & 38.6 & 10.6 & 0.19 \\
TIB $(2008)^{\mathrm{a}}$ & 18.5 & 66.7 & 13.3 & 0.50 \\
TIS & 61.5 & 15.6 & 3.1 & 0.95 \\
\hline$:$ 2008 & 0.9 & $5 y-1$ & 2012 \\
\hline
\end{tabular}

a: 2008 indicates value of parameters reported by Amaducci et al. (2008b); 2012 indicates value parameters reported by Amaducci et al. (2012)

The cultivars name are abbreviated as: BEN (Beniko); BIA (Bialobrzeskie); EPS (Epsilon 68); FED (Fedora 17); FEL (Felina 32); FER (Férimon); FUT (Futura 75); MAR (Markant); MON (Monoica); TYG (Tygra); CS (CS); KC (KC Dora); TIB (Tiborszallasi); TIS (Tisza).

yield, plant height and stem diameter were significant in all locations (Table 2.3). With the exception of FR, higher stem yields from taller and thicker stems were obtained from lateflowering cultivars (Figure 2.4). As a consequence of its long vegetative phase, the lateflowering cultivar CS produced the highest biomass yield across all experimental sites; among monoecious cultivars, FUT had the highest stem yield. Stem yield of monoecious cultivars increased significantly from full flowering to seed maturity in IT and CZ while, with the exception of IT, the stem yield of dioecious cultivars decreased significantly (Table 2.7). 
Chapter 2

Bast fibre content ranged from $21 \%$ to $43 \%$ at full flowering, depending on cultivar (Table 2.8). The ranking of the 14 cultivars according to bast fibre content was rather similar in the different experimental sites (Figure 2.5). Cultivars BEN and BIA had the highest bast fibre content while the lowest contents were found in TIB, KC and FED. The bast fibre content decreased significantly from full flowering to seed maturity in $\mathrm{CZ}$ in both monoecious and dioecious cultivars while only in monoecious cultivars in IT (Table 2.7).

Bast fibre yield depended on both stem yield and bast fibre content in the stem. Cultivar CS had the highest stem yield and a medium bast fibre content at full flowering; consequently,
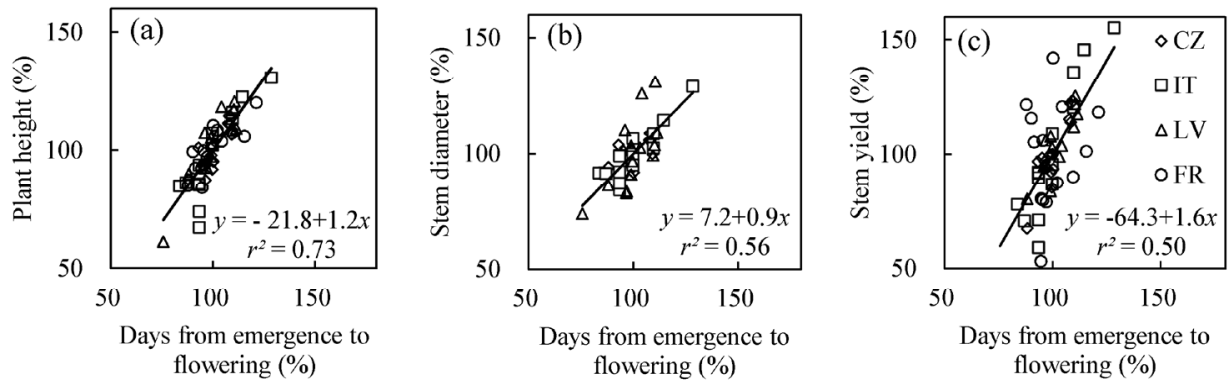

Figure 2.4 Plant height (panel a), stem diameter (panel b) and stem yield (panel c) against days from emergence to full flowering. Data are presented as percentage of the average at each location. The locations name are abbreviated as: LV (Latvia); CZ (the Czech Republic); FR (France); IT (Italy).

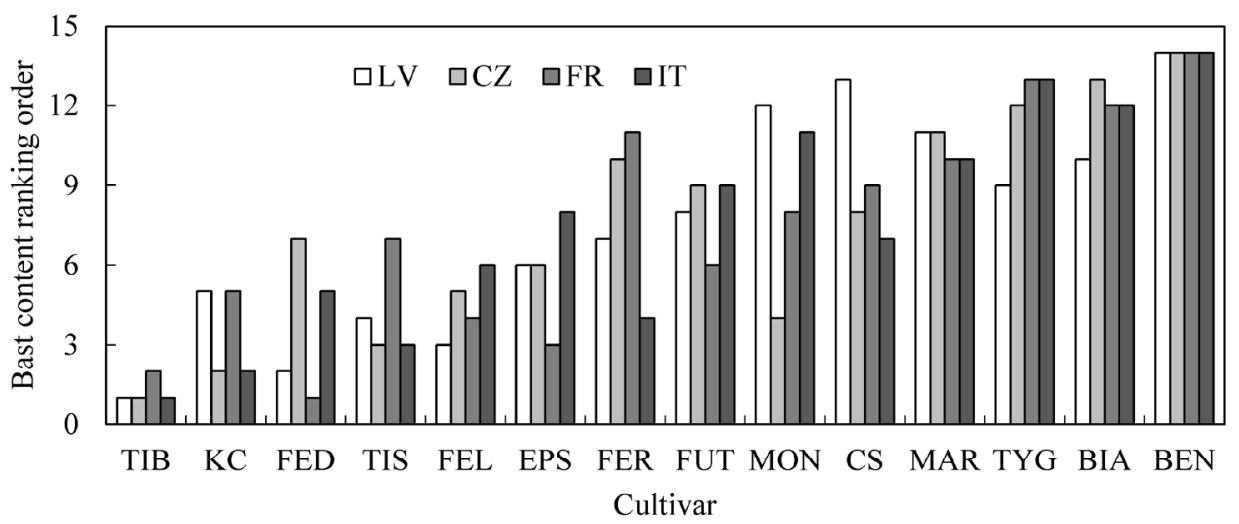

Figure 2.5 Bast content ranking order of the tested varieties in different locations at full flowering. The locations name are abbreviated as: LV (Latvia); CZ (the Czech Republic); FR (France); IT (Italy). The cultivars name are abbreviated as: BEN (Beniko); BIA (Bialobrzeskie); EPS (Epsilon 68); FED (Fedora 17); FEL (Felina 32); FER (Férimon); FUT (Futura 75); MAR (Markant); MON (Monoica); TYG (Tygra); CS (CS); KC (KC Dora); TIB (Tiborszallasi); TIS (Tisza). 


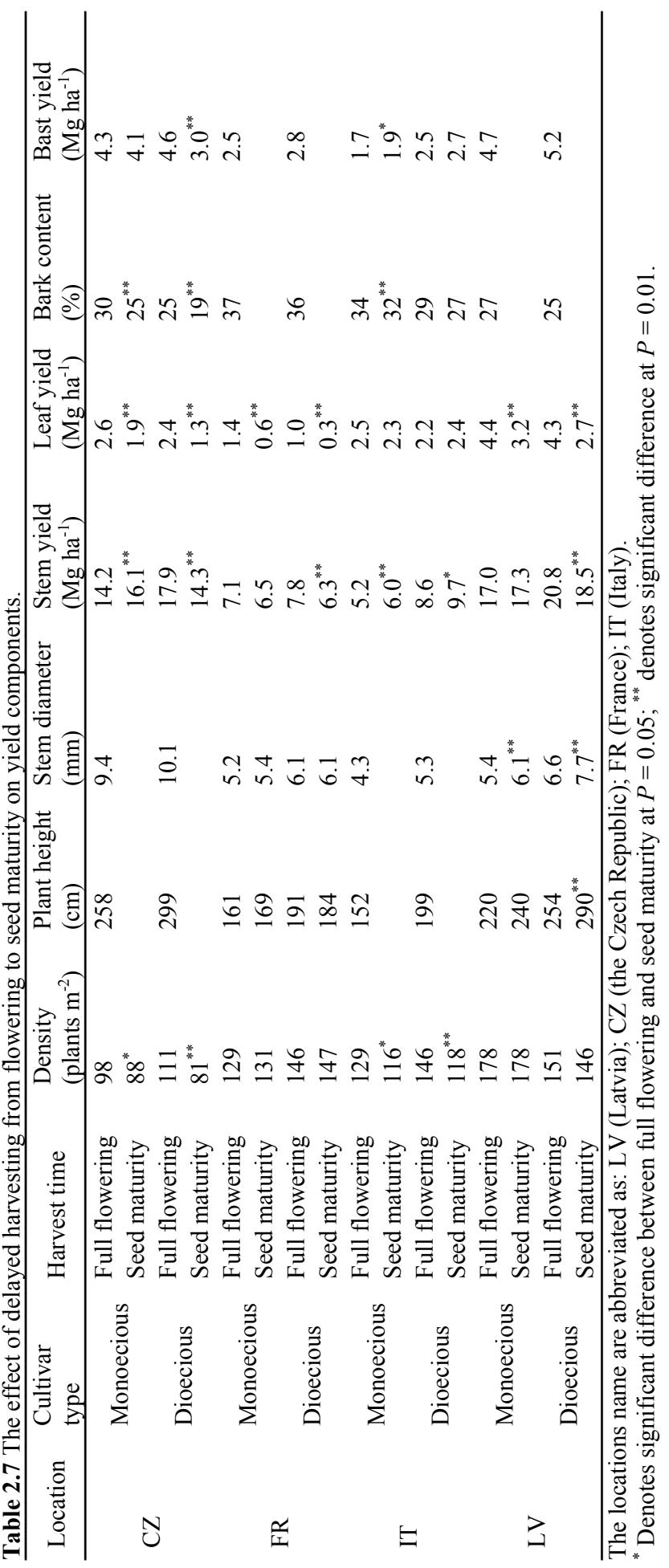




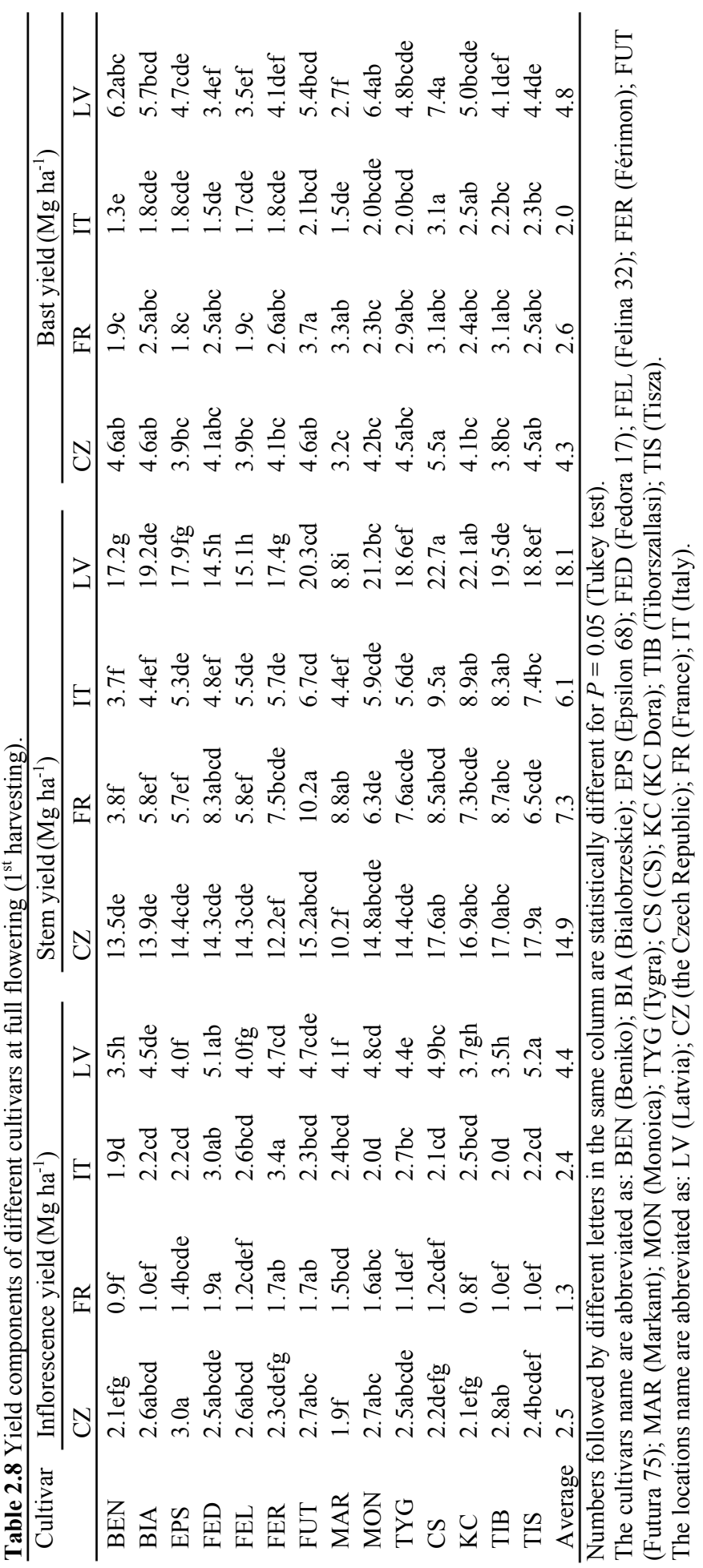


it had the highest bast fibre yield in CZ, IT and LV (Table 2.8). Similarly, FUT had the highest bast fibre yield among the monoecious cultivars in IT and FR. It is interesting to note that cultivars having a modest stem yield could still have a high bast yield, due to a high bast fibre content in the stem. As an example, the stem yield of BEN in $\mathrm{CZ}$ was significantly lower than that of the cultivars TIB and $\mathrm{KC}$ whereas its bast yield was significantly higher due to the high bast fibre content. At full flowering, bast fibre yield ranged from $1.3 \mathrm{Mg} \mathrm{ha}^{-1}$ to $3.1 \mathrm{Mg} \mathrm{ha}$ in IT, from $1.6 \mathrm{Mg} \mathrm{ha}^{-1}$ to $3.6 \mathrm{Mg} \mathrm{ha}^{-1}$ in FR, from $3.2 \mathrm{Mg} \mathrm{ha}^{-1}$ to $5.2 \mathrm{Mg} \mathrm{ha}^{-1}$ in $\mathrm{CZ}$ and from 2.6 $\mathrm{Mg} \mathrm{ha}^{-1}$ to $7.4 \mathrm{Mg} \mathrm{ha}^{-1}$ in LV. At seed maturity, the bast fibre yield of monoecious cultivars increased significantly in IT, whereas the bast fibre yield of dioecious cultivars decreased significantly in CZ (Table 2.7).

Seed yield ranged from 1.1 $\mathrm{Mg} \mathrm{ha}^{-1}$ to $2.4 \mathrm{Mg} \mathrm{ha}^{-1}$ in IT, from $0.7 \mathrm{Mg} \mathrm{ha}^{-1}$ to $2.3 \mathrm{Mg} \mathrm{ha}^{-1}$ in $\mathrm{CZ}$ and from $0.3 \mathrm{Mg} \mathrm{ha}^{-1}$ to $1.0 \mathrm{Mg} \mathrm{ha}^{-1}$ in FR (Table 2.9). Only FED (1.5 $\mathrm{Mg} \mathrm{ha}^{-1}$ ) and MAR (1.4 $\mathrm{Mg} \mathrm{ha}^{-1}$ ) produced seeds in $\mathrm{LV}$; the other cultivars flowered too late. In contrast to stem yield, the highest seed yield and seed harvest index were found in earlier cultivars (Figure 2.6). The early-flowering cultivar FED had the highest seed harvest index and the highest seed yield in all locations, while the seed yield of late-flowering dioecious cultivars was the lowest. Only
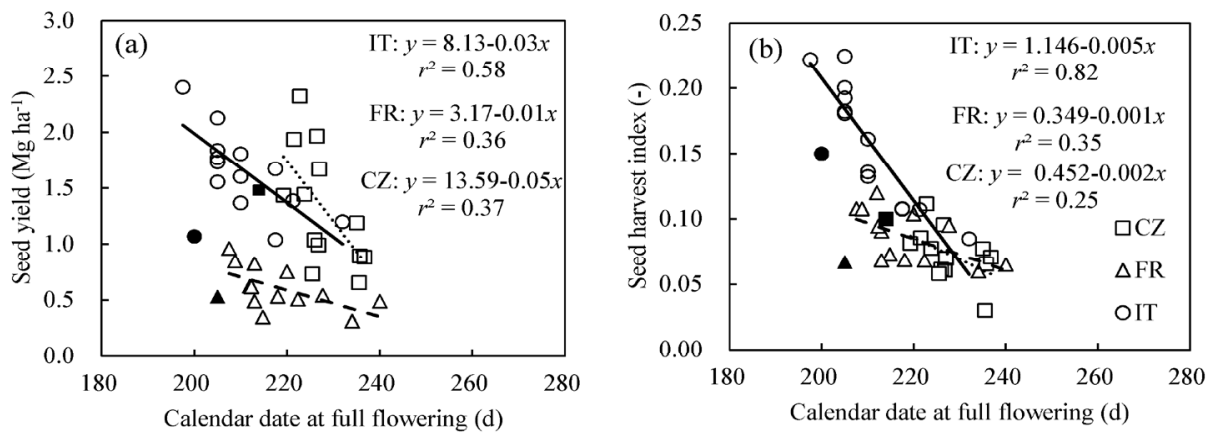

Figure 2.6 The seed yield (panel a) and seed harvest index (panel b) against calendar date at full flowering. Early-flowering varieties had high seed yield and seed harvest index, except for Markant (solid marker, excluded from regression) which flowered early while it had a low seed yield and a low harvest index. The locations name are abbreviated as: CZ (the Czech Republic); FR (France); IT (Italy). Regression lines are indicated as solid line (IT); dash line (FR); dot line (CZ). 


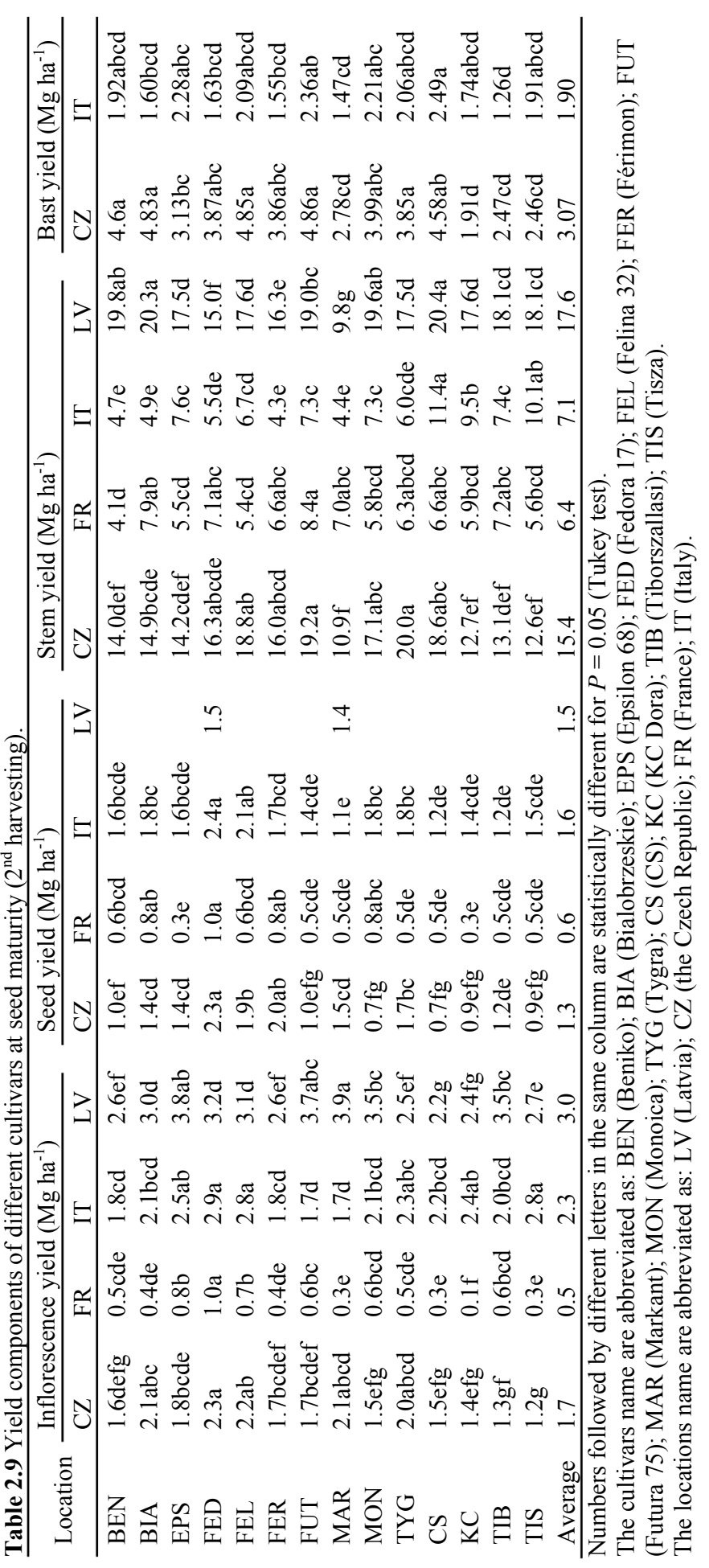


MAR deviated significantly from this behaviour, showing low seed yield and harvest index while being a relatively early cultivar in FR and IT (Figure 2.6).

\subsection{Discussion}

Hemp has a great potential as a high yielding multi-purpose crop (Amaducci et al., 2015; Salentijn et al., 2015) but so far it has been bred mainly for stem yield and bast fibre content (Salentijn et al., 2015) or for seed yield (Callaway \& Laakkonen, 1996). Since the value of hemp seed is being gradually recognized, the production of seed is gaining attention (Carus et $a l ., 2013$ ) but very limited information on yield potential from dual-purpose crops (fibre + seed) is available in the literature. In this paper we present and discuss the results from 14 commercial hemp cultivars tested in four contrasting environments, with the aim of providing novel information to support dual-purpose cultivation of hemp in Europe.

\subsubsection{The effect of genotype and environment on dual-purpose production}

Average hemp stem yield in Europe was 7.3 $\mathrm{Mg} \mathrm{ha}^{-1}$ in 2010 (Carus et al., 2013), so considering the maximum stem yield measured in our trial (22.7 $\mathrm{Mg} \mathrm{ha}^{-1}$ in LV) (Table 2.8), which was slightly higher than the maximum stem yield reported in a previous work that compared hemp yield potential across Europe (Struik et al., 2000), a large potential to improve actual hemp stem yield can be expected.

The significant effect of genotype on stem yield has been widely reported (Cosentino et al., 2013; Pahkala et al., 2008; Höppner \& Menge-Hartmann, 2007; Struik et al., 2000). In spite of the large variation in stem yields observed among locations, our results (Figure 2.4) confirm that stem yield at full flowering is proportional to the duration of the vegetative phase (Faux et al., 2013). Hemp tolerates low temperatures during early and late stages of growth, $0-2.5^{\circ} \mathrm{C}$ in early stages (Amaducci et al., 2012; Lisson et al., 2000a; Van der Werf et al., 1995) and even light frost $\left(-2^{\circ} \mathrm{C}\right)$ in late stages (Pahkala et al., 2008). In Northern Italy, it is often recommended to sow at the end of March or at the beginning of April (personal observation). In our experiment, the length of vegetative phase and stem yield in IT were limited by a combination of late sowing and early flowering (Tables 2.2, 2.4). Given the relation between stem yield and the duration of the vegetative phase, large increases in stem yield can be achieved by prolonging the vegetative growth phase, particularly in southern environments.

High bast fibre content is desirable because fibre has a higher economic value than the woody core (Carus et al., 2013). Our results show that the ranking of the tested cultivars based 


\section{Chapter 2}

on bast fibre content was relatively stable among locations (Figure 2.5), which is in agreement with previous studies (Amaducci et al., 2008a; Sankari, 2000) and indicates that fibre content is under strong genetic control (Hennink, 1994). Westerhuis et al. (2009b) reported that stem fibre content (retted) can be considered as a genotypic parameter because the difference of fibre content among genotypes was not influenced by environmental conditions and harvesting times. Thus, high bast fibre yield can be pursued by choosing late cultivars that in a given environment have the highest stem yield, and by selecting cultivars with a high bast fibre content, considering that a high variability for this trait was found in our experiment (Table 2.8).

Although stem yield was high in late-flowering cultivars, their seed yield was low (Figures 2.4, 2.6). Similarly, Höppner \& Menge-Hartmann (2007) reported that late-maturing cultivars produced consistently lower seed yield than early cultivars. This is most likely a consequence of the lower temperatures, shorter day-length and lower light intensities that are experienced during seed development of late-flowering cultivars. As an example, in IT the mean temperature between full flowering and seed harvesting of FED was $23.2{ }^{\circ} \mathrm{C}$, while it was $17.7^{\circ} \mathrm{C}$ for the late cultivar CS; day-length at full flowering was $15.0 \mathrm{~h}$ and $13.5 \mathrm{~h}$ for FED and CS, respectively; average daily global radiation between full flowering and seed harvesting was $21.2 \mathrm{MJ} \mathrm{m}^{-2} \mathrm{~d}^{-1}$ and 13.7 $\mathrm{MJ} \mathrm{m}^{-2} \mathrm{~d}^{-1}$ for FED and CS, respectively. The effects of such differences in temperature, day-length and light intensities during the reproductive period on hemp seed production are unknown. However, cold temperature could induce flower abortion, pollen and ovule infertility, causes reduced fertility and poor seed set (Thakur et al., 2010). Examples were widely reported on crops such as rice (Oryza sativa L.; Gunawardena et al., 2003), maize (Zea mays L.; Lafitte \& Edmeades, 1997) and soybean [Glycine max (L.) Merr; Ohnishi et al., 2010]. Faux et al. (2013) assumed that the temperature during seed-fill duration may affect seed yield in hemp. Short day-length was reported to promote leaf senescence in soybean (Han et al., 2006). As an evidence in hemp, the leaf yield of early-flowering cultivar FED was significantly higher than that of the late-flowering cultivar CS in all locations at seed maturity, in contrast to the low stem yield (Table 2.9). The fast senescence of leaf in association with low light intensities during the reproductive period of late-flowering cultivars suggests low availability of photosynthates for seed production. It was reported that decreasing total resource availability during reproductive period results in low seed number in soybean cultivars (Kantolic et al., 2013; Jiang et al., 2011; Kantolic \& Slafer, 2007, 2001).

Considering that long vegetative growth results in high stem yield while early flowering favours seed yield, it can be concluded that genotype affects the production of stem and seed 
mainly through its effect on flowering time. In our experiment, no cultivar produced both the highest stem and seed yields. Dioecious cultivar CS had the highest stem and bast fibre yield (Table 2.8) but low seed yield and it is therefore preferable for fibre production. Moreover, the stem yield of dioecious cultivars decreased significantly from flowering to seed maturity in FR and $\mathrm{CZ}$ (Table 2.7), which is an additional reason for discarding dioecious cultivars (i.e., CS, TIB, KC and TIS in our experiment) for dual-purpose production. FED had the highest seed yield in all locations due to early flowering (Figure 2.7), thus it can be considered as a good option for seed production. FED can also be cultivated for dual-purpose production in FR and $\mathrm{CZ}$ as it had a higher stem yield than average among the tested cultivars at seed maturity (Table 2.9). However, the low bast fibre content in the stem limits its bast fibre yield. Special attention should be paid when choosing MAR for seed production because its seed yield was low despite its early flowering (Figure 2.6). Such low seed yield was probably due to the high percentage of male flowers, which is under genetic as well as environmental control (Faux \& Bertin, 2014; Faux et al., 2013). The bast fibre yield of FUT was constantly the highest among the monoecious cultivars tested in IT, CZ and FR, as a consequence of late flowering and high bast fibre content, while its seed yield was close to the average yield in our experiment (Figure 2.7). Thus, FUT can be chosen for dual-purpose production when high fibre yield is desirable.
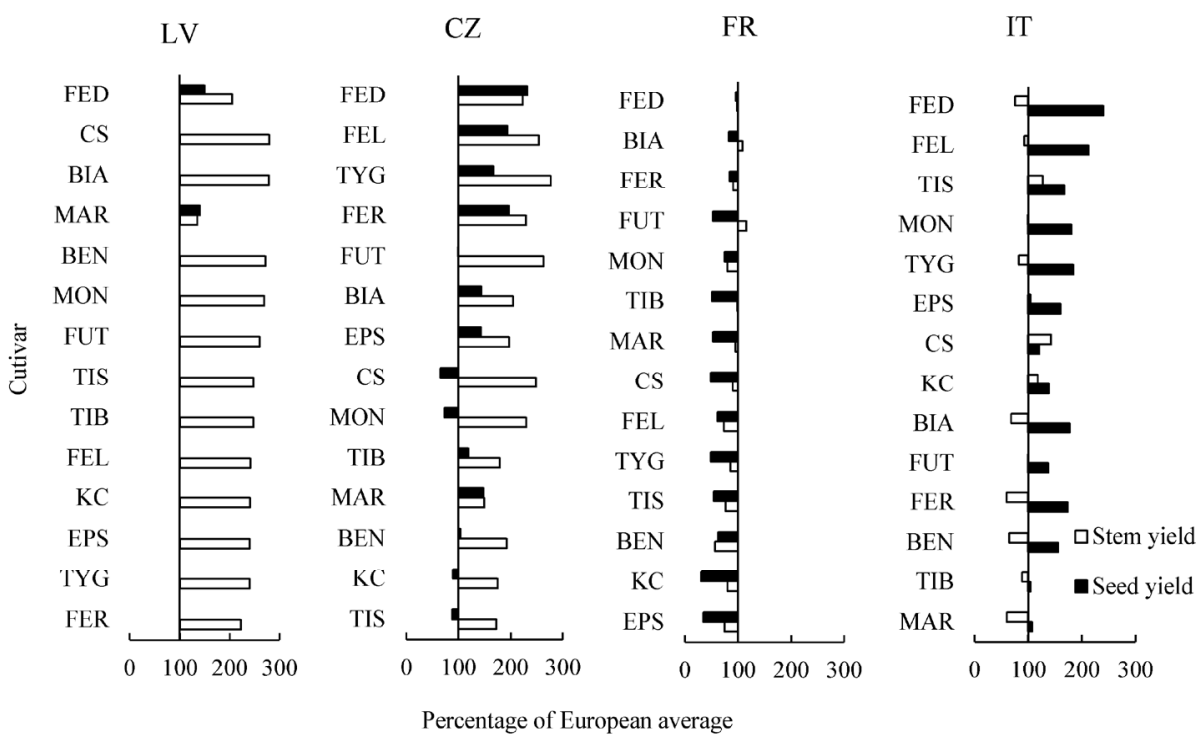

Figure 2.7 The stem and seed yields compared with the average in Europe. The average of stem yield was $7.3 \mathrm{Mg} \mathrm{ha}^{-1}$, given by Carus et al. (2013). The average of seed yield was $1.0 \mathrm{Mg} \mathrm{ha}^{-1}$, average between $0.9 \mathrm{Mg} \mathrm{ha}^{-1}$ and $1.1 \mathrm{Mg} \mathrm{ha}^{-1}$ given by Desanlis et al. (2013). The locations name are abbreviated as: CZ (the Czech Republic); FR (France); IT (Italy). 


\section{Chapter 2}

Among the tested locations, IT, FR and CZ had both seed and stem yield close to the average yield in Europe (Figure 2.7). Hemp cultivation for dual-purpose production is therefore foreseeable in these three locations by cultivating FED or FUT. High seed yield can also be expected in LV with cultivar FED. However, considering that FED was harvested in LV in the middle of September, which was very close to the first frost, it seems advisable to choose an earlier cultivar for dual-purpose production in LV, for example, Finola which flowered in the beginning of September in LV in 2014 (unpublished data) and had high seed yield at high latitude, 1.7 $\mathrm{Mg} \mathrm{ha}^{-1}$ seed yield was produced in Finland (Callaway, 2002).

\subsubsection{The effect of genotype and environment on hemp development}

Days from sowing to emergence measured in our study is in agreement with values reported from other European experiments (Cosentino et al., 2013; Van der Werf et al., 1995). The large variation of degree-days until emergence among locations was probably a consequence of soil structure and moisture at sowing (Hyatt et al., 2007; Nasr \& Selles, 1995), and sowing depth. Even though it was relatively small $(C V 8 \%)$, a significant variation in emergence time among cultivars was observed in our experiments (Table 2.4). Different germination rates among cultivars were also observed during germinability tests (unpublished data). The difference of germination rates among cultivars could be attributed to the variation of seed quality (i.e. maturation degree and storage duration) but also genetic differences as noted in other crops, such as soybean (Hopper et al., 1979) and wheat (Triticum aestivum L.) (Lafond \& Baker, 1986). In view of the importance to have a uniform and simultaneous emergence in hemp crop (Struik et al., 2000), further study is needed to investigate the effect of genotype on seed vigour and rate of emergence.

As discussed above, flowering is the main developmental event that affects the production of stem and seed in hemp genotypes. An accurate prediction of flowering time would facilitate agronomic activities. Hemp is a quantitative short-day crop that requires shorter thermal time to reach flowering at low latitude (Figure 2.2). The good fitness between observed and simulated flowering time, using the phenological model developed by Amaducci et al. (2008b) indicates that hemp flowering time can be modelled on the basis of temperature and photoperiod (Figure 2.3). However, it should be noted that the parameterisation found in our study is different from the one previously published Amaducci et al. (2012) and Amaducci et al. (2008b) for the common cultivars (i.e., FUT, FEL and TIB) (Table 2.6). Although the reason for this discrepancy is not clear, it might be partly due to the limited number of observations in our 
trials. The parameters reported in Amaducci et al. (2012) were derived from a wide range of environmental conditions, sites ranged from Sicily to Finland and sowing time ranged from March to August. The relatively accurate estimation of flowering time of FEL and FUT using the parameter values reported in Amaducci et al. (2012) indicates that these parameter values enable the prediction of flowering time of FEL and FUT across a wide range of environmental conditions in Europe.

\subsubsection{Strategies to develop dual-purpose cultivars - crop growth modelling approach}

Dual-purpose hemp production requires a long vegetative phase that leaves enough time for seed growth. Using the phenological model developed by Amaducci et al. (2008b) and parameter values reported in Amaducci et al. (2012), we explored the effect of emergence time on flowering date of FEL and FUT in IT. The results show that procrastinating emergence date from May to August in IT gradually decreases the length of vegetative phase of FEL and FUT while the flowering date is slightly delayed (Figure 2.8). Similar results were reported by Faux et al. (2013) in central Europe where early sowing resulted in a long vegetative growth period while flowering date was advanced. It would therefore be possible to prolong the vegetative phase of FEL and FUT while still having a relatively early flowering by sowing early in IT so that high yield of stem and seed can be obtained from the same crop. Unfortunately, early sowing of early cultivars at low latitudes results in very early flowering, which is documented as "pre-flowering" in sites like Southern Italy where hemp was once traditionally grown (Barbieri, 1952, cited by Amaducci et al., 2008). This behaviour is adequately simulated by the hemp phenological model (Figure 2.8, FEL, Amaducci et al., 2008b) and it is suggested not to
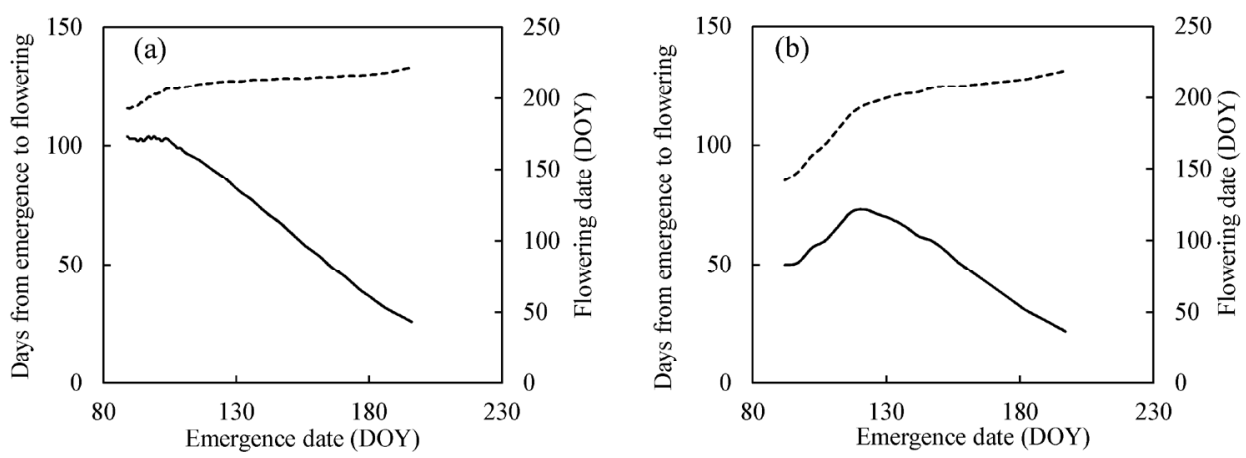

Figure 2.8 Simulated flowering time of Futura 75 (panel a) and Felina 32 (panel b) in response to emergence date in Italy by using the phenological model developed by Amaducci et al. (2008b) and parameters provided by Amaducci et al. (2012). Solid line: days from emergence to flowering; dashed line: flowering date. 


\section{Chapter 2}

plant FEL before May in IT.

The abovementioned application of modelling to develop strategies for dual-purpose hemp production is promising. However, the model parameterisation is time consuming and multilocation trials are required to accurately parameterise the model for all the available commercial cultivars. Considering that flowering is under genetic control (Table 2.6), the development of a gene-based phenological model, as done for rice (Nakagawa et al., 2005) and barley (Yin et al., 2005), would provide a powerful tool to plan hemp cultivation and to aid breeders in the development of hemp cultivars suitable for dual-purpose production in various environments.

Under the framework of the MultiHemp project (http://multihemp.eu/) a genome-wide association mapping is being carried out and a hemp crop growth model is being developed. These unique works will provide an excellent opportunity to use the combined modelling and genetic mapping approach for unravelling the complexity of hemp growth and production.

\subsection{Conclusions}

The stem and seed productivity of 14 commercial hemp cultivars were compared in four contrasting environmental conditions in Europe. The variation of stem and seed yield among genotypes was mainly determined by the difference in flowering time, which is under control of temperature and photoperiod. In late cultivars stem yield was high and seed yield was low. When harvesting was postponed from full flowering to seed maturity, the stem yield of monoecious cultivars significantly increased but that of the dioecious cultivars decreased, with the exception of Italy. Among the tested cultivars, not one combined the highest stem with the highest seed yield. The late cultivar CS is suitable for stem production as it had the highest stem yield. Both FED and FUT are suitable for dual-purpose production in IT, FR and CZ, with FED producing the highest seed yield and FUT the highest stem yield.

The application of modelling to develop strategies for dual-purpose hemp production is promising. However, accurate estimation of modelling parameters from field observations or based on genetic information is needed.

\section{Acknowledgements}

The research leading to these results has received funding from the European Union's Seventh Framework Programme for research, technological development and demonstration under grant agreement $n^{\circ}$ 311849. The authors gratefully acknowledge Birgit Uhrlaub 
(Hochschule Bremen) for fibre extraction and all the staff members and students involved in field trials.

\section{References}

Allegret, S., Bouloc, P. and Arnaud, L. (2013) The history of hemp. In: Hemp: industrial production and uses (eds Bouloc, P. , Allegret, S. and Arnaud, L.), pp. 4-26. CPi Group Ltd, Croydon, UK.

Amaducci, S. (2003) HEMP-SYS. Journal of Industrial Hemp, 8, 79-83.

Amaducci, S. (2005) Hemp production in Italy. Journal of Industrial Hemp, 10, 109-115.

Amaducci, S., Colauzzi, M., Bellocchi, G. et al. (2012) Evaluation of a phenological model for strategic decisions for hemp (Cannabis Sativa L.) biomass production across European sites. Industrial Crops and Products, 37, 100-110.

Amaducci, S., Zatta, A., Pelatti, F. et al. (2008a) Influence of agronomic factors on yield and quality of hemp (Cannabis sativa L.) fibre and implication for an innovative production system. Field Crops Research, 107, 161-169.

Amaducci, S., Colauzzi, M., Bellocchi, G. et al. (2008b) Modelling post-emergent hemp phenology (Cannabis sativa L.): Theory and evaluation. European Journal of Agronomy, 28, 90-102.

Amaducci, S., Colauzzi, M., Zatta, A., G. et al. (2008c) Flowering dynamics in monoecious and dioecious hemp genotypes. Journal of Industrial Hemp, 13, 5-19.

Amaducci, S. and Gusovius, H.J. (2010) Hemp - cultivation, extraction and processing. In: Industrial Applications of Natural Fibres: Structure, Properties and Technical Applications (ed Müssig, J.), pp. 109-134. John Wiley \& Sons Ltd, West Sussex, UK.

Amaducci, S., Pelatti, F. and Bonatti, P.M. (2005) Fibre development in hemp (Cannabis sativa L.) as affected by agrotechnique: preliminary results of a microscopic study. Journal of Industrial Hemp, 10, 31-48.

Amaducci, S., Scordia, D., Liu, F. et al. (2015) Key cultivation techniques for hemp in Europe and China. Industrial Crops and Products, 68, 2-16.

Barbieri, P. (1952) La prefioritura della canapa in Campania nell'annata. Agric. Napoletana, 79.

Barth, M. and Carus, M. (2015) Carbon footprint and sustainability of different natural fibres for biocomposites and insulation material. nova-Institute, Hürth, Germany. Available at (2017, February 29): http://multihemp.eu/media/2015/05/15-04-20_PR_CarbonFootprint-of-Natural-Fibres_nova.pdf

Berenji, J., Sikora, V., Fournier, G. et al. (2013) Genetics and selection of hemp. In: Hemp: industrial production and uses (eds Bouloc, P., Allegret, S. and Arnaud, L.), pp. 48-71. CPi Group Ltd, Croydon, UK.

Bertoli, A., Tozzi, S., Pistelli, L. et al. (2010) Fibre hemp inflorescences: From crop-residues to essential oil production. Industrial Crops and Products, 32, 329-337.

Bouloc, P. and Van der Werf, H.M.G. (2013) The role of hemp in sustainable development. In: 
Hemp: industrial production and uses (eds Bouloc, P., Allegret, S. and Arnaud, L.), pp. 278-289. CPi Group Ltd, Croydon, UK.

Callaway, J. and Laakkonen, T. (1996) Cultivation of Cannabis oil seed varieties in Finland. Journal of the International Hemp Association, 3, 32-34.

Callaway, J.C. (2002) Hemp as food at high latitudes. Journal of Industrial Hemp, 7, 105-117.

Callaway, J.C. (2004) Hempseed as a nutritional resource: An overview. Euphytica, 140, 6572.

Carus, M., Karst, S., Kauffmann, A. et al. (2013) The European hemp industry: Cultivation, processing and applications for fibres, shivs and seeds. European hemp Industry Association. Available at (2017, February 29): http://eiha.org/media/2014/10/13-06European-Hemp-Industry.pdf

Castaldini, M., Fabiani, A. and Santomassimo, F. (2001) Effects of hemp retting water on the composition of soil bacterial community and on wheat yield. Italian Journal of Agronomy, 5, 21-27.

Cosentino, S.L., Riggi, E., Testa, G. et al. (2013) Evaluation of European developed fibre hemp genotypes (Cannabis sativa L.) in semi-arid Mediterranean environment. Industrial Crops and Products, 50, 312-324.

Cosentino, S.L., Testa, G., Scordia, D. et al. (2012) Sowing time and prediction of flowering of different hemp (Cannabis sativa L.) genotypes in southern Europe. Industrial Crops and Products, 37, 20-33.

De Meijer, E.P.M. (1994) Variation of Cannabis with reference to stem quality for paper pulp production. Industrial Crops and Products, 3, 201-211.

De Meijer, E.P.M. and Van der Werf, H.M.G. (1994). Evaluation of current methods to estimate pulp yield of hemp. Industrial Crops and Products, 2, 111-120.

Faux, A.M. and Bertin, P. (2014) Modelling approach for the quantitative variation of sex expression in monoecious hemp (Cannabis sativa L.). Plant Breeding, 133, 782-787.

Faux, A.M., Draye, X., Lambert, R. et al. (2013) The relationship of stem and seed yields to flowering phenology and sex expression in monoecious hemp (Cannabis sativa L.). European Journal of Agronomy, 47, 11-22.

Finnan, J. and Styles, D. (2013) Hemp: A more sustainable annual energy crop for climate and energy policy. Energy Policy, 58, 152-162.

Gunawardena, T., Fukai, S. and Blamey, F. (2003) Low temperature induced spikelet sterility in rice. I. Nitrogen fertilisation and sensitive reproductive period. Crop \& Pasture Science, 54, 937-946.

Hall, J., Bhattarai, S.P. and Midmore, D.J. (2012) Review of dlowering control in industrial hemp. Journal of Natural Fibers, 9, 23-36.

Han, T., Wu, C., Tong, Z. et al. (2006) Postflowering photoperiod regulates vegetative growth and reproductive development of soybean. Environmental and Experimental Botany, 55, $120-129$.

Hennink, S. (1994) Optimisation of breeding for agronomic traits in fibre hemp (Cannabis sativa L.) by study of parent-offspring relationships. Euphytica, 78, 69-76. 
Hopper, N.W., Overhot, J.R. and Martin, J.R. (1979) Effect of cultivar, temperature and seed size on the germination and emergence of soybeans [Glycine max (L.) Merr.]. Annals of Botany, 44, 301-308.

Höppner, F. and Menge-Hartmann, U. (2007) Yield and quality of fibre and oil of fourteen hemp cultivars in Northern Germany at two harvest dates. Landbauforsch Volk, 57, 219-232.

Hyatt, J., Wendroth, O., Egli, D.B. et al. (2007) Soil compaction and soybean seedling emergence. Crop Science, 47, 2495-2503

Jiang, Y., Wu, C., Zhang, L. et al. (2011) Long-day effects on the terminal inflorescence development of a photoperiod-sensitive soybean [Glycine max (L.) Merr.] variety. Plant Science, 180, 504-510.

Kantolic, A.G., Peralta, G.E. and Slafer, G.A. (2013) Seed number responses to extended photoperiod and shading during reproductive stages in indeterminate soybean. European Journal of Agronomy, 51, 91-100.

Kantolic, A.G. and Slafer, G.A. (2001) Photoperiod sensitivity after flowering and seed number determination in indeterminate soybean cultivars. Field Crops Research, 72, 109-118.

Kantolic, A.G. and Slafer, G.A. (2007) Development and seed number in indeterminate soybean as affected by timing and duration of exposure to long photoperiods after flowering. Annals of Botany, 99, 925-933.

Keller, A., Leupin, M., Mediavilla, V. et al. (2001) Influence of the growth stage of industrial hemp on chemical and physical properties of the fibres. Industrial Crops and Products, 13, 35-48.

Lafitte, H.R. and Edmeades, G.O. (1997) Temperature effects on radiation use and biomass partitioning in diverse tropical maize cultivars. Field Crops Research, 49, 231-247.

Lafond, G.P. and Baker, R.J. (1986) Effects of genotype and seed size on speed of emergence and seedling vigor in nine spring wheat cultivars. Crop Science, 26, 341-346.

Legros, S., Picault, S. and Cerruti, N. (2013) Factors affecting the yield of industrial hemp experimental results from France. In Hemp: industrial production and uses (eds Bouloc, P. , Allegret, S. and Arnaud, L.), pp. 72-97. CPi Group Ltd, Croydon, UK.

Lisson, S.N., Mendham, N.J. and Carberry, P.S. (2000a) Development of a hemp (Cannabis sativa L.) simulation model 1. General introduction and the effect of temperature on the pre-emergent development of hemp. Australian Journal of Experimental Agriculture, 40, $405-411$.

Lisson, S.N., Mendham, N.J. and Carberry, P.S. (2000b) Development of a hemp (Cannabis sativa L.) simulation model 2. The flowering response of two hemp cultivars to photoperiod. Australian Journal of Experimental Agriculture, 40, 413-417.

Mediavilla, V., Leupin, M. and Keller, A. (2001) Influence of the growth stage of industrial hemp on the yield formation in relation to certain fibre quality traits. Industrial Crops and Products, 13, 49-56.

Nakagawa, H., Yamagishi, J., Miyamoto, N. et al. (2005) Flowering response of rice to photoperiod and temperature: a QTL analysis using a phenological model. Theoretical and Applied Genetics, 110, 778-786. 
Nasr, H.M. and Selles, F. (1995) Seedling emergence as influenced by aggregate size, bulk density, and penetration resistance of the seedbed. Soil \& Tillage Research, 34, 61-76.

Ohnishi, S., Miyoshi, T. and Shirai, S. (2010) Low temperature stress at different flower developmental stages affects pollen development, pollination, and pod set in soybean. Environmental and Experimental Botany, 69, 56-62.

Pahkala, K., Pahkala, E. and Syrjala, H. (2008) Northern limits to fiber hemp production in Europe. Journal of Industrial Hemp, 13, 104-116.

Prade, T., Svensson, S.E., Andersson, A. et al. (2011) Biomass and energy yield of industrial hemp grown for biogas and solid fuel. Biomass Bioenergy, 35, 3040-3049.

Salentijn, E.M.J., Zhang, Q., Amaducci, S. et al. (2015) New developments in fiber hemp (Cannabis sativa L.) breeding. Industrial Crops and Products, 68, 32-41.

Sankari, H.S. (2000) Comparison of bast fibre yield and mechanical fibre properties of hemp (Cannabis sativa L.) cultivars. Industrial Crops and Products, 11, 73-84.

Struik, P.C., Amaducci, S., Bullard, M.J. et al. (2000) Agronomy of fibre hemp (Cannabis sativa L.) in Europe. Industrial Crops and Products, 11, 107-118.

Thakur, P., Kumar, S., Malik, J.A. et al. (2010) Cold stress effects on reproductive development in grain crops: An overview. Environmental and Experimental Botany, 67, 429-443.

Van der Werf, H.M.G., Brouwer, K., Wijlhuizen, M. et al. (1995) The effect of temperature on leaf appearance and canopy establishment in fibre hemp (Cannabis sativa L.). Annals of Applied Biology, 126, 551-561.

Van der Werf, H.M.G., Harsveld van der Veen, J.E., Bouma, A.T.M. et al. (1994) Quality of hemp (Cannabis sativa L.) stems as a raw material for paper. Industrial Crops and Products, 2, 219-227.

Westerhuis, W., Amaducci, S., Struik, P.C. et al. (2009a) Sowing density and harvest time affect fibre content in hemp (Cannabis sativa L.) through their effects on stem weight. Annals of Applied Biology, 155, 225-244.

Westerhuis, W., Pakhala, K., Struik, P.C. et al. (2009b) Site does not affect the fibre content ranking order among fibre hemp varieties. Pflanzenbauwissenschaften, 13, 60-71.

Wirtshafter, D.E. (2004) Ten years of a modern hemp industry. Journal of Industrial Hemp, 9, 9-14.

Yin, X., Struik, P.C., Tang, J. et al. (2005) Model analysis of flowering phenology in recombinant inbred lines of barley. Journal of Experimental Botany, 6, 959-965. 


\section{Supplementary Materials in Chapter 2}

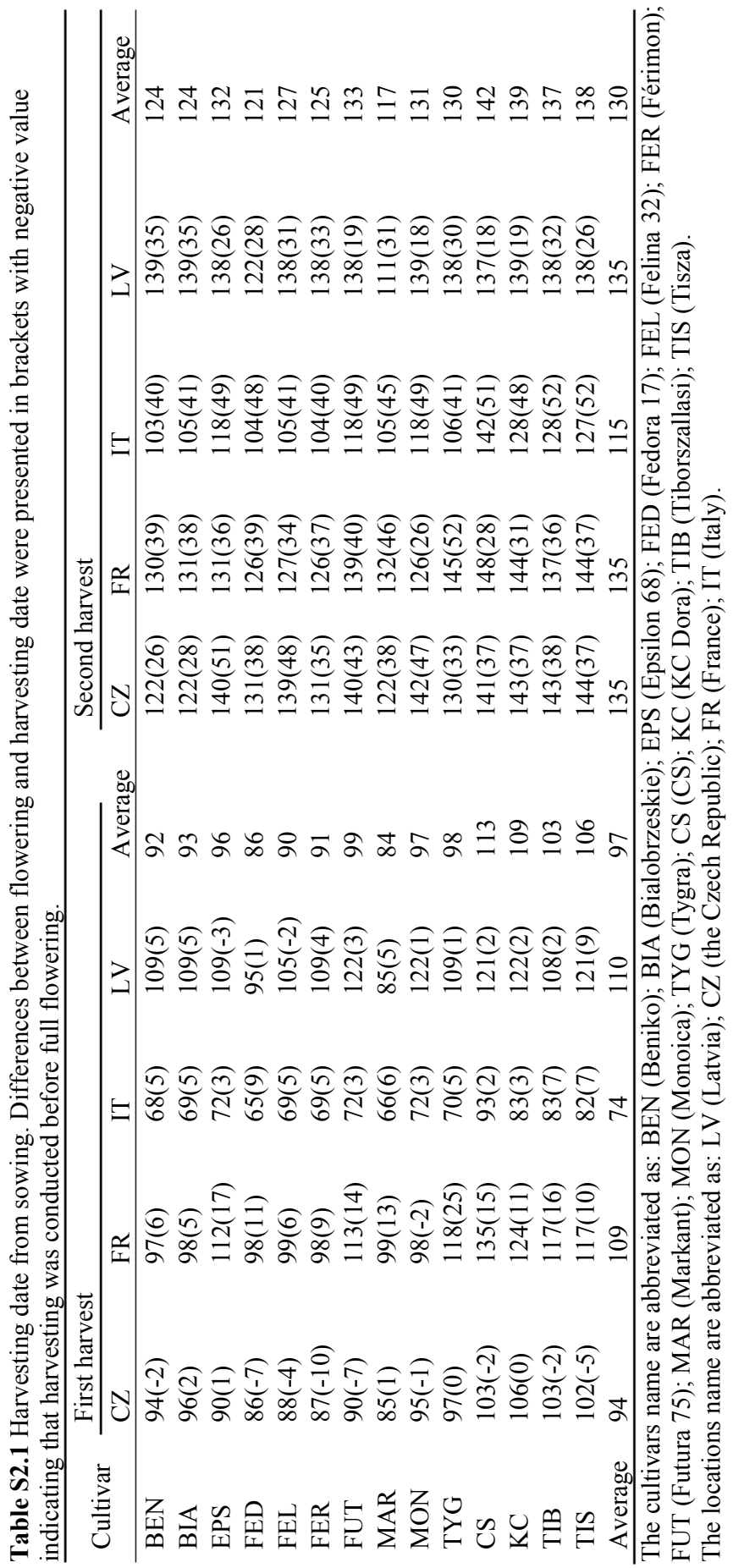




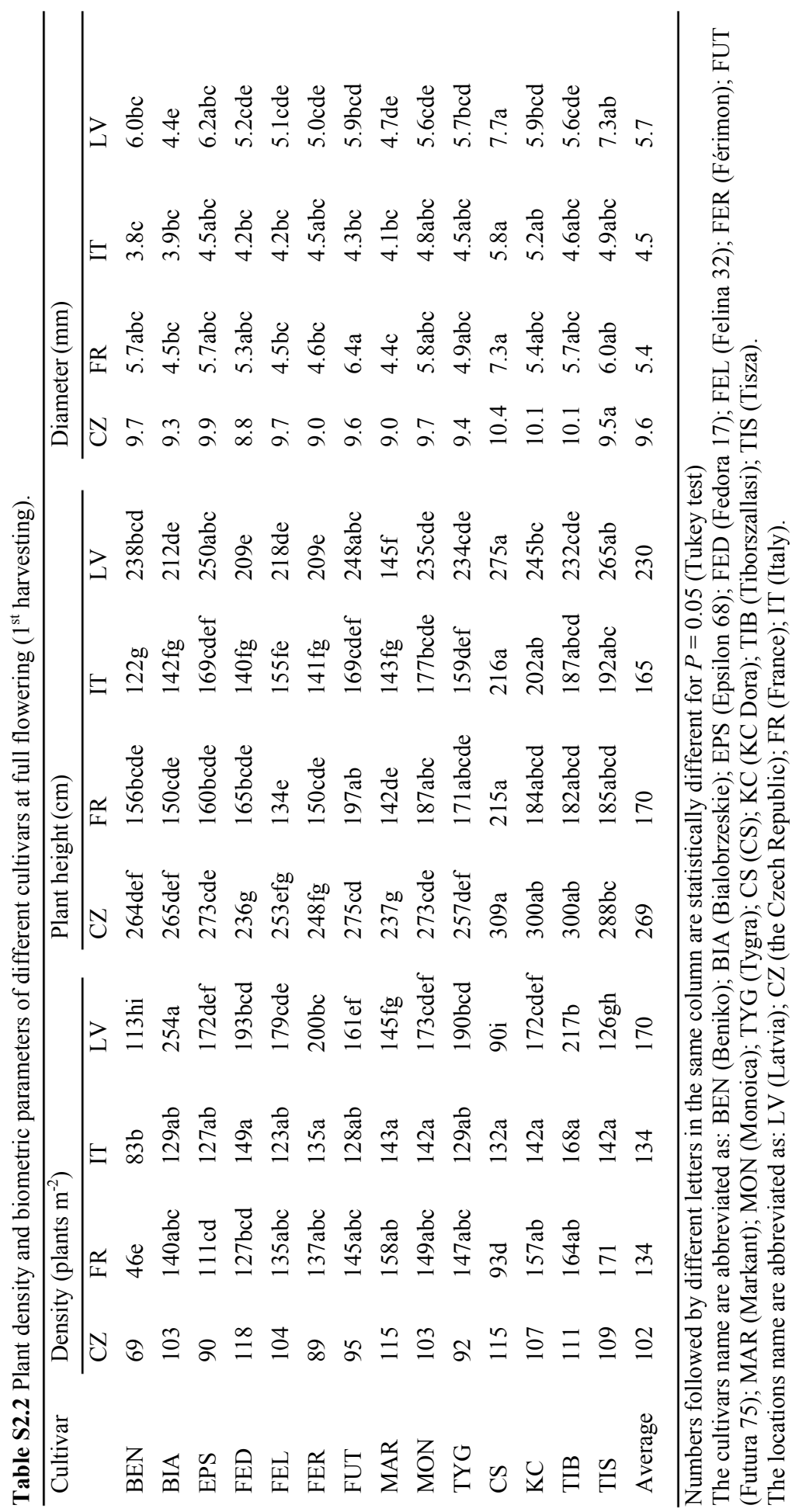




\section{Chapter 3}

\section{A comprehensive study of planting density and nitrogen fertilization effect on dual-purpose hemp (Cannabis sativa L.) cultivation}

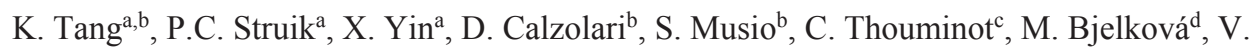
Stramkale , G. Magagnini ${ }^{\mathrm{f}}, \mathrm{S}$. Amaducci $^{\mathrm{b}}$

${ }^{a}$ Centre for Crop Systems Analysis, Department of Plant Sciences, Wageningen University \& Research, Droevendaalsesteeg 1, Wageningen, The Netherlands

${ }^{b}$ Department of Sustainable Crop Production, Università Cattolica del Sacro Cuore, via Emilia Parmense, 84, Piacenza, Italy

${ }^{c}$ Federation Nationale des Producteurs de Chanvre, 20, rue Paul Ligneul, Le Mans, France ${ }^{d}$ Department of Industrial Crops, AGRITEC Plant Research Ltd., Zemedělská 16, Šumperk, Czech Republic

${ }^{e}$ Latgale Agriculture Research Centre, Kulturas Laukums 1a, Vilani, Latvia

${ }^{f}$ Council for Research and Experimentation in Agriculture - Research Centre for Industrial Crops (CRA-CIN), Viale G. Amendola 82, Rovigo, Italy

This Chapter is published in Industrial Crops and Products 107 (2017), 427-438. 


\title{
Chapter 3
}

\begin{abstract}
Harvesting hemp (Cannabis sativa L.) for both stems and seeds is now a common practice in Europe while crop management strategies for dual-purpose hemp cultivation have not been properly addressed so far. In the present study, the effects of planting density and nitrogen fertilization on hemp stem and seed yields were tested with the cultivars Futura 75 and/or Bialobrzeskie in eight contrasting environments (Italy in 2013; Italy and Latvia in 2014; Italy (two sites), Latvia, the Czech Republic, and France in 2015). Stem yield ranged between $1.3 \mathrm{Mg} \mathrm{ha}^{-1}$ and $22.3 \mathrm{Mg} \mathrm{ha}^{-1}$. The effects of planting density and nitrogen fertilization on stem yield did not interact significantly with each other, or with cultivar and harvest time. Increasing planting density from 30 plants $\mathrm{m}^{-2}$ to 120 plants $\mathrm{m}^{-2}$ and increasing nitrogen fertilization rate from 0 to $60 \mathrm{~kg} \mathrm{~N} \mathrm{ha}^{-1}$ increased stem yield by $29 \%$ and $32 \%$, respectively. Further increase in planting density and nitrogen fertilization did not result in a significant increase in stem yield. Seed yield ranged from $0.3 \mathrm{Mg} \mathrm{ha}^{-1}$ to $2.1 \mathrm{Mg} \mathrm{ha}^{-1}$. The seed yield was not affected significantly by planting density between 30 plants $\mathrm{m}^{-2}$ and 240 plants $\mathrm{m}^{-2}$. Although the seed yield showed an increasing trend with increasing nitrogen fertilization, the effects of nitrogen fertilization on seed yield were not statistically significant.

To grow hemp as a dual-purpose crop it is recommended to plant $90-150$ plants $\mathrm{m}^{-2}$ across all tested environments. Nitrogen fertilization rate at $60 \mathrm{~kg} \mathrm{~N} \mathrm{ha}^{-1}$ was generally sufficient in the tested environments whereas further optimization of nitrogen fertilization requires accurate assessment of plant nitrogen status. To facilitate assessing plant nutritional status, a critical nitrogen dilution curve was determined for hemp and a practical method to determine nitrogen nutritional status was discussed.
\end{abstract}

Key words: hemp (Cannabis sativa L.); density; nitrogen; critical dilution curve; stem; seed. 


\subsection{Introduction}

Hemp (Cannabis sativa L.) is resurging as an ideal multipurpose crop worldwide (Aubin et al., 2016; Amaducci et al., 2015; Faux et al., 2013; Bertoli et al., 2010). For the first time, it was cultivated in Europe on more than 33,000 ha in 2016 mainly as a dual-purpose crop where stems and seeds were harvested simultaneously (Carus et al., 2017). However, hemp was traditionally a fibre crop and most past research focused on this purpose (Westerhuis et al., 2009; Amaducci et al., 2008a, 2002a; Struik et al., 2000; Van der Werf et al., 1996). Very limited information is available on growing dual-purpose hemp (Amaducci et al., 2015). In the frame of the EC funded project Multihemp (www.multihemp.eu), extensive experiments have been carried with the aim of providing novel information to support dual-purpose hemp cultivation in Europe. Aspects related to cultivar choice for dual-purpose hemp cultivation have been presented in Chapter 2. The present study focuses on the effect of the two main agronomic practices affecting the performance of dual-purpose hemp: planting density and nitrogen fertilization.

The effects of planting density and nitrogen fertilization on both stem and seed yields have not been properly addressed so far. Previous researches indicate that planting density has little effect on stem yield, but plants grown at high density are shorter and thinner than those grown at low density (Amaducci et al., 2002b; Struik et al., 2000). Slender stems are desirable for fibre hemp production because they produce more long fibre (Westerhuis et al., 2009) and require less energy for their mechanical processing (Khan et al., 2010). Thus, a high planting density is generally used, ranging from 90 plants $\mathrm{m}^{-2}$ to 350 plants $\mathrm{m}^{-2}$ (Martinov et al., 1996; Starcevic, 1996), to achieve required fibre quantity and quality. On the other hand, a low planting density, ranging from 30 plants $\mathrm{m}^{-2}$ to 75 plants $\mathrm{m}^{-2}$, is recommended for producing hemp seeds (Amaducci \& Gusovius, 2010 and references therein). Optimal planting density has not been researched for growing hemp as a dual-purpose crop.

The effect of nitrogen fertilization on stem yield varies in literature. For relatively low fertility conditions, Amaducci et al. (2002b) reported that stem yield increased by $20 \mathrm{~kg} \mathrm{~kg}^{-1}$ N. Finnan \& Burke (2013) reported a very high stem yield increase with increasing fertilization from 0 up to $120 \mathrm{~kg} \mathrm{~N} \mathrm{ha}^{-1}$ (as high as $60 \mathrm{~kg} \mathrm{~kg}^{-1} \mathrm{~N}$ ). In contrast, the yield response of hemp to nitrogen fertilization was found negligible when soil fertility was high (Prade et al., 2011; Struik et al., 2000). Few studies have been conducted considering the response of seed yield to nitrogen fertilization. Aubin et al. (2015) and Marija et al. (2011) reported that both stem 


\section{Chapter 3}

and seed yields were positively related to nitrogen fertilization. Vera et al. (2010, 2004) reported that hemp seed yield increased progressively with increasing nitrogen availability until a high fertilization rate, ranging from $99 \mathrm{~kg} \mathrm{~N} \mathrm{ha}^{-1}$ to $198 \mathrm{~kg} \mathrm{~N} \mathrm{ha}^{-1}$ depending on growing conditions. Given the wide range of the results regarding stem and seed yields in response to nitrogen fertilization and the large variation of soil nitrogen availability, it is a challenge for farmers to optimize fertilization rate and to maximize economic return.

Nitrogen fertilization affects crop yield mainly through its effect on plant nitrogen status (Sadras \& Lemaire, 2014). When nitrogen supply is deficient, aboveground biomass yield $(W)$ increases with increasing nitrogen uptake until a critical nitrogen concentration $\left(N_{\text {critical }}\right)$ has been reached; further increasing nitrogen uptake has little impact on increasing $W$ (Lemaire \& Meynard, 1997). In general, the $N_{\text {critical }}$ decreases exponentially with increasing $W$ during plant

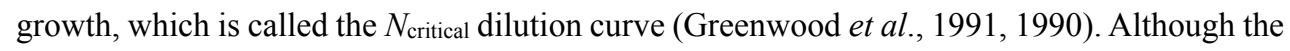

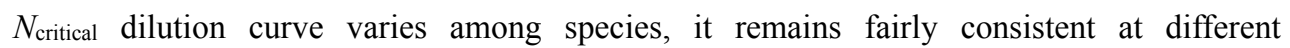
environmental growth conditions (Lemaire \& Gastal, 2009). Therefore, the $N_{\text {critical }}$ dilution curve has been used to determine the nitrogen status for many crops, including rice (Oryza sativa L.; Ata-Ul-Karim et al., 2013; Sheehy et al., 1998), maize (Zea mays L.; Ziadi et al., 2010), oilseed rape (Brassica napus L.; Colnenne et al., 1998) and linseed (Linum usitatissimum L.; Flénet et al., 2006). Estimating a $N_{\text {critical }}$ dilution curve for hemp would be useful to optimize its nitrogen fertilization.

The objective of this study was to assess the effects of planting density and nitrogen fertilization across a wide range of environments to support dual-purpose hemp cultivation in Europe. First, the effects of planting density and nitrogen fertilization on hemp stem and seed yields were investigated. Second, the characteristics of hemp's nitrogen demand were analysed, and a critical nitrogen dilution curve was assessed for hemp.

\subsection{Materials and methods}

\subsubsection{Experimental locations and field layout}

Field experiments were carried out at five locations in Europe: Piacenza-IT (Piacenza, Italy), Budrio-IT (Budrio, Italy), FR (La Trugalle, France), CZ (Sumperk, the Czech Republic) and LV (Vilani, Latvia) from 2013 to 2015 (Table 3.1). Latitude difference between the most northern (LV) and the most southern (Budrio-IT) location was $12^{\circ}$, which corresponds to $2 \mathrm{~h}$ of maximum day-length. Average temperature between May and October (during the hemp 


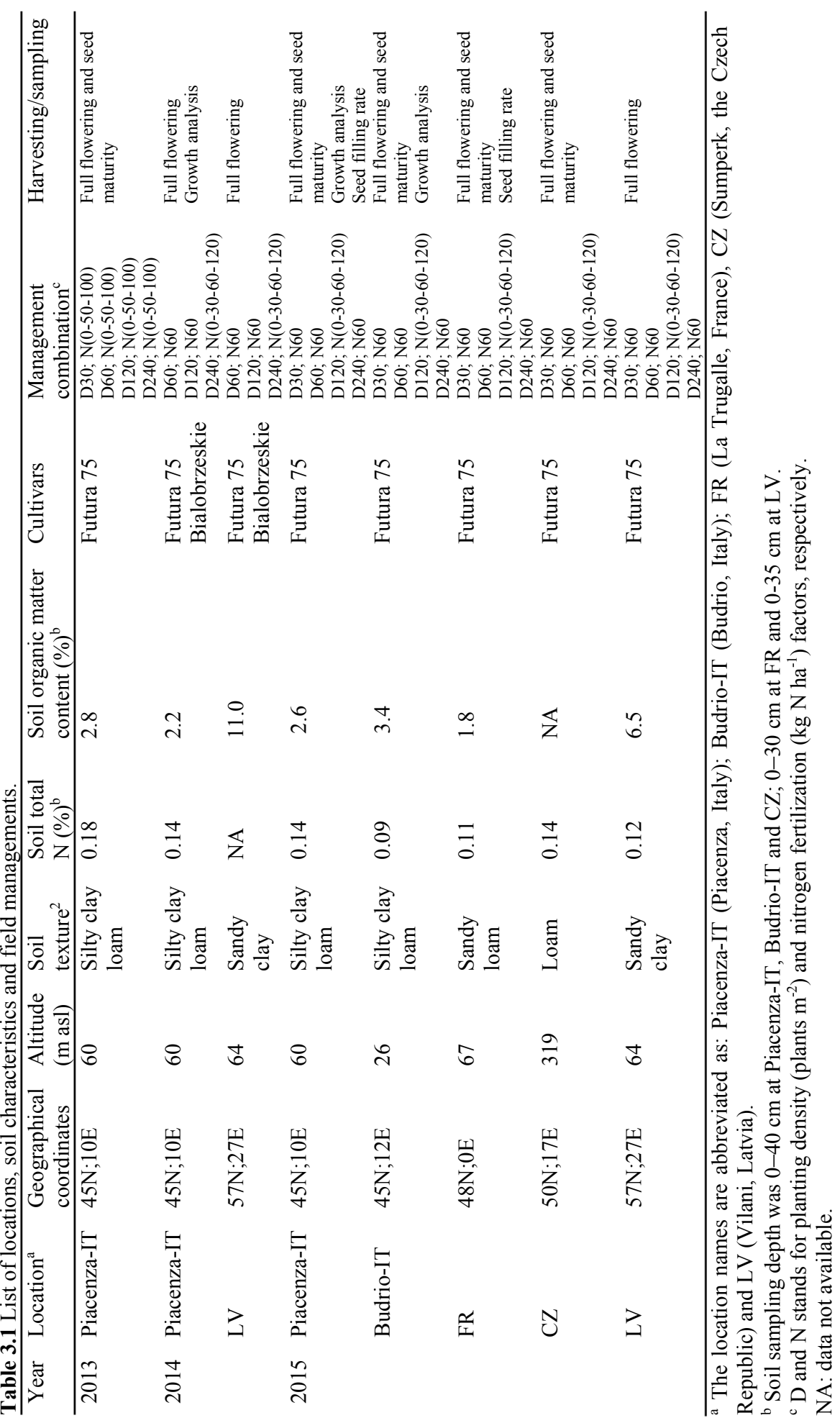




\section{Chapter 3}

growing season) ranged from $14.9^{\circ} \mathrm{C}(\mathrm{LV})$ to $21.8^{\circ} \mathrm{C}$ (Piacenza-IT); total precipitation ranged from $212 \mathrm{~mm}$ (CZ) to $297 \mathrm{~mm}$ (FR). The most southern locations, Piacenza-IT and Budrio-IT, were hot and dry in the summer while the other three locations were cool and humid (Supplementary Material Figure S3.1).

Planting density was varied from 30 plants $\mathrm{m}^{-2}$ to 240 plants $\mathrm{m}^{-2}$; nitrogen fertilization range was from 0 to $120 \mathrm{~kg} \mathrm{~N} \mathrm{ha}^{-1}$. The planting density $\times$ nitrogen fertilization interaction was tested with the cultivar Futura 75 in Piacenza-IT in 2013. The planting density $\times$ cultivar and nitrogen fertilization $\times$ cultivar interactions were tested with the cultivars Futura 75 and Bialobrzeskie in Piacenza-IT and LV in 2014. As the effects of planting density and nitrogen fertilization on stem and seed yields did not interact with each other in 2013 and did not interact with cultivar in 2014 (see Results section), the effects of planting density and nitrogen fertilization were tested separately in 2015 for the cultivar Futura 75 at all five locations (Piacenza-IT, BudrioIT, FR, CZ and LV).

The main factors (i.e., planting density, nitrogen fertilization and cultivar) were tested in a randomized complete block design with four replicates. Single plot size was $42 \mathrm{~m}^{2}$ when only two harvests were scheduled, or $60 \mathrm{~m}^{2}$ when multiple harvests were scheduled for a detailed growth analysis. Sowings were carried out as soon as the soil was accessible and average daily temperature rose above $8-10^{\circ} \mathrm{C}$. Sowing dates spanned from the earliest on 7 April 2014 in Piacenza-IT to the latest on 14 May 2015 in Budrio-IT (Supplementary Material Table S3.1). Seeds were drilled at 3-4 cm depth using experimental-plot sowing machines. The distance between rows varied between $15 \mathrm{~cm}$ and $25 \mathrm{~cm}$, depending on the sowing machine used at each location. Seed rates were calculated based on the target density considering weight of 1000 seeds and results of seed germination tests. In Piacenza-IT and Budrio-IT, densities of 30 plants $\mathrm{m}^{-2}$ and 60 plants $\mathrm{m}^{-2}$ were obtained by sowing seeds in excess $\left(90\right.$ plants $\mathrm{m}^{-2}$ ) and handthinning to target density after emergence. Hand-thinning was conducted carefully so that any impact (e.g. increase of soil compaction due to worker's footprint) on plant growth would be minimized. Nitrogen fertilizer was distributed at sowing or immediately after emergence. Irrigation was only applied in Piacenza-IT; in total $120 \mathrm{~mm}, 60 \mathrm{~mm}$ and $155 \mathrm{~mm}$ of water was provided with a travelling sprinkler in 2013, 2014 and 2015, respectively.

\subsubsection{Assessing crop development and yields}

Seedling emergence was monitored in the plots with 120 plants $\mathrm{m}^{-2}$ by counting the emerged plants in one row over a length of $1 \mathrm{~m}$ or in two rows over a length of $50 \mathrm{~cm}$, every two days 
from the appearance of the first plant until full emergence. Date of emergence was set when $50 \%$ of final seedlings had emerged. Flowering was monitored on 20 representative plants that were selected and labelled before flowering. A single plant was considered at the full flowering stage when its top appeared as a compact (i.e., with very short internodes) inflorescence with visible stigmata. The full flowering stage of a plot was set when $50 \%$ of the monitored plants had reached full flowering.

In each plot, harvest was carried out at least twice: at full flowering (H1) and at seed maturity (H2). At each harvest, all plants in an area of $4 \mathrm{~m}^{2}$ were cut just above the soil level. Fresh weight of all harvested plants was assessed immediately and the number of plants in the first harvested $1 \mathrm{~m}^{2}$ was counted. Among the plants of this first $1 \mathrm{~m}^{2}, 20$ representative plants were sampled. A subsample of 10 plants was dried at $75^{\circ} \mathrm{C}$ until constant weight to assess dry matter content. On the remaining 10 plants, stem diameter (at $10 \mathrm{~cm}$ from stem base), plant height and proportion of stem, leaf and seed (H2) in the above ground biomass (after oven drying) were assessed. $W$ (aboveground biomass yield) was calculated as the product of fresh weight and dry matter content. The yields of stem $\left(W_{\text {stem }}\right)$, leaf ( $\left.W_{\text {leaf }}\right)$ and seed ( $\left.W_{\text {seed }}\right)$ were estimated as the product of $W$ and the corresponding proportions.

In addition to $\mathrm{H} 1$ and $\mathrm{H} 2$, periodic samplings were carried out on $1 \mathrm{~m}^{2}$ area in Piacenza-IT (2014 and 2015) and in Burdio-IT (2015), in total 4-5 times. At each sampling date, all plants in an area of $1 \mathrm{~m}^{2}$ were cut just above the soil level using pruning scissors. Plant number, plant height, stem diameter, $W, W_{\text {stem }}, W_{\text {leaf }}$ and $W_{\text {seed }}$ (when present) were assessed following the same procedure described for $\mathrm{H} 1$ and $\mathrm{H} 2$. Total nitrogen concentration in stem $\left(N_{\text {stem }}\right)$, leaf $\left(N_{\text {leaf }}\right)$ and seed $\left(N_{\text {seed, }}\right.$ if present) was analysed for each nitrogen treatment plot using a $C N$ analyser (Vario Max CN Analyzer; Elementar Americas, Inc., Hanau, Germany). In PiacenzaIT (2014 and 2015), the interception of photosynthetically active radiation (PAR) by the canopy was measured before each sampling with a ceptometer (Decagon Devices, Inc., Pullman, Washington, USA); leaf area index ( $L A I)$ was calculated as the product of $W_{\text {leaf }}$ and specific leaf area $(S L A)$. The $S L A$ was determined as the ratio of leaf area and dry weight of all leaves of two representative plants per plot. The leaf area was determined from scanned pictures using ImageJ (version 1.49; https://imagej.nih.gov/). In Piacenza-IT in 2015, SPAD (SPAD-502, Minolta, Japan) measurements were taken at each harvesting time on 3 marked representative plants per plot. 


\subsubsection{Nitrogen demand analysis}

When plant nitrogen is limiting, $W$ generally increases with increasing nitrogen concentration

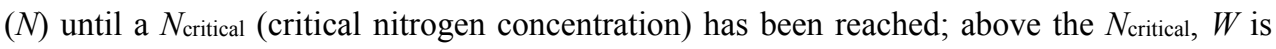
little dependent of $N$ indicating that nitrogen is in excess. The $N_{\text {critical }}(\%)$ decreases with increasing $W\left(\mathrm{Mg} \mathrm{ha}^{-1}\right)$ during the vegetative growth period. This relationship can be described by a negative power function (Lemaire et al., 2008a; Greenwood et al., 1991, 1990):

$$
N_{\text {critical }}= \begin{cases}a W^{-b} & W \geq W_{\text {threshold }} \\ N_{\text {constant }} & W<W_{\text {threshold }}\end{cases}
$$

Where $a$ represents the value of $N_{\text {critical }}$ for $W=1 \mathrm{Mg} \mathrm{ha}^{-1} ; b$ represents the ratio between the relative decline in $N_{\text {critical }}$ and the relative crop growth rate. $W_{\text {threshold }}\left(\mathrm{Mg} \mathrm{ha}^{-1}\right)$ represents the minimum $W$ for which the relationship between $N_{\text {critical }}$ and $W$ can be described using Eqn. (3.1);

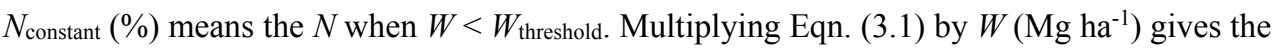
critical curve for above ground nitrogen uptake $\left(N_{\text {uptake,cri; }} \mathrm{kg} \mathrm{N} \mathrm{ha}^{-1}\right)$ :

$$
N_{\text {uptake,cri }}= \begin{cases}10 a W^{1-b} & W \geq W_{\text {threshold }} \\ 10 N_{\text {constant }} W & W<W_{\text {threshold }}\end{cases}
$$

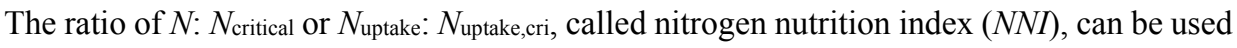
to diagnose plant nitrogen status. $N N I<1$ indicates nitrogen is limiting while $N N I \geq 1$ indicates nitrogen is sufficient.

To determine a $N_{\text {critical }}$ dilution curve for hemp, the relationship between $W$ and $N_{\text {uptake }}$ in Piacenza-IT (2014 and 2015) and in Budrio-IT (2015) was assessed for solving the coefficients $a, b, W_{\text {threshold }}$ and $N_{\text {constant }}$ in Eqn. (3.1) and Eqn. (3.2). The methodology proposed by Justes et al. (1994) was adopted. Specifically, for each sampling date when both nitrogen limiting and

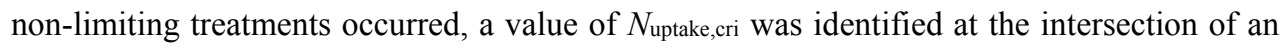
oblique line (positive linear regression between $N_{\text {uptake }}$ and $W$ ) and a vertical line (relative to

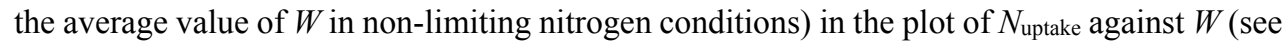
Figure 3.7a in Results section), using the GAUSS method in PROC NLIN of SAS (SAS Institute Inc., Cary, North Carolina, USA). The nitrogen limiting and non-limiting treatments were identified by analysis of variance (SPSS statistics 22.0, SPSS, Chicago, Illinois, USA). A condition of nitrogen limitation occurs whenever $W$ increased significantly $(P<0.05)$ with

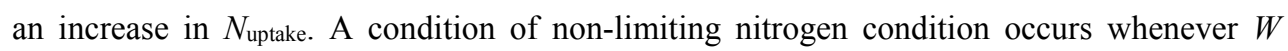
remained unchanged with an increase in $N_{\text {uptake. }}$ All identified $N_{\text {uptake,cri- }} W$ points were fitted to Eqn. (3.2) for the value of $a, b, W_{\text {threshold }}$ and $N_{\text {constant. }}$ 
Under changing nitrogen supply in the field, rather than instant nitrogen status, the plant biomass production is the result of the nitrogen nutrition status during the whole growth season. Therefore, nitrogen deficiency duration and intensity were integrated into an index of crop nitrogen status, $N N I_{\text {int }}$ (Jeuffroy \& Bouchard, 1999). The $N N I_{\text {int }}$ was calculated as: $1 / n \boldsymbol{\Sigma} n_{\mathrm{i}} N N I_{\mathrm{i}}$, where $n$ means the growth duration, expressed in degree-days $\left({ }^{\circ} \mathrm{Cd}\right)$ in this study; $n_{\mathrm{i}}$ means the representing duration of $i$ th sampling; $N N I_{\mathrm{i}}$ means the $N N I$ at $i$ th sampling. The degree-days was calculated as the time integral of $T_{\text {ave }}-T_{\mathrm{b}}$, with $T_{\text {ave }}$ being the daily average temperature and $T_{\mathrm{b}}=1^{\circ} \mathrm{C}$ (Lisson et al., 2000; Van der Werf et al., 1995a).

\subsubsection{Statistical analysis}

Mixed models were used to assess the effects of planting density (D) and nitrogen fertilization (N) on biomass production and biometric traits using SPSS statistics 22.0 (SPSS, Chicago, Illinois, USA). Harvests at different times were conducted in the same plot; therefore, harvesting time $(\mathrm{H})$ was considered as a repeated factor. Location, year and block were considered as random factors (Blouin et al., 2011). If the effect of one factor on a dependent variable was significant, multiple comparison was performed using the Bonferroni method. The data collected in 2013 was analysed to assess the $\mathrm{D} \times \mathrm{N}$ effect. The data collected in 2014 was analysed to assess the $\mathrm{D}$ and $\mathrm{N}$ effects in association with cultivar $(\mathrm{G})$. The overall $\mathrm{D}$ and $\mathrm{N}$ effects were analysed by pooling the data collected in 2014 and 2015 at different locations.

\subsection{Results}

Seedling emergence was attained at $75-112{ }^{\circ} \mathrm{Cd}$ after sowing and full flowering at 1150 $1982{ }^{\circ} \mathrm{Cd}$, depending on growing location and cultivar (Supplementary Material Table S3.1). Harvest was carried out on average at $94{ }^{\circ} \mathrm{Cd}$ and $878{ }^{\circ} \mathrm{Cd}$ after full flowering for $\mathrm{H} 1$ (full flowering) and H2 (seed maturity), respectively.

\subsubsection{The effects of planting density and nitrogen fertilization on stem and seed yields}

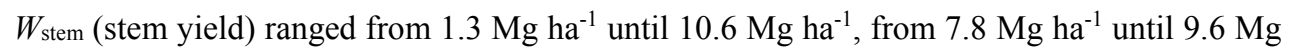
$\mathrm{ha}^{-1}$, from $2.8 \mathrm{Mg} \mathrm{ha}^{-1}$ until 5.2 $\mathrm{Mg} \mathrm{ha}^{-1}$, from 8.1 $\mathrm{Mg} \mathrm{ha}^{-1}$ until $18.8 \mathrm{Mg} \mathrm{ha}^{-1}$ and from 13.7 $\mathrm{Mg} \mathrm{ha}^{-1}$ until 22.3 $\mathrm{Mg} \mathrm{ha}^{-1}$ in Piacenza-IT (2013, 2014 and 2015), Budrio-IT, FR, CZ and LV (2014 and 2015), respectively. The effect of planting density and nitrogen fertilization on $W_{\text {stem }}$ did not interact significantly with each other (Supplementary Material Table S3.2), or with the effects of cultivar (Supplementary Material Table S3.3) and harvest time (Table 3.2). The $W_{\text {stem }}$ was increased significantly with increasing planting density and nitrogen fertilization rate 


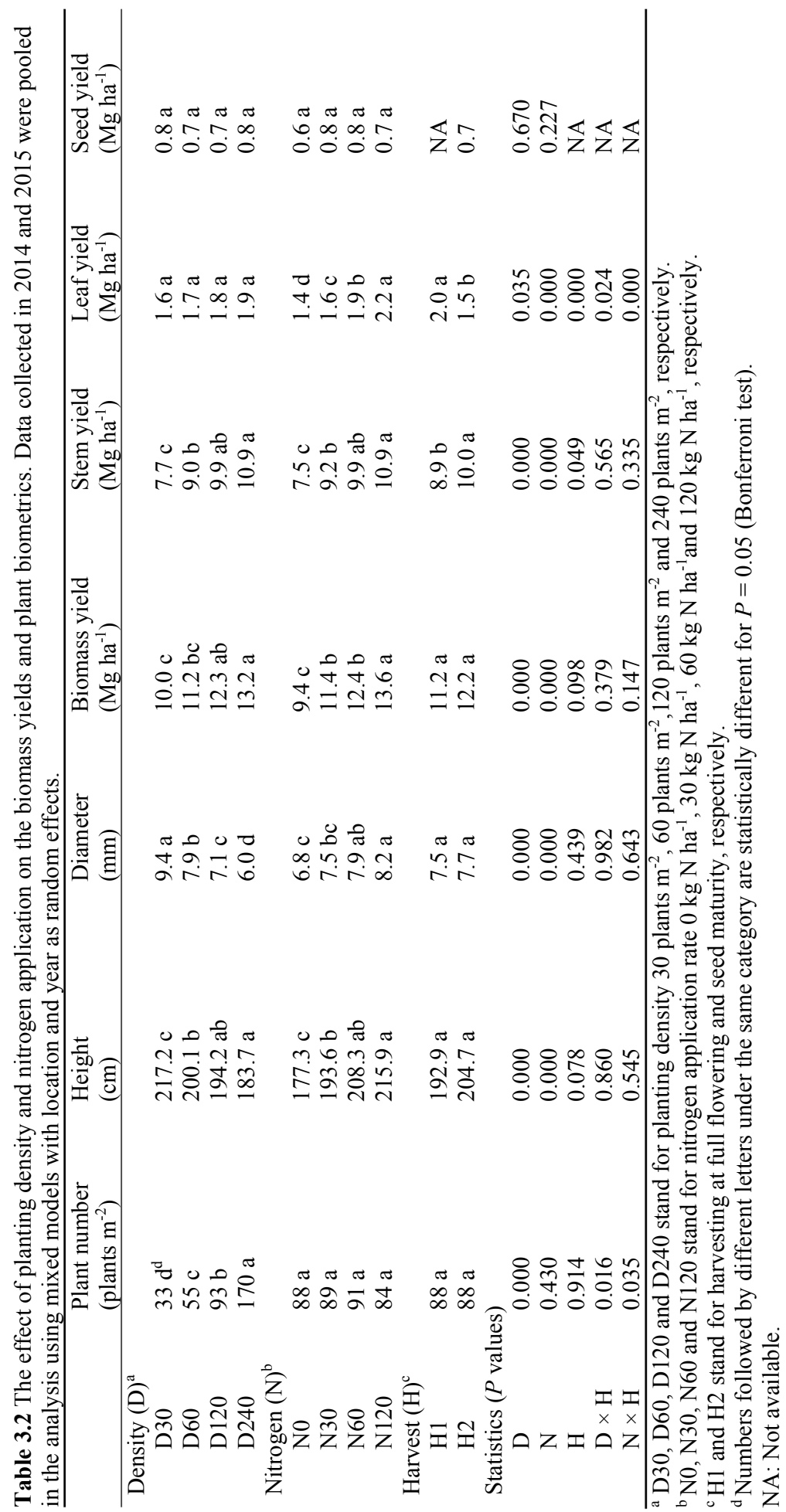


(Table 3.2). Increasing planting density from 30 plants $\mathrm{m}^{-2}$ to 120 plants $\mathrm{m}^{-2}$ resulted in an overall increase in $W_{\text {stem }}$ by $29 \%$ while the difference in $W_{\text {stem }}$ was not significant between 120 plants $\mathrm{m}^{-2}$ and 240 plants $\mathrm{m}^{-2}$ (Table 3.2). Increasing nitrogen fertilization rate from 0 to $60 \mathrm{~kg}$ $\mathrm{N} \mathrm{ha}^{-1}$ resulted in an overall increase in $W_{\text {stem }}$ by $32 \%$ while the difference in $W_{\text {stem }}$ was not significant between $60 \mathrm{~kg} \mathrm{~N} \mathrm{ha}^{-1}$ and $120 \mathrm{~kg} \mathrm{~N} \mathrm{ha}^{-1}$. The effect of planting density and nitrogen

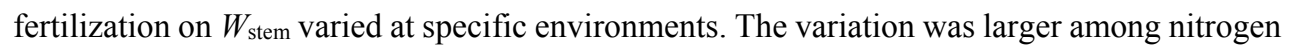
treatments than among planting densities (Figure 3.1).

Plant height ranged from $55 \mathrm{~cm}$ (Piacenza-IT, 2014) to $312 \mathrm{~cm}$ (LV, 2015); stem diameter ranged from $2.6 \mathrm{~mm}$ (Piacenza-IT, 2014) to $11.4 \mathrm{~mm}$ (CZ, 2015). Increasing planting density from 30 plants $\mathrm{m}^{-2}$ to 240 plants $\mathrm{m}^{-2}$ resulted in overall decreases in plant height and stem diameter by $15 \%$ and $37 \%$, respectively (Table 3.2). Increasing nitrogen fertilization rate from 0 to $120 \mathrm{~kg} \mathrm{~N} \mathrm{ha}^{-1}$ resulted in overall increases in plant height and stem diameter by $22 \%$ and $20 \%$, respectively.

$W_{\text {seed }}$ (seed yield) range was $0.75-2.14 \mathrm{Mg} \mathrm{ha}^{-1}, 0.26-0.37 \mathrm{Mg} \mathrm{ha}^{-1}, 0.56-0.75 \mathrm{Mg} \mathrm{ha}^{-1}$ and 0.88-1.09 $\mathrm{Mg} \mathrm{ha}^{-1}$ in Piacenza-IT (2013 and 2015), Budrio-IT, FR and CZ, respectively. $W_{\text {seed }}$
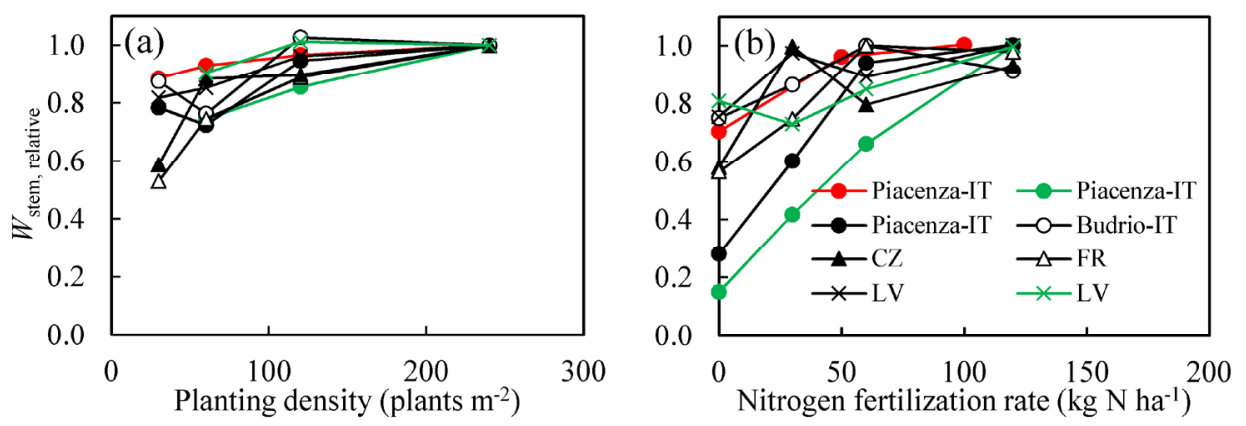

Figure 3.1 The effect of planting density (panel a) and nitrogen fertilization (panel b) on relative stem yield $\left(W_{\text {stem,relative }}\right)$ in different environments. The data presented was collected at full flowering in 2013 (red), 2014 (green) and 2015 (black). The location names are abbreviated as: Piacenza-IT (Piacenza, Italy); Budrio-IT (Budrio, Italy); FR (La Trugalle, France); CZ (Sumperk, the Czech Republic) and LV

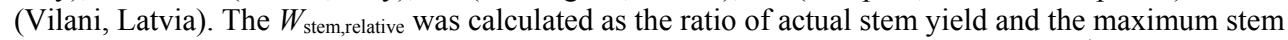
yield at each location. In 2013, the maximum stem yield in Piacenza-IT was $8.2 \mathrm{Mg} \mathrm{ha}^{-1}$ and $8.7 \mathrm{Mg} \mathrm{ha}$ ${ }^{1}$ across density and nitrogen treatments, respectively. In 2014, the maximum stem yield across density treatments in Piacenza-IT and LV was 5.6 Mg ha ${ }^{-1}$ and $19.2 \mathrm{Mg} \mathrm{ha}^{-1}$, respectively; across nitrogen treatments, it was $8.5 \mathrm{Mg} \mathrm{ha}^{-1}$ and $22.3 \mathrm{Mg} \mathrm{ha}^{-1}$, respectively. In 2015, the maximum stem yield across density treatments in Piacenza-IT, Budrio-IT, FR, CZ and LV was $7.9 \mathrm{Mg} \mathrm{ha}^{-1}, 9.5 \mathrm{Mg} \mathrm{ha}^{-1}, 5.6 \mathrm{Mg} \mathrm{ha}$ ${ }^{1}, 15.2 \mathrm{Mg} \mathrm{ha}^{-1}$ and $16.8 \mathrm{Mg} \mathrm{ha}^{-1}$, respectively; across nitrogen treatments, it was $7.9 \mathrm{Mg} \mathrm{ha}^{-1}, 9.5 \mathrm{Mg}$ $\mathrm{ha}^{-1}, 5.0 \mathrm{Mg} \mathrm{ha}^{-1}, 15.9 \mathrm{Mg} \mathrm{ha}^{-1}$ and $18.1 \mathrm{Mg} \mathrm{ha}^{-1}$, respectively. 

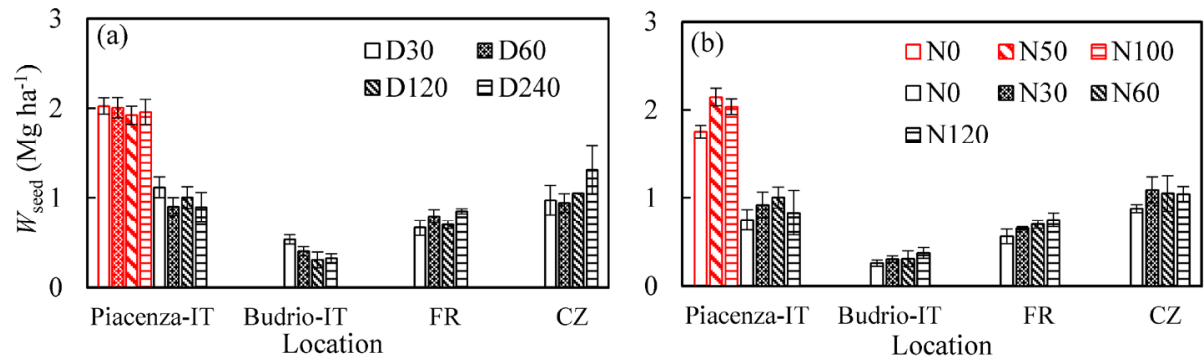

Figure 3.2 The effect of planting density (panel a) and nitrogen fertilization (panel b) on seed yield ( $\left.W_{\text {seed }}\right)$ in 2013 (red bars) and 2015 (black and white bars). The location names are abbreviated as: Piacenza-IT (Piacenza, Italy); Budrio-IT (Budrio, Italy); FR (La Trugalle, France) and CZ (Sumperk, the Czech Republic). Vertical bars indicate standard error. D30, D60, D120 and D240 stand for planting density 30 plants $\mathrm{m}^{-2}, 60$ plants $\mathrm{m}^{-2}, 120$ plants $\mathrm{m}^{-2}$ and 240 plants $\mathrm{m}^{-2}$, respectively. N0, N30, $\mathrm{N} 50, \mathrm{~N} 60, \mathrm{~N} 100$ and $\mathrm{N} 120$ stand for nitrogen application rate $0 \mathrm{~kg} \mathrm{~N} \mathrm{ha}^{-1}, 30 \mathrm{~kg} \mathrm{~N}^{-1}, 50 \mathrm{~kg} \mathrm{~N}^{-1}$, $60 \mathrm{~kg} \mathrm{~N} \mathrm{ha}^{-1}, 100 \mathrm{~kg} \mathrm{~N} \mathrm{ha}^{-1}$ and $120 \mathrm{~kg} \mathrm{~N}$ ha $^{-1}$, respectively.

was not determined in 2014 in both locations (i.e., Piacenza-IT and LV) nor in 2015 in LV. $W_{\text {seed }}$ showed an increasing trend with an increase in nitrogen fertilization whereas the overall effects of both planting density and nitrogen fertilization on $W_{\text {seed }}$ were not statistically significant (Table 3.2, Figure 3.2).

\subsubsection{The effects of planting density and nitrogen fertilization on plant growth}

Canopy closure was reached fast at high planting density and high nitrogen fertilisation. In Piacenza-IT in 2015, light interception with 240 plants $\mathrm{m}^{-2}$ reached $90 \%$ at $732{ }^{\circ} \mathrm{Cd}$ after emergence that was significantly earlier than with 30 plants $\mathrm{m}^{-2}\left(1065^{\circ} \mathrm{Cd}\right.$; Figure $\left.3.3 \mathrm{a}\right) ; 90 \%$ of light interception with $120 \mathrm{~kg} \mathrm{~N} \mathrm{ha}^{-1}$ was reached at $700{ }^{\circ} \mathrm{Cd}$ after emergence that was $402{ }^{\circ} \mathrm{Cd}$ and $1072{ }^{\circ} \mathrm{Cd}$ earlier than with $30 \mathrm{~kg} \mathrm{~N} \mathrm{ha}^{-1}$ and the unfertilised control treatment, respectively (Figure 3.4a). The overall light extinction coefficient was 0.96 . The earlier canopy closure was mainly a consequence of a significantly higher leaf area index (LAI) that was proportional to the level of planting density and nitrogen fertilization (Figures 3.3b, 3.4b). After canopy closure, the $L A I$ continued to increase until full flowering while light interception remained constant, slightly above $90 \%$. The difference of $L A I$ among planting density treatments progressively reduced after canopy closure while it remained significant among nitrogen fertilization treatments. In Piacenza-IT in 2015, no significant difference of $L A I$ among planting densities was observed at full flowering while the $L A I$ with the highest nitrogen fertilization level $\left(6.4 \mathrm{~m}^{2} \mathrm{~m}^{-2}\right)$ was about three times higher than that of the control treatment $\left(2.3 \mathrm{~m}^{2} \mathrm{~m}^{-2}\right) . W$ (aboveground biomass yield) increased in accordance with $L A I$ 

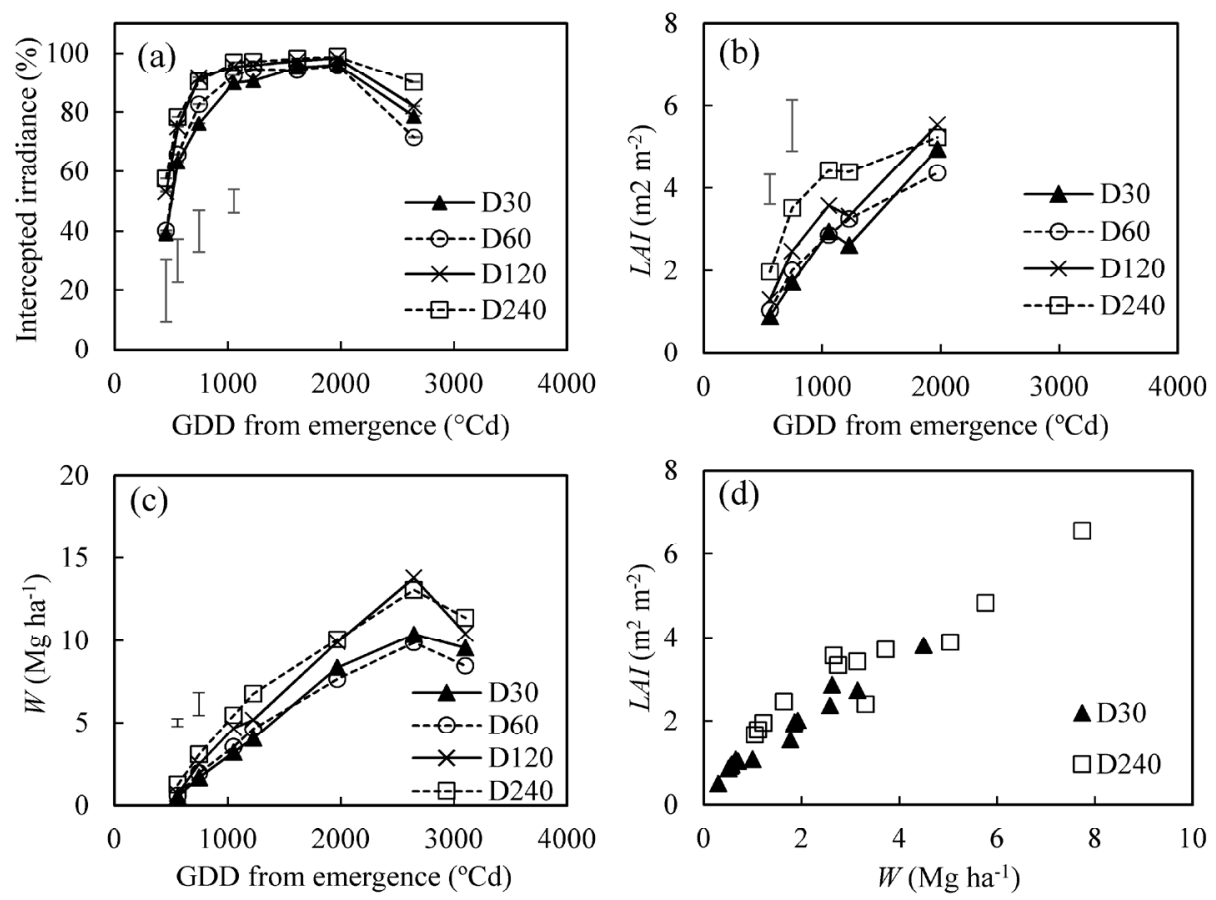

Figure 3.3 The effect of planting density on growth. Panels a, b and c indicate the time course of light interception, leaf area index $(L A I)$ and biomass yield $(W)$, respectively. Panel dis the plot of $L A I$ against $W$ before flowering. Data presented was collected in the field in Piacenza, Italy in 2015. D30, D60, $\mathrm{D} 120$ and D240 stand for planting density 30 plants $\mathrm{m}^{-2}, 60$ plants $\mathrm{m}^{-2}, 120$ plants $\mathrm{m}^{-2}$ and 240 plants $\mathrm{m}^{-2}$, respectively. Vertical bars in Panels a, b, c indicate the Bonferroni LSD for which the effect of planting density was significant at $P=0.05$.

(Figures 3.3b, 3.4b). The relationship between $L A I$ and $W$ was not affected by planting density or nitrogen fertilization (Figure 3.3d, 3.4d).

Plant height and stem diameter increased exponentially with increasing $W_{\text {stem }}\left(R^{2}>0.76\right.$; Figure 3.5). This relationship was affected by planting density but it was independent from nitrogen fertilization. Considering the same stem yield level, plants cultivated at low planting densities were tallest and thickest.

\subsubsection{Dynamics of nitrogen uptake and nitrogen concentration}

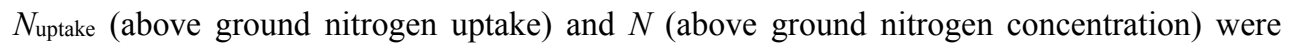
proportional to the level of nitrogen fertilisation. At the first sampling date in Piacenza-IT in 2015, $N$ uptake and $N$ of the unfertilised control treatment were $34.8 \mathrm{~kg} \mathrm{~N} \mathrm{ha}^{-1}$ and $4.3 \%$, respectively. Nitrogen fertilization with $120 \mathrm{~kg} \mathrm{~N} \mathrm{ha}^{-1}$ resulted in increases in $N$ uptake and $N$ by 

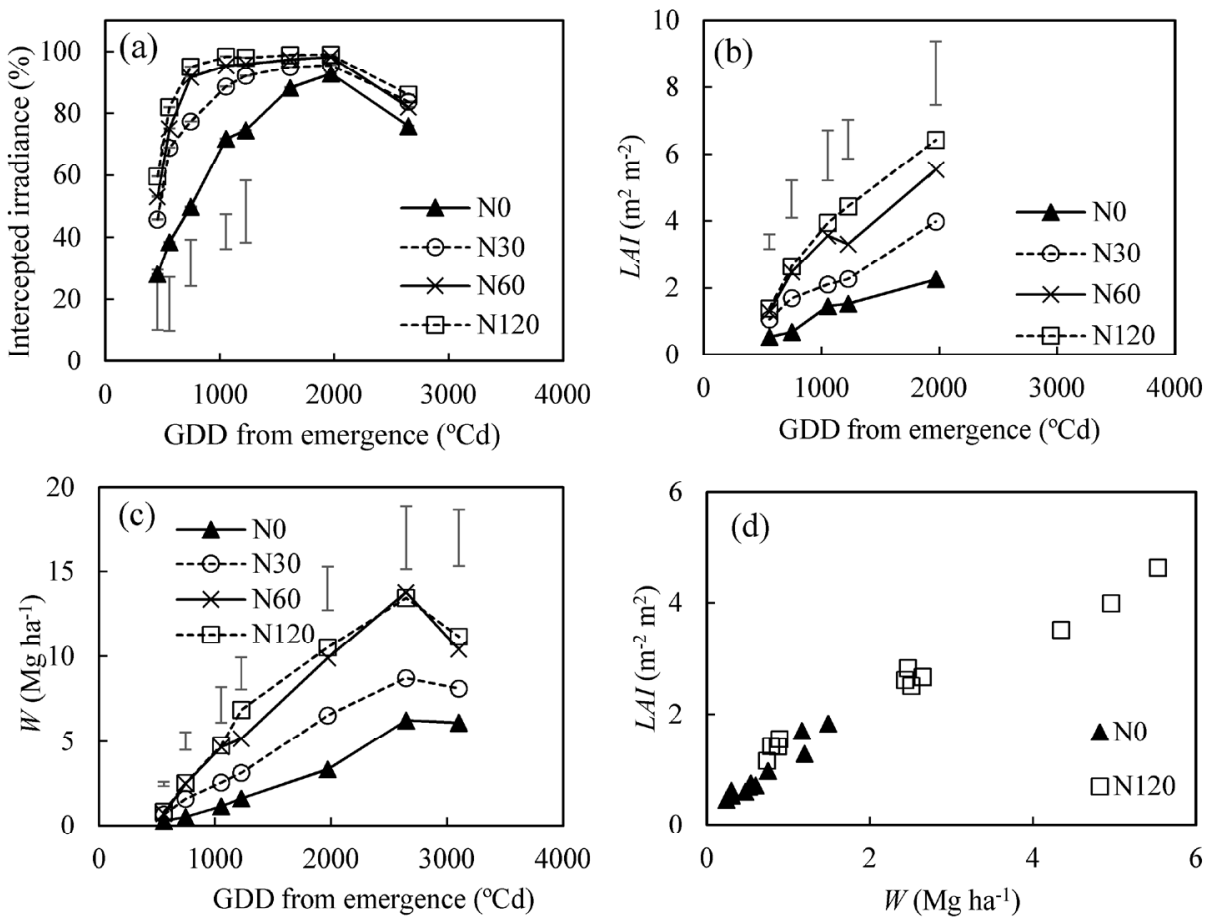

Figure 3.4 The effect of nitrogen fertilization on growth. Panels a, b and c indicate the time course of light interception, leaf area index $(L A I)$ and biomass yield $(W)$, respectively. Panel d is the plot of $L A I$ against $W$ before flowering. Data presented was collected in the field in Piacenza, Italy in 2015. N0, $\mathrm{N} 30, \mathrm{~N} 60$ and $\mathrm{N} 240$ stand for nitrogen fertilization rate $0 \mathrm{~kg} \mathrm{~N} \mathrm{ha}^{-1}, 30 \mathrm{~kg} \mathrm{~N} \mathrm{ha}^{-1}, 60 \mathrm{~kg} \mathrm{~N} \mathrm{ha}^{-1}$ and 120 $\mathrm{kg} \mathrm{N} \mathrm{ha}^{-1}$, respectively. Vertical bars in Panels $\mathrm{a}, \mathrm{b}$ and $\mathrm{c}$ indicate the Bonferroni LSD for which the effect of nitrogen fertilization was significant at $P=0.05$.

5.3 times and 1.9 times, respectively (Figure 3.6a, b). During the growing season, $N_{\text {uptake }}$ increased uniformly in the unfertilised control treatment until the end of flowering while the increase at increasing fertilisation levels was more intense before canopy closure. The $N_{\text {uptake: }}$ $L A I$ ratio was higher with additional fertilization than with no fertilization (Figure 3.6c). From the end of flowering to seed maturity, $N_{\text {uptake }}$ was consistent in the unfertilised control treatment while it decreased slightly in the fertilized plots. $N$ decreased moderately in the unfertilised control treatment and progressively more intense at increasing fertilisation levels. In PiacenzaIT in 2015, significant differences in $N$ among nitrogen treatments were present until full flowering $\left(1970{ }^{\circ} \mathrm{Cd}\right)$. After full flowering, the $N$ was identical among nitrogen treatments.

Considering the analysis of samples collected at seed maturity in Piacenza-IT in 2013-2015, $N_{\text {leaf, }} N_{\text {stem }}$ and $N_{\text {seed }}$ ranges were $1.5-2.6 \%, 0.5-0.7 \%$, and $2.7-4.0 \%$, respectively (Table 3.3). Without fertilization $N_{\text {uptake }}$ at seed maturity was $150.5 \mathrm{~kg} \mathrm{~N} \mathrm{ha}^{-1}, 23.0 \mathrm{~kg} \mathrm{~N} \mathrm{ha}^{-1}$, and 

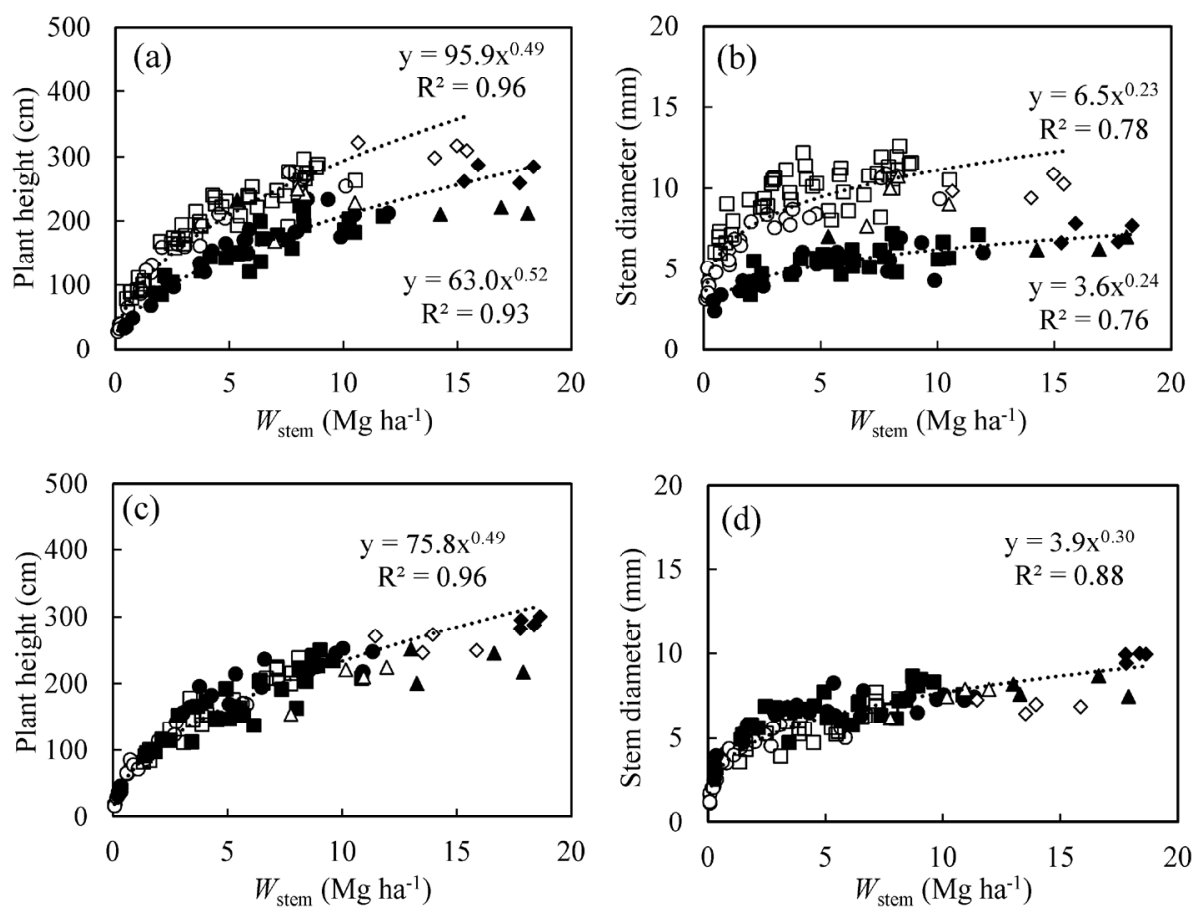

Figure 3.5 The relationship between stem yield $\left(W_{\text {stem }}\right)$ and plant height (panels a, c), and between $\left(W_{\text {stem }}\right)$ and stem diameter (panels b, d). Panels a and b: the open symbols denote planting density at 30 plants $\mathrm{m}^{-2}$ while the closed symbols indicate planting density at 240 plants $\mathrm{m}^{-2}$. Panels $\mathrm{c}$ and $\mathrm{d}$ : the open symbols indicate no fertilization was applied while the closed symbols indicate fertilization rate at 120 $\mathrm{kg} \mathrm{N} \mathrm{ha}^{-1}$. Data presented was collected in 2015 in Budrio, Italy $(\boldsymbol{\bullet}, \square)$, Piacenza, Italy $(\bullet, \circ)$, the Czech Republic $(\diamond, \diamond)$ and Latvia $(\boldsymbol{\Lambda}, \Delta)$.

$74.2 \mathrm{~kg} \mathrm{~N} \mathrm{ha}^{-1}$ in 2013, 2014, and 2015, respectively (Table 3.3). With respect to the unfertilised control treatment the $N_{\text {uptake }}$ at the highest fertilisation treatment $\left(120 \mathrm{~kg} \mathrm{~N} \mathrm{ha}^{-1}\right)$ increased by $57.7 \mathrm{~kg} \mathrm{~N} \mathrm{ha}^{-1}, 94.3 \mathrm{~kg} \mathrm{~N} \mathrm{ha}^{-1}$, and $53.5 \mathrm{~kg} \mathrm{~N} \mathrm{ha}^{-1}$ in 2013, 2014, and 2015, respectively. Nitrogen utilization efficiency at seed maturity ranged from $75.8 \mathrm{~kg} \mathrm{DM} \mathrm{kg} \mathrm{N} \mathrm{N}^{-1}$ to $108.8 \mathrm{~kg} \mathrm{DM} \mathrm{kgN}^{-1}$, independently of nitrogen treatments and growing years (Table 3.3).

\subsubsection{The plant nitrogen nutrition status}

None of the sampling dates in Piacenza-IT in 2014 includes both nitrogen limiting and nonlimiting treatments. Among the sampling dates in Piacenza-IT and Budrio-IT in 2015, 10 sampling dates were identified for which both nitrogen limiting and non-limiting treatments were included. By assessing $N_{\text {uptake,cri- }} W$ points for each of the 10 sampling dates and fitting the $N_{\text {uptake,cri- }} W$ points to Eqn. (3.2), the coefficients $a, b, W_{\text {threshold }}$ and $N_{\text {constant }}$ were obtained. 
Chapter 3

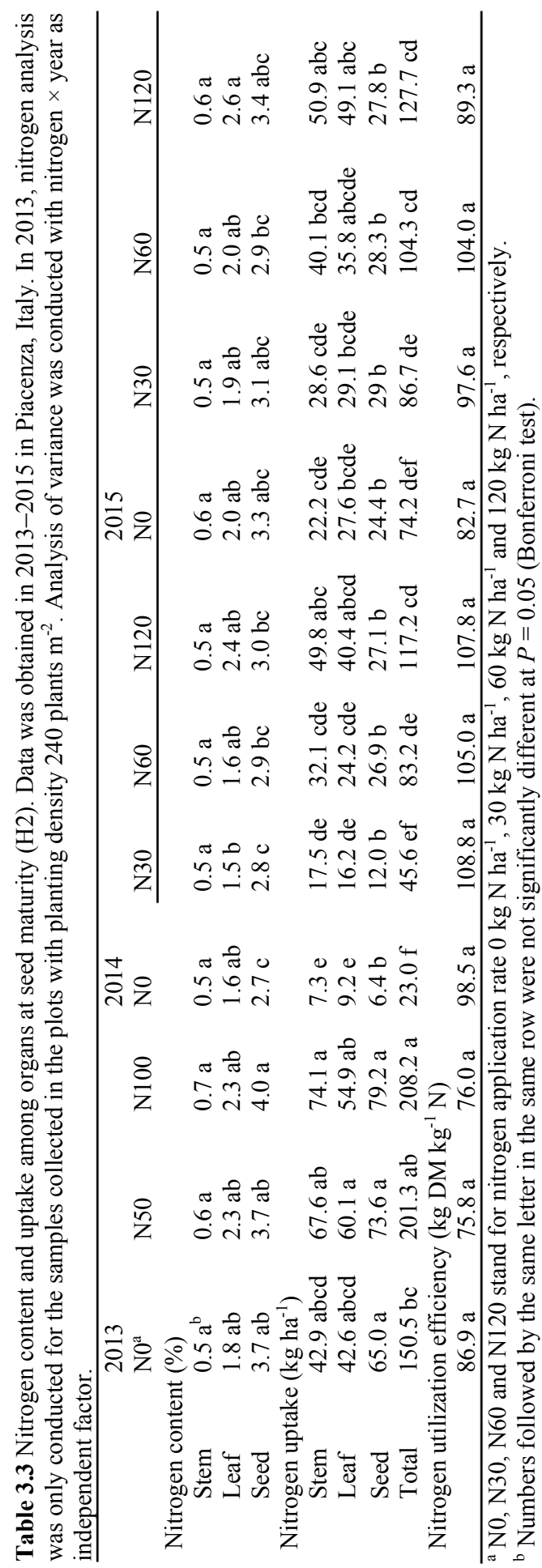



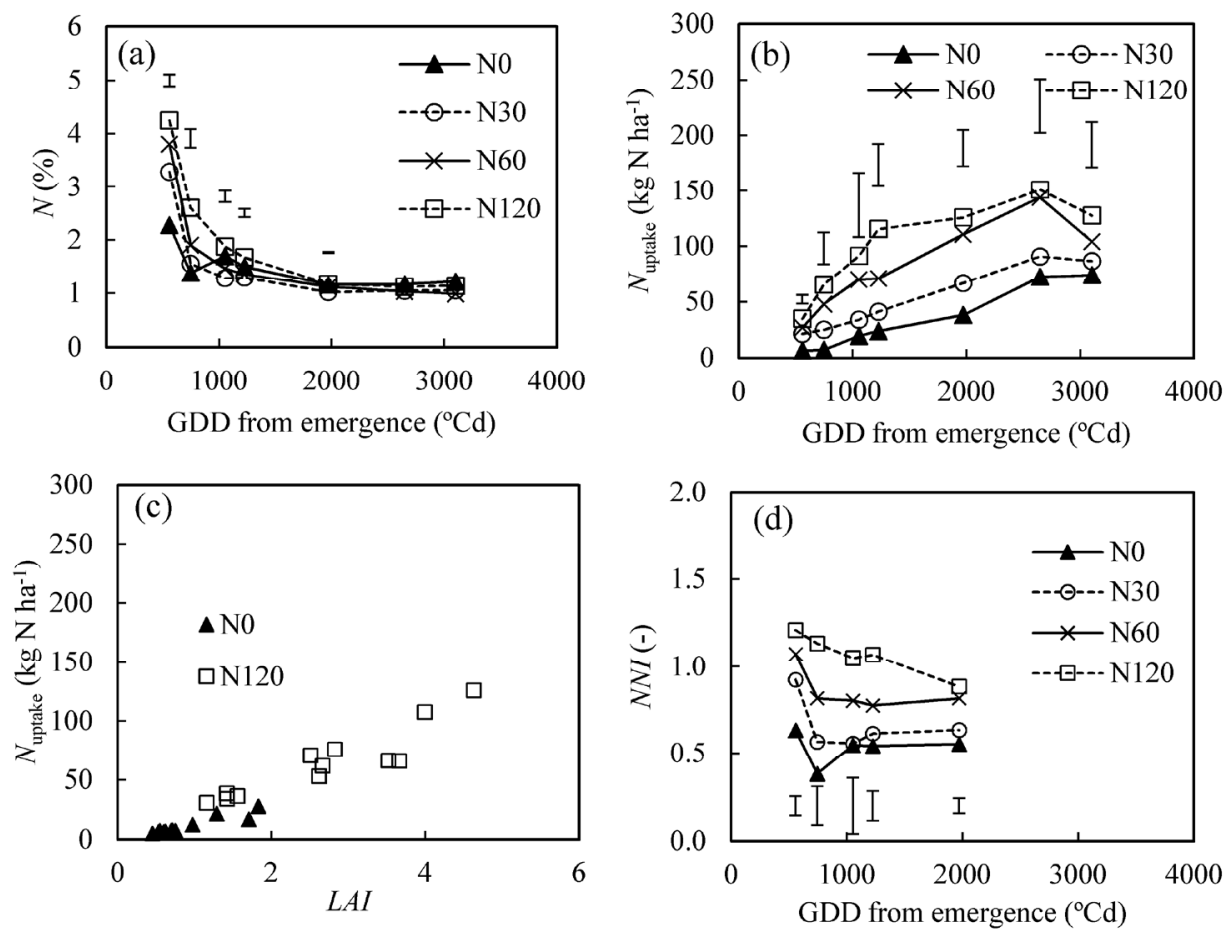

Figure 3.6 The effect of nitrogen fertilization on plant nitrogen dynamics. Panels $a, b$ and d indicate the time course of shoot nitrogen concentration $(N)$, nitrogen uptake $\left(N_{\text {uptake }}\right)$ and nitrogen nutrition index $(N N I)$, respectively. Panel c is the plot of $N_{\text {uptake }}$ against $L A I$ before flowering. Data presented was collected in the field in Piacenza, Italy in 2015. N0, N30, N60 and N240 stand for nitrogen fertilization rate $0 \mathrm{~kg} \mathrm{~N} \mathrm{ha}^{-1}, 30 \mathrm{~kg} \mathrm{~N} \mathrm{ha}^{-1}, 60 \mathrm{~kg} \mathrm{~N}^{-1}$ and $120 \mathrm{~kg} \mathrm{~N} \mathrm{ha}^{-1}$, respectively. Vertical bars in Panels a, b, $\mathrm{d}$ indicate the Bonferroni LSD for which the effect of nitrogen fertilization was significant at $P=0.05$.

The $N_{\text {uptake,cri }}\left(\mathrm{kg} \mathrm{N} \mathrm{ha}^{-1}\right)-W\left(\mathrm{Mg} \mathrm{ha}^{-1}\right)$ curve is represented in Figure 3.7 and its mathematical expression is as follows:

$$
N_{\text {uptake,cri }}= \begin{cases}32.6 W^{0.62} & W \geq 0.78 \mathrm{Mg} \mathrm{ha}^{-1} \\ 36.0 W & W<0.78 \mathrm{Mg} \mathrm{ha}^{-1}\end{cases}
$$

Therefore, the $N_{\text {critical }}(\%)$ dilution curve can be expressed as:

$$
N_{\text {critical }}= \begin{cases}3.26 W^{-0.38} & W \geq 0.78 \mathrm{Mg} \mathrm{ha}^{-1} \\ 3.60 & W<0.78 \mathrm{Mg} \mathrm{ha}^{-1}\end{cases}
$$

The $N_{\text {uptake,cri- }} W$ curve separated accurately the nitrogen status of hemp crops in PiacenzaIT (2014 and 2015) and Budrio-IT (2015) (Figure 3.7b). Nitrogen nutrition index (NNI),

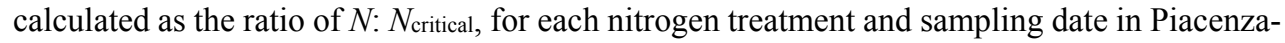
IT in 2015 is presented in Figure 3.6d. The NNI of the unfertilised control treatment remained 
constant throughout the whole growing season at about 0.5 . Nitrogen fertilization increased $N N I$ at all sampling dates. During plant growth, the $N N I$ with additional fertilization decreased gradually. At $30 \mathrm{~kg} \mathrm{~N} \mathrm{ha}^{-1}$ and $60 \mathrm{~kg} \mathrm{~N} \mathrm{ha}^{-1}$ the decrease of the $N N I$ was limited to the period between the first and the second samplings whereas it decreased steadily throughout the whole growing season with $120 \mathrm{~kg} \mathrm{~N} \mathrm{ha}^{-1}$. Consequently, at flowering the difference of $N N I$ among nitrogen treatments was reduced. $N N I_{\text {int }}$, calculated on the basis of nitrogen deficiency duration

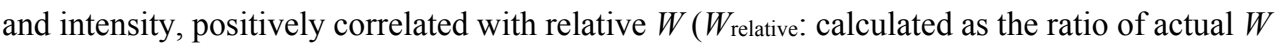
and maximum $W$ at the same sampling date) when the $N N I_{\text {int }}$ was lower than 1 . The relationship between $W_{\text {relative }}$ and $N N I_{\text {int }}$ was independent of growth environments (Figure 3.8).

\subsection{Discussion}

Growing hemp as a multi-purpose crop is gaining attention, particularly for producing both stems and seeds (Aubin et al., 2016; Faux et al., 2013). While numerous studies have been carried out to improve hemp cultivation for fibre production (e.g., Westerhuis et al., 2009; Amaducci et al., 2008a, 2002a; Struik et al., 2000; De Meijer et al., 1995), very limited information is available on the agronomy of dual-purpose (i.e., stems and seeds) hemp crops (Amaducci et al., 2015). In this paper, data obtained in eight environments (combinations of year and location) at five contrasting locations throughout Europe were analysed to study the effect on stem and seed yields of the main agronomic factors affecting hemp production:
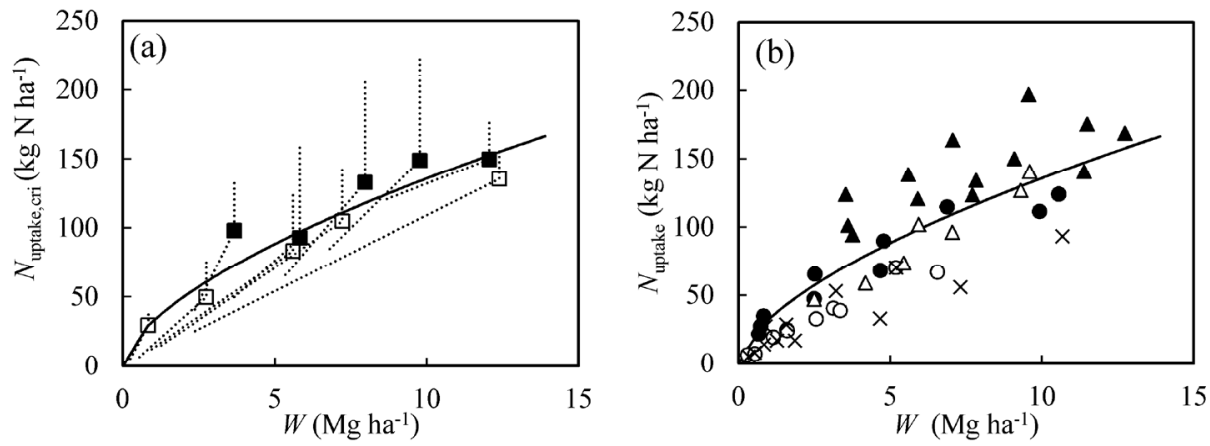

Figure 3.7 Panel a: Determination of critial nitrogen uptake ( $\left.N_{\text {uptake,cri }}\right)$ curve. Dotted lines represent broken stick model for relationship between nitrogen uptake $\left(N_{\text {uptake }}\right)$ and above ground biomass yield $(W)$; Squares denote $N_{\text {uptake,cri- } W}$ points obtained in Budrio ( $)$ and Piacenza ( $\square$ ), in Italy in 2015. The solid line represents the $N_{\text {uptake,cri }}$ as a function of $W$ (see Eqn. 3.2). Panel b: The $N_{\text {uptake,cri }}$ curve in relation to field measurements of $N_{\text {uptake. }}$ The solid line represents the $N_{\text {uptake, cri }}$ curve. $\times$ denotes data collected in Piacenza-IT, Italy in 2014. $\Delta$ and $\circ$ denote nitrogen limiting treatment in Budrio and Piacenza, Italy, respectively, in 2015. $\boldsymbol{\Delta}$ and $\bullet$ denote nitrogen non-limiting treatment in Budrio and Piacenza, Italy, respectively, in 2015. Note the data collected in 2015 were used to estimate the critial $N_{\text {uptake }}$ curve. 


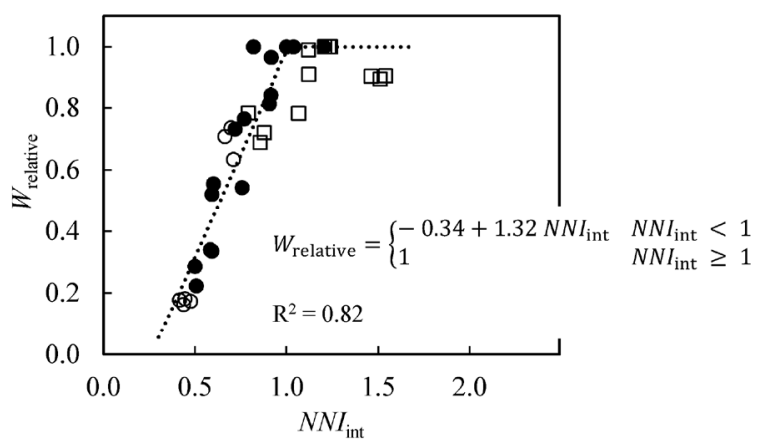

Figure 3.8 The relationship between integrated nitrogen nutrition index $\left(N N I_{\text {int }}\right)$ and relative biomass yield ( $W_{\text {relatvie; }}$ calculated as the ratio of actual and maximum biomass at the same sampling date) at H1 (full flowering). $\bigcirc$ and $\bullet$ denote samplings in Piacenza, Italy in 2014 and 2015, respectively; $\square$ denotes samplings in Budrio, Italy in 2015.

planting density and nitrogen fertilization. Considering that the effect of these two factors on hemp stem and seed yields did not interact with each other in 2013 in Piacenza-IT (Supplementary Material Table S3.2) and did not interact with cultivar in 2014 in Piacenza-IT and LV (Supplementary Material Table S3.3), which confirms results of previous research (Amaducci et al., 2008a, 2002a; Struik et al., 2000), results of planting density and nitrogen fertilization will be discussed separately.

\subsubsection{The effects of planting density on stem and seed yields}

In line with previous studies (Amaducci et al., 2008a, 2002a; Struik et al., 2000), increasing planting density from 30 plants $\mathrm{m}^{-2}$ to 240 plants $\mathrm{m}^{-2}$ had limited effect on $W_{\text {stem }}$ (stem yield) (Table 3.2). The lack of response of $W_{\text {stem }}$ across a wide density range is mainly a consequence of the high incidence of self-thinning at high planting density (Van der Werf et al., 1995b; Willey \& Heath, 1969) and of the plastic behaviour that hemp generally shows for above ground and below ground development (Amaducci et al., 2008b). Until canopy closure, LAI increases fast at high planting density which goes hand-in-hand with a high $W$ accumulation rate and is accompanied by a density independent ratio LAI: $W$ (Figure 3.3). Therefore, canopy closure is reached fast at high planting density. Hemp canopies have a light extinction coefficient $(k$ ) close to 1 (Amaducci \& Stutterheim, 1999; De Meijer et al., 1995). The initially high $L A I$ at high planting density results in severe light competition and reduction in plant number after canopy closure (unshown data and Van der Werf, 1997). As a result, the yield advantage in the first growth phases is lost at high planting density (Figure 3.3c). When planting density is extremely low, however, the canopy closure is significantly delayed and $W$ 


\section{Chapter 3}

is reduced due to the reduction of intercepted radiation during the growing cycle. Consequently, the $W_{\text {stem }}$ at 60 plants $\mathrm{m}^{-2}$ and 30 plants $\mathrm{m}^{-2}$ was the lowest among planting density treatments (Figure 3.1a). It should be noted that planting at extremely low density could result in weed competition, which could result in further significant yield reduction (Hall et al., 2014 and authors' experience).

Even when the effect of planting density on $W_{\text {stem }}$ is limited, there are very large effects on plant biometrics (Struik et al., 2000). Plants grown at high densities are usually shorter and thinner than those grown at low planting densities (Figure 3.5a, b). The results in this study suggest that the effect of planting density on stem diameter is higher than on plant height. For example, when yield was $5 \mathrm{Mg} \mathrm{ha}^{-1}$, at 240 plants $\mathrm{m}^{-2}$ stems were $31 \%$ shorter and $45 \%$ thinner than at 30 plants $\mathrm{m}^{-2}$ (Figure $3.5 \mathrm{a}, \mathrm{b}$ ). This effect indicates an increase in stem slenderness at high planting density (Westerhuis et al., 2009; De Meijer et al., 1995).

The $W_{\text {seed }}$ (seed yield) were not significantly affected by planting density between 30 plants $\mathrm{m}^{-2}$ and 240 plants $\mathrm{m}^{-2}$ (Table 3.2, Figure 3.2). This result confirms the observation of Legros et al. (2013) that $W_{\text {seed }}$ was independent of planting density until a seeding rate of $40 \mathrm{~kg} \mathrm{ha}^{-1}$ (corresponding to 200 plants $\mathrm{m}^{-2}$ ). A constant $W_{\text {seed }}$ across a wide range of planting densities is a consequence of the increase in seed yield per single plant with decreasing planting density, which is a result of the increase in inflorescence length (data not shown) and number of branches bearing seeds (Desanlis et al., 2013).

The optimal planting density for dual-purpose production should be chosen to optimise both stem and seed yields and also considering that planting density, affecting stem biometrics, interacts with long bast fibre production (Westerhuis et al., 2009; Amaducci et al., 2002b) and with mechanisation of harvest and post-harvest processing (Amaducci \& Gusovius, 2010; Amaducci et al., 2008a). It has been recommended to sow at a lower density for hemp seed production (30-75 plants $\mathrm{m}^{-2}$ ) than for fibre production (90-200 plants $\mathrm{m}^{-2}$ ) (Amaducci et al., 2015 and references therein). Seed yield in the present study was not significantly affected by plant population across a wide range of plant densities (Table 3.2, Figure 3.2a); it is therefore recommended to aim at plant populations exceeding 90 plants $\mathrm{m}^{-2}$ as lower densities reduce stem fineness, increase the cost of weeding and render mechanical harvesting more difficult due to increased plant height, stem diameter and spike length. On the other hand, although the stems are more slender at higher planting density, densities above 150 plants $\mathrm{m}^{-2}$ are not recommended because they do not only increase seed input but also the risk of lodging due to 
very fine stems (Legros et al., 2013), particularly when soil fertility and/or nitrogen fertilization are high. Considering that stems are more slender at high density and $W_{\text {stem }}$ reaches plateaus at a planting density above 120 plants $\mathrm{m}^{-2}$ in all environments in the present study (Tables 3.2, Figure 3.2), the optimum planting density for dual-purpose hemp cultivation could be set at 90-150 plants $\mathrm{m}^{-2}$. It should be noted that the optimal planting density should also consider the effects on fibre quality in terms of post-harvesting processing and final products, which requires further researches.

\subsubsection{The effect of nitrogen fertilization on stem and seed yields}

The effect of nitrogen fertilization on $W_{\text {stem }}$ interacted with the environment (Figure 3.1b), confirming the wide range of responses found in literature (Finnan \& Burke, 2013; Prade et al., 2011; Amaducci et al., 2002b; Struik et al., 2000). The results of this study suggest that the effect of nitrogen fertilization on hemp $W_{\text {stem }}$ is a consequence of the duration and the intensity of nitrogen deficiency (Figure 3.8). Crops respond to nitrogen deficiency through a reduction in resource capture and/or resource use efficiency (Lemaire et al., 2008b). In this study, the ratio $L A I: W$, which is an approximate measure of radiation capture efficiency, was not affected by nitrogen fertilisation, while the $N_{\text {uptake: }} L A I$ ratio, which is an approximate measure of radiation use efficiency, decreased when nitrogen was deficient (Figures 3.4d, 3.6c). The response of hemp to nitrogen deficiency is similar to that reported in maize and in tall fescue (Festuca arundinacea) while it is different to that of wheat (Triticum aestivum L.) and oilseed rape, which respond to nitrogen deficiency keeping $N_{\text {uptake: }} L A I$ constant while decreasing $L A I$ :

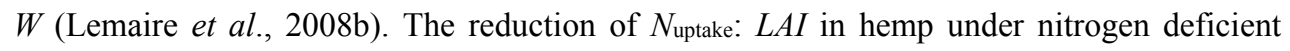
condition results in a low biomass accumulation rate (Figure 3.4c). Consequently, canopy development is restricted and canopy closure is delayed (Figure 3.4b). After canopy closure, self-shading occurs and as consequence nitrogen use efficiency of fertilized plots was reduced. Thus, the differences in biomass accumulation rate among nitrogen treatments decreased after canopy closure despite the level of nitrogen deficiency was still high (Figure 3.6d).

It has been commonly observed that additional nitrogen fertilization increases hemp plant height and stem diameter (Finnan \& Burke, 2013; Amaducci et al., 2008a; Forrest \& Young, 2006). The results of the present study suggest that plant height and stem diameter are strongly correlated with $W_{\text {stem }}$ (Figure 3.5c, d). Given that $W_{\text {stem }}$ is generally modelled in process based models (e.g. GECROS: Yin \& van Laar, 2005), the relationships presented in Figure 3.5 are useful to model plant biometrics under different nitrogen regimes. 


\section{Chapter 3}

The positive effect of nitrogen fertilisation on $W_{\text {seed }}$ (Table 3.2, Figure 3.2b) confirms the results of previous experiments (Aubin et al., 2015; Marija et al., 2011; Vera et al., 2010; Vera et al., 2004). $W_{\text {seed }}$ is the product of seed number and seed mass (i.e., 1000 seed weight). It has been reported that nitrogen availability has little effect on hemp seed mass (Marija et al., 2011; Vera et al., 2004). Therefore, we hypothesise that the increase of $W_{\text {seed }}$ achieved with additional nitrogen fertilization is a consequence of the positive effect of nitrogen on seed number, as reported for crops such as oilseed rape (Asare \& Scarisbrick, 1995; Allen \& Morgan, 1972). The reason for the lack of significant effect of nitrogen fertilisation on $W_{\text {seed }}$ in our study is not clear (Table 3.2). In 2015 in Piacenza-IT and Budrio-IT, this is probably a consequence of unfavourable weather during the seed filling period. From the beginning of August to September, the crops suffered from limited and unevenly distributed rainfall and high temperature (Supplementary Material Figure S3.1). Drought during the seed filling period results in a reduction in seed dry matter accumulation rate, seed mass and $W_{\text {seed }}$ (Plaut et al., 2004). Indeed, in Piacenza-IT in 2015, the seed mass at seed maturity was $37 \%$ lower than that measured for the seed used for sowing and the average $W_{\text {seed }}$ was $43 \%$ lower than that obtained in 2013. Further study is needed to investigate the effect of the interaction between nitrogen fertilization and drought on hemp $W_{\text {seed, }}$ which has been reported for crops such as wheat (Ercoli et al., 2008). Ercoli et al. (2008) reported that wheat grain yield reduction by severe post-anthesis water stress was high when combined with additional nitrogen application and was associated with a decrease in kernel weight.

It should be pointed out that determination of $W_{\text {seed }}$ at plot level in hemp is very challenging due to the large heterogeneity in the crop (Van der Werf et al., 1995b) and bird predation. Bird predation can only partially be prevented at high cost using nets or bird scarers. Heterogeneity is determined by the contemporary presence of plants of different height, with short plants having short inflorescences with few seeds, and it is aggravated by the duration of hemp seed ripening (from the first seed ripening to the last) which can last for weeks depending on genotype and environmental conditions (Amaducci et al., 2008c) and can cause significant reduction of seed yield by seed shattering or bird predation. The large degree of heterogeneity in our experiments is demonstrated by the high coefficients of variation for $W_{\text {seed }}$ ranging from $19 \%$ to $36 \%$. These high values might also partly explain the lack of nitrogen fertilization effect on $W_{\text {seed. }}$

While $W_{\text {stem }}$ and $W_{\text {seed }}$ are restricted by nitrogen deficiency, excess nitrogen supply is not desirable for hemp production. When nitrogen fertilisation is excess, stems stay green for 
longer and this can lead to difficulties in harvesting, longer drying times and difficulties with fibre processing (Legros et al., 2013). Moreover, not only does it increase production cost, excess nitrogen supply has also been widely criticized for its negative environmental effects such as eutrophication of surface water (London \& Häusser, 2005) and gaseous emissions of oxides and ammonia into the atmosphere (Stulen et al., 1998). Therefore, sustainable hemp production requires a supply of nitrogen considering the critical demand.

\subsubsection{Nitrogen demand of hemp}

To illustrate hemp nitrogen requirement, a comparison of $N_{\text {critical }}$ (critical nitrogen concentration in $W$ ) dilution curves between hemp and other crops is presented in Figure 3.9a and Supplementary Material Table S3.4. In hemp the relationship between $W$ and $N_{\text {critical became }}$ exponential at $W>0.78 \mathrm{Mg} \mathrm{ha}^{-1}$, a value lower than that found for wheat (Justes et al., 1994) and rice ( ssp. japonica, Ata-Ul-Karim et al., 2013) but close to that of oilseed rape (Colnenne et al., 1998) and sunflower (Helianthus annuus L.; Debaeke et al., 2012). Generally the decrease of $N_{\text {critical }}$ at increasing $W$ is a consequence of self-shading and of the decreasing ratio LAI: $W$ (Lemaire et al., 2008a). Considering that the LAI: $W$ ratio in hemp remained relatively stable until a high $W\left(>5 \mathrm{Mg} \mathrm{ha}^{-1}\right.$; Figure 3.4d) was reached, the low threshold $W\left(0.78 \mathrm{Mg} \mathrm{a}^{-}\right.$ ${ }^{1}$ ) is a sign that self-shading occurred before canopy closure (the incident radiation reached $90 \%$ at $W \approx 2 \mathrm{Mg} \mathrm{ha}^{-1}$ ) (Figure 3.4a, c). This is probably a consequence of the horizontal leaves and the high planting density that has triggered intra-row light competition shortly after emergence.
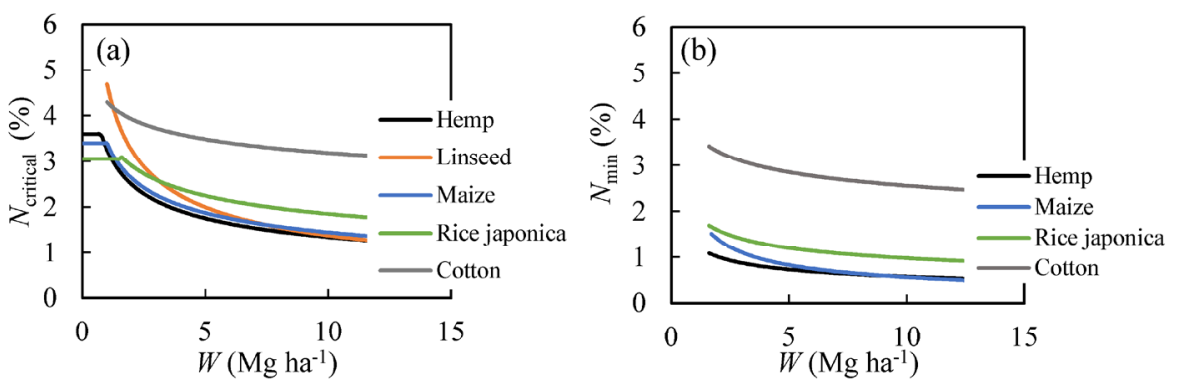

Figure 3.9 Illustration of hemp critical nitrogen $\left(N_{\text {critical }}\right)$ dilution curve (panel a) and minimum nitrogen $\left(N_{\min }\right)$ dilution curve (panel b) in comparison with linseed (only in panel a), maize, rice (ssp. japonica) and cotton. $W$ denotes above ground biomass yield. See Supplementary Material Table S3.4 for parameters and references of $N_{\text {critical }}$ dilution curve. The $N_{\min }$ dilution curve presented for hemp is determined using data collected from the unfertilised treatment. 


\section{Chapter 3}

The position of hemp $N_{\text {critical }}$ dilution curve is at the low range of $\mathrm{C}_{3}$ crops (Figure $3.9 \mathrm{a}$, Supplementary Material Table S3.4): consistently lower than that of rice (ssp. japonica; AtaUl-Karim et al., 2013) and cotton (Xiaoping et al., 2007) and similar to that of the C4 crop maize (Plénet \& Lemaire, 1999). The $N_{\text {critical }}$ is comparable for hemp and linseed (Flénet et al., 2006) when $W$ is higher than $5 \mathrm{Mg} \mathrm{ha}^{-1}$ whereas it is lower for hemp than linseed when $W$ is

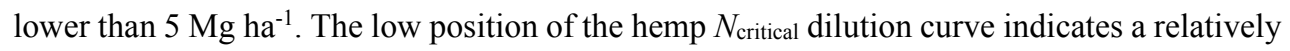
high nitrogen use efficiency (Table 3.3). For example, under non-limiting nitrogen conditions, the minimum nitrogen requirement to produce $10 \mathrm{Mg} \mathrm{ha}^{-1}$ of $W$ for hemp is $3 \%, 7 \%, 15 \%, 47 \%$ and $58 \%$ less than that for linseed, maize, sorghum, oilseed rape and cotton, respectively. The high nitrogen use efficiency of hemp confirms the widely reported low fertilization requirement of this crop (Finnan \& Burke, 2013; Prade et al., 2011; Struik et al., 2000).

Although the mechanisms underlying high nitrogen use efficiency for hemp are not clear, we speculate that this is probably the consequence of two reasons. First, hemp contains low structural nitrogen, which is confirmed by the low minimum nitrogen content in $W\left(N_{\min }\right)$ that is consistently lower than that of cotton (Xiaoping et al., 2007) and rice (ssp. japonica; Ata-UlKarim et al., 2013) (Figure 3.9b). The low $N_{\min }$ of hemp could be explained by the high proportion of stem, on above ground biomass, having very low nitrogen content. Second, hemp has high leaf photosynthetic nitrogen use efficiency at low nitrogen level. In Chapter 4, we found that the light saturated net leaf photosynthesis rate of hemp was higher than that of cotton when leaf nitrogen content is lower than $2 \mathrm{~g} \mathrm{~N} \mathrm{~m}^{-2}$.

\subsubsection{Determination of nitrogen nutrition status}

Direct determination of NNI (nitrogen nutrition index) requires very time consuming procedures and these procedures are beyond the expertise and labour availability of farmers (Lemaire et al., 2008a). Thus, a practical estimation is desirable for optimizing hemp fertilization. Several indirect methods to estimate $N N I$ have been summarized by Lemaire et al. (2008a). Since estimation of $N_{\text {leaf }}$ (leaf nitrogen concentration) is relatively easy, it has been proposed to correlate it with NNI directly (Ziadi et al., 2009). However, such a direct estimating does not seem correct for hemp because $N_{\text {leaf }}$ and $N_{\text {stem }}$ (stem nitrogen concentration) are not linearly correlated (Supplementary Material Figure S3.2a). As the relationship between $N_{\text {leaf }}$ and $N_{\text {stem }}$ is consistent, though, $N_{\text {stem }}$ can be approximated using $N_{\text {leaf. Having }} N_{\text {leaf }}$ and $W$ and an estimate of $N_{\text {stem, }}$, the $N N I$ can in turn be estimated. This empirical method resulted in a better 
estimation of NNI than by the correlation between $N_{\text {leaf }}$ and NNI (Supplementary Material Figure S3.3).

In agronomic practice, a fast and indirect estimation of $N_{\text {leaf }}$ is required. $S P A D$, an indicator of the leaf chlorophyll concentration, could be a useful index for quantifying $N$ leaf as a good correlation between $N_{\text {leaf }}$ and $S P A D$ was observed (Supplementary Material Figure S3.2b). However, despite the fact that many authors found a good correlation between SPAD and $N_{\text {leaf }}$ (Lin et al., 2010; Matsunaka et al., 1997), one should be aware that this relationship is highly variable from one study to another due to differences in environmental conditions and genotypes. In an attempt to eliminate the effect of environmental conditions and genotypes on the diagnosis of plant nitrogen status through $S P A D$, several $S P A D$ based indexes have been proposed such as: normalized SPAD index (Yuan et al., 2016) and positional differences chlorophyll measurements index (Zhao et al., 2016). Further study is necessary to evaluate the performance of these $S P A D$ based indexes on hemp nitrogen status diagnosis before a nitrogen nutrition status based decision on nitrogen management can be attempted.

\subsection{Conclusions}

The effects of planting density and nitrogen fertilization on hemp stem and seed productions were assessed in eight environments (combinations of year and location) at five contrasting locations throughout Europe. The effects of these two factors on hemp stem and seed yields neither interacted with each other nor with cultivar. Changing planting density over a wide range had limited effect on both stem and seed yields while plant height and stem diameter decreased with increasing population. The optimum planting density for dual-purpose hemp cultivation could be set at 90-150 plants $\mathrm{m}^{-2}$. Nitrogen deficiency reduced stem yield and seed yield. The effect of nitrogen deficiency on plant height and stem diameter was in accordance with its effect on stem yield. Hemp has a high nitrogen use efficiency and $60 \mathrm{~kg} \mathrm{~N} \mathrm{ha}^{-1}$ was generally sufficient in the tested environments for dual-purpose hemp cultivation. However, optimization of nitrogen fertilization requires assessment of plant nitrogen status. Direct determination of nitrogen status for hemp are too complex while SPAD based diagnosis techniques requires further investigations.

\section{Acknowledgements}

The research leading to these results has received funding from the European Union's Seventh Framework Programme for research, technological development and demonstration under 
Grant agreement $\mathrm{n}^{\circ}$ 311849. The authors gratefully acknowledge Sudati Rebecca for conducting nitrogen analysis, Tjeerd-Jan Stomph for his helpful comments on an earlier version of the manuscript and all the staff members and students involved in the field trials.

\section{References}

Allen, E.J. and Morgan, D.G. (1972) A quantitative analysis of the effects of nitrogen on the growth, development and yield of oilseed rape. Journal of Agricultural Science, 78, 315324.

Amaducci, S. and Stutterheim, N.C. (1999) The effect of light use on hemp (Cannabis Sativa L.) growth. In: Alternative crops for sustainable agriculture, pp. 205-214. Workshop held at Biocity, Turku, Finland.

Amaducci, S., Errani, M. and Venturi, G. (2002a). Response of hemp to plant population and nitrogen fertilisation. Italian Journal of Agronomy, 6, 103-111.

Amaducci, S., Errani, M. and Venturi, G. (2002b) Plant population effects on fibre hemp morphology and production. Journal of Industrial Hemp, 7, 33-60.

Amaducci, S., Zatta, A., Pelatti, F. et al. (2008a). Influence of agronomic factors on yield and quality of hemp (Cannabis sativa L.) fibre and implication for an innovative production system. Field Crops Research, 107, 161-169.

Amaducci, S., Zatta, A. and Raffanini, M. (2008b) Characterisation of hemp (Cannabis sativa L.) roots under different growing conditions. Plant Soil, 313, 227-235.

Amaducci, S., Colauzzi, M., Zatta, A. et al. (2008c). Flowering dynamics in monoecious and dioecious hemp genotypes. Journal of Industrial Hemp, 13, 5-19.

Amaducci, S. and Gusovius, H.J. (2010) Hemp - cultivation, extraction and processing. In: Industrial Applications of Natural Fibres: Structure, Properties and Technical Applications (ed Müssig, J.), pp. 109-134. John Wiley \& Sons Ltd, West Sussex, UK.

Amaducci, S., Scordia, D., Liu, F.H. et al. (2015) Key cultivation techniques for hemp in Europe and China. Industrial Crops and Products, 68, 2-16.

Asare, E. and Scarisbrick, D.H. (1995) Rate of nitrogen and sulphur fertilizers on yield, yield components and seed quality of oilseed rape (Brassica napus L.). Field Crops Research, 44, 41-46.

Ata-Ul-Karim, S.T., Yao, X., Liu, X. et al. (2013) Development of critical nitrogen dilution curve of Japonica rice in Yangtze River Reaches. Field Crops Research, 149, 149-158.

Aubin, M.P., Seguin, P., Vanasse, A. et al. (2015) Industrial hemp response to nitrogen, phosphorus, and potassium fertilization. Crop, Forage \& Turfgrass Management, 1, 110.

Aubin, M.P., Seguin, P. and Vanasse, A. (2016) Evaluation of eleven industrial hemp cultivars grown in Eastern Canada. Agronomy Journal, 108, 1972-1980.

Bertoli, A., Tozzi, S., Pistelli, L. et al. (2010) Fibre hemp inflorescences: From crop-residues to essential oil production. Industrial Crops and Products, 32, 329-337.

Blouin D.C., Webster E.P. and Bond J.A. (2011) On the analysis of combined experiments. 
Weed Technology, 25, 165-169.

Carus, M. (2017) Record cultivation of industrial hemp in Europe in 2016. European Industrial Hemp Association (EIHA), Hürth, Germany. Available at (2017, November 29): http://www.eiha-conference.org/media/files/2017/leaflet/EIHA-2017.pdf

Colnenne, C., Meynard, J.M. and Reau, R. (1998). Determination of a critical nitrogen dilution curve for winter oilseed rape. Annals of Botany, 81, 311-317.

De Meijer, W.J.M., Van der Werf, H.M.G., Mathijssen, E.W.J.M. et al. (1995) Constraints to dry matter production in fibre hemp (Cannabis sativa L.). European Journal of Agronomy, 4, 109-117.

Debaeke, P., Van Oosterom, E.J. and Justes, E. (2012) A species-specific critical nitrogen dilution curve for sunflower (Helianthus annuus L.). Field Crops Research, 136, 76-84.

Desanlis, F., Cerruti, N., Warner, P. et al. (2013) Hemp agronomics and cultivation. In Hemp: industrial production and uses (eds Allegret, S., Bouloc, P. and Arnaud, L.), pp. 98-124. CPi Group Ltd, Croydon, UK.

Ercoli, L., Lulli, L., Mariotti, M. et al. (2008) Post-anthesis dry matter and nitrogen dynamics in durum wheat as affected by nitrogen supply and soil water availability. European Journal of Agronomy, 28, 138-147.

Faux, A.M., Draye, X., Lambert, R. et al. (2013) The relationship of stem and seed yields to flowering phenology and sex expression in monoecious hemp (Cannabis sativa L.). European Journal of Agronomy, 47, 11-22.

Finnan, J. and Burke, B. (2013) Nitrogen fertilization to optimize the greenhouse gas balance of hemp crops grown for biomass. GCB Bioenergy, 5, 701-712.

Flénet, F., Guérif, M., Boiffin, J. et al. (2006) The critical N dilution curve for linseed (Linum usitatissimum L.) is different from other $\mathrm{C}_{3}$ species. European Journal of Agronomy, 24, 367-373.

Forrest, C. and Young, J.P. (2006) The effects of organic and inorganic nitrogen fertilizer on the morphology and anatomy of Cannabis sativa "Fedrina" (industrial fibre hemp) grown in Northern British Columbia, Canada. Journal of Industrial Hemp, 11, 3-24.

Greenwood, D.J., Gastal, F. and Lemaire, G. (1991) Growth rate and \%N of field grown crops: theory and experiments. Annals of Botany, 67, 181-190.

Greenwood, D.J., Lemaire, G., Gosse, G. et al. (1990) Decline in percentage N of $\mathrm{C}_{3}$ and $\mathrm{C}_{4}$ crops with increasing plant mass. Annals of Botany, 66, 425-436.

Hall, J., Bhattarai, S.P. and Midmore, D.J. (2014) Effect of industrial hemp (Cannabis sativa L.) planting density on weed suppression, crop growth, physiological responses, and fibre yield in the subtropics. Renewable Bioresources, 2, 1-7.

Jeuffroy, M.H. and Bouchard, C. (1999) Intensity and duration of nitrogen deficiency on wheat grain number. Crop Science, 39, 1385-1393.

Justes, E., Mary, B., Meynard J.-M. et al. 1994. Determination of a critical nitrogen dilution curve for winter wheat crops. Annals of Botany, 74, 397-407.

Khan, M.M.R., Chen, Y. and Laguë, C. (2010) Compressive properties of Hemp (Cannabis sativa L.) stalks. Biosystems Engineering, 106, 315-323. 
Legros, S., Picault, S. and Cerruti, N. (2013) Factors affecting the yield of industrial hemp experimental results from France. In: Hemp: industrial production and uses (eds Allegret, S., Bouloc, P. and Arnaud, L.), pp. 72-97. CPi Group Ltd, Croydon, UK.

Lemaire, G. and Meynard, J.M. (1997) Use of the nitrogen nutrition index for the analysis of agronomical data, in: Diagnosis of the Nitrogen Status in Crops (ed Lemaire, G.), pp. 45-55. Springer Berlin Heidelberg, Berlin, Heidelberg,

Lemaire, G., Jeuffroy, M.H. and Gastal, F. (2008a) Diagnosis tool for plant and crop N status in vegetative stage: Theory and practices for crop $\mathrm{N}$ management. European Journal of Agronomy, 28, 614-624.

Lemaire, G., Van Oosterom, E., Jeuffroy, M.-H. et al. (2008b) Crop species present different qualitative types of response to $\mathrm{N}$ deficiency during their vegetative growth. Field Crops Research, 105, 253-265.

Lemaire, G. and Gastal, F. (2009) Quantifying crop responses to nitrogen deficiency and avenues to improve nitrogen use efficiency, In: Crop Physiology: Applications for Genetic Improvement and Agronomy (eds Sadras V.O. and Calderini D.), pp. 171-211. Academic Press, San Diego, USA.

Lin, F., Deng, J. and Shi, Y. (2010) Investigation of SPAD meter-based indices for estimating rice nitrogen status. Computers and Electronics in Agriculture, 71, S60-S65.

Lisson, S.N., Mendham, N.J. and Carberry, P.S. (2000) Development of a hemp (Cannabis sativa L.) simulation model 1. General introduction and the effect of temperature on the pre-emergent development of hemp. Australian Journal of Experimental Agriculture, 40, 405-411.

London, J.G. (2005) Nitrogen study fertilises fears of pollution. Nature, 791-791.

Marija, M., Māra, V. and Veneranda, S. (2011) Changes of photosynthesis-related parameters and productivity of Cannabis sativa under different nitrogen supply. Environmental and Experimental Biology, 9, 61-69.

Martinov, M., Markovic, D., Tesic, M. et al. (1996) Hemp harvesting mechanization. Agricultural engineering, 2, 1-2.

Matsunaka, T., Watanabe, Y., Miyawaki, T. et al. (1997) Prediction of grain protein content in winter wheat through leaf color measurements using a chlorophyll meter. Soil Science and Plant Nutrition, 43, 127-134.

Plaut, Z., Butow, B.J., Blumenthal, C.S. et al. (2004) Transport of dry matter into developing wheat kernels and its contribution to grain yield under post-anthesis water deficit and elevated temperature. Field Crops Research, 86, 185-198.

Plénet, D. and Cruz, P. (1997) Maize and sorghum, In: Diagnosis of the Nitrogen Status in Crops (ed. Lemaire, G.), pp. 93-106. Springer Berlin Heidelberg, Berlin, Germany.

Plénet, D. and Lemaire, G. (1999) Relationships between dynamics of nitrogen uptake and dry matter accumulation in maize crops: Determination of critical N concentration. Plant Soil 216, 65-82.

Prade, T., Svensson, S.E., Andersson, A. et al. (2011) Biomass and energy yield of industrial hemp grown for biogas and solid fuel. Biomass and Bioenergy, 35, 3040-3049. 
Sadras, V.O. an Lemaire, G. (2014) Quantifying crop nitrogen status for comparisons of agronomic practices and genotypes. Field Crops Research, 164, 54-64.

Sheehy, J.E., Dionora, M.J.A., Mitchell, P.L. et al. (1998) Critical nitrogen concentrations: implications for high-yielding rice (Oryza sativa L.) cultivars in the tropics. Field Crops Research, 59, 31-41.

Starčević, L. (1996) Production technology of fibre hemp. Agricultural engineering, 2, 12-22.

Struik, P.C., Amaducci, S., Bullard, M.J. et al. (2000) Agronomy of fibre hemp (Cannabis sativa L.) in Europe. Industrial Crops and Products, 11, 107-118.

Stulen, I., Perez-Soba, M., De Kok, L.J. et al. (1998) Impact of gaseous nitrogen deposition on plant functioning. New Phytologist, 139, 61-70.

Van der Werf, H.M.G. (1997) The effect of plant density on light interception in hemp (Cannabis sativa L.). Journal of the International Hemp Association, 4, 8-13.

Van der Werf, H.M.G., Brouwer, K., Wijlhuizen, M. et al. (1995a) The effect of temperature on leaf appearance and canopy establishment in fibre hemp (Cannabis sativa L.). Annals of Applied Biology, 126, 551-561.

Van der Werf, H.M.G., Vangeel, W.C.A. and Vangils, L.J.C. (1995b) Nitrogen fertilization and row width affect self-thinning and productivity of fibre hemp (Cannabis sativa L.). Field Crops Research, 42, 27-37.

Van der Werf, H.M.G., Mathijssen, E.W.J.M. and Haverkort, A.J. (1996) The potential of hemp (Cannabis sativa L.) for sustainable fibre production: A crop physiological appraisal. Annals of Applied Biology, 129, 109-123.

Vera, C.L., Malhi, S.S., Phelps, S.M., et al. (2010) N, P, and S fertilization effects on industrial hemp in Saskatchewan. Canadian Journal of Plant Science, 90, 179-184.

Vera, C.L., Malhi, S.S., Raney, J.P. et al. (2004). The effect of N and P fertilization on growth, seed yield and quality of industrial hemp in the Parkland region of Saskatchewan. Canadian Journal of Plant Science, 84, 939-947.

Westerhuis, W., Amaducci, S., Struik, P.C. et al. (2009) Sowing density and harvest time affect fibre content in hemp (Cannabis sativa L.) through their effects on stem weight. Annals of Applied Biology, 155, 225-244.

Willey, R.W. and Heath, S.B. (1969) The quantitative relationships between plant population and crop yield. Advances in Agronomy, 21, 281-321.

Xiaoping, X., Jianguo, W., Zhiwei, W. et al. (2007) Determination of a critical dilution curve for nitrogen concentration in cotton. Journal of Plant Nutrition and Soil Science, 170, $811-817$.

Yin X. and Van Laar H.H. (2005) Crop systems dynamics: an ecophysiological simulation model for genotype-by-environment interactions, Wageningen, Wageningen Academic, the Netherlands.

Yuan, Z., Ata-Ul-Karim, S.T., Cao, Q. et al. (2016) Indicators for diagnosing nitrogen status of rice based on chlorophyll meter readings. Field Crops Research, 185, 12-20.

Zhao, B., Liu, Z., Ata-Ul-Karim, S.T. et al. (2016) Rapid and nondestructive estimation of the 
Chapter 3

nitrogen nutrition index in winter barley using chlorophyll measurements. Field Crops Research, 185, 59-68.

Ziadi, N., Bélanger, G., Claessens, A. et al. (2010) Plant-based diagnostic tools for evaluating wheat nitrogen status. Crop Science, 50, 2580-2590. 


\section{Supplementary Materials in Chapter 3}

Table S3.1 Sowing date and growth degree day at emergence, full flowering (H1) and harvesting (H2).

\begin{tabular}{|c|c|c|c|c|c|c|}
\hline Year & Location $^{\mathrm{a}}$ & $\begin{array}{l}\text { Sowing } \\
\text { date }\end{array}$ & $\begin{array}{l}\text { Emergence } \\
\left({ }^{\circ} \mathrm{Cd}\right)^{b}\end{array}$ & $\begin{array}{l}\text { Full flowering } \\
\left({ }^{\circ} \mathrm{Cd}\right)^{\mathrm{b}}\end{array}$ & $\begin{array}{l}\mathrm{H} 1 \\
\left({ }^{\circ} \mathrm{Cd}\right)^{\mathrm{b}}\end{array}$ & $\mathrm{H} 2\left({ }^{\circ} \mathrm{Cd}\right)^{\mathrm{b}}$ \\
\hline 2013 & Piacenza-IT & 14-May & 79.3 & 1532 (Futura 75$)$ & 1759 & 2608 \\
\hline \multirow[t]{2}{*}{2014} & Piacenza-IT & 07-Apr & 96.5 & $\begin{array}{l}1742 \text { (Futura 75) } \\
1150 \text { (Bialobrzeskie) }\end{array}$ & 1832 & 2970 \\
\hline & LV & 02-May & 75.1 & $\begin{array}{l}1835 \text { (Futura 75) } \\
1632 \text { (Bialobrzeskie) }\end{array}$ & 1717 & 2058 \\
\hline \multirow[t]{5}{*}{2015} & Piacenza-IT & 16-Apr & 112.5 & 1982 (Futura 75) & 1882 & 2966 \\
\hline & Budrio-IT & 14-May & NA & 1582 (Futura 75) & 1757 & 2648 \\
\hline & FR & 22-Apr & NA & 1772 (Futura 75) & 2085 & 2805 \\
\hline & $\mathrm{CZ}$ & 24-Apr & 77.0 & 1758 (Futura 75) & 1910 & 2396 \\
\hline & LV & 05-May & 97.4 & 1858 (Futura 75) & 1874 & NA \\
\hline
\end{tabular}

${ }^{a}$ The location names are abbreviated as: Piacenza-IT (Piacenza, Italy); Budrio-IT (Budrio, Italy); FR (La Trugalle, France); CZ (Sumperk, the Czech Republic) and LV (Vilani, Latvia).

${ }^{\mathrm{b}}$ The growth degree day was calculated with a base temperature of $1{ }^{\circ} \mathrm{C}$.

NA: data not available. 
Chapter 3

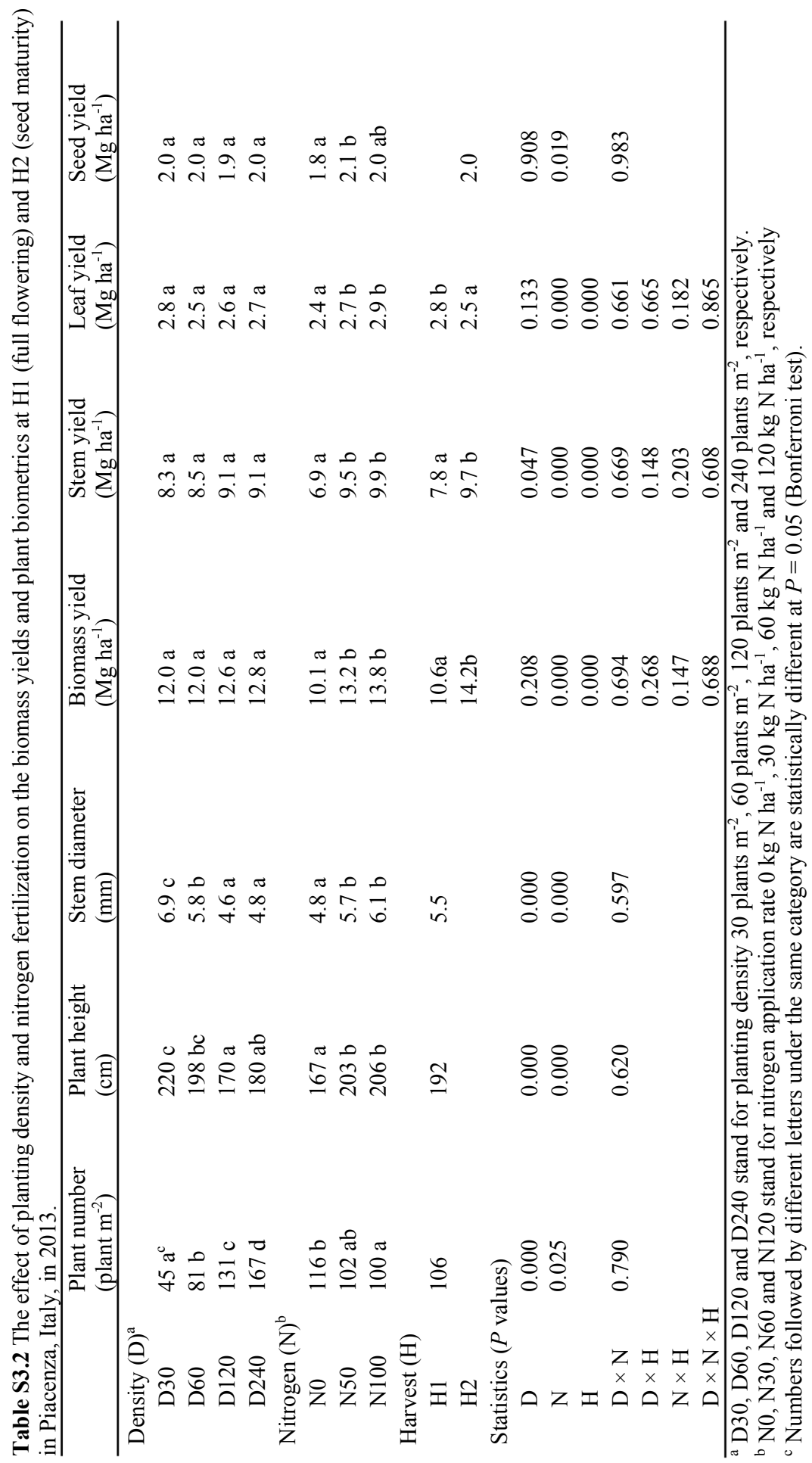


Table S3.3 The effect of planting density and nitrogen application associated with cultivar on the biomass yields and plant biometrics. Data presented was collected at full flowering in Piacenza-IT (Piacenza, Italy) and LV (Vilani, Latvia) in 2014.

\begin{tabular}{cccclcc}
\hline & $\begin{array}{l}\text { Plant number } \\
(\text { plants m }\end{array}$ & $\begin{array}{l}\text { Height } \\
(\mathrm{cm})\end{array}$ & $\begin{array}{l}\text { Diameter } \\
(\mathrm{mm})\end{array}$ & $\begin{array}{l}\text { Biomass yield } \\
\left(\mathrm{Mg} \mathrm{ha}^{-1}\right)\end{array}$ & $\begin{array}{l}\text { Stem yield } \\
\left(\mathrm{Mg} \mathrm{ha}^{-1}\right)\end{array}$ & $\begin{array}{l}\text { Leaf yield } \\
\left(\mathrm{Mg} \mathrm{ha}^{-1}\right)\end{array}$ \\
\hline $\begin{array}{l}\text { Density }(\mathrm{D})^{\mathrm{a}} \\
\text { D60 }\end{array}$ & $57.4 \mathrm{c}^{\mathrm{c}}$ & $185.6 \mathrm{a}$ & $6.9 \mathrm{a}$ & $11.6 \mathrm{~b}$ & $9.4 \mathrm{a}$ & $2.3 \mathrm{a}$ \\
D120 & $102.2 \mathrm{~b}$ & $191.4 \mathrm{a}$ & $6.6 \mathrm{a}$ & $13.2 \mathrm{ab}$ & $10.4 \mathrm{a}$ & $2.8 \mathrm{a}$ \\
D240 & $179.5 \mathrm{a}$ & $180.4 \mathrm{a}$ & $5.7 \mathrm{~b}$ & $13.8 \mathrm{a}$ & $11.0 \mathrm{a}$ & $2.1 \mathrm{a}$ \\
Nitrogen $(\mathrm{N})^{\mathrm{b}}$ & & & & & & \\
N0 & $107.3 \mathrm{a}$ & $152.3 \mathrm{~d}$ & $5.5 \mathrm{c}$ & $9.5 \mathrm{c}$ & $7.7 \mathrm{c}$ & $1.8 \mathrm{c}$ \\
N30 & $117.3 \mathrm{a}$ & $176.1 \mathrm{c}$ & $6.2 \mathrm{~b}$ & $10.9 \mathrm{c}$ & $8.7 \mathrm{c}$ & $2.2 \mathrm{c}$ \\
N60 & $110.1 \mathrm{a}$ & $197.0 \mathrm{~b}$ & $6.8 \mathrm{ab}$ & $13.8 \mathrm{~b}$ & $11.0 \mathrm{~b}$ & $2.9 \mathrm{~b}$ \\
N120 & $117.6 \mathrm{a}$ & $218.0 \mathrm{a}$ & $7.1 \mathrm{a}$ & $17.1 \mathrm{a}$ & $13.6 \mathrm{a}$ & $3.6 \mathrm{a}$ \\
Cultivar $(\mathrm{G})$ & & & & & & \\
Bialobrzeskie & $110.5 \mathrm{a}$ & $171.9 \mathrm{~b}$ & $6.1 \mathrm{a}$ & $12.0 \mathrm{a}$ & $9.3 \mathrm{~b}$ & $2.8 \mathrm{a}$ \\
Futura 75 & $115.6 \mathrm{a}$ & $199.7 \mathrm{a}$ & $6.7 \mathrm{a}$ & $13.6 \mathrm{a}$ & $11.2 \mathrm{a}$ & $2.5 \mathrm{a}$ \\
Statistics $(P$ values) & & & & & & \\
D & 0.000 & 0.323 & 0.000 & 0.310 & 0.055 & 0.050 \\
N & 0.387 & 0.000 & 0.000 & 0.000 & 0.000 & 0.000 \\
G & 0.517 & 0.001 & 0.340 & 0.750 & 0.009 & 0.235 \\
D $\times$ G & 0.511 & 0.651 & 0.968 & 0.870 & 0.863 & 0.945 \\
N $\times$ G & 0.895 & 0.236 & 0.340 & 0.687 & 0.687 & 0.828 \\
\hline
\end{tabular}

${ }^{a}$ D60, D120 and D240 stand for planting density 60 plants $\mathrm{m}^{-2}, 120$ plants $\mathrm{m}^{-2}$ and 240 plants $\mathrm{m}^{-2}$, respectively.

${ }^{\mathrm{b}} \mathrm{N} 0, \mathrm{~N} 30$, N60 and N120 stand for nitrogen application rate $0 \mathrm{~kg} \mathrm{~N} \mathrm{ha}^{-1}, 30 \mathrm{~kg} \mathrm{~N} \mathrm{ha}^{-1}, 60 \mathrm{~kg} \mathrm{~N}^{-1}$

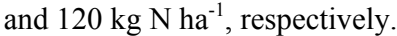

${ }^{\mathrm{c}}$ Numbers followed by different letters under the same category are statistically different at $P=0.05$ (Bonferroni test). 
Table S3.4 Comparison of the coefficients of hemp critical nitrogen concentration $\left(N_{\text {critical }}\right)$ dilution curve with other crops. $a$ denotes the $N_{\text {critical }}$ at above ground biomass yield ( $W$ ) equal to $1 \mathrm{Mg} \mathrm{ha}^{-1} ; b$ denotes the ratio between the relative decline in $N_{\text {critical }}$ and the relative $W$ increasing rate; $W_{\text {threshold }}$ means the minimum $W$ for which the relationship between $N_{\text {critical }}$ and $W$ can be described using a negative exponential curve (i.e. Eqn 3.3). $N_{\text {constant }}$ means the nitrogen concentration when $W \leq$ threshold $W$. NA: data not available.

\begin{tabular}{|c|c|c|c|c|c|}
\hline Species & $a$ & $b$ & $W_{\text {threshold }}$ & $N_{\text {constant }}$ & References \\
\hline \multicolumn{6}{|l|}{$\mathrm{C} 3$} \\
\hline Hemp (Cannabis sativa L.) & 3.3 & 0.38 & 0.80 & 3.57 & Present studies \\
\hline Linseed (Linum usitatissimum L.) & 4.7 & 0.53 & NA & NA & Flenet et al. 2006) \\
\hline Oilseed rape (Brassica napus L.) & 4.5 & 0.25 & 0.88 & 4.63 & Colnenne et al. (1998) \\
\hline Wheat (Triticum aestivum L.) & 5.3 & 0.44 & 1.55 & 4.4 & Justes et al. (1994) \\
\hline Rice (Oryza sativa L. ssp. indica) & 5.2 & 0.52 & NA & NA & Sheehy et al. (1998) \\
\hline $\begin{array}{l}\text { Rice (Oryza sativa L. ssp. } \\
\text { japonica) }\end{array}$ & 3.5 & 0.28 & 1.55 & 3.05 & $\begin{array}{l}\text { Ata-Ul-Karim et al. } \\
(2013)\end{array}$ \\
\hline Sunflower (Helianthus annuus L.) & 4.5 & 0.42 & 0.75 & 5.1 & Debaeke et al. (2012) \\
\hline Cotton (Gossypium hirsutum L.) & 4.3 & 0.13 & NA & NA & Xiaoping et al. (2007) \\
\hline \multicolumn{6}{|l|}{$\mathrm{C} 4$} \\
\hline Maize (Zea mays L.) & 3.4 & 0.37 & 1.0 & 3.4 & Plénet (1999) \\
\hline $\begin{array}{l}\text { Sorghum [Sorghum bicolor (L). } \\
\text { Moench] }\end{array}$ & 3.9 & 0.39 & NA & NA & $\begin{array}{l}\text { Plénet and Cruz } \\
\text { (1997) }\end{array}$ \\
\hline
\end{tabular}




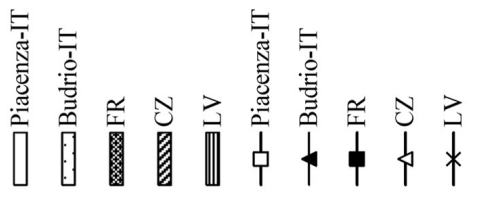

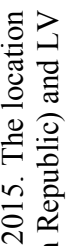

(uw) uo!̣

氖

衤

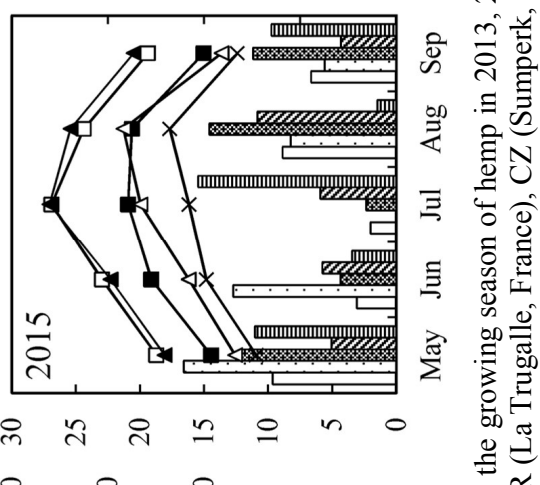

\&

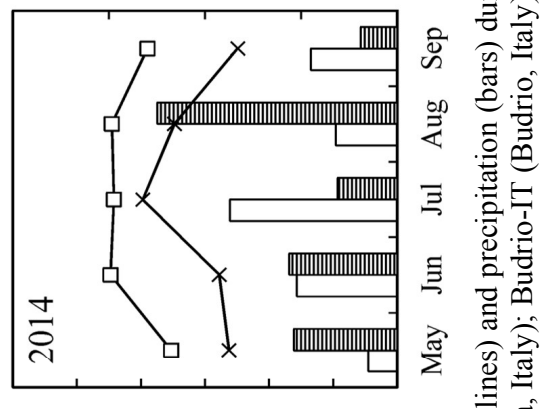

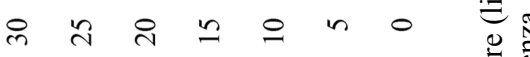

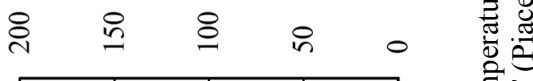

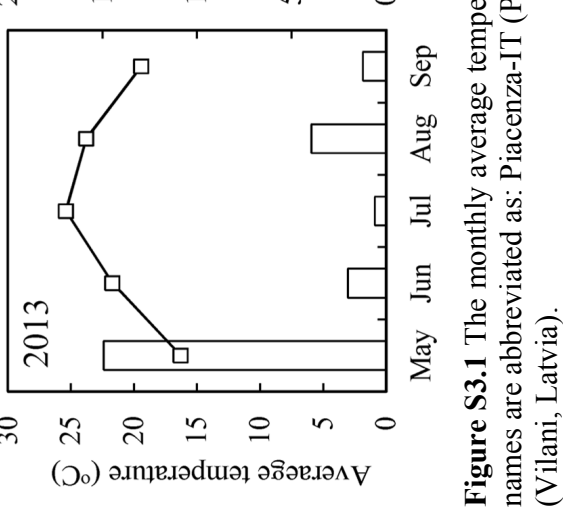



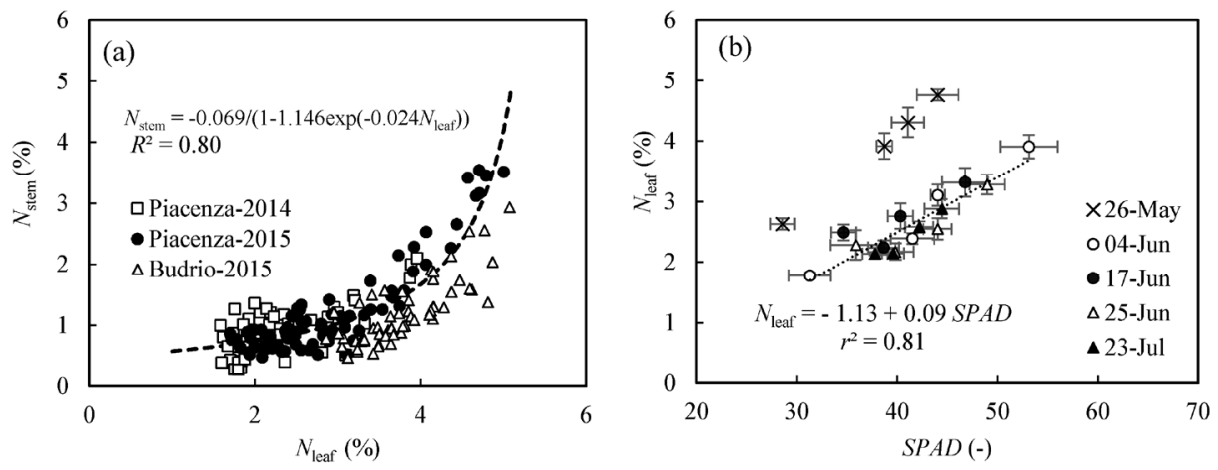

Figure S3.2 Panel a: the relationship between stem nitrogen concentration $\left(N_{\text {stem }}\right)$ and leaf nitrogen concentration $\left(N_{\text {leaf }}\right)$. Data was measured in Piacenza in 2014 and in 2015, and in Budrio in 2015, in Italy. Panel b: the relationship between $S P A D$ and $N_{\text {lear. }}$ Data was measured in Piacenza in 2015 . The first measurement was excluded from the regression line. Bars indicate standard error.
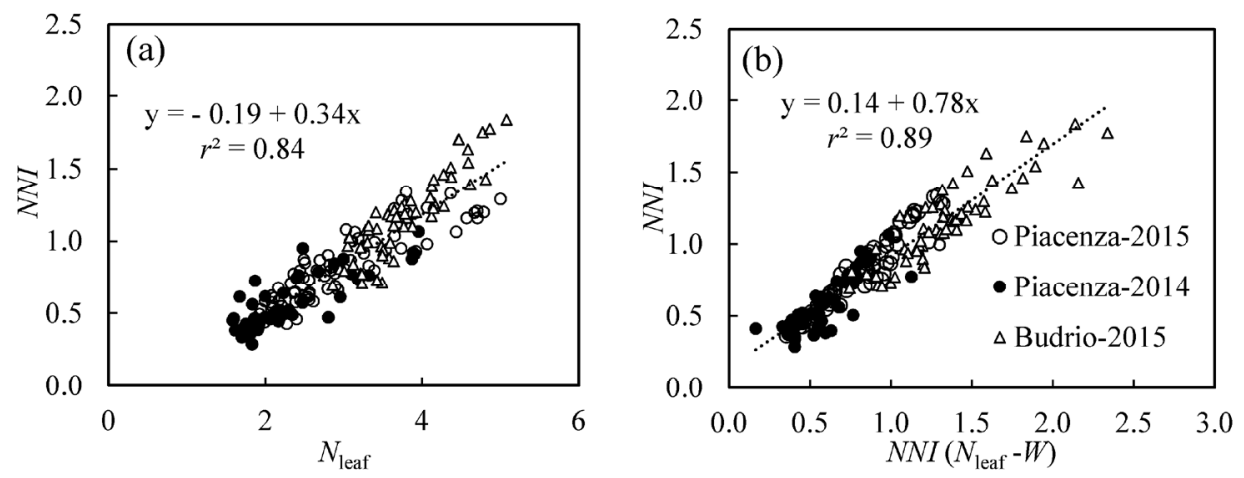

Figure S3.3 Indirect estimation of nitrogen nutrition index $(N N I)$. Panel a: relationship between leaf nitrogen concentration ( $\left.N_{\text {leaf }}\right)$ and $N N I$. Panel b: estimation of $N N I$ combining $N_{\text {leaf }}$ and above ground biomass yield $(W)$. Note the stem nitrogen concentration $\left(N_{\text {stem }}\right)$ is estimated using the relationship presented in Figure S3.2a. 


\section{Chapter 4}

\section{Hemp (Cannabis sativa $L$.) leaf photosynthesis in relation to nitrogen content and temperature: implications for hemp as a bio-economically sustainable crop}

K. Tang ${ }^{\mathrm{a}, \mathrm{b}}$, P.C. Struik ${ }^{\mathrm{a}}$, S. Amaducci ${ }^{\mathrm{b}}$, T.J. Stomph ${ }^{\mathrm{a}}$, X. Yin ${ }^{\mathrm{a}}$

${ }^{a}$ Centre for Crop Systems Analysis, Department of Plant Sciences, Wageningen University \& Research, Droevendaalsesteeg 1, Wageningen, The Netherlands

${ }^{b}$ Department of Sustainable Crop Production, Università Cattolica del Sacro Cuore, via Emilia Parmense, 84, Piacenza, Italy

This Chapter is published in GCB Bioenergy 9 (2017), 1573-1587. 


\title{
Chapter 4
}

\begin{abstract}
Hemp (Cannabis sativa L.) may be a suitable crop for the bio-economy as it requires low inputs while producing a high and valuable biomass yield. With the aim of understanding the physiological basis of hemp's high resource use efficiency and yield potential, photosynthesis was analysed on leaves exposed to a range of nitrogen and temperature levels. Light-saturated net photosynthesis rate $\left(A_{\max }\right)$ increased with an increase in leaf nitrogen up to $31.2 \pm 1.9 \mu \mathrm{mol} \mathrm{m}^{-2} \mathrm{~s}^{-1}$ at $25^{\circ} \mathrm{C}$. The $A_{\max }$ initially increased with an increase in leaf temperature $\left(T_{\mathrm{L}}\right)$, levelled off at $25-35^{\circ} \mathrm{C}$ and decreased when $T_{\mathrm{L}}$ became higher than $35^{\circ} \mathrm{C}$. Based on a $\mathrm{C}_{3}$ leaf photosynthesis model, we estimated mesophyll conductance $\left(g_{\mathrm{m}}\right)$, efficiency of converting incident irradiance into linear electron transport under limiting light $\left(\kappa_{2 \mathrm{LL}}\right)$, linear electron transport capacity $\left(J_{\max }\right)$, Rubisco carboxylation capacity $\left(V_{\mathrm{cmax}}\right)$, triose phosphate utilization capacity $\left(T_{\mathrm{p}}\right)$ and day respiration $\left(R_{\mathrm{d}}\right)$, using data obtained from gas exchange and chlorophyll fluorescence measurements at different leaf positions and various levels of incident irradiance, $\mathrm{CO}_{2}$ and $\mathrm{O}_{2}$. The effects of leaf nitrogen and temperature on photosynthesis parameters were consistent at different leaf positions and among different growth environments except for $\kappa_{2 \mathrm{LL}}$, which was higher for plants grown in the greenhouse than for those grown outdoors. Model analysis showed that compared with cotton and kenaf, hemp has higher photosynthetic capacity when leaf nitrogen is less than $2.0 \mathrm{~g} \mathrm{~N} \mathrm{~m}^{-2}$. The high photosynthetic capacity measured in this study, especially at low nitrogen level, provides additional evidence that hemp can be grown as a sustainable bio-energy crop over a wide range of climatic and agronomic conditions.
\end{abstract}

Key words: hemp (Cannabis sativa L.), photosynthesis, model, nitrogen, temperature, sustainable crop. 


\subsection{Introduction}

The multiple societal challenges such as climate change, natural resource scarcity and environmental pollution have fuelled interest in bio-economy (Jordan et al., 2007). Previous comprehensive research programmes indicated that hemp (Cannabis sativa $\mathrm{L}$.) fits well in the concept of bio-economy (Amaducci et al., 2015; McCormick \& Kautto, 2013). Hemp has the potential to produce up to $27 \mathrm{Mg} \mathrm{ha}^{-1}$ biomass yield (Chapter 2) at relatively low inputs (Amaducci et al., 2002; Struik et al., 2000) and has a positive impact on the environment (Barth \& Carus, 2015; Bouloc \& van der Werf, 2013). Its stem contains high-quality cellulose (De Meijer \& van der Werf, 1994), the seeds contain high-quality oil (Oomah et al., 2002) and the inflorescence contains valuable resins (Bertoli et al., 2010). From speciality pulp and paper to nutritional food, medicine and cosmetics, there are as many as 50,000 uses claimed for hemp products derived from its stem, seed and inflorescence (Carus \& Sarmento, 2016; Carus et al., 2013). Recent research demonstrated that hemp is also a suitable feedstock for bioenergy production (Kreuger et al., 2011; Prade et al., 2011; Rice, 2008).

Although once an important crop for the production of textiles and ropes, hemp has not been subjected to the intensive research that has driven great improvements in major crops in the last 50 years (Amaducci et al., 2015; Salentijn et al., 2015) due to the continuous decrease in hemp acreage after the Second World War and its slow revival in the last couple of decades (Allegret, 2013; Wirtshafter, 2004). To advance research needed to consolidate and expand the market of hemp renewable materials, within the frame of the EC funded project Multihemp (www.multihemp.eu), it was proposed to develop a process based hemp growth model similar to the successful models for major staple crops (Bouman et al., 2007). With the aim of understanding the physiological basis of hemp's high resource use efficiency and yield potential using a modelling approach, this study focuses on analysing leaf photosynthesis of hemp as a primary source of biomass production.

Very few studies report on leaf photosynthesis of hemp. De Meijer et al. (1995) reported a light-saturated rate of leaf photosynthesis for hemp of $30 \mathrm{~kg} \mathrm{CO}_{2} \mathrm{ha}^{-1} \mathrm{hr}^{-1}$ (equivalent to 19 $\left.\mu \mathrm{mol} \mathrm{m} \mathrm{m}^{-2} \mathrm{~s}^{-1}\right)$ under field conditions. Chandra et al. $(2015,2011 \mathrm{a}, \mathrm{b}, 2008)$ showed the response of leaf photosynthesis of hemp to irradiance intensity, $\mathrm{CO}_{2}$ concentration and temperature by measuring gas exchange of leaves from greenhouse grown plants. Marija et al. (2011) found that nitrogen fertilization significantly affected different aspects of photosynthetic photochemistry, as shown by chlorophyll $a$ fluorescence analysis. To the best of our knowledge, 


\section{Chapter 4}

a comprehensive analysis of the relation between leaf nitrogen status and photosynthesis rate is not yet available for hemp.

Leaf photosynthesis rate depends on both nitrogen nutrition status and environmental conditions (Sinclair \& Horie, 1989). Thanks to a thorough understanding of the biochemical mechanisms of leaf photosynthesis, the response of leaf photosynthesis to irradiance intensity and $\mathrm{CO}_{2}$ concentration can be modelled (von Caemmerer et al., 2009; Yin et al., 2006; Farquhar et al., 1980). Such a model dissects net leaf photosynthesis into mesophyll conductance $\left(g_{\mathrm{m}}\right)$, linear electron transport capacity $\left(J_{\max }\right)$, Rubisco carboxylation capacity $\left(V_{\mathrm{cmax}}\right)$, triose phosphate utilization capacity $\left(T_{\mathrm{p}}\right)$ and day respiration $\left(R_{\mathrm{d}}\right)$. The effects of leaf nitrogen status and temperature on leaf photosynthesis are considered through their effects on these photosynthetic parameters (Hikosaka et al., 2016). Experimental protocols for parameterizing the biochemical photosynthesis model have been well documented (Bellasio et al., 2015; Yin et al., 2009; Sharkey et al., 2007), and the model has been successfully embedded as a submodel in process based crop growth models for upscaling to canopy photosynthesis and crop production (Yin \& Struik, 2009), such as the GECROS crop model (Yin \& van Laar, 2005). Therefore, parameterizing the photosynthesis model for hemp is an excellent opportunity to understand its photosynthetic resource use efficiency, as well as to provide essential information for modelling hemp growth.

The first objective of the present study was to analyse leaf photosynthesis of hemp as affected by irradiance intensity, $\mathrm{CO}_{2}$ concentration, temperature and nitrogen status. Secondly, this study aimed to parameterize a widely used $\mathrm{C}_{3}$ leaf photosynthesis model (Yin et al., 2006; Farquhar et al., 1980) for hemp. In the final section, the photosynthetic capacity of hemp is compared with that of two other bio-economic crops, cotton (Gossypium hirsutum L.) and kenaf (Hibiscus cannabinus L.), using a modelling method. Cotton and kenaf were chosen because they are bioeconomically important crops and, in particular, kenaf is considered as an alternative for hemp in tropical and sub-tropical climates (Alexopoulou et al., 2015; Lips \& van Dam, 2013; Patanè \& Cosentino, 2013).

\subsection{Materials and methods}

\subsubsection{Plant growth and data collection}

Three independent experiments were carried out at the research facilities of the Università Cattolica del Sacro Cuore (45. $0^{\circ}$ N, $9.8^{\circ}$ E, $60 \mathrm{~m}$ asl; Piacenza, Italy). Seeds of hemp ( $c v$. Futura 
75) were received from the Fédération National des Producteurs de Chanvre, Le Mans, France. The plants were grown outdoors in 2013 and 2014, and in a greenhouse in 2015.

\subsubsection{An experiment on the effect of nitrogen on leaf photosynthetic capacity ( $N$-trial)}

Seeds were sown in 18 containers $\left(40 \times 40 \times 30 \mathrm{~cm}^{3}\right)$ placed outdoors on 9 May 2014. Each container was filled with $23 \mathrm{~kg}$ of soil (dry weight) that contained $0.22 \%$ total nitrogen and had a clay-silt-sand ratio of 30:43:27. After seedling emergence, the plants were hand-thinned to 18 plants per container and three levels of urea fertilization were applied $(0,1.0$ and $2.0 \mathrm{~g} \mathrm{~N}$ per container, respectively). There were six containers for each fertilization level. Other nutrients (e.g. phosphate and potassium) were assumed not limiting factors according to historic experience in the field from which the soil was collected. The same applies to the other two trials. During plant growth, all containers were positioned randomly and tightly in one block surrounded by a green shading net (transmitting 3\% of the light). The net height was adjusted daily according to the increment of plant height. The plants were well watered during the entire experiment. The daily temperature and global radiation during the growth period are presented in Supplementary Material Figure S4.1.

Photosynthetic measurements were started on 46 days after sowing (the $6^{\text {th }}-8^{\text {th }}$ pair of leaves had appeared) in a growth chamber with the temperature set at $25^{\circ} \mathrm{C}$. The container was moved into the growth chamber 2 hrs before measurements. On one representative plant in each container, the middle leaflets of the youngest, fully expanded top leaf and of the middle leaf (i.e., two nodes below the top leaf) were measured. Simultaneous gas exchange (GE) and chlorophyll fluorescence (CF) measurements were implemented in situ using a portable open gas exchange system with a $1.7 \mathrm{~cm}^{2}$ clamp-on leaf chamber (CIRAS-2, PP Systems International, Inc., USA) combining with FMS2 (Hansatech Instruments Ltd, UK). The system setup of the combined CIRAS-2 and FMS2 for performing simultaneous GE and CF measurements was implemented according to the instructions provided by PP Systems International, Inc., USA. Light response curve of net photosynthesis rate $(A)\left(A-I_{\text {inc }}\right)$ and its $\mathrm{CO}_{2}$ response curve $\left(A-C_{\mathrm{a}}\right)$ were assessed for each leaf under ambient $\mathrm{O}_{2}$ (i.e. $\left.21 \%\right)$ conditions. The $A$ - $I_{\text {inc }}$ curves were assessed by decreasing incident light intensity ( $\left.I_{\text {inc }}\right)$ as: 2000, 1500, 1000, $500,300,200,150,100,60$ and $30 \mu \mathrm{mol} \mathrm{m}^{-2} \mathrm{~s}^{-1}$, while keeping leaf chamber $\mathrm{CO}_{2}$ concentration $\left(C_{\mathrm{a}}\right)$ at $400 \mu \mathrm{mol} \mathrm{mol}{ }^{-1}$. At the end of assessing the $A-I_{\text {inc }}$ curve, the light source was turned off for 15 minutes to measure leaf respiration in darkness $\left(R_{\mathrm{dk}}\right)$. The $A-C_{\mathrm{a}}$ curves were assessed by changing $C_{\mathrm{a}}$ as: $400,250,150,80,70,60,50,400,400,600,800,1000$, and $1500 \mu \mathrm{mol} \mathrm{mol}^{-1}$, 


\section{Chapter 4}

while keeping $I_{\text {inc }}$ at $1000 \mu \mathrm{mol} \mathrm{m} \mathrm{m}^{-2} \mathrm{~s}^{-1}$. Leaf temperature $\left(T_{\mathrm{L}}\right)$ and vapour pressure of supplying air during measurements were set constant at $25{ }^{\circ} \mathrm{C}$ and $2 \mathrm{kPa}$, respectively. The response curves were started when the leaf had adapted to the condition at the first $I_{\text {inc }}$ or $C_{\text {a }}$ level for 30 min. Data was recorded programmatically with 2 min interval for $A-I_{\text {inc }}$ curves and 3 min interval for $A-C_{\mathrm{a}}$ curves. Pre-measurements indicated these time intervals were sufficiently long for $A$ to reach a steady state. Three plants were measured for each fertilization level.

To obtain a calibration factor that can properly convert fluorescence-based PSII efficiency into linear electron transport rate, parts of $A-I_{\text {inc }}$ and $A-C_{\text {a }}$ curves were also assessed under $2 \%$ $\mathrm{O}_{2}$. This condition was realized by supplying the CIRAS- 2 with a humidified mixture of $2 \% \mathrm{O}_{2}$ and $98 \% \mathrm{~N}_{2}$. To avoid $\mathrm{O}_{2}$ leakage, the air-in pump in the CIRAS-2 was replaced by a sealed one according to the manufacturer's instruction. The curves for $2 \% \mathrm{O}_{2}$ were assessed in accordance with the ones for ambient $\mathrm{O}_{2}$ but the $A$ - $I_{\text {inc }}$ curves were only assessed at $I_{\text {inc }} \leq 150$ $\mu \mathrm{mol} \mathrm{m} \mathrm{m}^{-2}$ and the $A-C_{\mathrm{a}}$ curves were only assessed at $C_{\mathrm{a}} \geq 600 \mu \mathrm{mol} \mathrm{mol} \mathrm{m}^{-1}$. These particular $I_{\text {inc }}$ and $C_{\text {a }}$ conditions are required for obtaining the calibration factor (Yin et al. 2009), i.e., to ensure that $A$ is limited by electron transport.

When the photosynthetic measurements were completed, $S P A D$, a proxy for chlorophyll concentration, was measured using a SPAD-502 (Minolta, Japan). Leaf area was determined from scans using ImageJ (version 1.49; https://imagej.nih.gov/). Dry weight was measured after drying at $75{ }^{\circ} \mathrm{C}$ until constant weight. Total leaf nitrogen concentration was analysed using a $C N$ analyser (Vario Max CN Analyzer; Elementar Americas, Inc., Hanau, Germany). Specific leaf nitrogen $\left(S L N ; \mathrm{g} \mathrm{N} \mathrm{m}^{-2}\right.$ ) was calculated for each measured leaf using the leaf dry weight, leaf area and nitrogen concentration. $\mathrm{CO}_{2}$ leakage of the CIRAS-2 leaf chamber was assessed by performing $A-C_{\mathrm{a}}$ curves on three heat-killed leaves. Based on these measurements, values of $A$ and the intercellular $\mathrm{CO}_{2}$ concentration $\left(C_{\mathrm{i}}\right)$ of $A$ - $C_{\mathrm{a}}$ curves were recalculated using the CIRAS-2 built-in formulae.

\subsubsection{An experiment on the effect of temperature on leaf photosynthetic capacity (T-trial)}

Seeds were sown in 6 pots $\left(10 \times 10 \times 15 \mathrm{~cm}^{3}\right)$ placed in a greenhouse on 12 February 2015 . Each pot contained $1 \mathrm{~kg}$ of soil that had identical properties with the ones in the $\mathrm{N}$-trial. The temperature in the greenhouse was maintained at approximately $25^{\circ} \mathrm{C}$. A LED lamp $(270 \mathrm{Watt}$, Shenzhen GTL Lighting Co. Ltd, China) mounted $50 \mathrm{~cm}$ above the canopy for $16 \mathrm{hrs}$ each day gave the light level in greenhouse of approximately $600 \mu \mathrm{mol} \mathrm{m} \mathrm{m}^{-2} \mathrm{~s}^{-1}$. After emergence, the 
plants were hand-thinned to 2 plants per pot and urea fertilization was applied $(0.3 \mathrm{~g} \mathrm{~N}$ per pot $)$. The plants were well watered during growth.

Starting on 46 days after sowing, GE measurements were conducted in a temperature controllable chamber. On one plant in each pot, the middle leaflet of the youngest, fully expanded top leaf was measured. The $A-I_{\text {inc }}$ and $A-C_{\text {a }}$ curves were assessed subsequently at $T_{\mathrm{L}}$ $15,20,25,30,35$ and $40{ }^{\circ} \mathrm{C}$. The levels of $I_{\text {inc }}$ and $C_{\text {a }}$ were set in accordance with the N-trial under ambient $\mathrm{O}_{2}$. During the measurements, the temperature in the growth chamber was controlled close to the targeting $T_{\mathrm{L}}$ and the vapour pressure of supplying air was set at $1.5 \mathrm{kPa}$ for all temperature levels except for $15{ }^{\circ} \mathrm{C}$, when it was set at $1.0 \mathrm{kPa}$ to avoid water condensation. Three plants were measured. SPAD, SLN and gas leakage were analysed using the procedures described for the N-trial.

\subsubsection{An experiment on leaf photosynthesis in response to fluctuating temperature under} different leaf nitrogen levels (TN-trial).

Seeds were sown in 18 containers $\left(60 \times 20 \times 18 \mathrm{~cm}^{3}\right)$ placed outdoor on 5 August 2013. Each container was filled with $10 \mathrm{~kg}$ of soil that contained $0.11 \%$ of total nitrogen and had a claysilt-sand ratio of 15:22:63. After seedling emergence, the plants were hand-thinned to 10 plants per container and three levels of urea fertilization were applied $(0,0.78$ and $1.95 \mathrm{~g} \mathrm{~N}$ per container, respectively). Each fertilization level had six containers. The plants were well watered during growth. Because of very late sowing, a halogen lamp (54 Watt) that was mounted at $50 \mathrm{~cm}$ from the top of canopy was turned on for $16 \mathrm{hrs}$ per day to prevent plants from flowering. The daily temperature and radiation during the growth period are presented in Supplementary Material Figure S4.1.

Starting on 50 days after sowing (the $8^{\text {th }}-10^{\text {th }}$ pair of leaves had appeared), GE measurements were conducted outdoors on three representative plants for each nitrogen level. $A-I_{\text {inc }}$ and $A-C_{\mathrm{a}}$ curves were assessed on the middle leaflet of the youngest, fully expanded leaf. The levels of light for the $A$ - $I_{\text {inc }}$ curves were identical to those in the $\mathrm{N}$-trial under ambient $\mathrm{O}_{2}$, while the $A$ $C_{\mathrm{a}}$ curves were assessed by increasing $C_{\mathrm{a}}$ as: 50, 60, 70, 80, 150, 250, 400, 650, 1000, and 1500

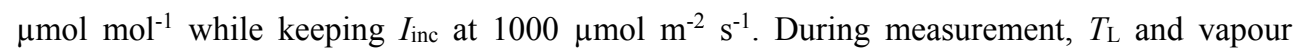
pressure were not controlled, therefore, varied depending on ambient conditions. A response curve was started when the leaf had adapted to the leaf chamber for $15 \mathrm{~min}$ at the first $I_{\mathrm{inc}} / C_{\mathrm{a}}$ level. Data were recorded manually when the real-time net photosynthesis $(A)$ had apparently 


\section{Chapter 4}

reached steady state ( $\sim 3 \mathrm{~min}$ for $A-I_{\text {inc }}$ and $\sim 5 \min$ for $A-C_{\mathrm{a}}$ ). SPAD, SLN and gas leakage were analysed using the procedures described for the $\mathrm{N}$-trial.

\subsubsection{Model description}

The photosynthesis model of Farquhar et al. (1980) coupled with $\mathrm{CO}_{2}$ diffusion model, as described in Yin \& Struik (2009), was used in this study.

\subsubsection{Modelling net leaf photosynthesis rate at the carboxylation sites of Rubisco}

The net leaf photosynthesis rate $\left(A, \mu \mathrm{mol} \mathrm{m} \mathrm{m}^{-2} \mathrm{~s}^{-1}\right)$ was modelled as the minimum of the Rubisco limited rate $\left(A_{\mathrm{c}}\right)$, the electron transport limited rate $\left(A_{\mathrm{j}}\right)$ and the triose phosphate utilization limited rate $\left(A_{\mathrm{p}}\right)$ :

$$
A=\min \left(A_{\mathrm{c}}, A_{\mathrm{j}}, A_{\mathrm{p}}\right)
$$

$A_{\mathrm{c}}$ is described, following the Michaelis-Menten kinetics, as:

$$
A_{\mathrm{c}}=\frac{\left(C_{\mathrm{c}}-\Gamma^{*}\right) V_{\mathrm{cmax}}}{C_{\mathrm{c}}+K_{\mathrm{mc}}\left(1+O / K_{\mathrm{mo}}\right)}-R_{\mathrm{d}}
$$

where $C_{\mathrm{c}}\left(\mu \mathrm{mol} \mathrm{mol}{ }^{-1}\right)$ and $O\left(\mathrm{mmol} \mathrm{mol}^{-1}\right)$ are the $\mathrm{CO}_{2}$ and $\mathrm{O}_{2}$ levels at the carboxylation sites of Rubisco; $V_{\mathrm{cmax}}\left(\mu \mathrm{mol} \mathrm{m} \mathrm{m}^{-2} \mathrm{~s}^{-1}\right)$ is the maximum rate of carboxylation; $K_{\mathrm{mc}}\left(\mu \mathrm{mol} \mathrm{mol}{ }^{-1}\right)$ and $K_{\mathrm{mo}}\left(\mathrm{mmol} \mathrm{mol}{ }^{-1}\right)$ are Michaelis-Menten constants of Rubisco for $\mathrm{CO}_{2}$ and $\mathrm{O}_{2}$, respectively; $R_{\mathrm{d}}$ $\left(\mu \mathrm{mol} \mathrm{m} \mathrm{m}^{-2} \mathrm{~s}^{-1}\right.$ ) is the day respiration (respiratory $\mathrm{CO}_{2}$ release other than by photorespiration); $\Gamma^{*}\left(\mu \mathrm{mol} \mathrm{mol}{ }^{-1}\right)$ is the $\mathrm{CO}_{2}$ compensation point in the absence of $R_{\mathrm{d}}$.

$A_{\mathrm{j}}$ is described as:

$$
A_{\mathrm{j}}=\frac{\left(C_{\mathrm{c}}-\Gamma^{*}\right) J}{4 C_{\mathrm{c}}+8 \Gamma^{*}}-R_{\mathrm{d}}
$$

where $J\left(\mu \mathrm{mol} \mathrm{m} \mathrm{m}^{-2} \mathrm{~s}^{-1}\right)$ is the potential linear $\mathrm{e}^{-}$transport rate that is used for $\mathrm{CO}_{2}$ fixation and photorespiration, and it is described as:

$$
J=\frac{\kappa_{2 \mathrm{LL}} I_{\mathrm{inc}}+J_{\max }-\sqrt{\left(\kappa_{2 \mathrm{LL}} I_{\mathrm{inc}}+J_{\max }\right)^{2}-4 \theta J_{\max } \kappa_{2 \mathrm{LL}} I_{\mathrm{inc}}}}{2 \theta}
$$

where $J_{\max }\left(\mu \mathrm{mol} \mathrm{m} \mathrm{m}^{-2} \mathrm{~s}^{-1}\right)$ is the maximum value of $J$ under saturated light; $I_{\text {inc }}$ is the incident light $\left(\mu \mathrm{mol} \mathrm{m} \mathrm{m}^{-2} \mathrm{~s}^{-1}\right) ; \kappa_{2} \mathrm{LL}\left(\mathrm{mol} \mathrm{mol}^{-1}\right)$ is the conversion efficiency of incident light into $J$ at strictly limiting light; $\theta$ (dimensionless) is convexity factor for the response of $J$ to $I_{\text {inc. }}$ 
$A_{\mathrm{p}}$ is described as:

$$
A_{\mathrm{p}}=3 T_{\mathrm{p}}-R_{\mathrm{d}}
$$

where $T_{\mathrm{p}}\left(\mu \mathrm{mol} \mathrm{m} \mathrm{m}^{-2} \mathrm{~s}^{-1}\right)$ is the rate of triose phosphate export from the chloroplast.

The $T_{\mathrm{L}}$ response of $R_{\mathrm{d}}, T_{\mathrm{p}}$ and kinetic properties of Rubisco (involving $V_{\mathrm{cmax}}, K_{\mathrm{mc}}, K_{\mathrm{mo}}$ and $\left.\Gamma^{*}\right)$ are described using an Arrhenius function normalized with respect to their values at $25^{\circ} \mathrm{C}$ (Eqn. 4.6) while the response of $J_{\max }$ is described using a peaked Arrhenius function (Eqn. 4.7):

$$
\begin{gathered}
X=X_{25} \exp \left[\frac{E_{\mathrm{X}}\left(T_{\mathrm{L}}-25\right)}{298 R\left(T_{\mathrm{L}}+273\right)}\right] \\
X=X_{25} \exp \left[\frac{E_{\mathrm{X}}\left(T_{\mathrm{L}}-25\right)}{298 R\left(T_{\mathrm{L}}+273\right)}\right]\left[\frac{1+\exp \left(\frac{298 S_{\mathrm{X}}-D_{\mathrm{X}}}{298 R}\right)}{1+\exp \left(\frac{\left(T_{\mathrm{L}}+273\right) S_{\mathrm{X}}-D_{\mathrm{X}}}{R\left(T_{\mathrm{L}}+273\right)}\right)}\right]
\end{gathered}
$$

where $X_{25}$ is the value of each parameter at $25^{\circ} \mathrm{C}$ (i.e., $R_{\mathrm{d}}, V_{\mathrm{cmax}}, K_{\mathrm{mc}}, K_{\mathrm{mo}}, \Gamma^{*}$ and $\left.J_{\max }\right) . E_{\mathrm{x}}$ and $D_{\mathrm{x}}$ are the energies of activation and deactivation (i.e., $E_{\mathrm{Rd}}, E_{\mathrm{Vcmax}}, E_{\mathrm{Kmc}}, E_{\mathrm{Kmo}}, E_{\mathrm{Tp}}, \mathrm{E}_{\Gamma^{*}}, E_{\mathrm{J} \max }$ and $D_{\mathrm{J} \max }$, all in $\left.\mathrm{J} \mathrm{mol}^{-1}\right) ; S_{\mathrm{x}}$ is the entropy term $\left(S_{\mathrm{J} \max }\right.$ in $\left.\mathrm{J} \mathrm{K}^{-1} \mathrm{~mol}^{-1}\right) ; R$ is the universal gas constant $\left(=8.314 \mathrm{~J} \mathrm{~K}^{-1} \mathrm{~mol}^{-1}\right)$.

\subsubsection{Modelling mesophyll conductance for $\mathrm{CO}_{2}$}

The $\mathrm{CO}_{2}$ concentration at intercellular space $\left(C_{\mathrm{i}}\right)$ was taken from gas exchange measurement whereas the estimation of $C_{\mathrm{c}}$ relies on proper estimation of mesophyll conductance $\left(g_{\mathrm{m}}\right) . g_{\mathrm{m}}$, calculated by the variable $J$ method (Harley et al., 1992a), appeared to vary with $\mathrm{CO}_{2}$ and irradiance levels (see Results section). Whether or not $g_{\mathrm{m}}$ varies with $\mathrm{CO}_{2}$ and irradiance levels is debatable (Flexas et al., 2012, 2007). We used the model of Yin et al. (2009) that is able to deal with both constant and variable $g_{\mathrm{m}}$ models, and have a similar form as Eqn. (4.8):

$$
g_{\mathrm{m}}=g_{\mathrm{m} 0}+\frac{\delta\left(A+R_{\mathrm{d}}\right)}{C_{\mathrm{c}}-\Gamma^{*}}
$$

where $g_{\mathrm{m} 0}\left(\mathrm{~mol} \mathrm{~m} \mathrm{~m}^{-2} \mathrm{~s}^{-1}\right)$ is the minimum $g_{\mathrm{m}}$ if irradiance approaches zero; parameter $\delta$ (dimensionless) in this model defines the $C_{\mathrm{c}}: C_{\mathrm{i}}$ ratio at saturating light as $\left(C_{\mathrm{c}}-\Gamma^{*}\right) /\left(C_{\mathrm{i}}-\right.$ $\left.\Gamma^{*}\right)=1 /(1+1 / \delta)$. Any positive value of $\delta$ predicts a variable $g_{\mathrm{m}}$ pattern in response to $C_{\mathrm{i}}$ and

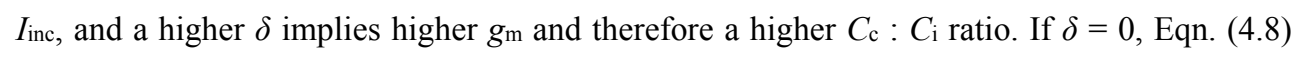
predicts an independence of $g_{\mathrm{m}}$ on $C_{\mathrm{i}}$ and $I_{\mathrm{inc}}$ (i.e., $g_{\mathrm{m}}=g_{\mathrm{m} 0}$ ), equivalent to the constant- $g_{\mathrm{m}}$ model. 


\subsubsection{Model parameterization and validation}

The data collected in the N-trial was used to assess the effect of leaf nitrogen on the values of model parameters at $25{ }^{\circ} \mathrm{C}$. The data collected in the T-trial was used to assess the effect of leaf temperature on the values of (peaked) Arrhenius model parameters. The parameterized model was validated against the data collected in the TN-trial. In the model, Rubisco kinetic properties related parameters (i.e., $K_{\mathrm{mc}}, K_{\mathrm{mo}}$ and $\Gamma^{*}$ ) and $\theta$, convexity factor for the response of $J$ to $I_{\mathrm{inc}}$, are conserved amongst $C_{3}$ species (von Caemmerer et al., 2009). Thus, the value of $\theta$ was set to 0.7 (Ögren \& Evans, 1993); the values of $K_{\mathrm{mc}}, K_{\mathrm{mo}}$ and $\Gamma^{*}$ at $25^{\circ} \mathrm{C}$ were set to $272 \mu \mathrm{mol}$ $\mathrm{mol}^{-1}, 165 \mathrm{mmol} \mathrm{mol}^{-1}$ and $37.5 \mu \mathrm{mol} \mathrm{mol}^{-1}$ (at 21\% $\mathrm{O}_{2}$ ), respectively (Bernacchi et al., 2002). The energies of activation $E_{\mathrm{Kmc}}, E_{\mathrm{Kmo}}$ and $E_{\Gamma^{*}}$ were adapted from the values of Bernacchi et al. (2002) as $E_{\mathrm{Kmc}}=80990 \mathrm{~J} \mathrm{~mol}^{-1} ; E_{\mathrm{Kmo}}=23720 \mathrm{~J} \mathrm{~mol}^{-1} ; E_{\Gamma^{*}}=24460 \mathrm{~J} \mathrm{~mol}^{-1}$.

\subsubsection{Model parameterization with data collected in the $N$-trial: nitrogen effect}

The step-wise parameterizing procedures described by Yin et al. (2009) were adapted in this study. Specifically:

Step 1: Estimating electron transport parameters $\left(J_{\max }\right.$ and $\left.\kappa_{2} \mathrm{LL}\right)$ and $R_{\mathrm{d}}$

According to Yin et al. (2009), the observed $A_{\mathrm{j}}$ under non-photorespiratory conditions can be expressed using Eqn. (4.9):

$$
\begin{aligned}
& A_{\mathrm{j}}=\frac{s I_{\mathrm{inc}} \Phi_{2}}{4}-R_{\mathrm{d}} \\
& s=\beta \rho_{2}\left(1-\frac{f_{\text {pseudo(b) }}}{1-f_{\text {cyc }}}\right)
\end{aligned}
$$

where $s$ is a lumped parameter; $\Phi_{2}$ is PSII operating efficiency, usually assessed from the chlorophyll fluorescence measurements, indicating quantum efficiency of PSII e- flow on PSIIabsorbed light basis; $\beta$ is leaf absorptance; $\rho_{2}$ is proportion of absorbed $I_{\text {inc }}$ partitioned to PSII; $f_{\text {cyc }}$ and $f_{\text {pseudo(b) }}$ are the fraction of cyclic and basal pseudocyclic electron transport, respectively. Thus, a simple linear regression can be performed for the observed $A$ against ( $\left.I_{\text {inc }} \Phi_{2} / 4\right)$ using data of the $\mathrm{e}^{-}$transport-limited range under non-photorespiratory conditions (measurements conducted at $2 \% \mathrm{O}_{2}$ ). The slope of the regression yields an estimate of the calibration factor $s$, and the intercept gives an estimate of $R_{\mathrm{d}}$ under $2 \% \mathrm{O}_{2}$ condition. The estimated $s$ allowed the conversion of CF-based PSII operating efficiency into the actual rate of linear electron transport as: 


$$
J=s I_{\text {inc }} \Phi_{2}
$$

Thus, $J_{\max }$ and $\kappa_{2 L L}$ can be estimated from fitting Eqn. (4.4) to the values of $J$.

The same linear regression for the observed $A$ against $\left(I_{\text {inc }} \Phi_{2} / 4\right)$ using data of the $\mathrm{e}^{-}$transportlimited range may be applied as well to photorespiratory conditions (i.e., ambient $\mathrm{O}_{2}$ ) for estimating $R_{\mathrm{d}}$ although the slight variation of $C_{\mathrm{i}}$ with $I_{\text {inc }}$ can have bearing under these conditions (Yin et al., 2011, 2009).

Step 2: Parameterization of the $g_{\mathrm{m}}$ model and $V_{\mathrm{cmax}}$ and $T_{\mathrm{p}}$

Combining Eqn. (4.8) with Eqn. (4.2) and Eqn. (4.3), and replacing $C_{\mathrm{c}}$ with $\left(C_{\mathrm{i}}-A / g_{\mathrm{m}}\right)$ yields (Yin et al. 2009):

$$
A_{\mathrm{c}} \text { or } A_{\mathrm{j}}=\frac{-b-\sqrt{b^{2}-4 a c}}{2 a}
$$

where

$$
\begin{gathered}
a=x_{2}+\Gamma^{*}+\delta\left(C_{\mathrm{i}}+x_{2}\right) \\
b=-\left\{\left(x_{2}+\Gamma^{*}\right)\left(x_{1}-R_{\mathrm{d}}\right)+\left(C_{\mathrm{i}}+x_{2}\right)\left[g_{\mathrm{m} 0}\left(x_{2}+\Gamma^{*}\right)+\delta\left(x_{1}-R_{\mathrm{d}}\right)\right]+\delta\left[x_{1}\left(C_{\mathrm{i}}-\Gamma^{*}\right)\right.\right. \\
\left.\left.-R_{\mathrm{d}}\left(C_{\mathrm{i}}+x_{2}\right)\right]\right\} \\
c=\left[g_{\mathrm{m} 0}\left(x_{2}+\Gamma^{*}\right)+\delta\left(x_{1}-R_{\mathrm{d}}\right)\right]\left[x_{1}\left(C_{\mathrm{i}}-\Gamma^{*}\right)-R_{\mathrm{d}}\left(C_{\mathrm{i}}+x_{2}\right)\right] \\
\text { with } x_{1}= \begin{cases}V_{\mathrm{cmax}} & \text { for } A_{\mathrm{c}} \\
\frac{J}{4} & \text { for } A_{\mathrm{j}}\end{cases} \\
\text { and } x_{2}= \begin{cases}K_{\mathrm{mc}}\left(1+\frac{o}{K_{\mathrm{mo}}}\right) & \text { for } A_{\mathrm{c}} \\
2 \Gamma^{*} & \text { for } A_{\mathrm{j}}\end{cases}
\end{gathered}
$$

Thus, $V_{\mathrm{cmax}}, T_{\mathrm{p}}$, and $\delta$ (or $g_{\mathrm{m} 0}$ ) can be estimated simultaneously by fitting Eqn. (4.1), Eqn. (4.4), Eqn. (4.5) and Eqn. (4.11) to $A-I_{\mathrm{inc}}$ and $A-C_{\mathrm{i}}$ using pre-estimated $J_{\max }, \kappa_{2 \mathrm{LL}}$ and $R_{\mathrm{d}}$ as input.

Since it is uncertain if $g_{\mathrm{m}}$ varies with $\mathrm{CO}_{2}$ and irradiance levels, $g_{\mathrm{m}}$ was first assessed according to the variable $J$ method (Harley et al., 1992a):

$$
g_{\mathrm{m}}=\frac{A}{C_{\mathrm{i}}-\frac{\Gamma^{*}\left[J+8\left(A+R_{\mathrm{d}}\right)\right]}{J-4\left(A+R_{\mathrm{d}}\right)}}
$$


where $A$ and $C_{\mathrm{i}}$ were taken from gas exchange measurements and $J$ was calculated by Eqn. (4.10). If $g_{\mathrm{m}}$ does vary in response to changing $C_{\mathrm{i}}$ and $I_{\mathrm{inc}}$, we could fit only $\delta$ by fixing $g_{\mathrm{m} 0}$ to 0 (Yin et al. 2009). In such a case, $g_{\mathrm{m}}$ can be calculated as:

$$
g_{\mathrm{m}}=\frac{A+\delta\left(A+R_{\mathrm{d}}\right)}{C_{\mathrm{i}}-\Gamma^{*}}
$$

\subsubsection{Model parameterization with data collected in the T-trial: temperature effect}

By assuming the value of $\delta$ is independent of leaf temperature, the values of $J_{\max }, \kappa_{2} \mathrm{LL}, V_{\mathrm{cmax}}$ and $T_{\mathrm{p}}$ at each leaf temperature were solved from Eqn. (4.1), Eqn. (4.4), Eqn. (4.5) and Eqn. (4.11) by simultaneously fitting $A-I_{\text {inc }}$ and $A-C_{\mathrm{i}}$. Subsequently, the parameter values at different $T_{\mathrm{L}}$ were fitted to either Eqn. (4.6) for estimating $E_{\mathrm{Rd}}, E_{\mathrm{V} c m a x}, E_{\mathrm{Tp}}$, or Eqn. (4.7) for estimating $E_{\mathrm{J} \max }, D_{\mathrm{J} \max }$ and $S_{\text {Jmax }}$.

\subsubsection{Model validation}

The parameterized model was validated against the data obtained in the TN-trial. The model parameters $R_{\mathrm{d}}, J_{\max }, V_{\mathrm{cmax}}$ and $T_{\mathrm{p}}$ at $25^{\circ} \mathrm{C}$ were derived from their linear relationships with $S L N$ (see Results section), and the effect of $T_{\mathrm{L}}$ on the values of these parameters was quantified through Eqn. (4.6) or Eqn. (4.7) with the estimated $E_{\mathrm{Rd}}, E_{\mathrm{V} c \max }, E_{\mathrm{Tp}}, E_{\mathrm{J} \max }, D_{\mathrm{J} \max }$ and $S_{\mathrm{J} \max }$.

\subsubsection{Comparison of hemp leaf photosynthetic competence with that of cotton and kenaf}

To illustrate the leaf photosynthetic competence of hemp in comparison with cotton and kenaf, $A-C_{\mathrm{i}}, A-I_{\text {inc }}, A-T_{\mathrm{L}}$ and $A-S L N$ curves were constructed for hemp using the validated model while those of cotton and kenaf were constructed using the FvCB models and corresponding parameters reported in Harley et al. (1992b) for cotton (cv. Coker 315) and in Archontoulis et al. (2011) for kenaf (cv. Everglades 41).

\subsubsection{Statistics}

Simple linear regression was performed using Microsoft Excel. Non-linear fitting was carried out using the GAUSS method in PROC NLIN of SAS (SAS Institute Inc., Cary, NC, USA). If parameters were proven independent from leaf nitrogen or temperature, the dummy variables method was used to estimate one common value (Yin et al., 2009). The goodness of fit was assessed by calculating the coefficient of determination $\left(r^{2}\right)$ and the relative mean root square ( $r R M S E)$. The effect of leaf position on parameter values was tested by performing ANOVA test considering leaf nitrogen as covariate. 


\subsection{Results}

\subsubsection{Results of model parameterization and validation}

\subsubsection{Results of the N-trial: nitrogen dependent photosynthetic capacity}

Measurements to assess the effect of leaf nitrogen on leaf photosynthetic capacity of hemp (Ntrial) were conducted on leaves having an average $S L N$ of $0.87 \mathrm{~g} \mathrm{~N} \mathrm{~m}^{-2}, 1.25 \mathrm{~g} \mathrm{~N} \mathrm{~m}^{-2}$ and 1.75 $\mathrm{g} \mathrm{N} \mathrm{m}^{-2}$ at the top of the canopy, or $0.65 \mathrm{~g} \mathrm{~N} \mathrm{~m}^{-2}, 0.78 \mathrm{~g} \mathrm{~N} \mathrm{~m}^{-2}$ and $1.22 \mathrm{~g} \mathrm{~N} \mathrm{~m}^{-2}$ at the middle of the canopy, for the three $\mathrm{N}$ treatments, respectively. Examples of $A-I_{\text {inc }}$ and $A-C_{\mathrm{i}}$ curves at different $S L N$ levels are shown in Figure 4.1. The $R_{\mathrm{dk}}\left(\mu \mathrm{mol} \mathrm{m} \mathrm{m}^{-2} \mathrm{~s}^{-1}\right.$; leaf respiration in the dark) and light-saturated net photosynthesis rate $\left(A_{\max }\right.$; measured at $\left.2000 \mu \mathrm{mol} \mathrm{m}{ }^{-2} \mathrm{~s}^{-1}\right)$ increased linearly with increasing $S L N$, and these linear relationships did not differ between the top and middle leaves (Figure 4.2).

Using the data of electron transport limited range under non-photorespiratory conditions (i.e., at $2 \% \mathrm{O}_{2}, C_{\mathrm{a}} \geq 600 \mu \mathrm{mol} \mathrm{mol}^{-1}$ in the $A-C_{\mathrm{a}}$ curve and $I_{\text {inc }} \leq 150 \mu \mathrm{mol} \mathrm{m}^{-2} \mathrm{~s}^{-1}$ in the $A-I_{\text {inc }}$ curve), parameter $s$ was estimated as the slope of a linear regression of $A$ against $\left(I_{\text {inc }} \Phi_{2} / 4\right)$. The value of $s$ was independent of $S L N$ and canopy position $(P>0.05$; see Supplementary Material Figure S4.2a). Thus, a common $s(0.33 \pm 0.01)$ was estimated from pooled data. $\kappa_{2} L L$ and $J_{\max }$ were estimated from fitting Eqn. (4.4) to the data on calculated $J$ from Eqn. (4.10). A preliminary estimation indicated that $\kappa_{2 L L}$ was unlikely to change with $S L N$ and canopy position
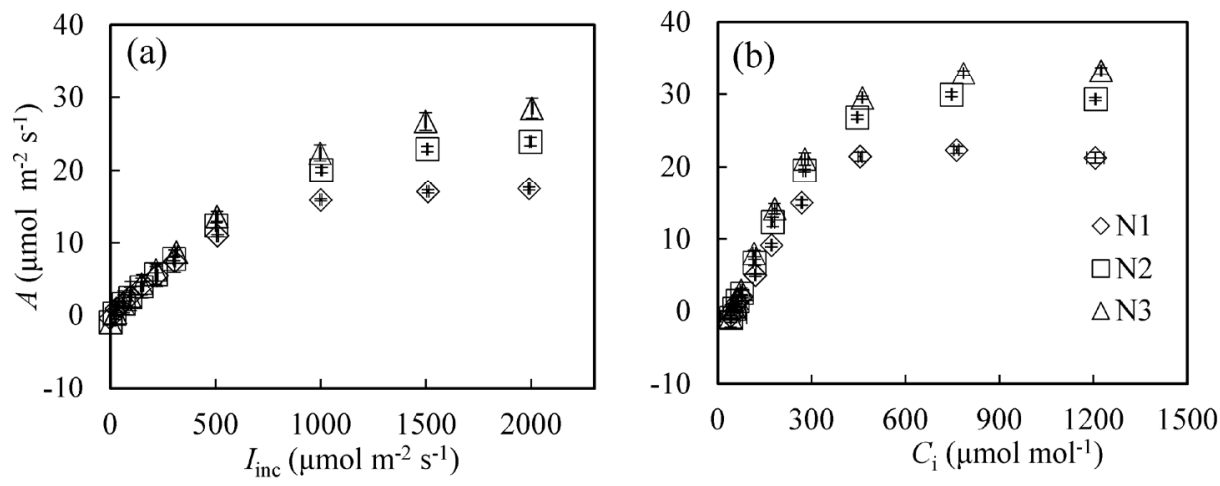

Figure 4.1 The net leaf photosynthesis $(A)$ in response to incident irradiance $\left(I_{\text {inc }} ;\right.$ panel a) and intercellular $\mathrm{CO}_{2}$ concentration $\left(C_{\mathrm{i}}\right.$; panel b) under different leaf nitrogen levels. Data presented were measured at $21 \% \mathrm{O}_{2}$ on the top leaves in the $\mathrm{N}$-trial. N1, N2 and $\mathrm{N} 3$ correspond to nitrogen treatments, resulting in average specific leaf nitrogen values of $0.87 \mathrm{~g} \mathrm{~N} \mathrm{~m}^{-2}, 1.25 \mathrm{~g} \mathrm{~N} \mathrm{~m}^{-2}$ and $1.75 \mathrm{~g} \mathrm{~N} \mathrm{~m}^{-2}$, respectively. The bars indicate standard errors of the mean $(n=3)$. 

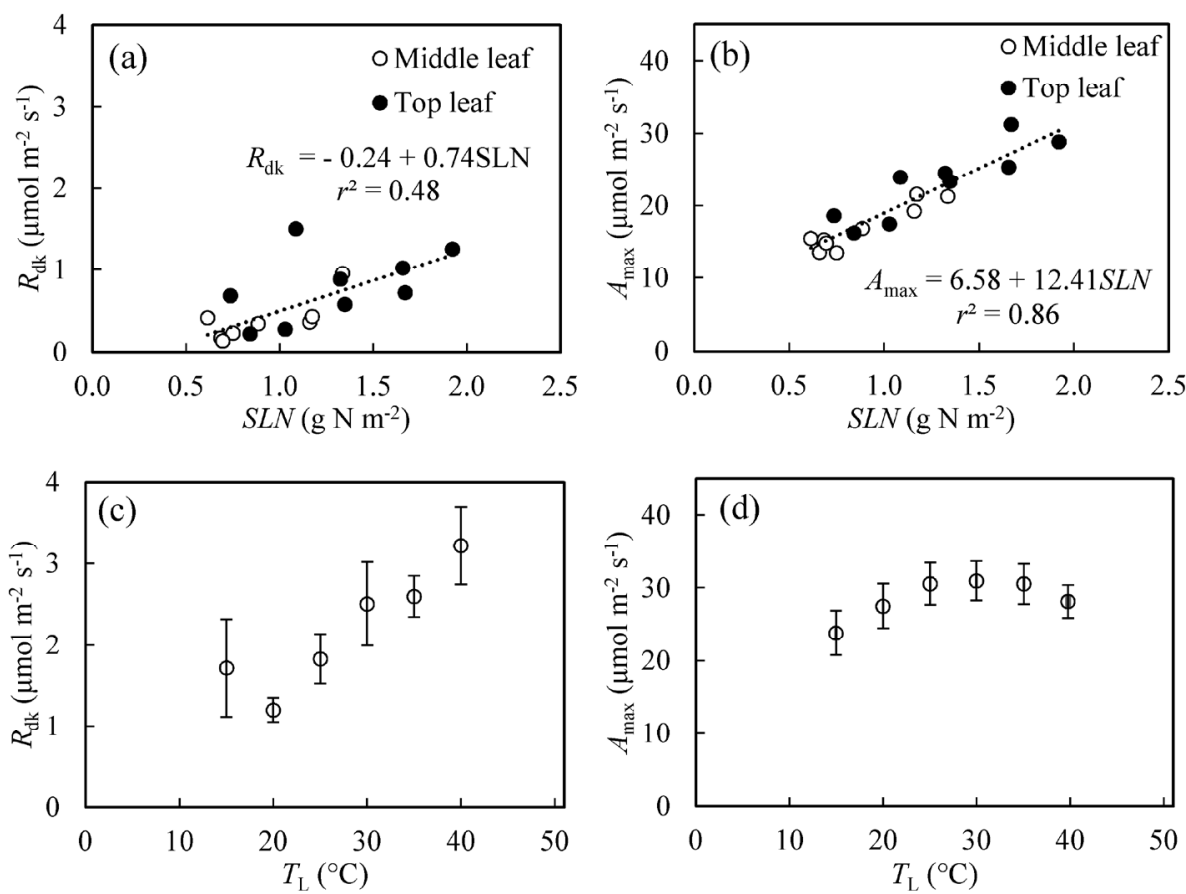

Figure 4.2 The response of leaf respiration in dark $\left(R_{\mathrm{dk}}\right.$, panels a and $\left.\mathrm{c}\right)$ and maximum light-saturated net photosynthesis rate ( $A_{\max }$; panels $\mathrm{b}$ and $\mathrm{d}$ ) to specific leaf nitrogen ( $S L N$; panels a and $\mathrm{b}$ ) and leaf temperature $\left(T_{\mathrm{L}}\right.$; panels $\mathrm{c}$ and d). $R_{\mathrm{dk}}$ was measured after adapting leaves in dark for 15 minutes after measuring the $A-I_{\text {inc }}$ curve. $A_{\max }$ was measured at $2000 \mu \mathrm{mol} \mathrm{m}^{-2} \mathrm{~s}^{-1}$ for incident light intensity and 400 $\mu \mathrm{mol} \mathrm{mol}{ }^{-1}$ for ambient $\mathrm{CO}_{2}$ concentration. The data presented in panel a and panel $\mathrm{b}$ were obtained in the $\mathrm{N}$-trial while those in panel $\mathrm{c}$ and panel $\mathrm{d}$ were obtained in the T-trial. The bars in panels $\mathrm{c}$ and $\mathrm{d}$ indicate standard errors of the mean $(n=3)$.

$\left(P>0.01\right.$; Supplementary Material Figure S4.2b). Thus, a common $\kappa_{2 \mathrm{LL}}(0.21 \pm 0.004 \mathrm{~mol}$ $\mathrm{mol}^{-1}$ ) was estimated together with $J_{\max }$ using the dummy variable method. The $J_{\max }$ ranged from $116.1 \mu \mathrm{mol} \mathrm{m} \mathrm{m}^{-2} \mathrm{~s}^{-1}$ to $316.4 \mu \mathrm{mol} \mathrm{m} \mathrm{m}^{-2} \mathrm{~s}^{-1}$ and increased linearly with an increase in $S L N$ at the rate of $132.9 \mu \mathrm{mol} \mathrm{s}^{-1}\left(\mathrm{~g} \mathrm{~N}^{-1}\right.$ (Figure 4.3a). The relationship between $J_{\max }$ and SLN was independent of canopy position $(P>0.05)$.

The estimated $R_{\mathrm{d}}$ values at $21 \% \mathrm{O}_{2}$ were roughly in line with the ones at $2 \% \mathrm{O}_{2}$ (Supplementary Material Figure S4.3). Although the latter were on average 25\% lower, a test of covariance indicated that $R_{\mathrm{d}}$ did not differ significantly between the different $\mathrm{O}_{2}$ levels $(P=$ $0.17)$. At $21 \% \mathrm{O}_{2}, R_{\mathrm{d}}$ ranged from $0.29 \mu \mathrm{mol} \mathrm{m}^{-2} \mathrm{~s}^{-1}$ to $1.61 \mu \mathrm{mol} \mathrm{m} \mathrm{m}^{-2} \mathrm{~s}^{-1}$, increasing linearly with $S L N$ at a rate of $0.85 \mu \mathrm{mol} \mathrm{s}^{-1}\left(\mathrm{~g} \mathrm{~N}^{-1}\right.$ (Figure $4.3 \mathrm{~b}$ ). The $R \mathrm{~d}-S L N$ relationship did not differ much between the middle and top leaves $(P>0.05)$. 

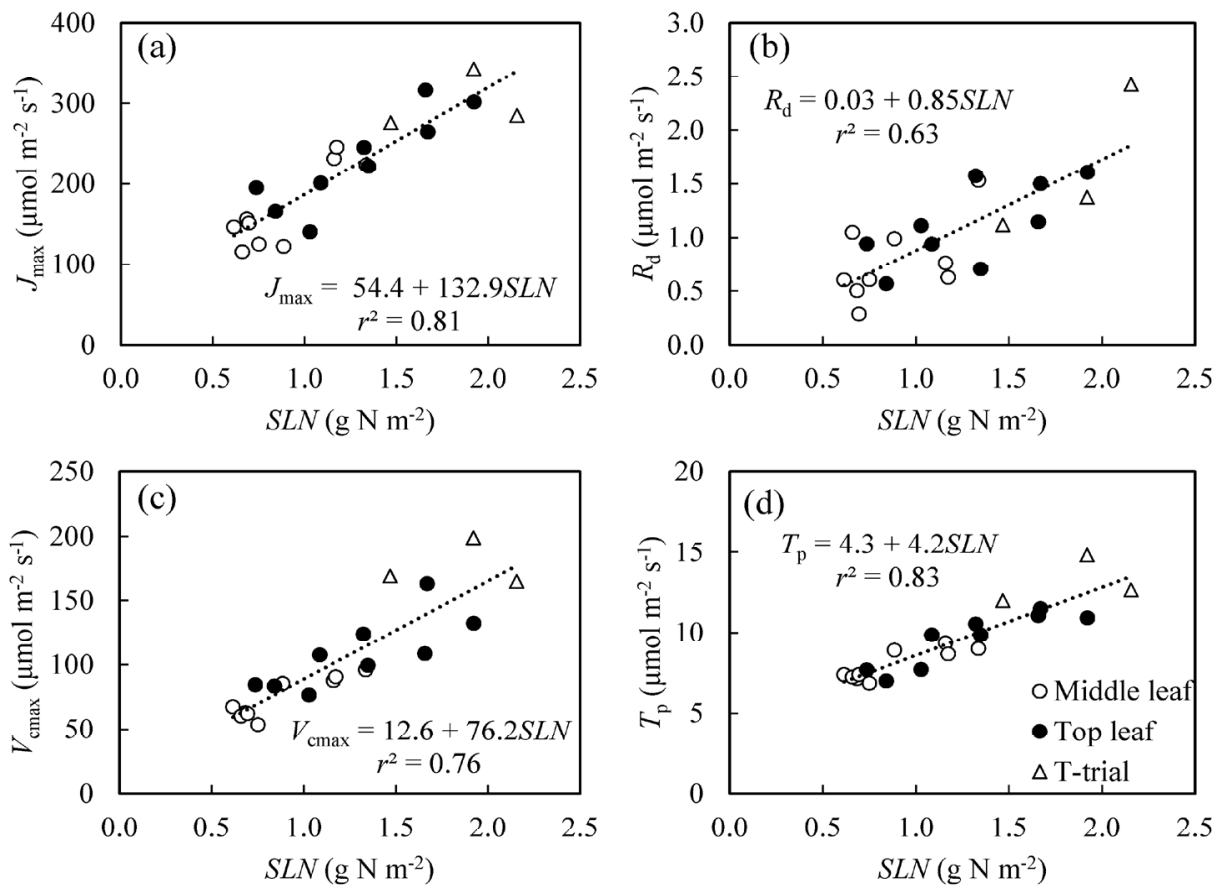

Figure 4.3 Dependence of maximum potential linear e- transport rate $\left(J_{\max } ;\right.$ panel a), day respiration $\left(R_{\mathrm{d}}\right.$; panel b), maximum rate of carboxylation $\left(V_{\text {cmax }}\right.$; panel c) and the rate of triose phosphate export from the chloroplast $\left(T_{\mathrm{p}}\right.$; panel d) on specific leaf nitrogen $(S L N)$. Values indicated as circles ( $\circ$ and $\bullet$ denote leaves at the middle and top of canopy, respectively) were derived from the data collected in the N-trial; values indicated as triangles $(\Delta)$ were derived from the data collected in the T-trial at a leaf temperature of $25^{\circ} \mathrm{C}$.

The $g_{\mathrm{m}}$ calculated using the variable $J$ method, Eqn. (4.12), indicated that it varied with changing $I_{\text {inc }}$ and $C_{\mathrm{i}}$ (Figure $4.4 \mathrm{a}, \mathrm{b}$ ). A preliminary analysis indicated that the value of $g_{\mathrm{m} 0}$ in Eqn. (4.8) was close to zero. By fixing $g_{\mathrm{m} 0}$ to zero, a common value of $\delta(2.12 \pm 0.09)$ was estimated together with $V_{\text {cmax }}$ and $T_{\mathrm{p}}$ using the dummy variable method. With the estimated $\delta$, Eqn. (4.13) estimates that $g_{\mathrm{m}}$ changes with $I_{\mathrm{inc}}$ and $C_{\mathrm{i}}$ in a similar trend as observed for the $g_{\mathrm{m}}$ calculated using Eqn. (4.12); the latter, however, was 38\% lower (Figure 4.4a, b), probably as a result that the variable $J$ method assumes the limitation on photosynthesis by electron transport over the full range of $A-I_{\text {inc }}$ and $A-C_{\mathrm{i}}$ curves (Yin et al. 2009). The estimated $g_{\mathrm{m}}$ with Eqn. (4.13) increases with an increase in $S L N$ (Figure 4.4c).

The estimated $V_{\text {cmax }}$ ranged from $53.7 \mu \mathrm{mol} \mathrm{m} \mathrm{m}^{-2} \mathrm{~s}^{-1}$ to $163.2 \mu \mathrm{mol} \mathrm{m} \mathrm{m}^{-2} \mathrm{~s}^{-1}$ and increased linearly with an increase in $S L N$ at the rate of $76.2 \mu \mathrm{mol} \mathrm{s}^{-1}\left(\mathrm{~g} \mathrm{~N}^{-1}\right.$ (Figure 4.3c). The estimated 

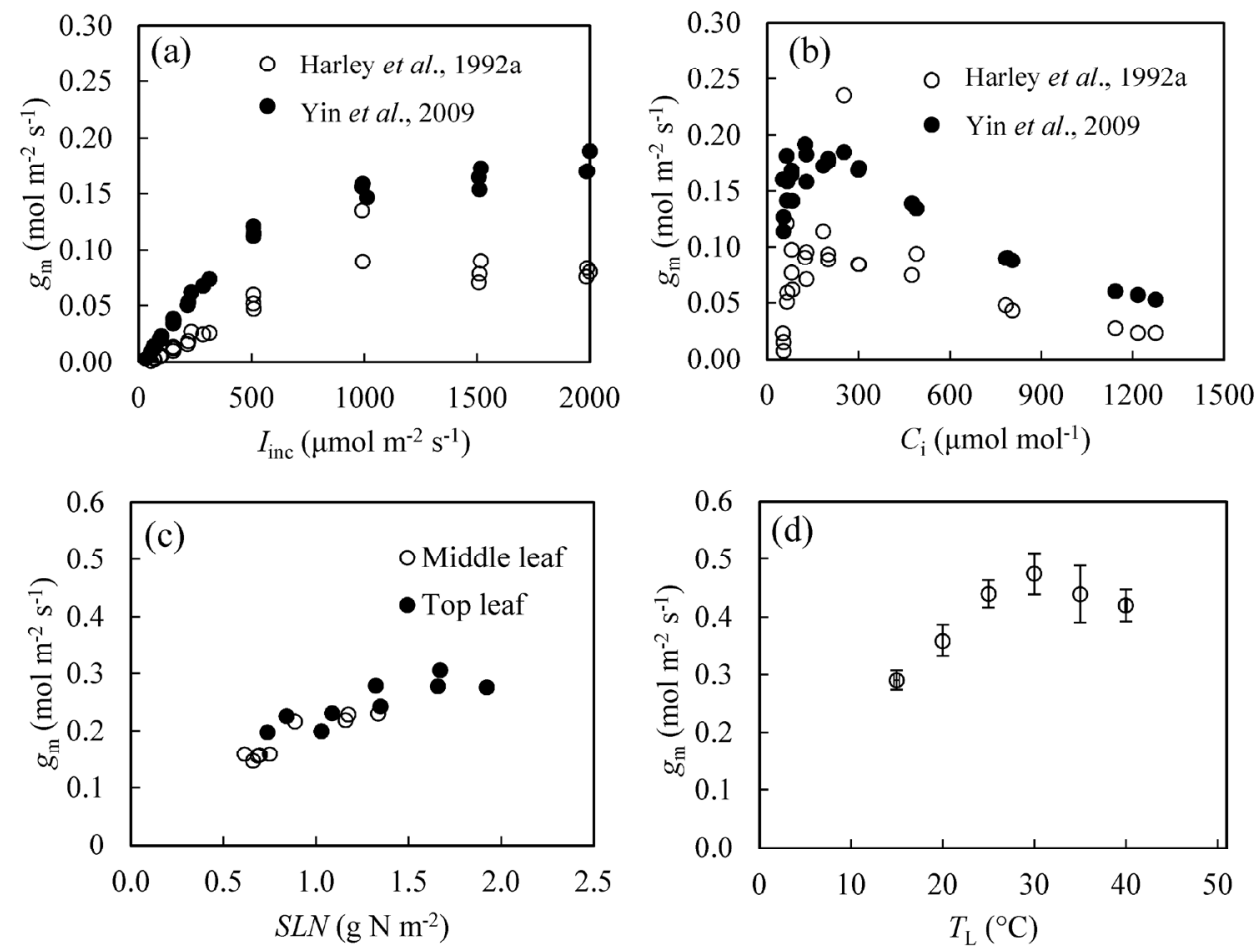

Figure 4.4 Illustration of mesophyll conductance $\left(g_{\mathrm{m}}\right)$ in relation to changing incident irradiance ( $I_{\mathrm{inc}}$ : panel a), intercellular $\mathrm{CO}_{2}$ concentration $\left(C_{\mathrm{i}}\right.$ : panel b), specific leaf nitrogen ( $S L N$; panel c) and leaf temperature $\left(T_{\mathrm{L}}\right.$; panel $\left.\mathrm{d}\right)$. In panels a and $\mathrm{b}$, the data presented were obtained from the leaves at the middle of the canopy in the treatment without nitrogen fertilization in the N-trial; the open (O) and closed $(\bullet)$ circles were calculated using the variable $J$ method of Harley et al. (1992a) (see Eqn. 4.12 in the text) and the method of Yin et al. (2009) (see Eqn. 4.13 in the text), respectively. In panel c, the data presented were obtained at $I_{\text {inc }}=1000 \mu \mathrm{mol} \mathrm{m}^{-2} \mathrm{~s}^{-1}$ and $C_{\mathrm{a}}=400 \mu \mathrm{mol} \mathrm{mol}^{-1}$ in the $\mathrm{N}$-trial; the open (o) and closed $(\bullet)$ circles represent data obtained from leaves from the middle and the top of the canopy, respectively. In panel d, the data presented were obtained at $I_{\mathrm{inc}}=1000 \mu \mathrm{mol} \mathrm{m}^{-2} \mathrm{~s}^{-1}$ and $C_{\mathrm{a}}=400 \mu \mathrm{mol}$ $\mathrm{mol}^{-1}$ in the T-trial; the bars indicate standard errors of the mean $(n=3)$. Note the differences in scale along the y-axes.

$T_{\mathrm{p}}$ ranged from $6.9 \mu \mathrm{mol} \mathrm{m} \mathrm{m}^{-2} \mathrm{~s}^{-1}$ to $11.5 \mu \mathrm{mol} \mathrm{m}^{-2} \mathrm{~s}^{-1}$ and increased linearly with an increase in $S L N$ at the rate of $4.2 \mu \mathrm{mol} \mathrm{s}^{-1}(\mathrm{~g} \mathrm{~N})^{-1}$ (Figure 4.3d). The effects of $S L N$ on $V_{\text {cmax }}$ and $T_{\mathrm{p}}$ were independent of leaf position ( $P>0.05$ ). With the estimated $R_{\mathrm{d}}, \kappa_{2} \mathrm{LL}, J_{\max }, \delta, V_{\mathrm{cmax}}$ and $T_{\mathrm{p}}$, the $r^{2}$ and $r R M S E$ of the model description of the measured $A$ in the N-trial were 0.99 and $18.5 \%$, respectively.

\subsubsection{Results of T-trial: temperature dependent photosynthetic capacity}

The $R_{\mathrm{dk}}$ increased continuously from $0.9 \mu \mathrm{mol} \mathrm{m} \mathrm{m}^{-2} \mathrm{~s}^{-1}$ to $4.1 \mu \mathrm{mol} \mathrm{m} \mathrm{m}^{-2} \mathrm{~s}^{-1}$ at increasing $T_{\mathrm{L}}$ from $15{ }^{\circ} \mathrm{C}$ to $40{ }^{\circ} \mathrm{C}$ while the $A$ max initially increased with increasing $T \mathrm{~L}$, levelled off at $25-35^{\circ} \mathrm{C}$ and decreased when $T_{\mathrm{L}}$ became higher than $35^{\circ} \mathrm{C}$ (Figure $4.2 \mathrm{c}, \mathrm{d}$ ). 

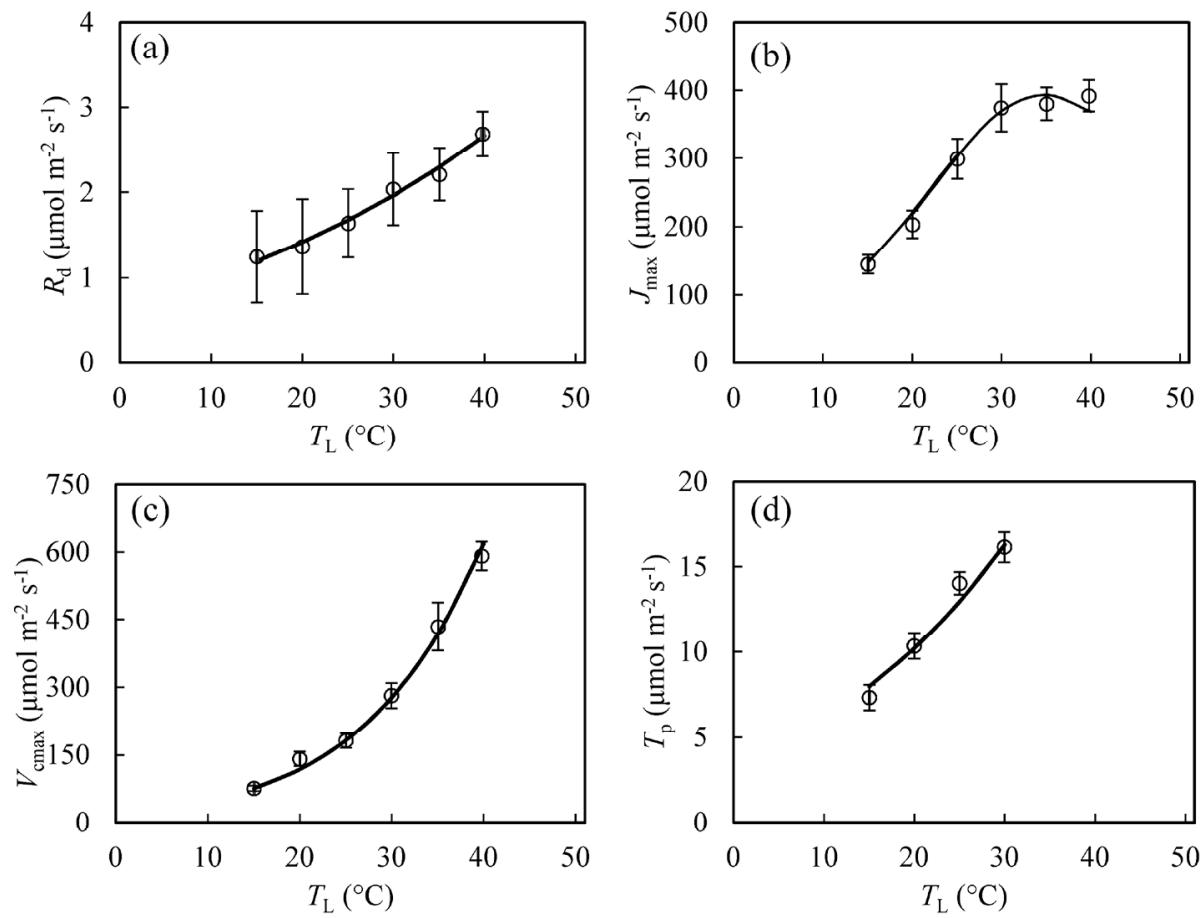

Figure 4.5 Response of day respiration $\left(R_{\mathrm{d}}\right.$; panel a), maximum potential linear e- transport rate $\left(J_{\max }\right.$; panel b), maximum rate of carboxylation $\left(V_{\mathrm{cmax}}\right.$; panel c) and the rate of triose phosphate export from the chloroplast $\left(T_{\mathrm{p}}\right.$; panel d) to leaf temperature $\left(T_{\mathrm{L}}\right)$. The solid lines denote the predicted relations according to Eqn. (4.6) or Eqn. (4.7) with values presented in Table 4.1. The bars indicate standard errors of the mean $(n=3)$.

The estimated $R_{\mathrm{d}}$ increased continuously with an increase in $T_{\mathrm{L}}$, ranging from $0.3 \mu \mathrm{mol} \mathrm{m} \mathrm{m}^{-2}$ $\mathrm{s}^{-1}$ until $3.2 \mu \mathrm{mol} \mathrm{m} \mathrm{m}^{-2} \mathrm{~s}^{-1}$ (Figure $4.5 \mathrm{a}$ ). The $\kappa_{2 \mathrm{LL}}, J_{\max }, V_{\mathrm{cmax}}$ and $T_{\mathrm{p}}$ were estimated simultaneously by assuming $\delta=2.12$ (estimated in $\mathrm{N}$-trial) at each $T \mathrm{~L}$. With the constant $\delta$, the model predicted that $g_{\mathrm{m}}$ changed with an increase in $T_{\mathrm{L}}$ following a similar trend as $A \max$ (cf. Figures $4.2 \mathrm{~d}, 4.4 \mathrm{~d})$. A preliminary analysis indicated that $\kappa_{2 \mathrm{LL}}$ was conserved at different levels of $T_{\mathrm{L}}(P>0.05$; see Supplementary Material Figure S4.2c) but significantly higher than the value estimated in the $\mathrm{N}$-trial (i.e., $\left.\kappa_{2 \mathrm{LL}}=0.21 \pm 0.004 \mathrm{~mol} \mathrm{~mol}^{-1}\right)$. Thus, a common $\kappa_{2 \mathrm{LL}}(0.37$ $\pm 0.01 \mathrm{~mol} \mathrm{~mol}^{-1}$ ) was estimated together with $J_{\max }, V_{\mathrm{cmax}}$ and $T_{\mathrm{p}}$ using the dummy variable method. The $J_{\max }, V_{\mathrm{cmax}}$ and $T_{\mathrm{p}}$ at $25^{\circ} \mathrm{C}$ were comparable with those derived from the N-trial (Figure 4.3). The value of $T_{\mathrm{p}}$ increased consistently with an increase in $T_{\mathrm{L}}$ from $15^{\circ} \mathrm{C}$ to $30{ }^{\circ} \mathrm{C}$ (Figure $4.5 \mathrm{~d}$ ). When $T_{\mathrm{L}}$ was higher than $30^{\circ} \mathrm{C}$, the curve fitting failed to assess $T_{\mathrm{p}}$ properly because the triose phosphate utilization is not limited at such high temperatures (Busch $\&$ Sage, 2016; Sage \& Kubien, 2007). Therefore, $T_{\mathrm{p}}$ limitation was excluded to estimate $J_{\max }$ and $V_{\text {cmax }}$ 
at $35{ }^{\circ} \mathrm{C}$ and $40{ }^{\circ} \mathrm{C}$. The $V_{\text {cmax }}$ increased continuously at increasing $T_{\mathrm{L}}$ from $15{ }^{\circ} \mathrm{C}$ to $40{ }^{\circ} \mathrm{C}$ while the value of $J_{\max }$ peaked at $30-35^{\circ} \mathrm{C}$ (Figure $4.5 \mathrm{~b}, \mathrm{c}$ ).

By fitting the $R_{\mathrm{d}}-T_{\mathrm{L}}, V_{\mathrm{cmax}}-T_{\mathrm{L}}$ and $T_{\mathrm{p}}-T_{\mathrm{L}}$ to Eqn. (4.6), the activation energies $E_{\mathrm{Rd}}, E_{\mathrm{Vcmax}}$ and $E_{\mathrm{Tp}}$ were estimated at $21634.8 \pm 4085.5 \mathrm{~J} \mathrm{~mol}^{-1}, 63042.7 \pm 1562.2 \mathrm{~J} \mathrm{~mol}^{-1}$ and $34417.8 \pm 5297.7$ $\mathrm{J} \mathrm{mol}^{-1}$, respectively. By fitting $J_{\max } T_{\mathrm{L}}$ to Eqn. (4.7), the values of $E_{\mathrm{J} \max }, D_{\mathrm{J} \max }$ and $S_{\mathrm{J} \max }$ were estimated at $67292.1 \pm 35985.5 \mathrm{~J} \mathrm{~mol}^{-1}, 114701.0 \pm 28709.6 \mathrm{~J} \mathrm{~mol}^{-1}$ and $375.6 \pm 82.3 \mathrm{~J} \mathrm{~K}^{-1}$ $\mathrm{mol}^{-1}$, respectively. With the estimated parameters, the model described well the response of $A$ to changing $I_{\text {inc }}$ and $C_{\mathrm{i}}$ at different $T_{\mathrm{L}}\left(r^{2}=0.94\right.$ and $\left.r R M S E=24.1 \%\right)$.

\subsubsection{Model validation}

The measurements in the TN-trial were conducted on leaves with $S L N$ ranging from $0.63 \mathrm{~g} \mathrm{~N}$ $\mathrm{m}^{-2}$ to $1.44 \mathrm{~g} \mathrm{~N} \mathrm{~m}^{-2}$. During the measurement, the $T_{\mathrm{L}}$ ranged from $21{ }^{\circ} \mathrm{C}$ to $33{ }^{\circ} \mathrm{C}$, and $V P D$ ranged from $0.61 \mathrm{kPa}$ to $2.61 \mathrm{kPa}$.

The parameterized model was validated against the data obtained in the TN-trial. The measured $A$ was overestimated with either the $\kappa_{2 \mathrm{LL}}$ derived in the $\mathrm{N}$-trial $\left(\kappa_{2 \mathrm{LL}}=0.21 \mathrm{~mol} \mathrm{~mol}^{-1}\right)$ or in the T-trial $\left(\kappa_{2 \mathrm{LL}}=0.37 \mathrm{~mol} \mathrm{~mol}^{-1}\right)$ (Figure $\left.4.6 \mathrm{a}, \mathrm{b}\right)$. The $r R M S E$ reduced significantly with decreasing value of $\kappa_{2} \mathrm{LL}$ until $0.13 \mathrm{~mol} \mathrm{~mol}^{-1}$ (Figure 4.6c). Assuming $\kappa_{2} \mathrm{LL}=0.13 \mathrm{~mol} \mathrm{~mol}^{-1}$ for the TN-trial, the $r^{2}$ and $r R M S E$ were 0.94 and 26\%, respectively; the error of model prediction distributed evenly across measured $S L N$ and $T_{\mathrm{L}}$ (see Supplementary Material Figure S4.4).
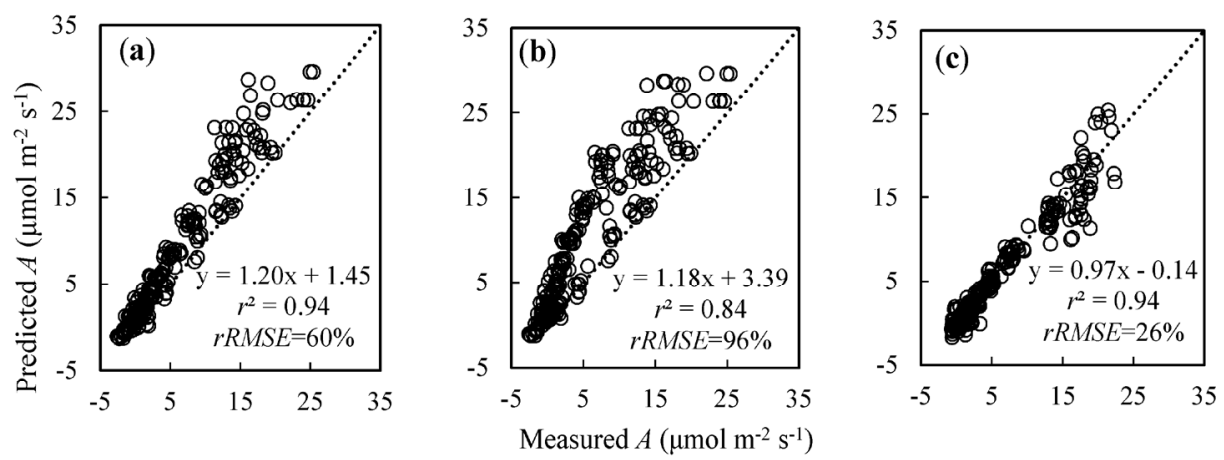

Figure 4.6 Results of model validation against the data measured net photosynthesis rate $(A)$ in the TNtrial. The dotted lines represent the 1:1 line. The predicted $A$ values in panels a, b and c were with a value of $\kappa_{2 \mathrm{LL}}=0.21 \mathrm{~mol} \mathrm{~mol}^{-1}$ (derived from the $\mathrm{N}$-trial), $\kappa_{2 \mathrm{LL}}=0.37 \mathrm{~mol} \mathrm{~mol}^{-1}$ (derived from the Ttrial) and $\kappa_{2 \mathrm{LL}}=0.13 \mathrm{~mol} \mathrm{~mol}^{-1}$ (obtained by minimizing prediction error of $A$ ), respectively. 

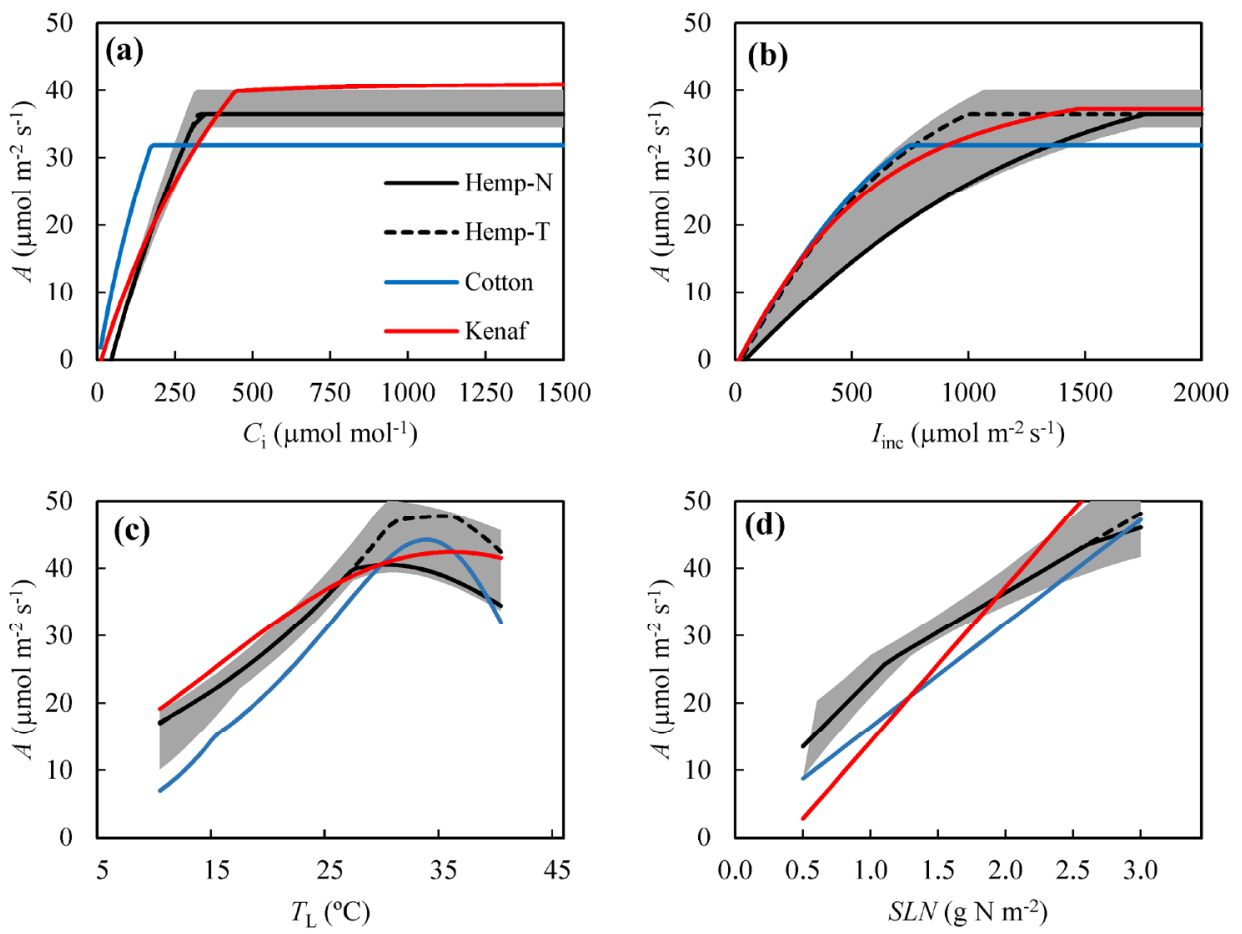

Figure 4.7 Simulation of leaf photosynthetic capacity $(A)$ of hemp (black lines), kenaf (red line) and cotton (blue line) in response to intercellular $\mathrm{CO}_{2}$ concentration $\left(C_{\mathrm{i}}\right.$; panel a), incident light intensity $\left(I_{\text {inc }}\right.$; panel b), leaf temperature $\left(T_{\mathrm{L}}\right.$; panel c) and leaf nitrogen $(S L N$; panel d). The hemp leaf photosynthesis presented by a continuous line was simulated with $\kappa_{2 \mathrm{LL}}=0.21 \mathrm{~mol} \mathrm{~mol}^{-1}$ (derived from the $\mathrm{N}$-trial) while the dashed line was simulated with $\kappa_{2 \mathrm{LL}}=0.37 \mathrm{~mol} \mathrm{~mol}^{-1}$ (derived from the T-trial). The shaded area presents $95 \%$ confidence interval of hemp leaf photosynthesis. The photosynthesis rates of cotton were simulated using the model and values described in Harley et al. (1992b) while for kenaf the model and values came from Archontoulis et al. (2011). Except when used as the independent variable, the variables were set constant as: $C_{\mathrm{i}}=400 \mu \mathrm{mol} \mathrm{mol}^{-1} ; I_{\text {inc }}=2000 \mu \mathrm{mol} \mathrm{m}^{-2} \mathrm{~s}^{-1} ; S L N=2.0 \mathrm{~g}$ $\mathrm{N} \mathrm{m}^{-2} ; T_{\mathrm{L}}=25^{\circ} \mathrm{C}$.

\subsubsection{Leaf photosynthetic competence of hemp in comparison with kenaf and cotton}

Comparison of leaf photosynthetic competence of hemp with kenaf and cotton is presented in Figure 4.7. The values of the main parameters are summarised in Table 4.1. In this illustration, we considered the uncertainty in estimated values of parameters (i.e., $R_{\mathrm{d}}, J_{\max }, V_{\mathrm{cmax}}$ and $T_{\mathrm{p}}$ ) for their linear relationships with $S L N$ and non-linear relationships with $T_{\mathrm{L}}$ (presented as the shaded area). The modelled values of $A$ for hemp are shown using lower and upper bounds of $95 \%$ confidence interval of these parameter values. Given that there was a large variation in the value of $\kappa_{2} \mathrm{LL}$ among different growth environments and each estimate of $\kappa_{2} \mathrm{LL}$ had a very small standard error (Table 4.1), the lower bounds were combined with $\kappa_{2 \mathrm{LL}}$ of $0.21 \mathrm{~mol} \mathrm{~mol}{ }^{-1}$ 
Table 4.1 List of model parameters ( \pm standard errors if available) of hemp, cotton and kenaf.

\begin{tabular}{|c|c|c|c|c|c|}
\hline Parameter & & Unit & Hemp & Cotton $^{\mathrm{b}}$ & Kenaf $^{d}$ \\
\hline \multicolumn{6}{|l|}{ Respiration } \\
\hline \multirow[t]{2}{*}{$R_{\mathrm{d}}-S L N$} & Slope & $\mu \mathrm{mol} \mathrm{s}^{-1}\left(\mathrm{~g} \mathrm{~N}^{-1}\right.$ & $0.85 \pm 0.15$ & $0^{c}$ & 0.80 \\
\hline & Intercept & $\mu \mathrm{mol} \mathrm{m}{ }^{-2} \mathrm{~s}^{-1}$ & $0.03 \pm 0.19$ & $0.82^{\mathrm{c}}$ & -0.37 \\
\hline$E_{\mathrm{Rd}}$ & & $\mathrm{J} \mathrm{mol}^{-1}$ & $21634 \pm 4085$ & 84450 & 83440 \\
\hline \multicolumn{6}{|c|}{$e^{-}$transport parameters } \\
\hline \multirow[t]{2}{*}{$J_{\max }-S L N$} & Slope & $\mu \mathrm{mol} \mathrm{s}^{-1}\left(\mathrm{~g} \mathrm{~N}^{-1}\right.$ & $132.9 \pm 14.6$ & 98.1 & 122.1 \\
\hline & Intercept & $\mu \mathrm{mol} \mathrm{m} \mathrm{m}^{-2} \mathrm{~s}^{-1}$ & $54.4 \pm 18.8$ & -4.6 & -47.6 \\
\hline$E_{\mathrm{J} \max }$ & & $\mathrm{J} \mathrm{mol}^{-1}$ & $67292 \pm 35986$ & 79500 & 28149 \\
\hline$D_{\text {Jmax }}$ & & $\mathrm{J} \mathrm{mol}^{-1}$ & $114701 \pm 28710$ & 201000 & $474614^{\mathrm{f}}$ \\
\hline$S_{\text {Jmax }}$ & & $\mathrm{J} \mathrm{K}^{-1} \mathrm{~mol}^{-1}$ & $375 \pm 82$ & 650 & $1482^{f}$ \\
\hline$\kappa_{2 \mathrm{LL}}$ & & $\mathrm{mol} \mathrm{mol}^{-1}$ & $0.21 \pm 0.004(\mathrm{~N}$-trial $)$ & $0.24^{\mathrm{a}}$ & 0.28 \\
\hline$\theta$ & & - & $0.70^{\mathrm{a}}$ & $0.83^{\mathrm{a}}$ & 0.63 \\
\hline \multicolumn{6}{|c|}{ Rubisco parameters } \\
\hline \multirow[t]{2}{*}{$V_{\mathrm{cmax}}-S L N$} & Slope & $\mu \mathrm{mol} \mathrm{s}^{-1}\left(\mathrm{~g} \mathrm{~N}^{-1}\right.$ & $76.2 \pm 9.8$ & $60.0^{\mathrm{e}}$ & $66.7^{\mathrm{e}}$ \\
\hline & Intercept & $\mu \mathrm{mol} \mathrm{m}{ }^{-2} \mathrm{~s}^{-1}$ & $12.6 \pm 12.5$ & $-9.6^{\mathrm{e}}$ & $26.0^{\mathrm{e}}$ \\
\hline$E_{\mathrm{vcmax}}$ & & $\mathrm{J} \mathrm{mol}^{-1}$ & $63024 \pm 1562$ & 116300 & 61812 \\
\hline \multicolumn{6}{|l|}{ TPU parameters } \\
\hline \multirow[t]{2}{*}{$T_{\mathrm{p}}-S L N$} & Slope & $\mu \mathrm{mol} \mathrm{s}^{-1}\left(\mathrm{~g} \mathrm{~N}^{-1}\right.$ & $4.2 \pm 0.4$ & 5.1 & NA \\
\hline & Intercept & $\mu \mathrm{mol} \mathrm{m} \mathrm{m}^{-2} \mathrm{~s}^{-1}$ & $4.3 \pm 0.6$ & $0.6^{\mathrm{e}}$ & \\
\hline$E_{\mathrm{Tp}}$ & & $\mathrm{J} \mathrm{mol}^{-1}$ & $34417 \pm 5298$ & 53100 & NA \\
\hline \multicolumn{6}{|l|}{$g_{\mathrm{m}}$ parameters } \\
\hline$\delta$ & & - & $2.12 \pm 0.09$ & NA & NA \\
\hline$g_{\mathrm{m} 0}$ & & $\mathrm{~mol} \mathrm{~m}^{-2} \mathrm{~s}^{-1}$ & $0^{\mathrm{a}}$ & NA & NA \\
\hline
\end{tabular}

NA: not estimated or not available

${ }^{a}$ : parameter values are fixed beforehand.

${ }^{b}$ : parameter values are derived from Harley et al. (1992b) with plants grown at an ambient $\left[\mathrm{CO}_{2}\right]$ of 35 $\mathrm{Pa}$; the parameter values of temperature response are converted to fit Eqn. (4.6) or Eqn. (4.7) in the text; the value of $\theta$ is converted to fit Eqn. (4.4) in the text.

c: $R_{\mathrm{d}}$ was held constant at different nitrogen levels and equal to $0.82 \mu \mathrm{mol} \mathrm{m} \mathrm{m}^{-2} \mathrm{~s}^{-1}$.

d: parameter values are derived from Archontoulis et al. (2011). In his paper, the value of $E_{\mathrm{Rd}}$ is a function of $S L N$. The value presented here is derived at $S L N=2.0 \mathrm{~g} \mathrm{~N} \mathrm{~m}^{-2}$. Slopes of $R_{\mathrm{d}}-S L N$ are calculated from simulation of $R_{\mathrm{d}}$ against $S L N$ using original model.

e: note that the absolute value of these parameters may be lower than the presented one when $g_{\mathrm{m}}$ is considered;

f: the optimum temperature $J_{\max }$ was not observed, so its $J_{\max }$ was fitted to the Arrhenius Eqn. (4.6), thereby $D_{\mathrm{J} \max }$ and $S_{\mathrm{J} \max }$ were not estimated. The presented value gave equal temperature sensitivities but it was rejected by the authors due to a high standard error of the estimate.

(derived from N-trial) while the upper bounds were combined with $\kappa_{2} \mathrm{LL}$ of $0.37 \mathrm{~mol} \mathrm{~mol}^{-1}$ (derived from T-trial).

For the response to $C_{\mathrm{i}}$, these three crops had similar $A$ at the current atmosphere $\mathrm{CO}_{2}$ level (Figure 4.7a). In case of a further increase in $\mathrm{CO}_{2}$ level in the future, kenaf may become more productive than hemp. For both crops, there was a large uncertainty in the responses of $A$ to $I_{\text {inc }}$ and $T_{\mathrm{L}}$ (Figure $4.7 \mathrm{~b}, \mathrm{c}$ ) because these curves are affected by the value of $\kappa_{2} \mathrm{LL}$. When using $\kappa_{2} \mathrm{LL}$ 
of $0.37 \mathrm{~mol} \mathrm{~mol}^{-1}$, a value close to that of healthy $\mathrm{C}_{3}$ leaves (presented as dashed black lines), the calculated $A$ for hemp was similar to that for kenaf across different $I_{\text {inc }}$ levels, but was slightly higher than for cotton at intermediate $I_{\text {inc. Reducing } \kappa 2 \mathrm{LL}}$ to $0.21 \mathrm{~mol} \mathrm{~mol}^{-1}$ (presented as solid black lines) resulted in a reduction of $A$ under light limiting condition and in a reduction of the optimal temperature. For the response to leaf nitrogen, the leaf photosynthetic competence of hemp, including its $95 \%$ confidence interval, was consistently higher than that of cotton and kenaf at $S L N<2.0 \mathrm{~g} \mathrm{~N} \mathrm{~m}^{-2}$, which is close to the maximum $S L N$ measured in this study (Figure 4.7d).

\subsection{Discussion}

Hemp is considered an ideal annual crop for the bio-economy as it has the potential to produce a high multipurpose biomass yield while requiring little inputs (Chapters 2, 3; Finnan \& Burke, 2013). However, very limited information is available on the physiological basis of hemp resource use efficiency. With the aim of understanding the response of leaf photosynthesis capacity of hemp to leaf nitrogen status and environmental factors and setting the basis for a hemp growth model, this study presents the results of extensive hemp leaf photosynthetic measurements and parameterization of a widely-used photosynthesis model.

\subsubsection{Parameterization of the leaf photosynthesis model for hemp}

Theoretically, the method to estimate $R_{\mathrm{d}}$ (day respiration) works best for the NPR (nonphotorespiratory) condition (Yin et al., 2011). The estimated $R_{\mathrm{d}}$ in this study did not differ significantly between PR (photorespiratory) and NPR conditions $(P>0.05)$. This result suggests that estimating $R_{\mathrm{d}}$ from Eqn. (4.9) is practicable even under PR condition (Yin et al., 2009,2011 ). Note that assessing the true $R_{\mathrm{d}}$ is somewhat difficult and the estimated $R_{\mathrm{d}}$ differs according to methodologies. A comparison of the method used in this study with other ones to estimate $R_{\mathrm{d}}$ is discussed in Yin et al. (2011). The estimated $R_{\mathrm{d}}$ values were on average $20 \%$ lower than $R_{\mathrm{dk}}$ values (respiration in the dark) in line with other reports (Yin et al., 2011, 2009, Brooks \& Farquhar, 1985). An in vivo metabolic study (Tcherkez et al., 2005) indicated that the main inhibited steps were the entrance of hexose molecules into the glycolytic pathway and the Krebs cycle. Nevertheless, detailed mechanism of this difference still needs further research (Tcherkez et al., 2012).

Both $R_{\mathrm{d}}$ and $R_{\mathrm{dk}}$ increased monotonically with an increase in $S L N$ and $T_{\mathrm{L}}$ (Figures 4.2, 4.3, 4.5) within the tested ranges. The result agrees with those of Yin et al. (2011, 2009), but does 


\section{Chapter 4}

not support those in Harley et al. (1992b) for cotton, where a constant $R_{\mathrm{d}}$ was considered at changing nitrogen and temperature. For hemp, Chandra et al. $(2011 \mathrm{a}, 2008)$ reported that $R_{\mathrm{dk}}$ levelled off or slightly decreased with an increase in temperature from $30^{\circ} \mathrm{C}$ to $40{ }^{\circ} \mathrm{C}$. This was not confirmed in the present study, although the highest $R_{\mathrm{dk}}$ measured at $25{ }^{\circ} \mathrm{C}$ in our study is comparable with the value observed in Chandra et al. (2011a, 2008). The reason for such discrepancy of $R_{\mathrm{dk}}$ in response to $T_{\mathrm{L}}$ is not clear. It is probably due to an artefact of different protocols or due to changes of thermal sensitivity of respiration at different growth environments and plant status (e.g., drought, nutrient availability and sugar concentration) (Katja et al., 2012; Atkin et al., 2005). If an increase of respiration with increasing $S L N$ and $T_{\mathrm{L}}$ is proven for hemp, it could counteract, at least partly, the positive effects of $S L N$ and $T_{\mathrm{L}}$ on $A$ (net photosynthesis rate) when considering at daily basis.

Based on the findings that the maximum quantum yields (the initial slopes of the response of $\mathrm{CO}_{2}$ uptake to photon absorption) were conserved across age classes within species or across the mature photosynthetic organs of different species (Long et al., 1993), 22L $^{2}$ was often fixed as a constant across different growth environments and species in studies of plant photosynthesis (Medlyn et al., 2002; Harley et al., 1992b). However, very different values have been assumed in different studies without clear explanation, ranging from $0.18 \mathrm{~mol} \mathrm{~mol}^{-1}$ until $0.39 \mathrm{~mol} \mathrm{~mol}^{-1}$ (Yamori et al., 2010; Medlyn et al., 2002; Wullschleger, 1993; Harley et al., $1992 \mathrm{~b})$. The estimated $\kappa_{2 \mathrm{LL}}$ in the present study did not change with $S L N$ and with $T_{\mathrm{L}}$ but it was not constant across growth environments $\left(0.21 \mathrm{~mol} \mathrm{~mol}^{-1}\right.$ for the $\mathrm{N}$-trial; $0.37 \mathrm{~mol} \mathrm{~mol}^{-1}$ for the T-trial and $0.13 \mathrm{~mol} \mathrm{~mol}^{-1}$ resulted in the best prediction of measurements in the TN-trial), in line with Archontoulis et al. (2011) who observed that cardoon (Cynara cardunculus) had a higher $\kappa_{2} \mathrm{LL}$ in the cold season than in the warm season. The reason for the variation in $\kappa_{2} \mathrm{LL}$ in different environments is still not fully understood. We speculate that the low $\kappa_{2} \mathrm{LL}$ in the N-trial and the TN-trial in comparison with the $\kappa_{2} \mathrm{LL}$ in the T-trial is a consequence of photoinhibition that occurs naturally in field plants grown in West-Europe when the temperature is low and the sky is clear (Long et al., 1994). The plants of the N-trial and the TN-trial were grown outdoors, with fluctuations in temperature and irradiance, particularly the plants in the TN-trial experienced a sudden drop of temperature five days before measuring (Supplementary Material Figure S4.1). These conditions could have resulted in severe photoinhibition (Long et al., 1983; Powles et al., 1983) causing a reduction in $\Phi_{2 \mathrm{LL}}$ (PSII quantum use efficiency under strictly

limiting light) and an increase in the fraction of alternative electonic transport (i.e., $\frac{f_{\text {pseudo(b) }}}{1-f_{c y c}}$; 
cf. Eqn. 4.9a) (Murata et al., 2012; Curwiel \& van Rensen, 1993), hence a low $\kappa_{2}$ LL. In contrast, the plants of the T-trial were grown in the greenhouse where both light intensity and temperature were controlled at a condition free of photoinhibition. Thus, the value of $\kappa_{2} \mathrm{LL}(0.37$ mol mol-1) was high and close to the range for healthy $\mathrm{C}_{3}$ leaves (between $0.32 \mathrm{~mol} \mathrm{~mol}^{-1}$ and $0.35 \mathrm{~mol} \mathrm{~mol}^{-1}$ ) (Hikosaka et al., 2016 and their references). Moreover, the variation in $\kappa_{2 \mathrm{LL}}$ could be partly attributed to the change in $\beta$ (leaf absorbance; cf. Eqn. 4.9a) as a result of environmental acclimation (Archontoulis et al., 2011). A higher $\beta$ in the T-trial than in the Ntrial and the NT-trial is reflected by the higher $S P A D$ values when considered at the same $S L N$ (Supplementary Material Figure S4.5). Given that the value of $\kappa_{2 L L}$ varied significantly across different environments and that it affected significantly the prediction of photosynthesis when electron transport was limited (i.e., $A_{\mathrm{j}}$ ) (Figure 4.7), caution is needed when modelling photosynthesis rate using a value of $\kappa_{2} \mathrm{LL}$ derived from different environments, particularly if these include both greenhouse and open field conditions. To improve modelling of crop growth in field conditions, further study should be conducted to investigate the mechanisms underlying variation in $\kappa_{2 L L}$ during the whole growth season.

The relationships $J_{\max }-S L N, V_{\mathrm{cmax}}-S L N$ and $T_{\mathrm{p}}-S L N$ were consistent across canopy positions and growth environments whereas linear regression of these relationships resulted in negative intersections at the $x$-axis (Figure 4.3), in line with Akita et al. (2012) but different from Archontoulis et al. (2011) and Braune et al. (2009) where the intersection of linear extrapolating resulted in a minimum $S L N$ required for photosynthesis $\left(S L N_{\mathrm{b}}\right)$. Given that it is not physiologically possible to have a negative $S L N_{\mathrm{b}}$, the results in this study indicate that the relationships $J_{\max }-S L N, V_{\mathrm{cmax}}-S L N$ and $T_{\mathrm{p}}-S L N$ for hemp may not be perfectly linear. Further study would be needed to elucidate the relationship between these parameters and SLN at SLN levels approaching zero.

It is well recognized that $g_{\mathrm{m}}$ is not infinite (Bernacchi et al., 2002). Using both the variable $J$ method and the modelling method, our analysis for hemp (Figure 4.4) supports that $g_{\mathrm{m}}$ varies with changing $C_{\mathrm{i}}$ and $I_{\text {inc }}$ (Flexas et al., 2012, 2007; Yin et al., 2009), which is in contrast with the assumption that $g_{\mathrm{m}}$ is independent of $C_{\mathrm{i}}$ and $I_{\text {inc }}$ (Bernacchi et al., 2002). This highlights an important uncertainty in the present understanding of $\mathrm{CO}_{2}$ diffusion processes in leaves. The $g_{\mathrm{m}}$ obtained from Eqn. (4.13) with a constant $\delta$ changed in line with $A$ (cf. Figures 4.2, 4.4), confirming the assumption of Piel et al. (2002) and Ethier et al. (2006) that $g_{\mathrm{m}}$ is correlated with $A$. The value of $\delta(2.12)$ is lower than that of wheat (2.54) (Yin et al., 2009) but higher than that of rice (0.45 1.57) (Gu et al., 2012). 


\subsubsection{Does hemp have high photosynthetic competence?}

The observed $A_{\max }$ was levelled off at $25-35^{\circ} \mathrm{C}$ (Figure 2d) that is comparable with the $27{ }^{\circ} \mathrm{C}$ reported in Cosentino et al. (2012) and the $30^{\circ} \mathrm{C}$ reported in Chandra et al. (2011a) for hemp leaf photosynthesis. The wide range of optimal temperature for leaf photosynthesis confirms the fact that hemp has been cultivated from the tropic (Tang et al., 2012) to the polar circle (Pahkala et al., 2008).

The highest $A_{\max }$ (light-saturated net photosynthesis rate) at $25^{\circ} \mathrm{C}$ was measured at $31.2 \pm$ $1.9 \mu \mathrm{mol} \mathrm{m} \mathrm{m}^{-2} \mathrm{~s}^{-1}$ (Figure 4.2b). This value is higher than the highest value reported for hemp in De Meijer et al. (1995) and (Chandra et al., 2011a, 2008), which were $19.0 \mu \mathrm{mol} \mathrm{m}^{-2} \mathrm{~s}^{-1}$ and $24.0 \mu \mathrm{mol} \mathrm{m} \mathrm{m}^{-2} \mathrm{~s}^{-1}$, respectively. The highest $A_{\max }$ in this study is comparable with that of other $\mathrm{C}_{3}$ bioenergy crops. Archontoulis et al. (2011) reported that the highest $A_{\max }$ of kenaf, sunflower (Helianthus annuus L.) and cardoon ranged between $30 \mu \mathrm{mol} \mathrm{m}^{-2} \mathrm{~s}^{-1}$ and $35 \mu \mathrm{mol} \mathrm{m}^{-2} \mathrm{~s}^{-1}$ under optimum temperature.

As direct comparison of $A \max$ among crops is difficult due to the variation of experimental protocols and plant status, we constructed $A-C_{\mathrm{i}}, A-I_{\text {inc }}, A-T_{\mathrm{L}}$ and $A-S L N$ curves for hemp, cotton and kenaf with the same values of variables (i.e. $C_{\mathrm{i}}, I_{\mathrm{inc}}, T_{\mathrm{L}}$ and $S L N$ ) (Figure 4.7). The comparison highlighted that hemp has higher leaf photosynthesis rate than cotton and kenaf at a low nitrogen condition (i.e., $S L N<2.0 \mathrm{~g} \mathrm{~N} \mathrm{~m}^{-2}$ ). This was presumably because hemp has a relatively low $S L N_{\mathrm{b}}$. Analysis of newly senesced hemp leaves resulted in a nitrogen content of $0.25 \pm 0.01 \mathrm{~g} \mathrm{~N} \mathrm{~m}^{-2}$. This value is at the low range of $S L N_{\mathrm{b}}$ among $\mathrm{C}_{3}$ crops and weeds (average value $\left.=0.31 \pm 0.03 \mathrm{~g} \mathrm{~N} \mathrm{~m}^{-2}\right)$ and is considerably lower than the estimation for kenaf $(0.39 \pm$ $0.13 \mathrm{~g} \mathrm{~N} \mathrm{~m}^{-2}$ ) (Archontoulis et al., 2011).

The high photosynthesis rate of hemp at low nitrogen condition is in line with its observed high productivity at low nitrogen input (Finnan \& Burke, 2013, Struik et al., 2000) and puts hemp ahead of cotton and kenaf from a perspective of bio-economy. However, our model approach has limitations. Firstly, the comparison was based on parameters derived from different studies conducted in different environments. Secondly, even though the FvCB model is biochemically based and the relationships $J_{\max }-S L N, V_{\mathrm{cmax}}-S L N$ and $T_{\mathrm{p}}-S L N$ were consistent in this study across canopy positions and growth environments (Figure 4.3), increasing evidences show that the model parameters may change when plant acclimates to growing environments. For example, Harley et al., (1992b) reported that the slope of $V_{\mathrm{cmax}}-S L N$ decreased with an increase in $\mathrm{CO}_{2}$ concentration in the growth environment. The present study 
also indicated that the value of $\kappa_{2 L L}$ may differ among growth environments. Thirdly, variation of photosynthetic competence among cultivars has been reported for hemp (Chandra et al., 2011b). As only one cultivar was studied, it is not clear if the advantage of photosynthetic competence of hemp is persistent across cultivars. Therefore, to consolidate the potential of hemp as a bio-economic sustainable crop, further study is needed to compare hemp leaf photosynthetic competence with those of cotton, kenaf and other bioenergy crops in the same growing environment with multiple cultivars.

\section{Acknowledgements}

The research leading to these results has received funding from the European Union's Seventh Framework Programme for research, technological development and demonstration under grant agreement $n^{\circ} 311849$.

\section{References}

Akita, R., Kamiyama, C. and Hikosaka, K. (2012) Polygonum sachalinense alters the balance between capacities of regeneration and carboxylation of ribulose-1,5-bisphosphate in response to growth $\mathrm{CO}_{2}$ increment but not the nitrogen allocation within the photosynthetic apparatus. Physiologia Plantarum, 146, 404-412.

Alexopoulou, E., Li, D., Papatheohari, Y. et al. (2015) How kenaf (Hibiscus cannabinus L.) can achieve high yields in Europe and China. Industrial Crops and Products, 68, 131-140.

Allegret, S. (2013) The history of hemp. In: Hemp: industrial production and uses. (eds Allegret, S., Bouloc, P. and Arnaud, L.), pp. 4-26. CPi Group Ltd, Croydon, UK.

Amaducci, S., Errani, M. and Venturi, G. (2002) Response of hemp to plant population and nitrogen fertilisation. Italian Journal of Agronomy, 6, 103-111.

Amaducci, S., Scordia, D., Liu F. et al. (2015) Key cultivation techniques for hemp in Europe and China. Industrial Crops and Products, 68, 2-16.

Archontoulis, S.V., Yin, X., Vos, J. et al. (2011) Leaf photosynthesis and respiration of three bioenergy crops in relation to temperature and leaf nitrogen: how conserved are biochemical model parameters among crop species? Journal of Experimental Botany, 63, 895-911.

Atkin, O.K., Bruhn, D., Hurry, V.M. et al. (2005) The hot and the cold: unravelling the variable response of plant respiration to temperature. Functional Plant Biology, 32, 87-105.

Barth, M. and Carus, M. (2015) Carbon footprint and sustainability of different natural fibres for biocomposites and insulation material, Hürth, Germany, nova-Institute. Available at (2017, November 29): http://bio-based.eu/ecology/.

Bellasio, C., Beerling, D.J. and Griffiths, H. (2015) An Excel tool for deriving key photosynthetic parameters from combined gas exchange and chlorophyll fluorescence: theory and practice. Plant, Cell \& Environment, 69, 80-97. 
Bernacchi, C.J., Portis, A.R., Nakano, H. et al. (2002) Temperature response of mesophyll conductance. Implications for the determination of Rubisco enzyme kinetics and for limitations to photosynthesis in vivo. Plant Physiology, 130, 1992-1998.

Bertoli, A., Tozzi, S., Pistelli, L. et al. (2010) Fibre hemp inflorescences: From crop-residues to essential oil production. Industrial Crops and Products, 32, 329-337.

Bouloc, P. and Van der Werf, H.M.G. (2013) The role of hemp in sustainable development. In: Hemp: industrial production and uses (eds Bouloc, P., Allegret, S. and Arnaud, L.), pp. 278-289. CPi Group Ltd, Croydon, UK.

Bouman, B.M., Feng, L., Tuong ,T.P. et al. (2007) Exploring options to grow rice using less water in northern China using a modelling approach: II. Quantifying yield, water balance components, and water productivity. Agricultural Water Management, 88, 23-33.

Braune, H., Müller, J. and Diepenbrock, W. (2009) Integrating effects of leaf nitrogen, age, rank, and growth temperature into the photosynthesis-stomatal conductance model LEAFC3$\mathrm{N}$ parameterised for barley (Hordeum vulgare L.). Ecological Modelling, 220, 1599-1612.

Brooks, A. and Farquhar, G.D. (1985) Effect of temperature on the $\mathrm{CO}_{2} / \mathrm{O}_{2}$ specificity of ribulose-1,5-bisphosphate carboxylase/oxygenase and the rate of respiration in the light. Planta, 165, 397-406.

Busch, F.A. and Sage, R.F. (2016) The sensitivity of photosynthesis to $\mathrm{O}_{2}$ and $\mathrm{CO}_{2}$ concentration identifies strong Rubisco control above the thermal optimum. New Phytologist, 213, 1036-1051.

Carus, M., Karst, S., Kauffmann, A. et al. (2013) The European Hemp Industry: Cultivation, processing and applications for fibres, shivs and seeds. European Industrial Hemp Association (EIHA), Hürth, Germany. Available at (2017, November 29): http://eiha.org/media/2014/10/13-06-European-Hemp-Industry.pdf

Carus, M. and Sarmento, L. (2016) The European Hemp Industry: Cultivation, processing and applications for fibres, shivs and seeds. European Industrial Hemp Association (EIHA), Hürth, Germany. Available at (2017, November 29): http://eiha.org/media/2016/05/1605-17-European-Hemp-Industry-2013.pdf

Chandra, S., Lata, H., Khan, I.A. et al. (2008) Photosynthetic response of Cannabis sativa L. to variations in photosynthetic photon flux densities, temperature and $\mathrm{CO} 2$ conditions. Physiology and Molecular Biology of Plants, 14, 299-306.

Chandra, S., Lata, H., Khan, I.A. et al. (2011a) Temperature response of photosynthesis in different drug and fiber varieties of Cannabis sativa L. Physiology and Molecular Biology of Plants, 17, 297-303.

Chandra, S., Lata, H., Khan, I.A. et al. (2011b) Photosynthetic response of Cannabis sativa L., an important medicinal plant, to elevated levels of $\mathrm{CO}_{2}$. Physiology and Molecular Biology of Plants, 17, 291-295.

Chandra, S., Lata, H., Mehmedic, Z. et al. (2015) Light dependence of photosynthesis and water vapor exchange characteristics in different high $\Delta 9$-THC yielding varieties of Cannabis sativa L. Journal of Applied Research on Medicinal and Aromatic Plants, 2, $39-47$.

Cosentino, S.L., Testa, G., Scordia, D. et al. (2012) Sowing time and prediction of flowering of 
different hemp (Cannabis sativa L.) genotypes in southern Europe. Industrial Crops and Products, 37, 20-33.

Curwiel, V.B. and Van Rensen, J.J.S. (1993) Influence of photoinhibition on electron transport and photophosphorylation of isolated chloroplasts. Physiologia Plantarum, 89, 97-102.

De Meijer, E.P.M. and Van der Werf, H.M.G. (1994) Evaluation of current methods to estimate pulp yield of hemp. Industrial Crops and Products, 2, 111-120.

De Meijer, W.J.M., Van der Werf, H.M.G., Mathijssen E.W.J..M et al. (1995) Constraints to dry matter production in fibre hemp (Cannabis sativa L.). European Journal of Agronomy, 4, 109-117.

Ethier, G., Livingston, N., Harrison, D. et al. (2006) Low stomatal and internal conductance to $\mathrm{CO}_{2}$ versus Rubisco deactivation as determinants of the photosynthetic decline of ageing evergreen leaves. Plant, Cell \& Environment, 29, 2168-2184.

Farquhar, G.D., Von Caemmerer, S. and Berry, J.A. (1980) A biochemical model of photosynthetic $\mathrm{CO}_{2}$ assimilation in leaves of $\mathrm{C}_{3}$ species. Planta, 149, 78-90.

Finnan, J. and Burke, B. (2013) Nitrogen fertilization to optimize the greenhouse gas balance of hemp crops grown for biomass. GCB Bioenergy, 5, 701-712.

Flexas, J., Barbour, M.M. and Brendel, O. et al. (2012) Mesophyll diffusion conductance to $\mathrm{CO}_{2}$ : an unappreciated central player in photosynthesis. Plant Science, 193, 70-84.

Flexas, J., Diaz-Espejo, A., Galmes, J. et al. (2007) Rapid variations of mesophyll conductance in response to changes in $\mathrm{CO}_{2}$ concentration around leaves. Plant, Cell \& Environment, 30, 1284-1298.

Gu, J, Yin, X, Stomph, T.J. et al. (2012) Physiological basis of genetic variation in leaf photosynthesis among rice (Oryza sativa L.) introgression lines under drought and wellwatered conditions. Journal of Experimental Botany, 63, 5137-5153.

Harley, P.C., Loreto, F., Di Marco, G. et al. (1992a) Theoretical considerations when estimating the mesophyll conductance to $\mathrm{CO}_{2}$ flux by analysis of the response of photosynthesis to $\mathrm{CO}_{2}$. Plant Physiology, 98, 1429-1436.

Harley, P.C., Thomas, R.B., Reynolds, J.F. et al. (1992b) Modelling photosynthesis of cotton grown in elevated $\mathrm{CO}_{2}$. Plant, Cell \& Environment, 15, 271-282.

Hikosaka, K., Noguchi, K. and Terashima, I. (2016) Modeling leaf gas exchange. In: Canopy Photosynthesis: From Basics to Applications (eds Hikosaka, K., Niinemets, Ü. and Anten N.P.R.), pp 61-100. Springer, London, UK.

Jordan, N., Boody, G., Broussard, W. et al. (2007) Sustainable development of the agricultural bio-economy. Science, 316, 1570-1571.

Katja, H., Irina, B., Hiie, I. et al. (2012) Temperature responses of dark respiration in relation to leaf sugar concentration. Physiologia Plantarum, 144, 320-334.

Kreuger, E., Prade, T., Escobar, F. et al. (2011) Anaerobic digestion of industrial hemp - Effect of harvest time on methane energy yield per hectare. Biomass and Bioenergy, 35, 893900.

Lips, S.J.J. and van Dam, J.E.G. (2013) Kenaf fibre crop for bioeconomic industrial 
development. In: Kenaf: a multi-purpose crop for several industrial applications. (eds Monti, A. and Alexopoulou, E.), pp. 105-143. Springer, London, UK.

Long, S., East, T. and Baker, N. (1983) Chilling damage to photosynthesis in young Zea mays I. Effects of light and temperature variation on photosynthetic $\mathrm{CO}_{2}$ assimilation. Journal of Experimental Botany, 34, 177-188.

Long, S., Humphries, S. and Falkowski, P.G. (1994) Photoinhibition of photosynthesis in nature. Annual review of plant biology, 45, 633-662.

Long, S., Postl, W.F. and Bolhár-Nordenkampf, H.R. (1993) Quantum yields for uptake of carbon dioxide in $\mathrm{C}_{3}$ vascular plants of contrasting habitats and taxonomic groupings. Planta, 189, 226-234.

Marija, M., Māra, V. and Veneranda, S. (2011) Changes of photosynthesis-related parameters and productivity of Cannabis sativa under different nitrogen supply. Environmental and Experimental Biology, 9, 61-69.

Mccormick, K. and Kautto, N. (2013) The bioeconomy in Europe: An overview. Sustainability, 5, 2589-2608.

Medlyn, B.E., Dreye,r E., Ellsworth, D. et al. (2002) Temperature response of parameters of a biochemically based model of photosynthesis. II. A review of experimental data. Plant, Cell \& Environment, 25, 1167-1179.

Murata, N., Allakhverdiev, S.I. and Nishiyama, Y. (2012) The mechanism of photoinhibition in vivo: Re-evaluation of the roles of catalase, $\alpha$-tocopherol, non-photochemical quenching, and electron transport. Biochimica et Biophysica Acta (BBA) - Bioenergetics, 1817, 1127 1133.

Ögren, E. and Evans, J. (1993) Photosynthetic light-response curves. Planta, 189, 182-190.

Oomah, B.D., Busson, M., Godfrey, D.V. et al. (2002) Characteristics of hemp (Cannabis sativa L.) seed oil. Food Chemistry, 76, 33-43.

Patanè, C. and Cosentino, S.L. (2013) Yield, water use and radiation use efficiencies of kenaf (Hibiscus cannabinus L.) under reduced water and nitrogen soil availability in a semiarid Mediterranean area. European Journal of Agronomy, 46, 53-62.

Piel, C., Frak, E., Le Roux, X. et al. (2002) Effect of local irradiance on $\mathrm{CO}_{2}$ transfer conductance of mesophyll in walnut. Journal of Experimental Botany, 53, 2423-2430.

Powles, S.B., Berry, J.A. and Bjorkman, O. (1983) Interaction between light and chilling temperature on the inhibition of photosynthesis in chilling ${ }^{-}$sensitive plants. Plant, Cell \& Environment, 6, 117-123.

Prade, T., Svensson, S-E, Andersson, A. et al. (2011) Biomass and energy yield of industrial hemp grown for biogas and solid fuel. Biomass and Bioenergy, 35, 3040-3049.

Rice, B. (2008) Hemp as a feedstock for biomass-to-energy conversion. Journal of Industrial Hетp, 13, 145-156.

Sage, R.F. and Kubien, D.S. (2007) The temperature response of $\mathrm{C}_{3}$ and $\mathrm{C}_{4}$ photosynthesis. Plant, Cell \& Environment, 30, 1086-1106.

Salentijn, E.M.J., Zhang, Q., Amaducci, S. et al. (2015) New developments in fiber hemp 
(Cannabis sativa L.) breeding. Industrial Crops and Products, 68, 32-41.

Sharkey, T.D., Bernacchi, C.J., Farquhar, G.D. et al. (2007) Fitting photosynthetic carbon dioxide response curves for $\mathrm{C}_{3}$ leaves. Plant, Cell \& Environment, 30, 1035-1040.

Sinclair, T.R. and Horie, T. (1989) Leaf nitrogen, photosynthesis, and crop radiation use efficiency: a review. Crop Science, 29, 90-98.

Struik, P.C., Amaducci, S., Bullard, M.J. et al. (2000) Agronomy of fibre hemp (Cannabis sativa L.) in Europe. Industrial Crops and Products, 11, 107-118.

Tang, Z., Hu, X., Sun, T. et al. (2012) Adaptability of different hemp varieties (lines) in Xishuangbanna prefecture. Journal of southern agriculture, 43, 160-163. (Chinese with English abstract)

Tcherkez, G., Boex-Fontvieille, E., Mahé, A. et al. (2012) Respiratory carbon fluxes in leaves. Current Opinion in Plant Biology, 15, 308-314.

Tcherkez, G., Cornic, G., Bligny, R. et al. (2005) In vivo respiratory metabolism of illuminated leaves. Plant Physiology, 138, 1596-1606.

Von Caemmerer, S., Farquhar, G. and Berry, J. (2009) Biochemical model of C3 photosynthesis. In: Photosynthesis in silico (eds Laisk, A., Nedbal, L. and Govindjee), pp 209-230, Springer, London, UK.

Wirtshafter, D.E. (2004) Ten years of a modern hemp industry. Journal of Industrial Hemp, 9, 9-14.

Wullschleger, S.D. (1993) Biochemical Limitations to Carbon Assimilation in $\mathrm{C}_{3}$ Plants: A Retrospective Analysis of the $\mathrm{A} / \mathrm{C}_{\mathrm{i}}$ Curves from 109 Species. Journal of Experimental Botany, 44, 907-920.

Yamori, W., Evans, J.R. and Von Caemmerer, S. (2010) Effects of growth and measurement light intensities on temperature dependence of $\mathrm{CO}_{2}$ assimilation rate in tobacco leaves. Plant, Cell \& Environment, 33, 332-343.

Yin, X., Harbinson, J. and Struik, P.C. (2006) Mathematical review of literature to assess alternative electron transports and interphotosystem excitation partitioning of steady-state C-3 photosynthesis under limiting light. Plant Cell \& Environment, 29, 1771-1782.

Yin, X., Struik, P.C., Romero, P. et al. (2009) Using combined measurements of gas exchange and chlorophyll fluorescence to estimate parameters of a biochemical $\mathrm{C}_{3}$ photosynthesis model: a critical appraisal and a new integrated approach applied to leaves in a wheat (Triticum aestivum L.) canopy. Plant, Cell \& Environment, 32, 448-464.

Yin, X. and Struik, P.C. (2009) $\mathrm{C}_{3}$ and $\mathrm{C}_{4}$ photosynthesis models: An overview from the perspective of crop modelling. NJAS-Wageningen Journal of Life Sciences, 57, 27-38.

Yin, X. and Van Laar, H.H. (2005) Crop systems dynamics : an ecophysiological simulation model for genotype-by-environment interactions, Wageningen Academic, Wageningen, the Netherlands.

Yin, X., Sun, Z.P., Struik, P.C. et al. (2011) Evaluating a new method to estimate the rate of leaf respiration in the light by analysis of combined gas exchange and chlorophyll fluorescence measurements. Journal of Experimental Botany, 62, 3489-3499. 


\section{Supplementary Materials in Chapter 4}
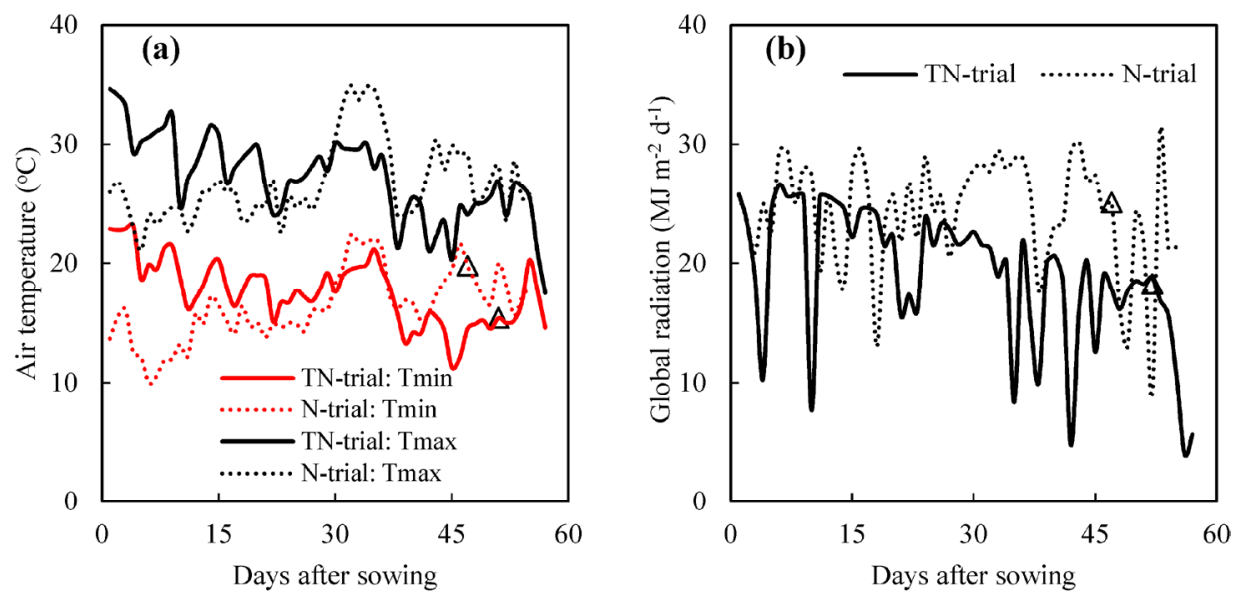

Figure S4.1 The daily temperature and global radiation during the period from sowing to the end of the experiment for plants grown in the open field (i.e., TN-trial in 2013 and N-trial in 2014).
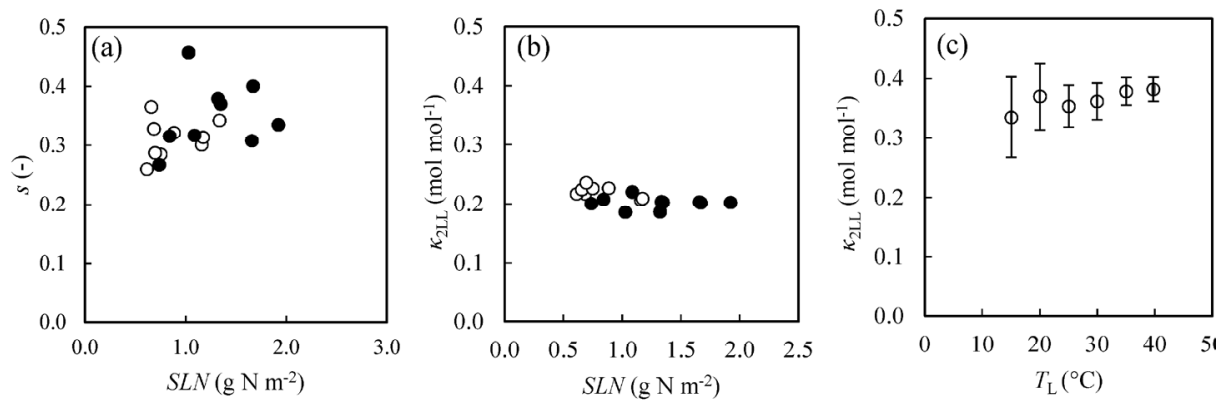

Figure S4.2 Dependence of lumped parameter $(s)$ in Eqn. (4.9) on leaf nitrogen $(S L N)$ and dependence of the efficiency of converting incident irradiance into linear electron transport under limiting light $\left(\kappa_{2 \mathrm{LL}}\right)$ on $S L N$ and leaf temperature $\left(T_{\mathrm{L}}\right)$. 


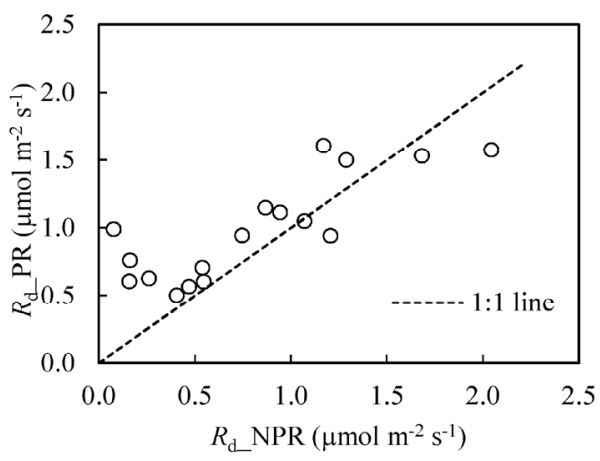

Figure S4.3 The estimated day respiration under photorespiratory condition, i.e. at $21 \% \mathrm{O}_{2},\left(R_{\mathrm{d}} \mathrm{PR}\right)$ against that under non-photorespiratory condition, i.e. at $2 \% \mathrm{O}_{2}\left(R_{\mathrm{d}} \mathrm{NPR}\right)$.
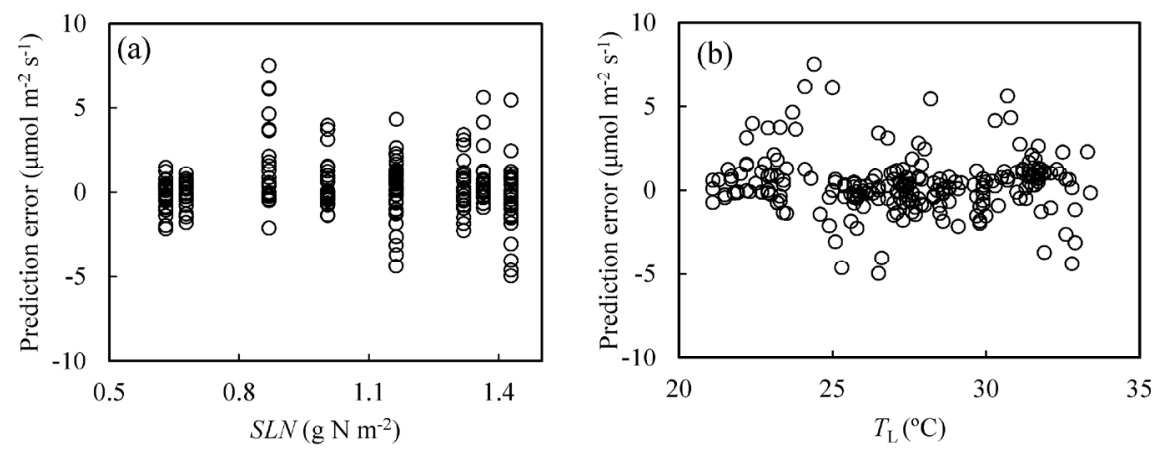

Figure S4.4 The error of model validation against leaf nitrogen $\left(S L N\right.$, panel a) and temperature $\left(T_{\mathrm{L}}\right.$, panel b).

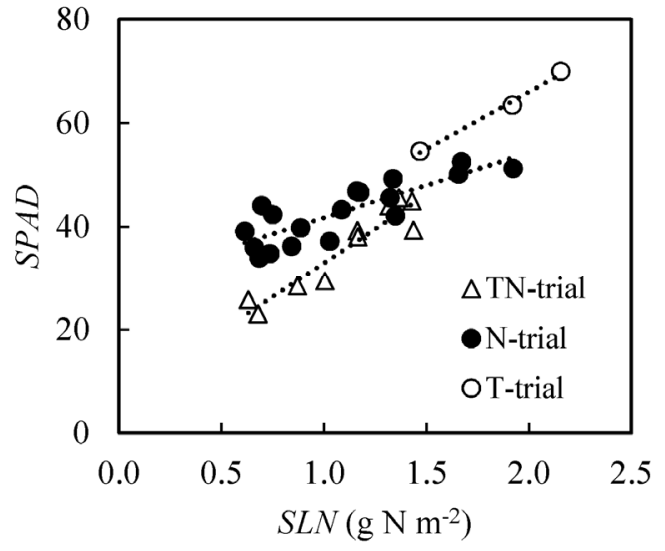

Figure S4.5 The effect of growth environment on the relationship between $S P A D$ values and leaf nitrogen $(S L N)$. 



\section{Chapter 5}

\section{Water- and nitrogen-use efficiencies of hemp (Cannabis sativa $L_{\text {.) }}$ based on whole-canopy measurements and modelling}

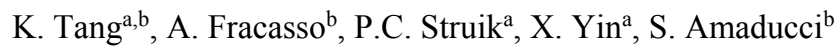

${ }^{a}$ Centre for Crop Systems Analysis, Department of Plant Sciences, Wageningen University \& Research, Droevendaalsesteeg 1, Wageningen, The Netherlands

${ }^{b}$ Department of Sustainable Crop Production, Università Cattolica del Sacro Cuore, via Emilia Parmense, 84, Piacenza, Italy

This chapter is submitted. 


\title{
Chapter 5
}

\begin{abstract}
Interest in hemp (Cannabis sativa L.) as a bio-economical crop is growing worldwide because hemp produces a high and valuable biomass while requiring low inputs. To understand the physiological basis of hemp's resource-use efficiency, canopy gas exchange was assessed using a chamber technique on canopies exposed to a range of nitrogen $(\mathrm{N})$ and water levels. Since canopy transpiration and carbon assimilation were very sensitive to variations in microclimate among canopy chambers, observations were adjusted for microclimatic differences using a physiological canopy model, with leaf-level parameters estimated for hemp from our previous study. Canopy water-use efficiency ( $\left.W U E_{\mathrm{c}}\right)$, defined as the ratio of gross canopy photosynthesis to canopy transpiration, ranged from $4.0 \mathrm{mmol} \mathrm{CO}_{2}(\mathrm{~mol}$ $\left.\mathrm{H}_{2} \mathrm{O}\right)^{-1}$ to $7.5 \mathrm{mmol} \mathrm{CO}_{2}\left(\mathrm{~mol} \mathrm{H}_{2} \mathrm{O}\right)^{-1}$. Canopy nitrogen-use efficiency $\left(N U E_{\mathrm{c}}\right)$, the ratio of the gross canopy photosynthesis to canopy leaf-N content, ranged from $0.3 \mathrm{~mol} \mathrm{CO}_{2} \mathrm{~d}^{-1}\left(\mathrm{~g} \mathrm{~N}^{-1}\right.$ to $0.7 \mathrm{~mol} \mathrm{CO}_{2}$ $\mathrm{d}^{-1}(\mathrm{~g} \mathrm{~N})^{-1}$. The effect of $\mathrm{N}$-input levels on $W U E_{\mathrm{c}}$ and $N U E_{\mathrm{c}}$ was largely determined by the $\mathrm{N}$ effect on canopy size or leaf area index ( $L A I)$, whereas the effect of water-input levels differed between shortand long-term stresses. The effect of short-term water stress was reflected by stomatal regulation. The long-term stress increased leaf senescence, decreased $L A I$ but retained total canopy $\mathrm{N}$ content; however, the increased average leaf- $\mathrm{N}$ could not compensate for the lost $L A I$, leading to a decreased $N U E_{\mathrm{c}}$. Although hemp is known as a resource-use efficient crop, its final biomass yield and nitrogen use efficiency may be restricted by water limitation during growth. Our results also suggest that crop models should take stress-induced senescence into account in addition to stomatal effects if crops experience a prolonged water stress during growth.
\end{abstract}

Key words: canopy gas exchange, hemp (Cannabis sativa L.), nitrogen use efficiency, water use efficiency. 


\subsection{Introduction}

The pressures of climate change, natural resource scarcity and environmental pollution have fuelled interest in bio-economically sustainable agronomy that requires effective use of scarcely available resources. A range of focused studies have indicated that hemp (Cannabis sativa L.) may be a suitable crop for the bio-economy (Amaducci \& Gusovius, 2010). Hemp is a highyielding multi-purpose crop that requires low inputs (Chapters 2, 3; Struik et al., 2000) and has a positive impact on the environment (Barth \& Carus, 2015; Bouloc \& Werf, 2013). Its stems contain high-quality cellulose (De Meijer \& van der Werf, 1994); high added-value compounds can be recovered from the female inflorescence and from threshing residues (Calzolari et al., 2017; Bertoli et al., 2010) after harvesting the seeds, that contain healthy oil (Leizer et al., 2000). Although once an important crop to produce raw materials for textiles and ropes, hemp acreage declined in the last century and was displaced largely by cotton and synthetic fibres. Consequently, little attention has been paid to understanding the physiological basis of the high resource-use efficiency of hemp.

Crop water-use efficiency ( $W U E$ ) and nitrogen-use efficiency $(N U E)$ can be measured at different organizational levels from leaf to canopy. A range of focused studies provided key insights at leaf level (Cabrera-Bosquet et al., 2007; Van den Boogaard et al., 1995). However, canopy water-use efficiency ( $W U E_{\mathrm{c}}$, defined as the ratio of gross canopy photosynthesis to canopy transpiration) and nitrogen-use efficiency ( $N U E_{\mathrm{c}}$, the ratio of the gross canopy photosynthesis to canopy leaf-N content) reflect the actual balance between photosynthate gain and its water and nitrogen costs (Linderson et al., 2012). While lack of significant correlations between leaf and canopy WUE or NUE has been reported (Tomás et al., 2012), there is a need for focused quantitative studies on the scaling up of $W U E$ and $N U E$ from leaf to canopy.

One challenge in studying $W U E_{\mathrm{c}}$ and $N U E_{\mathrm{c}}$ is to properly assess canopy $\mathrm{CO}_{2}$ and $\mathrm{H}_{2} \mathrm{O}$ exchange rates under varying nitrogen and water regimes. To date, the canopy gas exchange rate is mainly assessed by micro-meteorological methods or by means of canopy-enclosure chamber systems. The micro-meteorological techniques such as the eddy covariance or Bowen ratio methods enable gas flux measurements without disturbing canopy micro-environment, and they are often applied to large homogeneous areas but are unsuitable in plot/pot-sized experiments (Jones, 2013). In contrast, the canopy chamber technique enables to determine precisely canopy gas exchange at a relatively small scale (Müller et al., 2009, 2005). However, enclosing a crop canopy with a chamber might result in significant changes in micro- 


\section{Chapter 5}

environmental variables (e.g., $\mathrm{CO}_{2}$ concentration, air temperature and vapour pressure) as a consequence of photosynthetic $\mathrm{CO}_{2}$ uptake, the greenhouse effect and transpiration (Müller et al., 2009; Takahashi et al., 2008). The effect of micro-environmental changes within a canopy chamber on photosynthesis rates should be assessed when the chamber is used to analyse the responses of canopy photosynthesis to water shortage and nitrogen deficiency.

On the basis of a thorough understanding of the underlying mechanisms of leaf and canopy photosynthesis, models have been developed to quantify the response of canopy photosynthesis to varying micro-environments under different physiological conditions (Hikosaka et al., 2016). Such canopy models are capable of simulating instantaneous canopy gas exchange measurements by micro-meteorological techniques (Wright et al., 2013; Leuning et al., 1998) and in canopy chambers (Müller et al., 2005). In that context, a well-defined canopy model is a useful tool to normalize the changes in micro-environmental variables within a canopy chamber and to quantitatively assess the responses of canopy photosynthesis to nitrogen and water deficiencies.

The objective of this study was to experimentally assess hemp $W U E_{\mathrm{c}}$ and $N U E_{\mathrm{c}}$ in relation to nitrogen and water availabilities. To that end, we parameterized a canopy photosynthesis model (Yin \& Struik, 2017; Yin \& van Laar, 2005), with leaf-level parameters estimated from our previous study for hemp (Chapter 4). This model was used to correct gas exchange measurements within different canopy chambers and to assess the main components of hemp $W U E_{\mathrm{c}}$ and $N U E_{\mathrm{c}}$, providing supporting information for effective use of water and nitrogen resources.

\subsection{Materials and methods}

\subsubsection{Experimental design and data collection}

Field and container experiments were carried out at the research facilities of the Università Cattolica del Sacro Cuore $\left(45.0^{\circ} \mathrm{N}, 9.8^{\circ} \mathrm{E}, 60 \mathrm{~m}\right.$ asl; Piacenza, Italy). Field experiments were carried out in 2014 and 2015 to assess light and nitrogen distribution profiles of hemp canopies in response to nitrogen deficiency. A container experiment was carried out in 2014 to assess instantaneous and daily canopy gas exchange of hemp in response to nitrogen and water limitations. Between May and October (during the hemp season), the study site had monthly average temperatures ranging from $17.7^{\circ} \mathrm{C}$ to $26.9^{\circ} \mathrm{C}$; the monthly sum of precipitation ranged from $13.5 \mathrm{~mm}$ to $87 \mathrm{~mm}$. 


\subsubsection{Field experiments to assess light and nitrogen distribution profiles of hemp canopies}

The experimental fields had silty clay loam soil (the clay:silt:sand ratio was 39:46:15) that contained $0.14 \%$ of total nitrogen and $2.2-2.6 \%$ of organic matter. Seeds of hemp $c v$. Futura 75 (obtained from Fédération National des Producteurs de Chanvre, Le Mans, France) were drilled, with a target density of 120 plants $\mathrm{m}^{-2}$, at 3-4 $\mathrm{cm}$ depth using an experimental plot machine on 7 April in 2014 and on 16 April in 2015. Single plot size was $60 \mathrm{~m}^{2}$. Nutrients other than nitrogen were assumed to be abundantly available in the experimental fields based on past experience. During the growth season, plants were irrigated when signs of water deficiency emerged. A total of $60 \mathrm{~mm}$ and $155 \mathrm{~mm}$ water was provided with a travelling sprinkler in 2014 and 2015, respectively.

Nitrogen fertilization effect was investigated in a randomized complete block design with four replicates. In both years, four levels of calcium nitrate were top-dressed after seedling emergence as: N0 (no fertilizer applied); N30 (30 kg N ha $\left.{ }^{-1}\right)$; N60 (60 kg N ha'-1), and N120 (120 kg N ha-1). In the field experiment in 2014, the plants suffered from severe weed competition. Therefore, only the data collected in the plots of N60 that were not affected by weeds were reported in this chapter.

Two destructive samplings were conducted in each plot at the onset of the linear growth phase and at full flowering. At each sampling, light interception by the canopy (the ratio of light intensity at depth $\mathrm{i}$ to that at the top of canopy: $I_{\mathrm{i}} / I_{0}$ ) was first assessed at $90 \%, 75 \%, 50 \%$ and $0 \%$ of canopy height using a ceptometer (AccuPAR LP-80, Decagon Devices, Inc., Pullman, Washington, USA). Subsequently, all plants in an area of $1 \mathrm{~m}^{2}$ were cut at ground surface to assess leaf area index $(L A I)$ and specific leaf nitrogen $(S L N)$ on four layers according to canopy height: $0-50 \%, 50-75 \%, 75-90 \%$, and 90-100\%. The $L A I$ was calculated as the product of leaf weight and specific leaf area $(S L A)$ that was obtained by measuring the weight and area of all leaves of two representative plants. Leaf nitrogen concentration $\left(N_{\text {leaf }}\right)$ was assessed using a $\mathrm{CN}$ analyser (Vario Max CN Analyzer; Elementar Americas, Inc., Hanau, Germany). The SLN was calculated as $N_{\text {leaf }}$ divided by $S L A$.

\subsubsection{Container experiment to assess canopy gas exchange rate}

Seeds of $c v$. Futura 75 were sown on 9 May 2014 in 18 containers (length $\times$ width $\times$ height: 40 $\times 40 \times 30 \mathrm{~cm}^{3}$ ). Each container was filled with $23 \mathrm{~kg}$ of soil (dry weight) that contained $0.22 \%$ total nitrogen and had a clay:silt:sand ratio of 30:43:27. Seeds were sown in excess in two rows 


\section{Chapter 5}

and seedlings were hand-thinned to 18 uniform plants per container ( $c a .113$ plants $\left.\mathrm{m}^{-2}\right)$. Other nutrients than nitrogen were assumed to be abundantly available based on past experience in the field from which the soil was collected. During the growth period, sufficient water was supplied daily to each container. The containers were placed outdoor and positioned tightly in a $1.2 \times 2.4 \mathrm{~m}^{2}$ block. To avoid any border effect, the block perimeter was surrounded with a green shading net (transmitting 3\% of the light); the height of the shading net was adjusted daily to account for the increment in plant height. The containers were rearranged weekly.

Three levels of dissolved urea fertilizer were applied to the soil after seedling emergence as: $\mathrm{N} 1$, no fertilizer applied; N2, $1.0 \mathrm{~g} \mathrm{~N}$ per container; N3, $2.0 \mathrm{~g} \mathrm{~N}$ per container, equivalent to $c a$. 0,60 , and $120 \mathrm{~kg} \mathrm{~N}$ (ha ground) ${ }^{-1}$, respectively. There were six containers per $\mathrm{N}$ level, subject to different levels of water supply during measurement (see later).

Whole canopy gas exchange was assessed twice during the course of the experiment by enclosing the canopy of each container in a flow-through gas exchange system. The first cycle of measurements (CAN1 hereafter) aimed to assess the response of diurnal canopy gas exchange to nitrogen and short-term water shortage. Canopy gas exchange in this cycle was assessed on 12 containers for three days, four containers per $\mathrm{N}$ treatment. Two of the containers per $\mathrm{N}$ treatment were supplied with sufficient water (measured as the amount of transpired water in the previous day) during the measurement while the water supply for the other two was halved. This cycle of measurements started 49 days after sowing when the $6^{\text {th }}-8^{\text {th }}$ pair of leaves appeared, the same leaf stages at which gas exchange at leaf level was assessed (Chapter 4). The second cycle of canopy gas exchange assessment (CAN2 hereafter) aimed to assess the response of canopy gas exchange to prolonged water shortage. In this cycle canopy gas exchange was assessed on six containers for 13 days, two containers per $\mathrm{N}$ treatment. Measurement in this cycle started 79 days after sowing at the beginning of flowering. During the measurement, one container received sufficient water while the other one received half the amount. At the $8^{\text {th }}$ day from the start of measurement, plants under stress showed signs of severe wilting, and were re-watered briefly to avoid their possible death before the end of the experimental period.

Configuration of the flow-through gas exchange system was described by Poni et al. (2014) and refined by Fracasso et al. (2017). It consists of 12 cylindrical canopy chambers (diameter $50 \mathrm{~cm}$ ) that are sealed with flexible plastic polyethylene on the side wall (transmitting $87 \%$ of the light) and a plastic polymethylmethacrylate disc on the top (transmitting 93\% of the light). 
The air flowing through the canopy chamber (from the bottom to the top) was drawn from $3 \mathrm{~m}$ above ground using two centrifugal blowers (Vorticent C25/2M, Vortice, Milan, Italy). The system records instantaneous information for each chamber every 12 minutes using a CR1000 datalogger wired to an AM16/32B Multiplexer (Campbell Scientific, Logan, USA) as follows: $\mathrm{CO}_{2}$ concentration, vapour pressure and air temperature at the entrance of the chamber $\left(\mathrm{CO}_{2}\right.$,in, $V P_{\text {in }}$ and $T_{\text {in, }}$ respectively $)$ and the differences at the exit $\left(C O_{2, \text { dif, }} V P_{\text {dif }}\right.$ and $T_{\text {dif, }}$ respectively; calculated as the value at exit minus that at entrance), container weight ( $\left.W_{\text {container }}\right)$ and incident solar radiation intensity outside the chamber. The $\mathrm{CO}_{2}$,in, $C \mathrm{O}_{2}$, dif, $V P$ in and $V P_{\text {dif }}$ were assessed using a CIRAS-DC dual-channel absolute $\mathrm{CO}_{2} / \mathrm{H}_{2} \mathrm{O}$ infrared gas analyser (PP-Systems, Amesbury, USA). The $T_{\text {in }}$ and $T_{\text {dif }}$ were assessed using PFA-Teflon insulated type-T thermocouples (Omega Engineering, Stamford, USA). The $W_{\text {container }}$ was monitored using a single cell platform scale placed under each container (ABC Bilance, Campogalliano, Italy).

In this study, the volume of each canopy chamber was $0.3 \mathrm{~m}^{3}$ (cross cutting area was $0.2 \mathrm{~m}^{2}$ and height was $1.5 \mathrm{~m}$ ). Air flux entering each chamber was regulated at $4.3 \times 10^{-3} \mathrm{~m}^{3} \mathrm{~s}^{-1}$. Thus, a complete volume air change required $c a .70 \mathrm{~s}$. The flow rate was maintained constant during the whole measurement period. To prevent gas exchange between soil and plant chamber, the surface of each container was sealed with a plastic polyethylene film in which little slits were cut to allow hemp plants growing through. A small hole was made on the side wall of the container to supply water and allow gas exchange between soil and open air.

At the end of the canopy gas exchange assessment of each cycle, each container was assessed for the following parameters: the biomass weight of stems $\left(W_{\text {stem }}\right)$, green leaves $\left(W_{\text {leaf,g }}\right)$, senesced leaves ( $W_{\text {leaf,s; }}$; if present), inflorescences ( $W_{\text {inflo }}$; if present $)$ and roots $\left(W_{\text {root }}\right), I_{\mathrm{i}} / I_{0}, L A I$ and $S L N$. For the containers receiving sufficient water in CAN1 the $I_{\mathrm{i}} / I_{0}, L A I$ and $S L N$ were assessed for four layers according to canopy height: 0-50\%, 50-75\%, 75-90\%, and 90-100\%, while for the remaining containers the same parameters were assessed on the entire canopy. To estimate any system error introduced by gas leakage or soil respiration, gas exchange measurements were performed for 1-2 days on each container after the plants had been cut.

\subsubsection{Data analysis}

\subsubsection{Estimation of light and nitrogen extinction coefficients}

$P A R$ was assumed to attenuate through the canopy following the Beer's law, based on $L A I$ :

$$
\frac{I_{\mathrm{i}}}{I_{0}}=e^{-k_{L} L A I_{\mathrm{i}}}
$$


where $L A I_{\mathrm{i}}$ is the $L A I$ at depth i measured from the top; $k_{\mathrm{L}}$ is the light extinction coefficient. $k \mathrm{~L}$ was estimated by fitting the measured $I_{\mathrm{i}} / I_{0}$ and $L A I_{\mathrm{i}}$ to Eqn. (5.1). To avoid any effect of measuring hour on the value of $k \mathrm{~L}$, all measured $I_{\mathrm{i}} / I_{0}$ were normalized to a value at zenith angle $0^{\circ}$, according to the manufacturer manual of AccuPAR LP-80.

The vertical gradient of $S L N$ can be similarly described (Archontoulis et al., 2011; Yin et al., 2003):

$$
S L N_{\mathrm{i}}=S L N_{0} e^{-k_{\mathrm{n}} L A I_{\mathrm{i}}}
$$

where $k_{\mathrm{n}}$ is the $S L N$ extinction coefficient, $S L N_{0}$ and $S L N_{\mathrm{i}}$ are the $S L N$ at the top of the canopy (i.e. at $L A I_{\mathrm{i}}=0$ ) and at depth $\mathrm{i}$, respectively. Thus, from canopy top to bottom, the cumulative nitrogen at depth i $\left(N_{\mathrm{i}}\right)$ can be solved from Eqn. (5.2) as:

$$
N_{\mathrm{i}}=\int_{0}^{L A I_{\mathrm{i}}} S L N_{\mathrm{i}} \mathrm{d} L A I_{\mathrm{i}}=\operatorname{SLN}_{0}\left(1-e^{-k_{\mathrm{n}} L A I_{\mathrm{i}}}\right) / k_{\mathrm{n}}
$$

By fitting the measured data for $N_{\mathrm{i}}-L A I_{\mathrm{i}}$ relationships to Eqn. (5.3), $k_{\mathrm{n}}$ and $S L N_{0}$ were estimated.

\subsubsection{Calculation of canopy photosynthesis and transpiration rates}

Data recorded from the multi-chamber gas exchange system was filtered to eliminate measurements impaired by short time fluctuations of air $\mathrm{CO}_{2}$ concentration and vapour pressure, and system mishaps. Subsequently, the values of $\mathrm{CO}_{2}$,dif and $V P_{\text {dif }}$ were corrected for potential system error due to gas leakage or soil respiration using data recorded in the chamber after the plants had been cut. Instantaneous canopy transpiration rate $\left(E_{\mathrm{c}} ; \mathrm{mmol} \mathrm{H}_{2} \mathrm{O} \mathrm{m}^{-2} \mathrm{~s}^{-1}\right)$ and net photosynthesis rate $\left(A_{\mathrm{c}, \text { net}}\right.$; $\left.\mu \mathrm{mol} \mathrm{CO} \mathrm{C}^{-2} \mathrm{~s}^{-1}\right)$ were calculated using Eqn. (5.4) and Eqn. (5.5), respectively. These formulae were based on the study of Von Caemmerer and Farquhar (1981) for leaf gas exchange measurements. Different forms of these formulae were commonly used for calculating $E_{\mathrm{c}}$ and $A_{\mathrm{c}, \text { net }}$ in the studies of canopy gas exchange using the chamber system (Poni et al., 2014; Baker et al., 2009; Müller et al., 2005).

$$
\begin{gathered}
E_{\mathrm{c}}=\frac{1000 u_{\mathrm{e}} V P_{\mathrm{dif}}}{a\left[P-\left(V P_{\mathrm{in}}+V P_{\mathrm{dif}}\right)\right]} \\
A_{\mathrm{c}, \text { net }}=-\left(\frac{u_{\mathrm{e}} C O_{2, \mathrm{dif}}}{a}+10^{-3} E_{\mathrm{c}} C O_{2, \text { out }}\right)
\end{gathered}
$$

where $u_{\mathrm{e}}\left(\mathrm{mol} \mathrm{s}^{-1}\right)$ is air flux entering the plant chamber; $a\left(\mathrm{~m}^{2}\right)$ is the ground area of the canopy chamber; $P(\mathrm{kPa})$ is the air pressure inside the plant chamber. The standard air pressure $(101.3$ $\mathrm{kPa})$ was used as a proxy of $P$ in the present study although a slight overpressure was maintained 
inside the plant chamber (less than $10 \mathrm{~Pa}$ ) to avoid any flux of ambient air through possible leaks. The effect of overpressure on $E_{\mathrm{c}}$ and $A_{\mathrm{c}, \text { net }}$ was considered negligible (Burkart et al., 2007).

Canopy gross photosynthesis $\left(A_{\mathrm{c}, \text { gross }}\right)$ is the sum of $A_{\mathrm{c} \text {,net }}$ and canopy respiration $\left(R_{\mathrm{c}}\right) . R_{\mathrm{c}}$ during the night was estimated directly from Eqn. (5.5) as $\mathrm{CO}_{2}$,dif during the night was mainly a result of canopy respiration. During daytime, $R_{\mathrm{c}}$ was estimated considering the variation of temperature as:

$$
R_{\mathrm{c}}=R_{\mathrm{c}, 25} \exp \left[\frac{E_{\mathrm{Rc}}\left(T_{\mathrm{air}}-25\right)}{298 R\left(T_{\mathrm{air}}+273\right)}\right]
$$

where $R_{\mathrm{c}, 25}$ is the value of $R_{\mathrm{c}}$ at $25{ }^{\circ} \mathrm{C} ; E_{\mathrm{Rc}}$ is the energy of activation; $R$ is the universal gas constant $\left(=8.314 \mathrm{~J} \mathrm{~K}^{-1} \mathrm{~mol}^{-1}\right)$. The values of $R_{\mathrm{c} 25}$ and $E_{\mathrm{Rc}}$ were estimated from the measurements of $R_{\mathrm{c}}$ during night (Reichstein et al., 2005).

\subsubsection{Validation of a canopy photosynthetic model}

The sun/shade model of de Pury \& Farquhar (1997), as implemented in the crop model GECROS (Yin \& Struik, 2017; Yin \& Laar, 2005), was validated against measured $A_{\mathrm{c}, \text { gross. In }}$ this model, canopy leaves are divided into sunlit and shaded fractions and each fraction is modelled separately using a leaf photosynthesis model. When there is no water stress, potential leaf photosynthesis rate $\left(A_{\mathrm{p}}\right)$ is calculated using analytical solution of combined stomatal conductance, $\mathrm{CO}_{2}$ diffusion and biochemical leaf-photosynthesis models (Yin \& Struik, 2017, 2009). In the presence of water limitation, actual canopy photosynthesis is calculated considering the change of actual stomatal resistance to water vapour $\left(r_{\mathrm{sw}, \mathrm{a}}\right)$ due to stomatal closure. The $r_{\mathrm{sw}, \mathrm{a}}$ is modelled as (Yin \& Struik 2017):

$$
r_{\mathrm{sw}, \mathrm{a}}=\left(E_{\mathrm{p}}-E_{\mathrm{a}}\right)\left(s r_{\mathrm{bh}}+\gamma r_{\mathrm{bw}}\right) /\left(\gamma E_{\mathrm{a}}\right)+r_{\mathrm{sw}, \mathrm{p}} E_{\mathrm{p}} / E_{\mathrm{a}}
$$

where $E_{\mathrm{p}}$ and $E_{\mathrm{a}}$ are potential leaf transpiration rate and actual available water for leaf transpiration, respectively; $s$ is the slope of the saturated vapour pressure curve; $r_{\mathrm{bh}}, r_{\mathrm{bw}}$ and $r_{\mathrm{sw}, \mathrm{p}}$ are boundary layer resistances to heat, boundary resistance to water, and stomatal resistance to water transfer in absence of water stress, respectively; $\gamma$ is the psychrometric constant $(=0.067$ $\left.\mathrm{kPa}^{\circ} \mathrm{C}^{-1}\right)$. For calculation of $s, r_{\mathrm{bh}}$ and $r_{\mathrm{bw}}$, see Yin \& van Laar (2005) and Yin \& Struik (2017). $r_{\mathrm{sw}, \mathrm{p}}$ is assumed equal to $1 /\left(1.6 g_{\mathrm{s}}\right)$, where $g_{\mathrm{s}}$ is calculated according to $A_{\mathrm{p}}$. The $E_{\mathrm{p}}$ is calculated using Penman-Monteith equation while $E_{\mathrm{a}}$ depends on the actual plant water uptake. Relevant model algorithms are summarised in the Supplementary Material Text S5.1. 


\section{Chapter 5}

The values of model input parameters required for leaf photosynthesis were presented in Chapter 4 for the same hemp cultivar and are summarized in Supplementary Material Table S5.1. The canopy related parameters $L A I, S L N, k \mathrm{~L}$ (for diffuse light) and $k_{\mathrm{n}}$ were derived in this study. The leaf angle that was used to calculate the direct light extinction coefficient was fixed at $15^{\circ}$, an average value assessed using a goniometer. Instantaneous environmental parameters, i.e. $\mathrm{CO}_{2}, V P, T_{\text {air }}$ and irradiation intensity, were recorded by the canopy chamber system. $E_{\mathrm{a}}$ is obtained from the measured $E_{\mathrm{c}}$ (see Results).

\subsubsection{Normalization of gas exchange measurements within canopy chambers}

The micro-environment differed between canopy chamber and ambient open air, and among treatments (see Results). Thus, the measured $E_{\mathrm{c}}$ and $A_{\mathrm{c}, \text { gross }}$ in the canopy chamber were normalized to that in the open air using the validated canopy model. Firstly, a correction factor $f_{\text {Ec }}$ was obtained, based on simulated potential canopy transpiration $E_{\mathrm{cp}}$ as:

$$
f_{\mathrm{Ec}}=\frac{E_{\mathrm{cp}, \mathrm{air}(\mathrm{s})}}{E_{\mathrm{cp}, \mathrm{chamber}(\mathrm{s})}}
$$

where $E_{\mathrm{cp}, \text { air(s) }}$ and $E_{\mathrm{cp}, \text { chamber(s) }}$ are simulated potential canopy transpiration using weather data in open air and in the canopy chamber, respectively. The value of $E_{\mathrm{c}}$ corresponding to the openair condition was then obtained by multiplying the measured $E_{\mathrm{c}}$ in the chamber with the correction factor $f_{\mathrm{Ec}}$. Subsequently, the corrected value of $E_{\mathrm{c}}$ for the open air and the measured $E_{\mathrm{c}}$ in the canopy chamber were used as inputs to obtain simulated canopy photosynthesis,

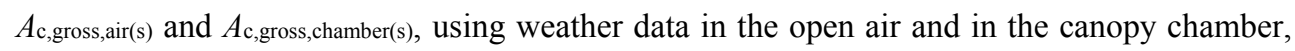
respectively. This gave a correction factor for $A_{\mathrm{c}, \text { gross }}\left(f_{\mathrm{Ac}}\right)$ as:

$$
f_{\text {Ac }}=\frac{A_{\mathrm{c}, \operatorname{gross}, \mathrm{air}(\mathrm{s})}}{A_{\mathrm{c}, \mathrm{gross}, \mathrm{chamber}(\mathrm{s})}}
$$

Finally, the value of $A_{\text {c,gross }}$ corresponding to the open-air condition was calculated by multiplying the measured $A_{\mathrm{c}, \text { gross }}$ in the chamber with the factor $f_{\mathrm{Ac}}$.

\subsubsection{Statistical analysis}

Nonlinear fitting was carried out using the GAUSS method in PROC NLIN of SAS (SAS Institute Inc., Cary, NC, USA). Analysis of variance was conducted to assess the effects of nitrogen fertilization and water shortage on canopy structure and gas exchange related parameters using SPSS statistics 22.0 (SPSS, Chicago, Illinois, USA). 


\subsection{Results}

\subsubsection{The effects of nitrogen and water levels on canopy physiological parameters}

Nitrogen fertilization resulted in an increase in canopy size and leaf nitrogen content. In the N60 plots where weed competition was negligible in the field experiment in 2014, LAI (leaf area index) was on average $3.2 \mathrm{~m}^{2} \mathrm{~m}^{-2}$ and $4.8 \mathrm{~m}^{2} \mathrm{~m}^{-2}$ at linear growth stage and full flowering, respectively; $S L N$ (specific leaf nitrogen) was on average $0.97 \mathrm{~g} \mathrm{~N}\left(\mathrm{~m}^{2} \text { leaf) }\right)^{-1}$ and $0.67 \mathrm{~g} \mathrm{~N}\left(\mathrm{~m}^{2}\right.$ leaf $)^{-1}$, respectively. In the field experiment in $2015, L A I$ of the $\mathrm{N} 120$ plots was $4.0 \mathrm{~m}^{2} \mathrm{~m}^{-2}$ and $6.4 \mathrm{~m}^{2} \mathrm{~m}^{-2}$ at the onset of the linear growth stage and at full flowering, respectively, while $S L N$ was $\left.1.27 \mathrm{~g} \mathrm{~N}_{\left(\mathrm{m}^{2} \text { leaf)}\right.}\right)^{-1}$ and $1.17 \mathrm{~g} \mathrm{~N}\left(\mathrm{~m}^{2}\right.$ leaf) ${ }^{-1}$, respectively (Figure 5.1). The $L A I$ and $S L N$ were on average 2.8 times and 1.2 times higher than those of non-fertilized canopies. In CAN1, $L A I$ ranged from $1.8 \mathrm{~m}^{2} \mathrm{~m}^{-2}$ to $2.6 \mathrm{~m}^{2} \mathrm{~m}^{-2} ; S L N$ ranged from $0.84 \mathrm{~g} \mathrm{~N}\left(\mathrm{~m}^{2} \text { leaf }\right)^{-1}$ to $1.02 \mathrm{~g} \mathrm{~N}$ $\left(\mathrm{m}^{2} \text { leaf }\right)^{-1}$. Nitrogen fertilization in CAN1 resulted in increases in $L A I$ and $S L N$ by $40 \%$ and $19 \%$, respectively (Table 5.1). For the well-watered containers in CAN2, the average values of $L A I$ and $S L N$ were $2.0 \mathrm{~m}^{2} \mathrm{~m}^{-2}$ and $0.68 \mathrm{~g} \mathrm{~N}\left(\mathrm{~m}^{2}\right.$ leaf) ${ }^{-1}$, respectively (Table 5.2). Withholding water for 13 days in CAN2 resulted in an increase in the weight of senesced leaves while the weight of green leaves was reduced (Table 5.3). Consequently, water-stressed canopies had a $36 \%$ lower $L A I$ than well-watered canopies (Table 5.2). While water stress resulted in a reduction in canopy size, the $S L N$ of water-stressed canopies was $51 \%$ higher than that of wellwatered canopies.

Light intensity and SLN decreased progressively with increasing depth from top to bottom (Supplementary Material Figure S5.1). The value of $k_{\mathrm{L}}$ (the light extinction coefficient) was
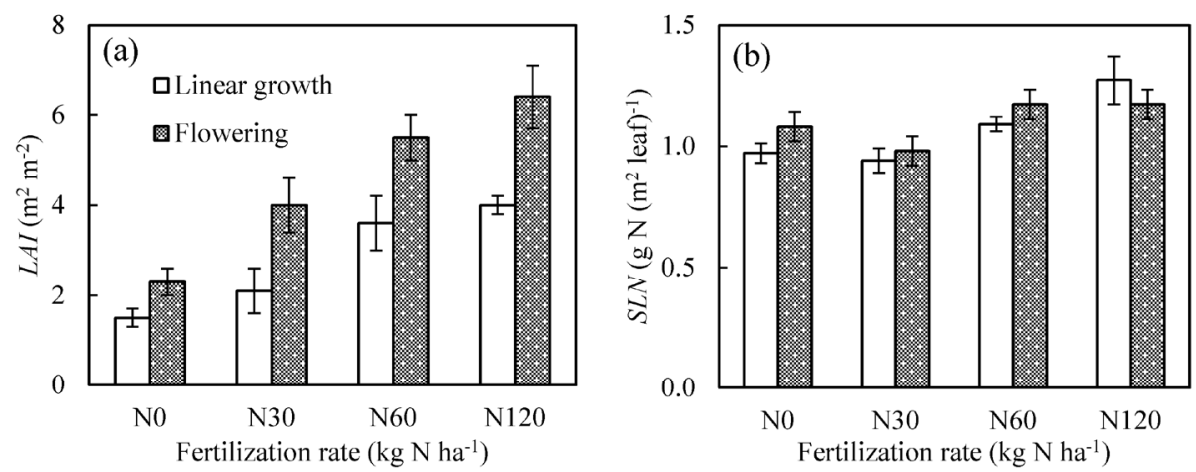

Figure 5.1 The effects of nitrogen fertilization on leaf area index ( $L A I$; panel a) and specific leaf nitrogen $(S L N$; panel b) at the onset of linear growth and at full flowering in the field experiment in 2015 . 
Table 5.1 The effects of nitrogen deficiency and water shortage on canopy transpiration and carbon assimilation. Data presented was collected in CAN1. The data of the last four columns is presented as the average of 3 days after being normalized to the open-air conditions.

\begin{tabular}{llllllll}
\hline & $N_{\mathrm{C}}$ & $L A I$ & $S L N$ & $E_{\mathrm{c}}$ & $A_{\mathrm{c}, \text { gross }}$ & $W U E_{\mathrm{c}}$ & $N U E_{\mathrm{c}}$ \\
\hline Nitrogen & & & & & & & \\
$\mathrm{N} 1$ & $1.53 \mathrm{~b}$ & $1.84 \mathrm{~b}$ & $0.84 \mathrm{~b}$ & $162 \mathrm{~b}$ & $0.70 \mathrm{~b}$ & 4.49 & 0.46 \\
$\mathrm{~N} 2$ & $2.11 \mathrm{a}$ & $2.26 \mathrm{ab}$ & $0.94 \mathrm{ab}$ & $236 \mathrm{ab}$ & $0.94 \mathrm{ab}$ & 4.09 & 0.44 \\
$\mathrm{~N} 3$ & $2.58 \mathrm{a}$ & $2.59 \mathrm{a}$ & $1.02 \mathrm{a}$ & $268 \mathrm{a}$ & $1.14 \mathrm{~b}$ & 4.41 & 0.44 \\
$P$-value & 0.00 & 0.00 & 0.03 & 0.03 & 0.02 & 0.32 & 0.78 \\
Water & & & & & & & \\
WS & 2.08 & 2.36 & 0.88 & $187 \mathrm{~b}$ & 0.84 & $4.65 \mathrm{a}$ & $0.40 \mathrm{~b}$ \\
WW & 2.07 & 2.01 & 0.97 & $256 \mathrm{a}$ & 1.01 & $4.00 \mathrm{~b}$ & $0.49 \mathrm{a}$ \\
$P$-value & 0.95 & 0.07 & 0.06 & 0.03 & 0.11 & 0.03 & 0.02 \\
\hline
\end{tabular}

Acronyms: canopy nitrogen content $\left(N_{\mathrm{c}} ; \mathrm{g} \mathrm{N}\left(\mathrm{m}^{2} \text { ground }\right)^{-1}\right)$, leaf area index $\left(L A I ; \mathrm{m}^{2} \mathrm{~m}^{-2}\right)$, specific leaf

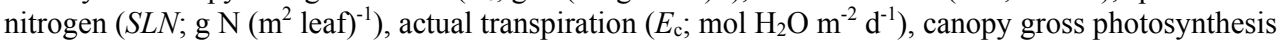
$\left(A_{\mathrm{c}, \text { gross }}\right.$; mol CO $\left.\mathrm{CO}_{2} \mathrm{~m}^{-2} \mathrm{~d}^{-1}\right)$, canopy water-use efficiency $\left(W U E_{\mathrm{c}} ; \mathrm{mmol} \mathrm{CO}_{2}\left(\mathrm{~mol} \mathrm{H} \mathrm{H}_{2} \mathrm{O}\right)^{-1}\right)$ and canopy nitrogen-use efficiency $\left(N U E_{\mathrm{c}} ; \mathrm{mol} \mathrm{CO}_{2} \mathrm{~d}^{-1}(\mathrm{~g} \mathrm{~N})^{-1}\right)$. N1, N2 and $\mathrm{N} 3$ denote nitrogen fertilization rate at $0,1.0$, and $2.0 \mathrm{~g} \mathrm{~N}$ container $^{-1}$, respectively. WW denotes well-watered containers while WS denotes the containers where water supply was half of WW.

ANOVA analysis was conducted considering nitrogen and water levels as main factors and measuring day as repeated factor. Interaction between nitrogen and water was excluded because it was not significant for all parameters in a preliminary test. Numbers followed by different letters under the same category are statistically different for $P=0.05$ (Tukey HSD).

Table 5.2 The effects of nitrogen deficiency and long-term water shortage on canopy transpiration and carbon assimilation. The data of the last four columns was collected in the last consecutive 3 days in CAN2 and is presented after being normalized to the open-air conditions.

\begin{tabular}{llllllll}
\hline \multicolumn{1}{l}{} & $N_{\mathrm{C}}$ & $L A I$ & $S L N$ & $E_{\mathrm{c}}$ & $A_{\text {c,gross }}$ & $W U E_{\mathrm{c}}$ & $N U E_{\mathrm{c}}$ \\
\hline Nitrogen & & & & & & & \\
$\mathrm{N} 1$ & $0.79 \mathrm{~b}$ & 1.15 & 0.71 & 69 & 0.36 & 6.28 & 0.44 \\
$\mathrm{~N} 2$ & $1.19 \mathrm{~b}$ & 1.69 & 0.73 & 164 & 0.67 & 5.74 & 0.58 \\
$\mathrm{~N} 3$ & $2.08 \mathrm{a}$ & 1.99 & 1.12 & 182 & 0.87 & 5.58 & 0.42 \\
$P$-value & 0.024 & 0.06 & 0.19 & 0.39 & 0.36 & 0.72 & 0.61 \\
Water & & & & & & & \\
WS & 1.35 & $1.26 \mathrm{~b}$ & 1.03 & 43 & 0.31 & $7.53 \mathrm{a}$ & 0.26 \\
WW & 1.35 & $1.97 \mathrm{a}$ & 0.68 & 234 & 0.96 & $4.20 \mathrm{~b}$ & 0.70 \\
$P$-value & 0.95 & 0.03 & 0.11 & 0.08 & 0.10 & 0.04 & 0.62 \\
\hline Act
\end{tabular}

Acronyms: canopy nitrogen content $\left(N_{\mathrm{c}} ; \mathrm{g} \mathrm{N}\left(\mathrm{m}^{2} \text { ground }\right)^{-1}\right)$, leaf area index $\left(L A I ; \mathrm{m}^{2} \mathrm{~m}^{-2}\right)$, specific

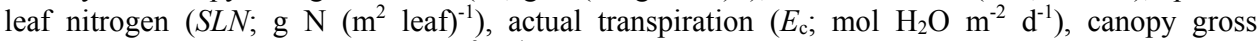
photosynthesis $\left(A_{\mathrm{c}, \text { gross }} ;\right.$ mol $\left.\mathrm{CO}_{2} \mathrm{~m}^{-2} \mathrm{~d}^{-1}\right)$, canopy water-use efficiency $\left(W U E_{\mathrm{c}} ; \mathrm{mmol} \mathrm{CO}_{2}(\mathrm{~mol}\right.$ $\left.\left.\mathrm{H}_{2} \mathrm{O}\right)^{-1}\right)$ and canopy nitrogen-use efficiency $\left(N U E_{\mathrm{c}}\right.$; mol $\mathrm{CO}_{2} \mathrm{~d}^{-1}\left(\mathrm{~g} \mathrm{~N}^{-1}\right)$. N1, N2 and N3 denote nitrogen fertilization rate at $0,1.0$, and $2.0 \mathrm{~g} \mathrm{~N}$ container $^{-1}$, respectively. WW denotes well-watered containers while WS denotes the containers where water supply was half of WW.

ANOVA analysis was conducted considering nitrogen and water levels as main factors and measuring day as repeated factor. Interaction between nitrogen and water was excluded because it was not significant for all parameters in a preliminary test. Numbers followed by different letters under the same category are statistically different for $P=0.05$ (Tukey HSD). 
$0.96 \pm 0.04 \mathrm{~m}^{2} \mathrm{~m}^{-2}$ and was similar for nitrogen fertilization levels and growth environments (Figure 5.2a). The $S L N_{0}$ (SLN at the top of the canopy) ranged from $1.43 \mathrm{~g} \mathrm{~N}^{\left(\mathrm{m}^{2}\right.}$ leaf) ${ }^{-1}$ to 2.72 $\mathrm{g} \mathrm{N}\left(\mathrm{m}^{2} \text { leaf) }\right)^{-1}$ and the $k_{\mathrm{n}}$ (nitrogen extinction coefficient) ranged from $0.09 \mathrm{~m}^{2} \mathrm{~m}^{-2}$ to $0.89 \mathrm{~m}^{2}$ $\mathrm{m}^{-2}$. The values of $k_{\mathrm{n}}$ decreased exponentially with an increase in LAI (Figure 5.2b). This relationship between $k_{\mathrm{n}}$ and $L A I$ was consistent among nitrogen fertilization levels and growth environments. Thus, this relationship was applied to calculate $k_{\mathrm{n}}$ in subsequent model analyses.

\subsubsection{The effects of chamber system on canopy transpiration and photosynthesis}

The night-time chamber air temperature $T_{\text {air }}$ ranged from $14.7^{\circ} \mathrm{C}$ to $25.7{ }^{\circ} \mathrm{C}$ and from $17.1{ }^{\circ} \mathrm{C}$ to $27.0{ }^{\circ} \mathrm{C}$ during the measurements in CAN1 and CAN2, respectively. There was little difference in micro-environmental variables (i.e., $T_{\text {air }}, \mathrm{CO}_{2}$ and $V P$ ) during the night-time between chamber and ambient open air, and among treatments within chambers (Figure 5.3). During daytime, incident $P A R$ reached up to $2100 \mu \mathrm{mol} \mathrm{m} \mathrm{m}^{-2} \mathrm{~s}^{-1}$ while $T_{\text {air }}, C O_{2}$ and $V P$ in the

Table 5.3 The effects of long-term water shortage on the partitioning of biomass. Data presented was collected in CAN2.

\begin{tabular}{lllllll}
\hline & $\begin{array}{l}\text { Biomass } \\
\left(\mathrm{g} \mathrm{m}^{-2}\right)\end{array}$ & $\begin{array}{l}\text { Stem } \\
\left(\mathrm{g} \mathrm{m}^{-2}\right)\end{array}$ & $\begin{array}{l}\text { Green leaf } \\
\left(\mathrm{g} \mathrm{m}^{-2}\right)\end{array}$ & $\begin{array}{l}\text { Senesced leaf } \\
\left(\mathrm{g} \mathrm{m}^{-2}\right)\end{array}$ & $\begin{array}{l}\text { Inflorescence } \\
\left(\mathrm{g} \mathrm{m}^{-2}\right)\end{array}$ & $\begin{array}{l}\text { Root } \\
\left(\mathrm{g} \mathrm{m}^{-2}\right)\end{array}$ \\
\hline $\mathrm{WS}^{\mathrm{a}}$ & 480 & 245 & 62.0 & 43.6 & 30.7 & 99 \\
$\mathrm{WW}^{\mathrm{a}}$ & 590 & 278 & 96.9 & 37.3 & 49.0 & 128 \\
$P$-value & 0.10 & 0.23 & 0.04 & 0.05 & 0.08 & 0.22 \\
\hline
\end{tabular}

Acronyms: WW denotes well-watered containers while WS denotes the containers where water supply was half of WW.

Analysis of variance was performed considering canopy nitrogen content as covariate.
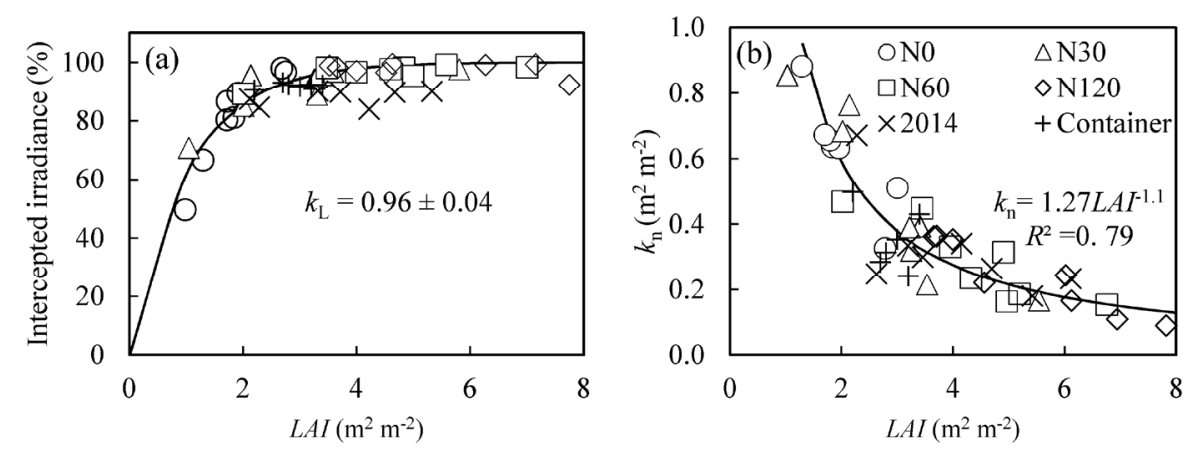

Figure 5.2 Canopy light interception (panel a) and nitrogen extinction coefficient ( $k_{\mathrm{n}}$; panel b) against leaf area index $(L A I)$ at different growth conditions. N0, N30, N60, N120 denote nitrogen fertilization rate in 2015 at $0,30,60$, and $120 \mathrm{~kg} \mathrm{~N}$ ha $^{-1}$, respectively. " 2014 " denotes data collected in 2014 in the plots that received a nitrogen fertilization of $60 \mathrm{~kg} \mathrm{~N} \mathrm{ha}^{-1}$. Data collected in the other plots is not shown because there was severe weed competition. "Container" denotes data collected in the container experiment. 
open air ranged from $17.6^{\circ} \mathrm{C}$ to $35.9^{\circ} \mathrm{C}$, from $359.7 \mu \mathrm{mol} \mathrm{mol}^{-1}$ to $439.4 \mu \mathrm{mol} \mathrm{mol}^{-1}$, and from $1.7 \mathrm{kPa}$ to $2.5 \mathrm{kPa}$, respectively. The daytime $T_{\text {air }}$ and $V P$ within chambers were higher than those in the open air while the $\mathrm{CO}_{2}$ was lower (Figure 5.3). Increasing nitrogen fertilization rate increased the differences in $T_{\text {air, }} V P$ and $\mathrm{CO}_{2}$ between chamber and ambient open air while
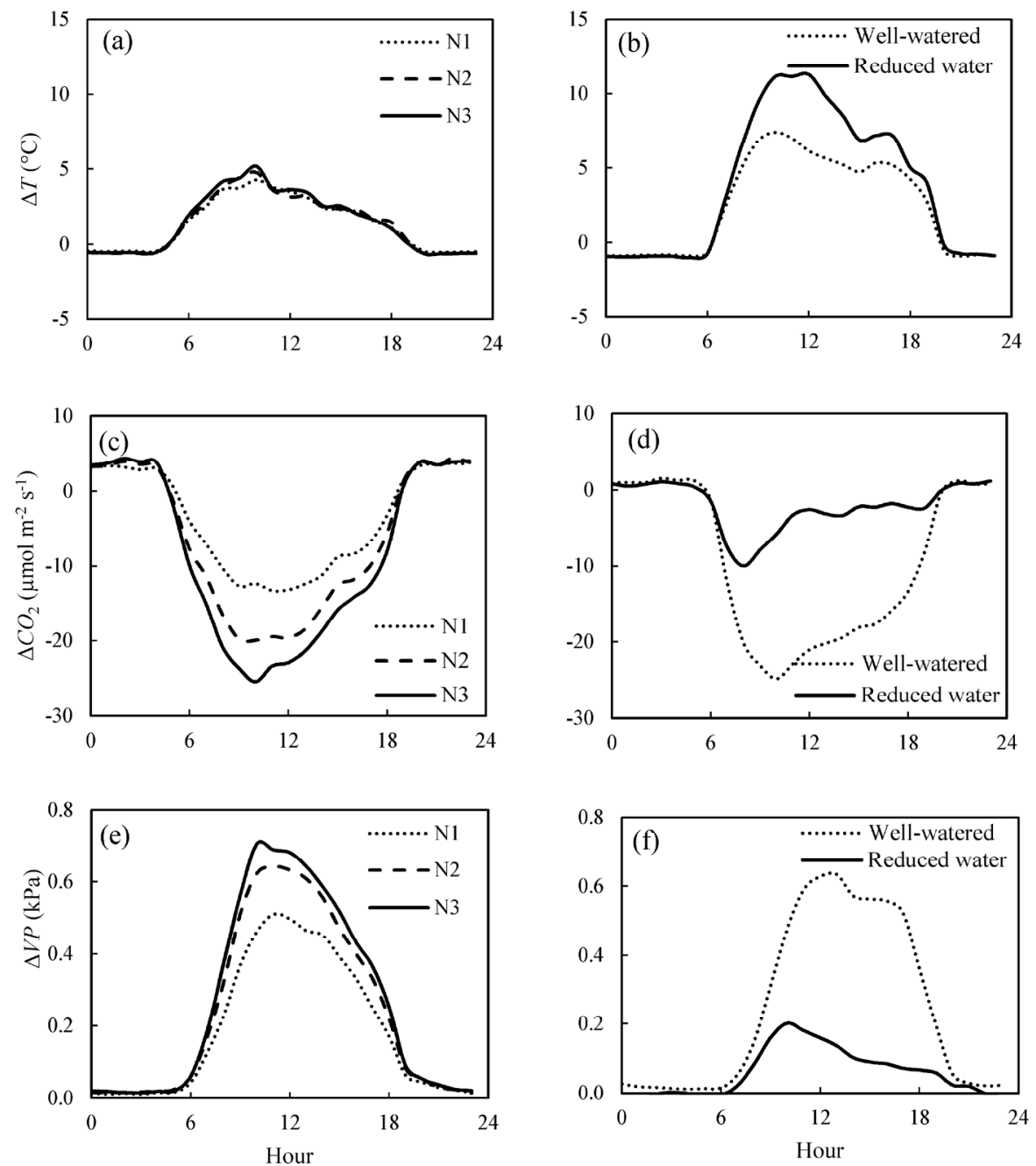

Figure 5.3 Diurnal courses of canopy chamber effects on air temperature $(\Delta T), \mathrm{CO}_{2}$ concentration $\left(\triangle C O_{2}\right)$ and vapour pressure $(\triangle V P)$ under different nitrogen (panels a, c, e) and water (panels b, d, f) regimes. Data presented in Panels a, c, e is the average of 3 days in CAN1. N1, N2 and N3 denote the level of received nitrogen, see text for details. Data presented in panels $b, d, f$ is the average of the last consecutive 3 days in CAN2. 
reducing water supply increased the difference in $T_{\text {air }}$ but decreased the differences in $V P$ and $\mathrm{CO}_{2}$.

The night-time canopy respiration $R_{\mathrm{c}}$ varied largely from minute to minute, presumably due to a relatively low $R_{\mathrm{c}}$ and high flow rate. Nevertheless, $R_{\mathrm{c}}$ increased slightly with increasing chamber $T_{\text {air }}$ (Supplementary Material Figure S5.2). By fitting these data to Eqn. (5.6), $E_{\mathrm{Rc}}$ (activation energy for $R_{\mathrm{c}}$ ) was estimated as $9559 \pm 2779 \mathrm{~J} \mathrm{~mol}^{-1}$. The estimate of $R_{\mathrm{c} 25}\left(R_{\mathrm{c}}\right.$ at 25 ${ }^{\circ} \mathrm{C}$ ) ranged from $3.9 \mu \mathrm{mol} \mathrm{CO} 2 \mathrm{~m}^{-2} \mathrm{~s}^{-1}$ to $4.9 \mu \mathrm{mol} \mathrm{CO} \mathrm{Cm}^{-2} \mathrm{~s}^{-1}$ in CAN1, and from $0.50 \mu \mathrm{mol}$ $\mathrm{CO}_{2} \mathrm{~m}^{-2} \mathrm{~s}^{-1}$ to $2.09 \mu \mathrm{mol} \mathrm{CO} 2 \mathrm{~m}^{-2} \mathrm{~s}^{-1}$ in CAN2 (Figure 5.4a). With the estimated $E_{\mathrm{Rc}}$ and $R_{\mathrm{c} 25}$, instantaneous gross canopy photosynthesis rate $A_{c, \text { gross }}$ in CAN1 and CAN2 was estimated. The daily $R_{\mathrm{c}}$ (canopy respiration) increased with increasing $A_{\mathrm{c}, \text { gross }}$ in both CAN1 and CAN2 but with different relationships (Figure 5.4b), and accounted for on average $40 \%$ and $15 \%$ of $A_{\text {c,gross }}$ in CAN1 and CAN2, respectively.

Examples of diurnal courses of measured canopy transpiration $E_{\mathrm{c}}$ and $A_{\mathrm{c}, \text { gross }}$ within canopy chambers are presented in Figure 5.5. The $E_{\mathrm{c}}$ and $A_{\mathrm{c} \text {,gross }}$ were close to nil during night-time while during the daytime their values rose up to $11.1 \mathrm{mmol} \mathrm{H}_{2} \mathrm{O} \mathrm{m}^{-2} \mathrm{~s}^{-1}$ and $38.1 \mu \mathrm{mol} \mathrm{CO}_{2} \mathrm{~m}^{-}$ ${ }^{2} \mathrm{~s}^{-1}$, respectively. For the containers that received sufficient water, the values of $E_{\mathrm{c}}$ and $A_{\mathrm{c}, \text { gross }}$ throughout the day followed closely their simulated potential transpiration $E_{\mathrm{cp}}$ and simulated potential photosynthesis $A_{\mathrm{cp}, \text { gross }}$ (Figure 5.5). As expected, the values of $E_{\mathrm{c}}$ and $A_{\mathrm{c}, \text { gross }}$ of the
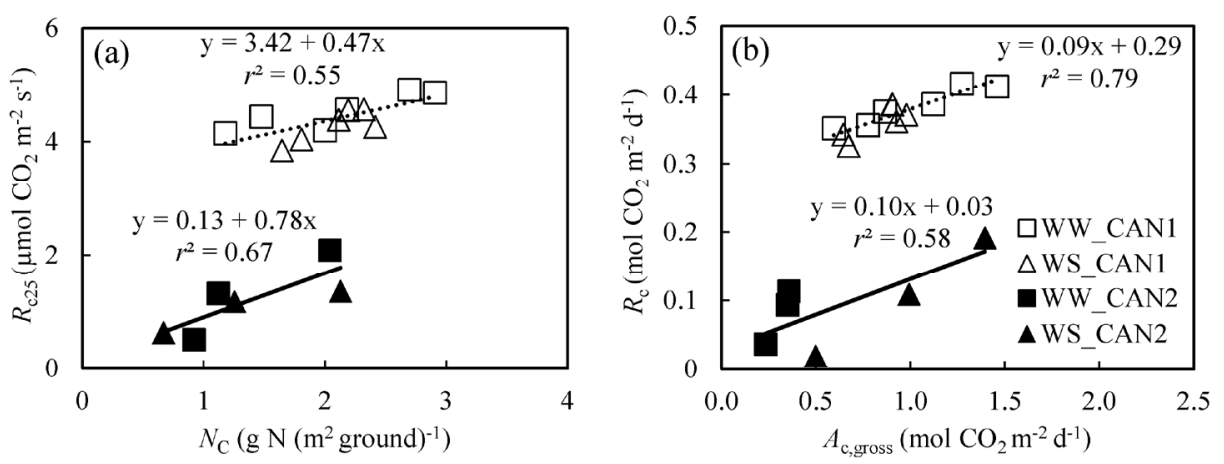

Figure 5.4 Panel a: responses of canopy respiration at $25^{\circ} \mathrm{C}\left(R_{\mathrm{c} 25}\right)$ to canopy leaf nitrogen content $\left(N_{\mathrm{C}}\right)$. Panel b: relationship between daily integrated canopy respiration $\left(R_{\mathrm{c}}\right)$ and gross photosynthesis $\left(A_{\mathrm{c}, \text { gross }}\right)$. WW and WS denote well-watered and water-limited conditions, respectively. CAN1 and CAN2 are experimental codes, see text for details. 

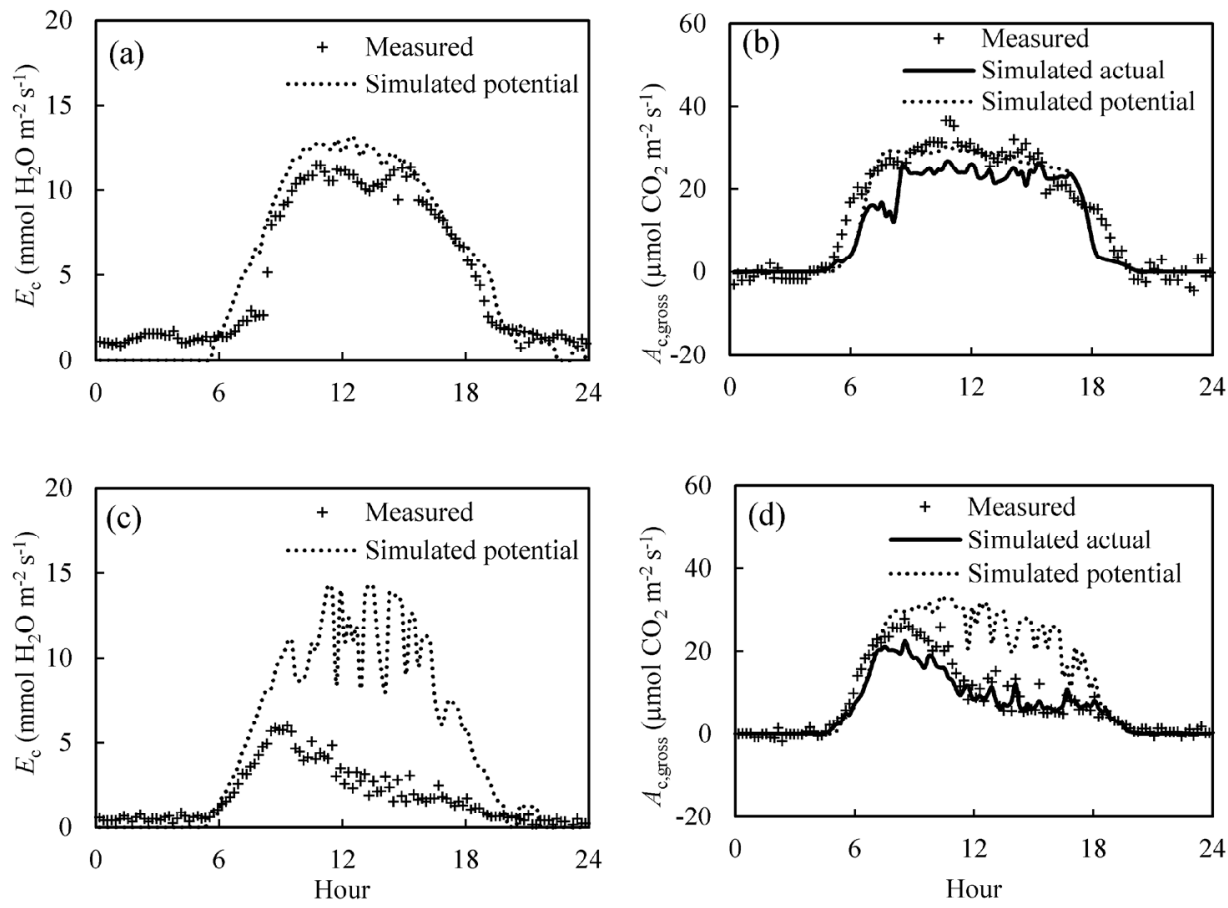

Figure 5.5 Diurnal courses of measured and simulated canopy transpiration $\left(E_{\mathrm{c}}\right.$; panels a, c) and gross photosynthesis rates $\left(A_{\mathrm{c}, \text { gross }}\right.$; panels $\left.\mathrm{b}, \mathrm{d}\right)$. Data presented was collected in the first day of $\mathrm{N} 2$ in CAN1.The canopy in panels $\mathrm{a}, \mathrm{b}$ received sufficient water while water supply in panels $\mathrm{c}, \mathrm{d}$ was halved.

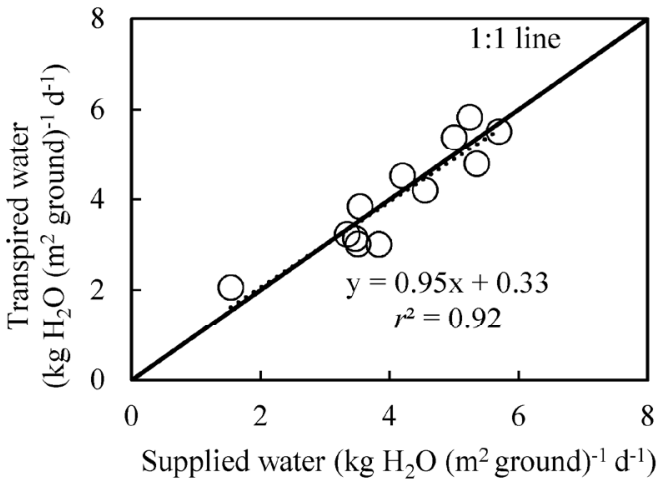

Figure 5.6 Integrated water loss through transpiration as measured by canopy gas exchange in comparison with the amount of supplied water. Each point represents the daily average of water loss versus water gain over the measuring period for each container in CAN1. The amount of supplied water was calculated as the difference of container weight at before and after watering. 
containers that received half amount of water were lower than their $E_{\mathrm{cp}}$ and $A_{\text {cp,gross }}$ from the late morning to the end of daytime. Integration of the instantaneous $E_{\mathrm{c}}$ to daily values matched well with the amount of supplied water per day (Figure 5.6). Thus, the $A_{\text {c,gross }}$ was simulated considering $E_{\mathrm{c}}$ as available water for transpiration at canopy level. The $E_{\mathrm{c}}$ was partitioned between sunlit and shaded leaves according to the relative share of their $E_{\mathrm{cp}}$ to obtain their actual transpiration $\left(E_{\mathrm{a}}\right)$ in Eqn. (5.7). There was a good agreement between the measured and simulated $A_{\mathrm{c}, \text { gross }}$ under different nitrogen and water regimes (Figure 5.5). The values of $r^{2}$ and rRMSE for the comparison between simulated and measured values of all data points in CAN1 were 0.80 and $32 \%$, respectively (part of the data points can be seen in Supplementary Material Figure S5.3). For the measurements in CAN2, they were 0.78 and $66 \%$, respectively.

The effects of micro-environmental differences between chamber and open air, and among treatments within chambers on canopy gas exchange were assessed using the validated model (Table 5.4). The presence of the plant chamber increased $E_{\mathrm{cp}}$ by $6.9-11.2 \%$ in CAN1 and by 19.6-34.2\% in CAN2 while it decreased $A_{\text {cp,gross }}$ by $0.3-1.4 \%$ in CAN1 and by $3.5-4.2 \%$ in CAN2. The chamber effect on $E_{\mathrm{cp}}$ varied little among nitrogen treatments while the effect on $A_{\text {cp,gross }}$ increased with an increase in nitrogen rate. Water shortage increased the effects of the

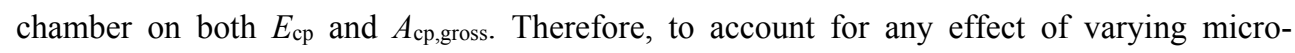
environmental variables due to the presence of the canopy chamber, the measured $E_{\mathrm{c}}$ and $A_{\mathrm{c} \text {,gross }}$ within each chamber were normalized to the conditions in the open air.

Table 5.4 The effects of plant chamber on canopy transpiration and photosynthesis under different nitrogen and water regimes. Potential canopy transpiration $\left(E_{\mathrm{cp}}\right)$ and photosynthesis $\left(A_{\mathrm{cp}, \text { gross }}\right)$ were simulated using weather data in the open air and in the chambers for each treatment while the other parameters were kept at the average value of well-watered $\mathrm{N} 3$ containers. The differences of simulated $E_{\mathrm{cp}}$ and $A_{\mathrm{cp}, \mathrm{gross}}$ between open air and plant chamber are presented as percentage of the value in the open air. The presence of the plant chamber resulted in an increase in $E_{\mathrm{cp}}$ while it resulted in a decrease in $A_{\text {cp,gross. }}$

\begin{tabular}{lllll}
\hline & CAN1 & \multicolumn{3}{c}{ CAN2 } \\
\cline { 2 - 5 } & $\Delta E_{\mathrm{cp}}(\%)$ & $\Delta A_{\text {cp,gross }}(\%)$ & $\Delta E_{\mathrm{cp}}(\%)$ & $\Delta A_{\mathrm{cp}, \text { gross }}(\%)$ \\
\hline N1 & 9.0 & -1.0 & 28.5 & -3.5 \\
N2 & 8.9 & -1.0 & 25.5 & -3.7 \\
N3 & 9.1 & -1.4 & 26.8 & -4.2 \\
WS & 11.2 & -1.2 & 34.2 & -4.0 \\
WW & 6.9 & -0.3 & 19.6 & -3.6 \\
\hline
\end{tabular}

Acronyms: N1, N2 and N3 denote nitrogen fertilization rate at $0,1.0$, and $2.0 \mathrm{~g} \mathrm{~N}$ container ${ }^{-1}$, respectively; WW denotes well-watered containers while WS denotes the containers where water supply was half of WW; CAN1 and CAN2 are experimental codes, see text for details. 


\subsubsection{The effects of nitrogen fertilization and short-term water shortage on canopy water-}

\section{and nitrogen-use efficiencies}

Examples of the diurnal courses of normalised $E_{\mathrm{c}}$ and $A_{\mathrm{c}, \text { gross }}$ in CAN1 are presented in Figure 5.7. Despite minute-to-minute fluctuation due to environmental variability, the $E_{\mathrm{c}}$ and $A_{\mathrm{c} \text {,gross }}$ were consistently higher in the fertilized canopies than those of non-fertilized and water shortage resulted in reductions in $E_{\mathrm{c}}$ and $A_{\mathrm{c} \text {,gross }}$ that emerged from the late morning to the end of the day. Consequently, daily integrated $E_{\mathrm{c}}$ and $A_{\mathrm{c} \text {,gross }}$ increased with an increase in nitrogen fertilization rate while they decreased under water limiting conditions (Table 5.1). The daily integrated $E_{\mathrm{c}}$ and $A_{\mathrm{c} \text {,gross }}$ ranged from $162 \mathrm{~mol} \mathrm{H}_{2} \mathrm{O} \mathrm{m}^{-2} \mathrm{~d}^{-1}$ to $268 \mathrm{~mol} \mathrm{H}_{2} \mathrm{O} \mathrm{m}^{-2} \mathrm{~d}^{-1}$ and from $0.70 \mathrm{~mol} \mathrm{CO}_{2} \mathrm{~m}^{-2} \mathrm{~d}^{-1}$ to $1.14 \mathrm{~mol} \mathrm{CO}_{2} \mathrm{~m}^{-2} \mathrm{~d}^{-1}$, respectively. Calculated as $A_{\mathrm{c} \text {,gross }} / E_{\mathrm{c}}$, the canopy water-use efficiency $\left(W U E_{\mathrm{c}}\right)$ ranged from $4.00 \mathrm{mmol} \mathrm{CO}_{2}\left(\mathrm{~mol} \mathrm{H}_{2} \mathrm{O}\right)^{-1}$ to $4.65 \mathrm{mmol} \mathrm{CO}_{2}(\mathrm{~mol}$ $\left.\mathrm{H}_{2} \mathrm{O}\right)^{-1}$. The $W U E_{\mathrm{c}}$ did not vary significantly among nitrogen treatments while it increased by $16 \%$ under water limiting conditions because the $W U E_{\mathrm{c}}$ increased with decreasing ratio of $E_{\mathrm{c}} / E_{\mathrm{cp}}$ (Figure 5.8), an indicator of the degree of water shortage. Calculated as $A_{\mathrm{c}, g r o s s} / N_{\mathrm{c}}$, canopy
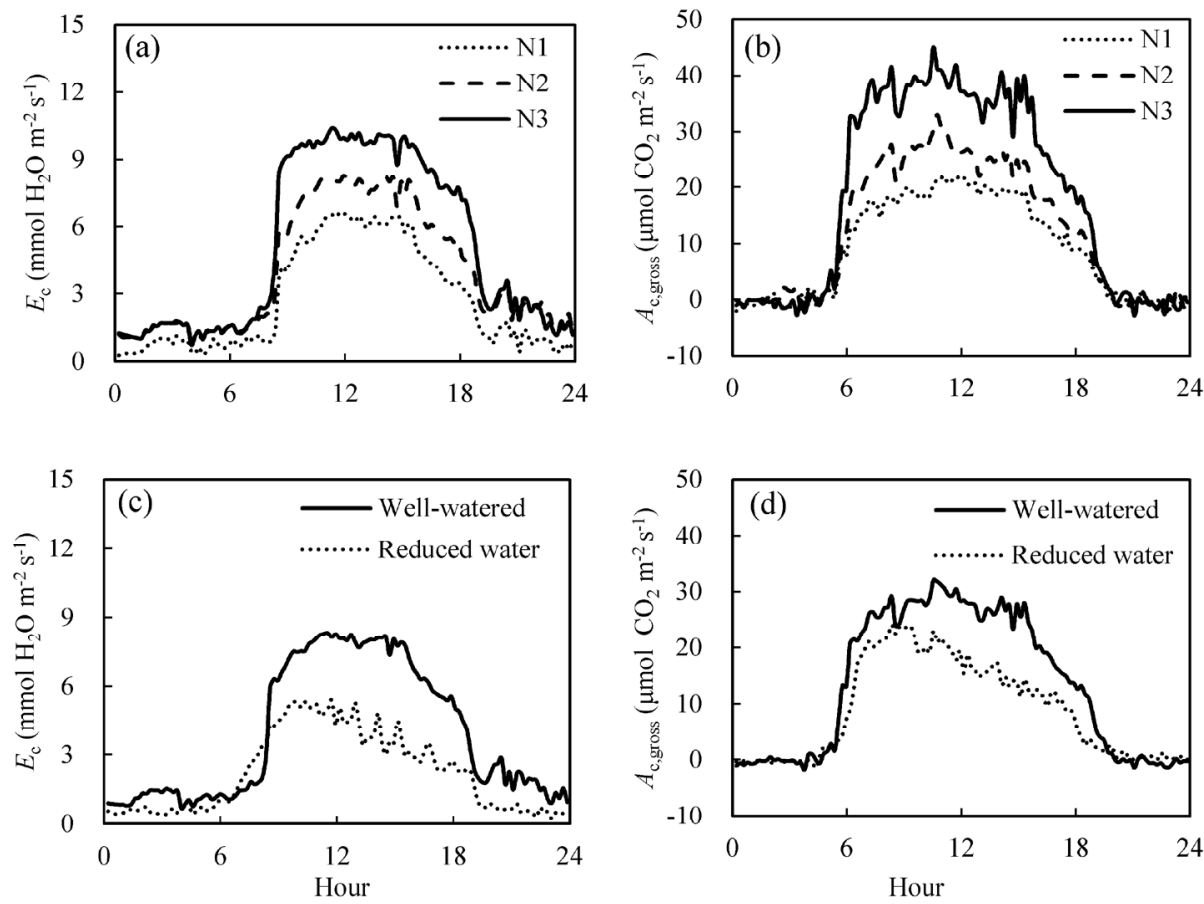

Figure 5.7 The effect of nitrogen (panels a, b) and short-term water stress (panels c, d) on instantaneous canopy transpiration (panels a, c) and photosynthesis rate (panels b, d). Data presented was collected in the first day in CAN1. The data has been normalized to the open-air conditions. N1, $\mathrm{N} 2$ and $\mathrm{N} 3$ denote the level of received nitrogen, see text for details. 


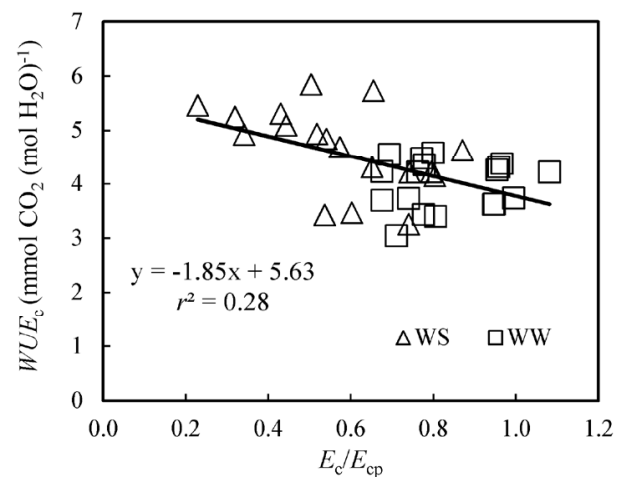

Figure 5.8 Relationship between gross canopy water-use efficiency ( $\left.W U E_{\mathrm{c}}\right)$ and the degree of water shortage $\left(E_{\mathrm{c}} / E_{\mathrm{cp}}\right)$. Data presented were collected in CAN1. Each point represents the daily value of each container. WW denotes well-watered containers while WS denotes the containers where water supply was half of WW.

nitrogen-use efficiency $\left(N U E_{\mathrm{c}}\right)$ ranged from $0.40 \mathrm{~mol} \mathrm{CO}_{2} \mathrm{~d}^{-1}\left(\mathrm{~g} \mathrm{~N}^{-1}\right.$ to $0.49 \mathrm{~mol} \mathrm{CO}_{2} \mathrm{~d}^{-1}(\mathrm{~g}$ $\mathrm{N})^{-1}$. No significant effect of nitrogen fertilization on $N U E_{\mathrm{c}}$ was observed $(P>0.05)$, while $N U E_{\mathrm{c}}$ decreased significantly (by $18 \% ; P<0.05$ ) under water limiting conditions (Table 5.1).

\subsubsection{The effects of long-term water shortage on canopy water- and nitrogen-use efficiencies}

As water shortage was prolonged in CAN2, the progressive responses of $E_{\mathrm{c}}, A_{\mathrm{c}, \text { gross }}, W U E_{\mathrm{c}}$ and $N U E_{\mathrm{c}}$ are presented in Figure 5.9. Reductions of $E_{\mathrm{c}}$ and $A_{\mathrm{c}, \text { gross }}$ emerged 4 days after withholding water and lasted until the end of the gas exchange measurement (except for the $8^{\text {th }}$ day) when all plants were cut for analysis. A short recovery was observed during the $8^{\text {th }}$ day due to a brief re-watering of wilting plants in the water-stressed canopies (see the Materials and Methods section). During the last three days, the average daily $E_{\mathrm{c}}, A_{\mathrm{c}, \text { gross, }} W U E_{\mathrm{c}}$ and $N U E_{\mathrm{c}}$ in the wellwatered canopies were $234 \mathrm{~mol} \mathrm{H}_{2} \mathrm{O} \mathrm{m}^{-2} \mathrm{~d}^{-1}, 0.96 \mathrm{~mol} \mathrm{CO}_{2} \mathrm{~m}^{-2} \mathrm{~d}^{-1}, 4.20 \mathrm{mmol} \mathrm{CO}_{2}\left(\mathrm{~mol} \mathrm{H}_{2} \mathrm{O}\right)^{-}$ ${ }^{1}$ and $0.70 \mathrm{~mol} \mathrm{CO}_{2} \mathrm{~d}^{-1}\left(\mathrm{~g} \mathrm{~N}^{-1}\right.$, respectively (Table 5.2). The values of $E_{\mathrm{c}}, A_{\mathrm{c} \text {,gross }}$ and $N U E_{\mathrm{c}}$ were higher than those of water-stressed canopies by $82 \%, 68 \%$ and $63 \%$, respectively, while the $W U E_{\mathrm{c}}$ was lower than that of water-stressed canopies by $79 \%$.

\subsubsection{The importance of canopy physiological parameters in determining canopy water- and nitrogen-use efficiencies}

Model analyses were performed to assess the relative importance of $L A I$ and $S L N$, the two important canopy physiological parameters, in determining potential $W U E_{\mathrm{c}}\left(W U E_{\mathrm{cp}}\right)$ and $N U E_{\mathrm{c}}$ $\left(N U E_{\mathrm{cp}}\right)$ in both the field experiment and the chamber experiment. This was done by first using 

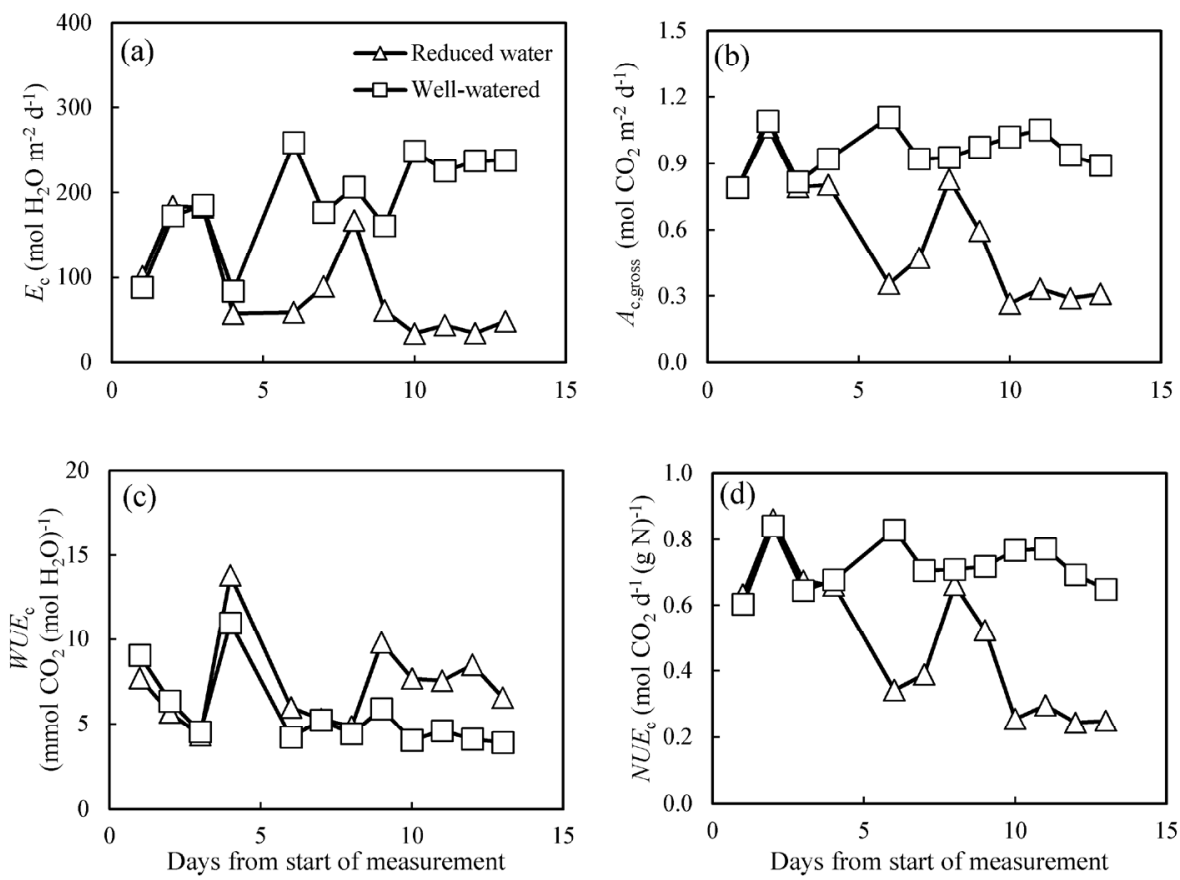

Figure 5.9 The evolution of prolonged water limitation effects on daily canopy transpiration $\left(E_{\mathrm{c}}\right)$, gross photosynthesis $\left(A_{\mathrm{c}, \text { gross }}\right)$, canopy water-use efficiency $\left(W U E_{\mathrm{c}}\right)$ and canopy nitrogen-use efficiency $\left(N U E_{\mathrm{c}}\right)$. Data presented was collected in CAN2. The data has been normalized to the open-air conditions.

the measured $S L N$ and $L A I$ of each nitrogen level as the default simulation and then forcing $L A I$ or $S L N$ of all treatments to their respective values at the non-fertilized or water stressed treatment (Figure 5.10). For both linear-growth and flowering stages of the field experiment, when forcing $S L N$ to the value at non-fertilized treatment the values of $E_{\mathrm{cp}}, A_{\mathrm{cp}, \text { gross, }} W U E_{\mathrm{cp}}$ and $N U E_{\mathrm{cp}}$ changed little in comparison with those of the default simulation, whereas when forcing $L A I$ to the value at non-fertilized treatment their values deviated significantly from the default simulation. In the chamber experiment in CAN1, the variations of $E_{\mathrm{cp}}, A_{\mathrm{cp}, \text { gross }}$ and $W U E_{\mathrm{cp}}$ with increasing nitrogen rate were mainly due to a change in $L A I$ whereas the variation of $N U E_{\mathrm{cp}}$ was due to combined changes in $L A I$ and $S L N$. In the chamber experiment in CAN2, the decrease in $E_{\text {cp }}$ under long-term stress was mainly due to a change in $L A I$ while the variations of $A_{\mathrm{c}, \text { gross, }} W U E_{\mathrm{cp}}$ and $N U E_{\mathrm{cp}}$ were due to combined changes in $L A I$ and $S L N$. 
Linear growth-2015
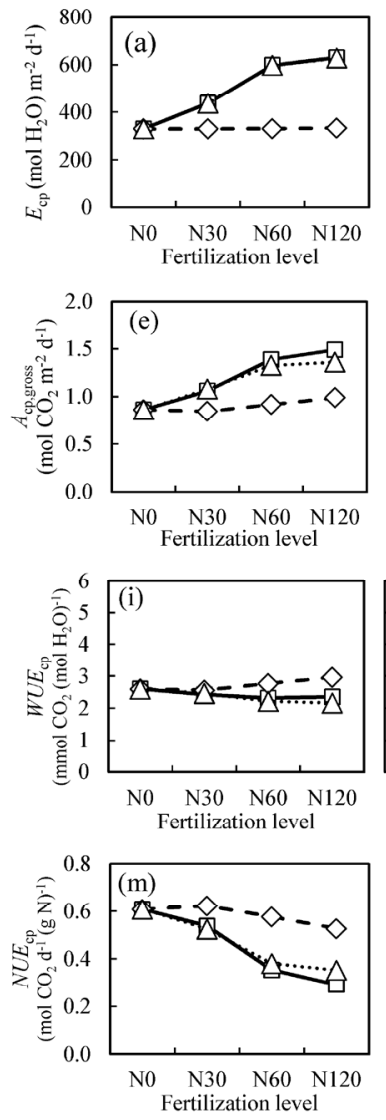

Flowering-2015
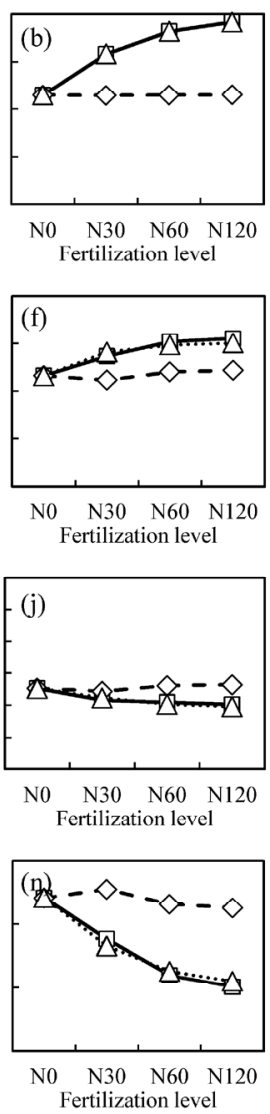

CAN1
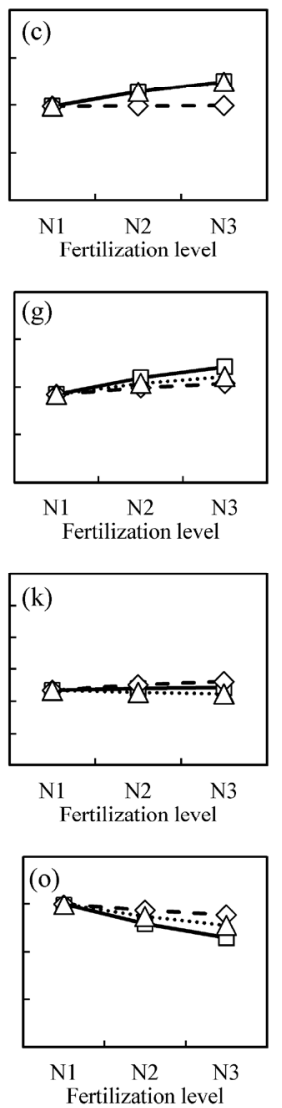

CAN2
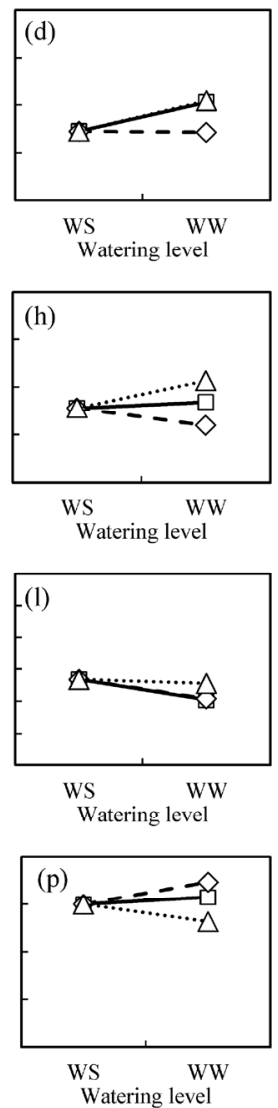

Figure 5.10 The simulated effects of nitrogen fertilization and water shortage on daily potential canopy transpiration $\left(E_{\mathrm{cp}}\right.$; panels a-d), gross photosynthesis $\left(A_{\mathrm{cp}, \mathrm{gross}}\right.$; panels $\left.\mathrm{e}-\mathrm{h}\right)$, and canopy wateruse efficiency ( $W U E_{\mathrm{cp}}$; panels i-1). and nitrogen-use efficiency ( $N U E_{\mathrm{cp}}$; panels $\left.\mathrm{m}-\mathrm{p}\right)$. Continuous line with squares: the default simulations performed using the measured leaf area index $(L A I)$ and specific leaf nitrogen $(S L N)$ at each nitrogen level or each water level. Dashed line with diamonds: simulations performed with measured $S L N$ at each nitrogen level (or each water level) while keeping $L A I$ fixed at the values of non-fertilization (or water-stressed) treatment. Dot line with triangles: simulations performed with measured $L A I$ at each nitrogen level (or each water level) while keeping $S L N$ fixed at the values of non-fertilization (or water-stressed) treatment. Linear growth-2015 (panels a, e, i and m) denotes the case where the values of $L A I$ and $S L N$ were collected at the linear growth stage in the field experiment in 2015; Flowering-2015 (panels b, f, j and $\mathrm{n}$ ) denotes the case where the values of $L A I$ and $S L N$ were collected at full flowering in the field experiment in 2015; CAN1 (panels c, g, $\mathrm{k}$ and o) denotes the case where the values of $L A I$ and $S L N$ were collected in the CAN1; CAN2 (panels d, h, 1 and $\mathrm{p}$ ) denotes the case where values of $L A I$ and $S L N$ were collected in the CAN2. N0, N30, N60, N120 denote nitrogen fertilization rate in 2015 at $0,30,60$, and $120 \mathrm{~kg} \mathrm{~N}^{-1}$, respectively; N1, N2 and $\mathrm{N} 3$ denote nitrogen fertilization rate in CAN1 at $0,1.0$, and $2.0 \mathrm{~g} \mathrm{~N}$ container ${ }^{-1}$, respectively; WW denotes well-watered containers in CAN2 while WS denotes the containers where water supply was half of WW. 


\subsection{Discussion}

Bio-economically sustainable agronomy requires effective use of scarce nitrogen and water resources. While hemp is considered as a bio-economically sustainable crop (Amaducci et al., 2015; Finnan \& Styles, 2013), its canopy water- and nitrogen-use efficiencies have not been studied. In this study, experimental and modelling analyses were conducted to assess hemp canopy water- and nitrogen-use efficiencies in relation to leaf and canopy physiological parameters under different nitrogen and water regimes.

\subsubsection{Determination of canopy transpiration and photosynthesis}

The canopy chamber technique is a useful tool to assess crop responses to nitrogen deficiency and water shortage at canopy scale. However, the presence of the chamber wall had a significant effect on the micro-environment within the chambers (Figure 5.3), in line with the results of previous studies (Müller et al., 2009; Takahashi et al., 2008; Poni et al., 1997). In the present study, the micro-environment conditions within the chamber resulted in a lower $A_{\text {cp,gross }}$ and a higher $E_{\mathrm{cp}}$ than those in the open air, and this effect was larger in the chambers with higher fertilization rate and lower water supply (Table 5.4). As responses of $E_{\mathrm{c}}$ and $A_{\mathrm{c} \text {,gross }}$ to environmental variables are probably not linear (Hikosaka et al., 2016), it is necessary to normalize measurements within different chambers to avoid any confounding effect due to the differences in chamber micro-environmental factors.

In line with previous studies (Müller et al., 2005; Leuning et al., 1998), the variation of $E_{\mathrm{c}}$ and $A_{\text {c,gross }}$ in response to fluctuating environmental condition under different nitrogen and water regimes can be precisely described using a process-based physiological model (Figure 5.5). Thus, discrepancies in $E_{\mathrm{c}}$ and $A_{\mathrm{c}, \text { gross }}$ among chambers due to differences in microenvironment at measuring time could be properly accounted for through correction factors $f_{\mathrm{Ec}}$ and $f_{\text {Ac, }}$, respectively (see Eqns 5.8 and 5.9), in our study.

\subsubsection{Hemp canopy water- and nitrogen-use efficiencies in relation to nitrogen availability}

The reason for the lack of significant responses of $W U E_{\mathrm{c}}$ and $N U E_{\mathrm{c}}$ to the decrease nitrogen rate in the container experiments is not clear (Table 5.1). It is probably a consequence of small variations in $L A I$ and $S L N$ among nitrogen treatments. This is confirmed in the model analysis for the field experiment in 2015, where the variation in $L A I$ among $\mathrm{N}$ treatments was much more significant than that in our container experiment. This model analysis suggested that both $W U E_{\mathrm{c}}$ and $N U E_{\mathrm{c}}$ increased with decreasing nitrogen fertilization rate, and that the increases in 
$W U E_{\mathrm{c}}$ and $N U E_{\mathrm{c}}$ were mainly a result of a reduction in $L A I$ (Figure 5.10). The reduced $L A I$

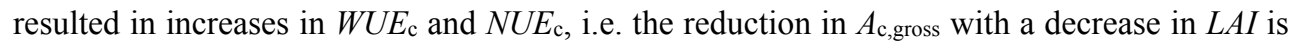
less than the reductions in $E_{\mathrm{c}}$ and in $N_{\mathrm{C}}$. This could be explained by an optimum $S L N$ gradient relative to the light gradient in the canopy. It has been reported that the profile of SLN in a canopy is a whole-plant process that depends on canopy size (Moreau et al., 2012). Our data showed that the value of $k_{\mathrm{n}}$ increased with decreasing $L A I$ (Figure 5.2b), up to a value of $c a$. 0.9 close to the LAI-independent value of $k_{\mathrm{L}}\left(0.96 \mathrm{~m}^{2} \mathrm{~m}^{-2}\right.$, Figure $\left.5.2 \mathrm{a}\right)$. So, the value of $k_{\mathrm{n}}$ in a large hemp canopy was generally lower than its theoretical value for a maximized canopy photosynthesis, which could be achieved only when $k_{\mathrm{n}}=k_{\mathrm{L}}$ (Hikosaka et al., 2016; Hirose \& Werger, 1987). When $L A I$ is low, canopy photosynthesis is close to a maximum value as a result of $k_{\mathrm{n}}$ being close to $k_{\mathrm{L}}$; in such a case, the average leaf photosynthesis rate could be increased for a given amount of $N_{\mathrm{c}}$, while $E_{\mathrm{c}}$ stayed largely unchanged.

The variation in $W U E_{\mathrm{c}}$ and $N U E_{\mathrm{c}}$ with decreasing nitrogen fertilization rate may also be attributed to the variation in the absolute amount of $S L N$. It has been widely reported that $S L N$ positively correlates with water-use efficiency while it negatively correlates with nitrogen-use efficiency at leaf level (Shangguan et al., 2000; Van den Boogaard et al., 1995). However, in response to nitrogen stress, hemp tends to maintain $S L N$ at the expense of $L A I$ (Figure 5.1). This response is in line with that of sunflower (Helianthus annuus L.), canola (Brassica napus L.) and wheat (Triticum aestivum L.) whereas it contrasts with that of maize (Zea mays L.), which tends to maintain $L A I$ under nitrogen stress at the expense of $S L N$ (Lemaire et al., 2008). As a result of the relative small variation in $S L N$ among nitrogen treatments, little effect of $S L N$ was detected on the hemp $W U E_{\mathrm{c}}$ and $N U E_{\mathrm{c}}$ (Figure 5.10).

The effects of nitrogen fertilization on crop water-use efficiency and nitrogen-use efficiency are whole plant process that depends on leaf photosynthetic capacity and canopy size, and our analysis showed that relative to leaf photosynthetic capacity (determined by $S L N$ ), canopy size (LAI) plays a predominant role on this.

\subsubsection{Hemp canopy water- and nitrogen-use efficiencies in relation to water availability}

Field observations generally show that water stress results in an increase in hemp water-use efficiency (Cosentino et al., 2013). This is confirmed by our results showing both short-term and long-term water shortages that resulted in an increase in $W U E_{\mathrm{c}}$ (Tables 5.1, 5.2). However, our study further showed that the effect differed between short- and long-term stresses. 


\section{Chapter 5}

In response to short-term water stress, the increase in $W U E_{\mathrm{c}}$ is mainly a consequence of stomatal closure as the variations in $E_{\mathrm{c}}$ and $A_{\mathrm{c} \text {,gross }}$ with decreasing water supply were precisely captured by considering the response of stomatal conductance (Figure 5.5). In fact, stomatal closure is one of the earliest responses to water deficit, protecting the plants from extensive water loss (Chaves et al., 2003). Stomatal closure restricts both $\mathrm{H}_{2} \mathrm{O}$ and $\mathrm{CO}_{2}$ exchange between leaf intercellular and ambient air that leads to great decreases in $E_{\mathrm{c}}$ and $A_{\mathrm{c}, \text { gross }}$ (Table 5.1, Figure 5.5). However, the reductions in $E_{\mathrm{c}}$ and $A_{\mathrm{c}, \text { gross }}$ are not parallel and the $W U E_{\mathrm{c}}$ gradually increases with decreasing $E_{\mathrm{c}} / E_{\mathrm{cp}}$ (Figure 5.8), probably because of the non-linear relationship between carbon assimilation rate and $\mathrm{CO}_{2}$ concentration in the intercellular space (Chapter 4) that results in an increase in $W U E_{\mathrm{c}}$. The increase in $W U E_{\mathrm{c}}$ with decreasing $E_{\mathrm{c}} / E_{\mathrm{cp}}$ indicates that the estimation of canopy photosynthesis under water limiting condition by assuming a consistent $W U E_{\mathrm{c}}$ in the crop models, such as SUCROS (van Laar et al. 1997), is only approximate. Instead, the present study considered the response of stomatal conductance using Eqn. (5.7) that results in an increase in $W U E_{\mathrm{c}}$ with decreasing $E_{\mathrm{c}} / E_{\mathrm{cp}}$. This approach is therefore preferable in the simulation of canopy photosynthesis under short-term water stress conditions. Nevertheless, we could not exclude the possibility that non-stomatal limitations were involved in our experiment. Further researches are needed to understand the effect of non-stomatal change under water stress condition on canopy photosynthesis, such as change of leaf angle (Archontoulis et al., 2011).

As water stress continued, hemp responded through reducing $L A I$ and increasing $S L N$, while $N_{C}$ stayed unchanged (Table 5.2). The reduced $L A I$ was largely caused by increased senescence (Table 5.3). Because of this additional response, model analysis for the sensitivity in response to changing $L A I$ or $S L N$ was contrasting between CAN1 and CAN2 (Figure 5.10). This type of response to a long-term water stress was also observed in studies on other species such as kenaf (Hibiscus cannabinus) and sunflower (Archontoulis et al., 2011; Danalatos \& Archontoulis, 2010). The response could result in more significant increases in $W U E_{\mathrm{c}}$ as a result of both the stomatal response discussed above and the reduced evaporative surfaces. However, an increase in $S L N$ could not compensate for the loss in $L A I$; so, the long-term stress resulted in large reductions in the $A_{\text {cp,gross, }} E_{\mathrm{cp}}$ and $N U E_{\mathrm{c}}$ (Table 5.2). This result indicates that crop models for predicting the effect of long-term water stress should introduce mechanisms on the responses of canopy-level traits (like $L A I$ ) in addition to stomatal regulation. It also suggests that although hemp is tolerant to long-term water stress through improving water-use efficiency (Cosentino 
et al., 2013), its final biomass yield and nitrogen-use efficiency may be restricted largely by water limitation during growth.

\section{Acknowledgements}

The research leading to these results has received funding from the European Union's Seventh Framework Programme for research, technological development and demonstration under grant agreement $n^{\circ}$ 311849. Drs Steven Driever and Tjeerd-Jan Stomph are thanked for their early discussions.

\section{References}

Amaducci, S. and Gusovius, H.J., (2010) Hemp - cultivation, extraction and processing, In: Industrial applications of natural fibres: Structure, properties and technical applications (ed, Müssig, J.), pp. 109-134. John Wiley \& Sons Ltd, West Sussex, UK.

Amaducci, S., Scordia, D., Liu, F. et al. (2015) Key cultivation techniques for hemp in Europe and China. Industrial Crops and Products, 68, 2-16.

Archontoulis, S.V., Vos, J., Yin, X. et al. (2011) Temporal dynamics of light and nitrogen vertical distributions in canopies of sunflower, kenaf and cynara. Field Crops Research, 122, 186-198.

Baker, J.T., Van Pelt, S., Gitz, D.C. et al. (2009) Canopy gas exchange measurements of cotton in an open system. Agronomy Journal, 101, 52-59.

Barth, M. and Carus, M. (2015) Carbon footprint and sustainability of different natural fibres for biocomposites and insulation material, Hürth, Germany, nova-Institute. Available at (2017, November 29): http://bio-based.eu/ecology/.

Bertoli, A., Tozzi, S., Pistelli, L. et al. (2010) Fibre hemp inflorescences: From crop-residues to essential oil production. Industrial Crops and Products, 32, 329-337.

Bouloc, P. and Van der Werf, H.MG. (2013) The role of hemp in sustainable development. In: Hemp: industrial production and uses. (eds Bouloc P, Allegret S and Arnaud L), pp. 278-289. CPi Group Ltd, Croydon, UK.

Burkart, S., Manderscheid, R. and Weigel, H.J. (2007) Design and performance of a portable gas exchange chamber system for $\mathrm{CO}_{2}$-and $\mathrm{H}_{2} \mathrm{O}$-flux measurements in crop canopies. Environmental and Experimental Botany, 61, 25-34.

Cabrera-Bosquet, L., Molero, G. and Bort, J. (2007) The combined effect of constant water deficit and nitrogen supply on WUE, NUE and $\Delta^{13} \mathrm{C}$ in durum wheat potted plants. Annals of Applied Biology, 151, 277-289.

Calzolari, D., Magagnini, G., Lucini, L. et al. (2017) High added-value compounds from Cannabis threshing residues. Industrial Crops and Products, 108,: 558-563.

Chaves, M.M., Maroco, J.P. and Pereira, J.S. (2003) Understanding plant responses to drought — from genes to the whole plant. Functional plant biology, 30, 239-264.

Cosentino, S.L., Riggi, E., Testa, G. et al. (2013) Evaluation of European developed fibre hemp 
genotypes (Cannabis sativa L.) in semi-arid Mediterranean environment. Industrial Crops and Products, 50, 312-324.

Danalatos, N.G. and Archontoulis, S.V. (2010) Growth and biomass productivity of kenaf (Hibiscus cannabinus, L.) under different agricultural inputs and management practices in central Greece. Industrial Crops and Products, 32, 231-240.

De Meijer, E.P.M. and van der Werf, H.M.G. (1994) Evaluation of current methods to estimate pulp yield of hemp. Industrial Crops and Products, 2, 111-120.

De Pury, D. and Farquhar, G. (1997) Simple scaling of photosynthesis from leaves to canopies without the errors of big-leaf models. Plant, Cell \& Environment, 20, 537-557.

Finnan, J. and Styles, D. (2013) Hemp: A more sustainable annual energy crop for climate and energy policy. Energy Policy, 58, 152-162.

Fracasso, A., Magnanini, E., Marocco, A. et al. (2017) Real-time determination of photosynthesis, transpiration, water-use efficiency and gene expression of two sorghum bicolor (Moench) genotypes subjected to dry-down. Frontiers in Plant Science, 8, 1-12.

Hikosaka, K., Noguchi, K. and Terashima, I. (2016) Modeling leaf gas exchange. In: Canopy Photosynthesis: From Basics to Applications (eds eds Hikosaka, K., Niinemets, Ü. and Anten N.P.R.), pp 61-100. Springer, London, UK.

Jones, H.G., (2013) Heat, mass and momentum transfer. In: Plants and microclimate: a quantitative approach to environmental plant physiology (ed, Jones, H.G.), pp. 47-67. Cambridge university press, UK.

Leizer, C., Ribnicky, D., Poulev, A. et al. (2000). The Composition of Hemp Seed Oil and Its Potential as an Important Source of Nutrition. Journal of Nutraceuticals, Functional \& Medical Foods, 2, 35-53.

Lemaire, G., Van Oosterom, E., Jeuffroy, M.H. et al. (2008) Crop species present different qualitative types of response to $\mathrm{N}$ deficiency during their vegetative growth. Field Crops Research, 105, 253-265.

Leuning, R., Dunin, F. and Wang, Y.P. (1998) A two-leaf model for canopy conductance, photosynthesis and partitioning of available energy. II. Comparison with measurements. Agricultural and Forest Meteorology, 91, 113-125.

Linderson, M.L., Mikkelsen, T.N., Ibrom, A. et al. (2012) Up-scaling of water use efficiency from leaf to canopy as based on leaf gas exchange relationships and the modeled incanopy light distribution. Agricultural and Forest Meteorology, 152, 201-211.

Moreau, D., Allard, V. and Gaju, O. (2012) Acclimation of leaf nitrogen to vertical light gradient at anthesis in wheat is a whole-plant process that scales with the size of the canopy. Plant physiology, 160, 1479-1490.

Müller, J., Behrens, T. and Diepenbrock, W. (2005) Measurement and modelling of canopy gas exchange of oilseed rape. Agricultural and Forest Meteorology, 132, 181-200.

Müller, J., Eschenröder, A. and Diepenbrock, W. (2009) Through-flow chamber $\mathrm{CO}_{2} / \mathrm{H}_{2} \mathrm{O}$ canopy gas exchange system - Construction, microclimate, errors, and measurements in a barley (Hordeum vulgare L.) field. Agricultural and Forest Meteorology, 149, 214 229. 
Poni, S., Magnanini, E. and Rebucci, B. (1997) An automated chamber system for measurements of whole-vine gas exchange. HortScience, 32, 64-67.

Poni, S., Merli, M.C., Magnanini, E. et al. (2014) An improved multichamber gas exchange system for determining whole canopy water use efficiency in the grapevine. American Journal of Enology and Viticulture, 65, 268-276.

Reichstein, M., Falge, E., Baldocchi, D. et al. (2005) On the separation of net ecosystem exchange into assimilation and ecosystem respiration: review and improved algorithm. Global Change Biology, 11, 1424-1439.

Shangguan, Z., Shao, M. and Dyckmans, J. (2000) Nitrogen nutrition and water stress effects on leaf photosynthetic gas exchange and water use efficiency in winter wheat. Environmental and Experimental Botany, 44, 141-149.

Struik, P.C., Amaducci, S., Bullard, M.J. et al. (2000) Agronomy of fibre hemp (Cannabis sativa L.) in Europe. Industrial Crops and Products, 11, 107-118.

Takahashi, N., Ling, P.P. and Frantz, J.M. (2008) Considerations for accurate whole plant photosynthesis measurement. Environmental Control in Biology, 46, 91-101.

Tomás, M., Medrano, H., Pou, A. et al. (2012) Water-use efficiency in grapevine cultivars grown under controlled conditions: effects of water stress at the leaf and whole-plant level. Australian Journal of Grape and Wine Research, 18, 164-172.

Van den Boogaard, R., Kostadinova, S., Veneklaas, E. et al. (1995) Association of water use efficiency and nitrogen use efficiency with photosynthetic characteristics of two wheat cultivars. Journal of Experimental Botany, 46, 1429-1438.

Van Laar, H.H., Goudriaan, J. and van Keulen, H. (1997) SUCROS97: Simulation of crop growth for potential and water-limited production situations, as applied to spring wheat. Wageningen, The Netherlands.

Von Caemmerer, S. and Farquhar, G.D. (1981) Some relationships between the biochemistry of photosynthesis and the gas exchange of leaves. Planta, 153, 376-387.

Wright, J., Williams, M., Starr, G. et al. (2013) Measured and modelled leaf and stand-scale productivity across a soil moisture gradient and a severe drought. Plant, Cell \& Environment, 36, 467-483.

Yin, X. and Struik, P.C. (2009) $\mathrm{C}_{3}$ and $\mathrm{C}_{4}$ photosynthesis models: An overview from the perspective of crop modelling. NJAS - Wageningen Journal of Life Sciences, 57, 27-38.

Yin, X. and Struik, P.C. (2017) Can increased leaf photosynthesis be converted into higher crop mass production? A simulation study for rice using the crop model GECROS. Journal of Experimental Botany, 68, 2345-2360.

Yin, X. and Van Laar, H.H. (2005) Crop systems dynamics: an ecophysiological simulation model for genotype-by-environment interactions, Wageningen Academic, Wageningen, the Netherlands.

Yin, X., Lantinga, E.A. and Schapendonk, A.H.C.M. et al. (2003) Some quantitative relationships between leaf area index and canopy nitrogen content and distribution. Annals of Botany, 91, 893-903. 


\section{Supplementary Materials in Chapter 5}
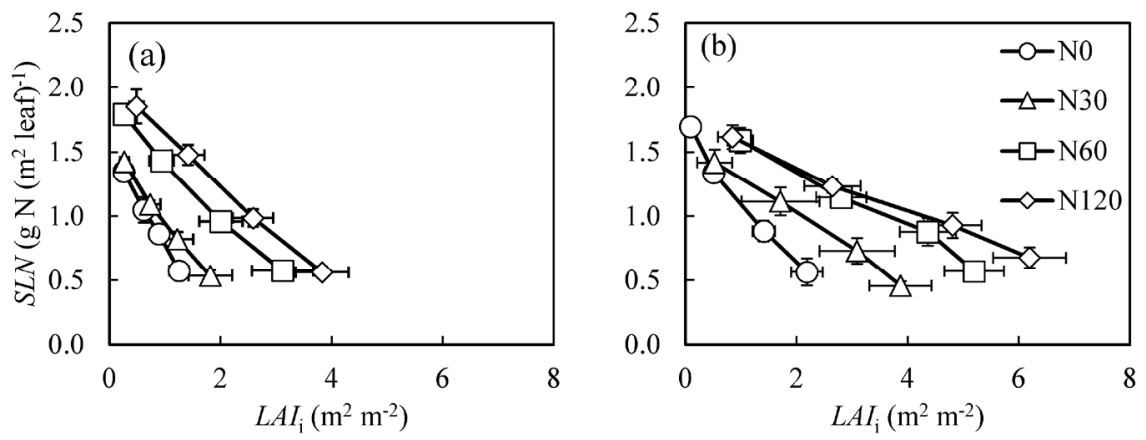

Figure S5.1 Specific leaf nitrogen (SLN) against the leaf area index at depth i measured from the top $\left(L A I_{\mathrm{i}}\right)$. Data presented was obtained at linear growth (on 17 June in panel a) and at full flowering (on 23 July in panel b) in 2015. N0, N30, N60, N120 denote nitrogen fertilization rate in 2015 at 0, 30, 60 and $120 \mathrm{~kg} \mathrm{~N} \mathrm{ha}^{-1}$, respectively.

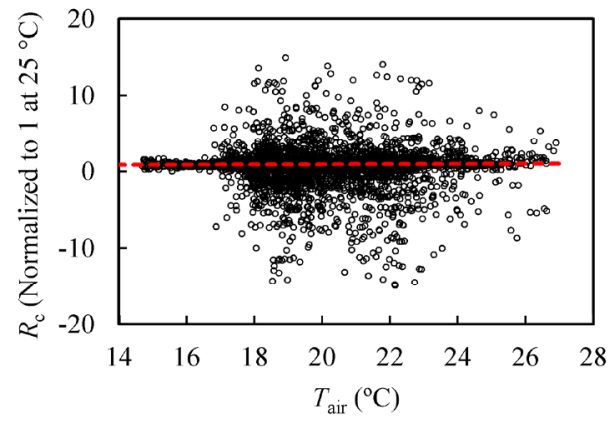

Figure S5.2 Normalized canopy respiration $\left(R_{\mathrm{c}}\right)$ in relation to air temperature $T_{\text {air }}$.
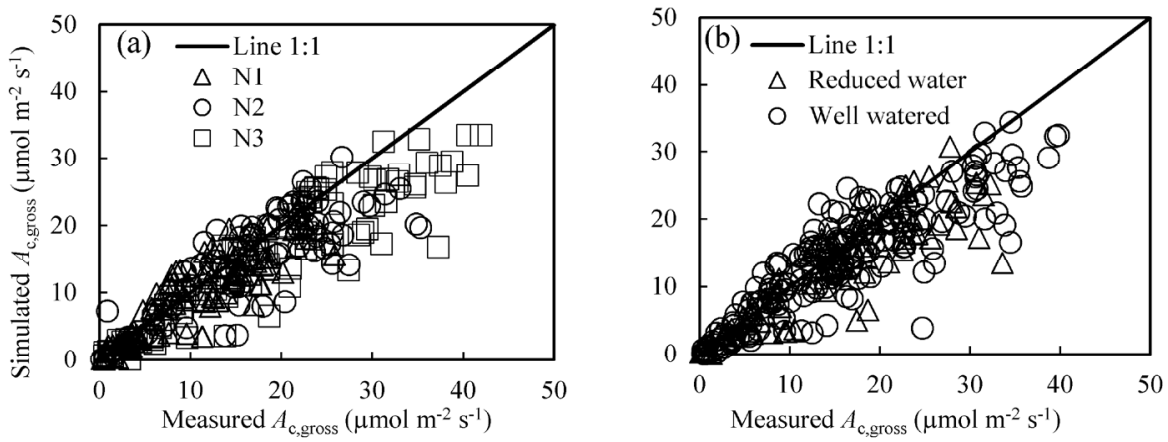

Figure S5.3 Plots of simulated $A_{\mathrm{c}, \text { gross }}$ against measured $A_{\mathrm{c}, \text { gross }}$ under different nitrogen and water regimes. Data presented were collected in CAN1. To avoid overcrowding of data points, only one tenth of the data is presented. N1, N2 and N3 denote the level of received nitrogen, see text for details. 


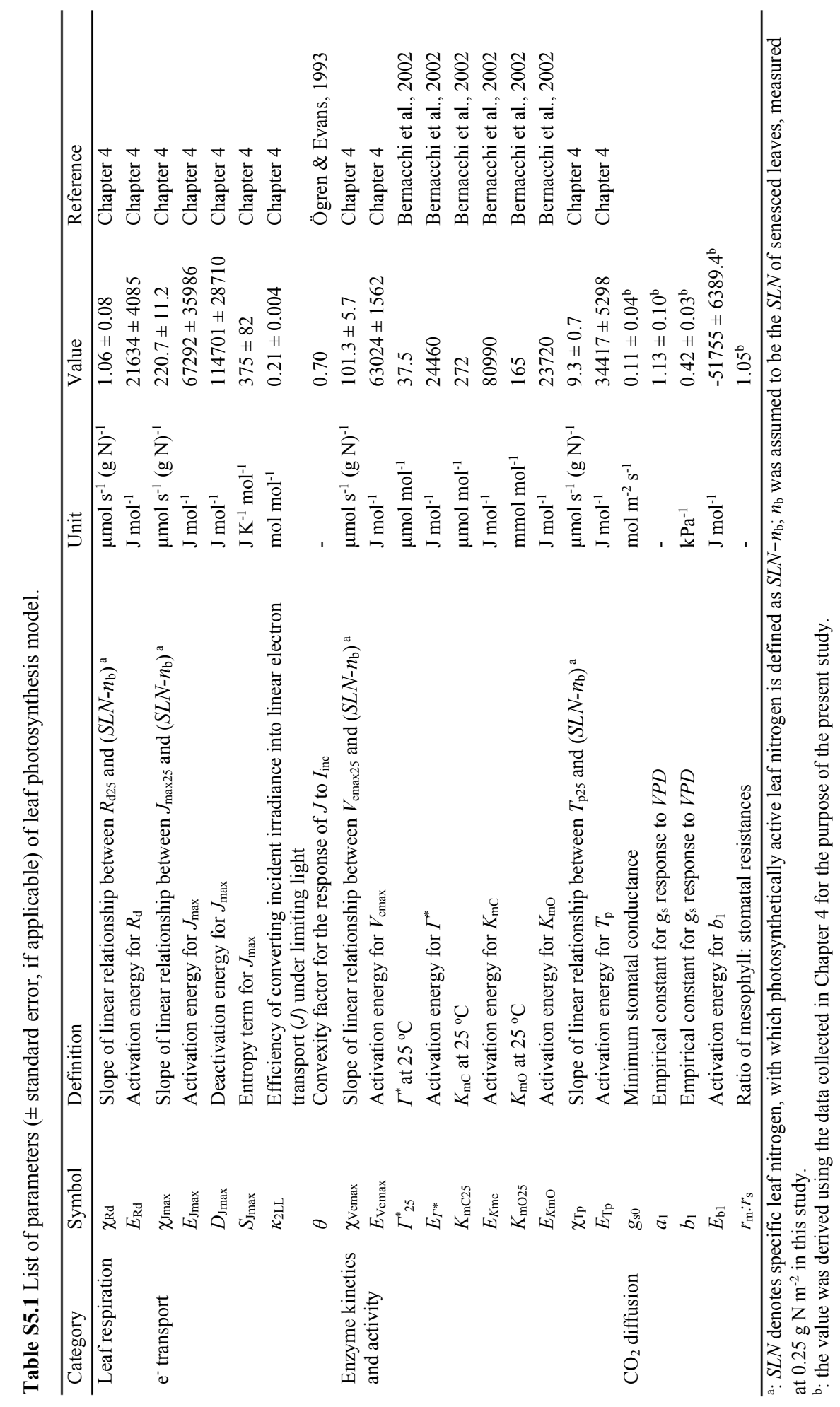




\section{Chapter 5}

Text S5.1 Summary information for the models used in Chapter 5

Leaf photosynthesis model The model of Farquhar, von Caemmerer \& Berry (1980; the FvCB model hereafter) calculates net $\mathrm{CO}_{2}$-assimilation rate $(A)$ as the minimum of the Rubisco-limited $\left(A_{\mathrm{c}}\right)$, electron $\left(\mathrm{e}^{-}\right)$transport-limited $\left(A_{\mathrm{j}}\right)$, and triose phosphate utilisation-limited $\left(A_{\mathrm{p}}\right)$ rates. The three limiting rates can be expressed collectively as:

$$
A=\frac{\left(C_{\mathrm{c}}-\Gamma_{*}\right) x_{1}}{C_{\mathrm{c}}+x_{2}}-R_{\mathrm{d}}
$$

where for $A_{\mathrm{c}}: x_{1}=V_{\mathrm{cmax}}$ and $x_{2}=K_{\mathrm{mC}}\left(1+O / K_{\mathrm{mo}}\right)$; for $A_{\mathrm{j}}: x_{1}=J / 4$ and $x_{2}=2 \Gamma_{*} ;$ and for $A_{\mathrm{p}}: x_{1}=3 T_{\mathrm{p}}$ and $x_{2}$ $=-\Gamma$. In the model, $C_{\mathrm{c}}$ and $O$ are the $\mathrm{CO}_{2}$ and $\mathrm{O}_{2}$ level, respectively, at the carboxylation sites of Rubisco, $\Gamma *$ is the $\mathrm{CO}_{2}$ compensation point in the absence of day respiration $\left(R_{\mathrm{d}}\right)$, and $J$ is the linear $\mathrm{e}^{-}$ transport rate and is described as a function of incident irradiance $I_{\text {inc }}$ as:

$$
J=\left(\kappa_{2 \mathrm{LL}} I_{\mathrm{inc}}+J_{\max }-\sqrt{\left(\kappa_{2 \mathrm{LL}} I_{\mathrm{inc}}+J_{\max }\right)^{2}-4 \theta J_{\max } \kappa_{2 \mathrm{LL}} I_{\mathrm{inc}}}\right) /(2 \theta)
$$

The sub-model for stomatal conductance for $\mathrm{CO}_{2} \operatorname{transfer}\left(g_{\mathrm{s}}\right)$ is:

$$
g_{\mathrm{s}}=g_{0}+\frac{A+R_{\mathrm{d}}}{C_{\mathrm{i}}-C_{\mathrm{i}^{*}}} f_{\mathrm{vpd}}
$$

where $g_{0}$ is the residual value of $g_{\mathrm{s}}$ when irradiance approaches to zero, $C_{\mathrm{i}^{*}}$ is the intercellular $\mathrm{CO}_{2}$ level $\left(C_{\mathrm{i}}\right)$ at which $A+R_{\mathrm{d}}=0$, and $f_{\text {vpd }}$ is the relative effect of the leaf-to-air vapour difference (VPD) on $g_{\mathrm{s}}$ (see later).

$\mathrm{CO}_{2}$ transfer from $C_{\mathrm{a}}$ (the ambient $\mathrm{CO}_{2}$ level) to $C_{\mathrm{c}}$ can be written as (Flexas et al. 2013):

$$
\begin{gathered}
C_{\mathrm{i}}=C_{\mathrm{a}}-A\left(1 / g_{\mathrm{b}}+1 / g_{\mathrm{s}}\right) \\
C_{\mathrm{c}}=C_{\mathrm{i}}-A / g_{\mathrm{m}}
\end{gathered}
$$

Combining Eqns (S5.1, S5.3-S5.5) gives a standard cubic equation for solution to $A$. The solution is complicated and not shown here but see Yin \& Struik $(2009,2017)$.

In the $g_{\mathrm{s}}$ model, Eqn (S5.3), $f_{\mathrm{vpd}}$ is the function for the effect of VPD, which may be described phenomenologically as (Yin \& Struik 2009):

$$
f_{\mathrm{vpd}}=\frac{1}{1 /\left(a_{1}-b_{1} \cdot V P D\right)-1}
$$

where $a_{1}$ and $b_{1}$ represent the $C_{\mathrm{i}}: C_{\mathrm{a}}$ ratio in water vapour saturated air and the slope of the decrease of this ratio with increasing VPD, respectively, if $g_{0}$ approaches nil. 
A number of parameters are related to leaf temperature $\left(T_{\mathrm{L}}\right)$, and some of these can be described by the Arrhenius equation normalised with respect to $25^{\circ} \mathrm{C}$ :

$$
\text { Parameter }=\text { Parameter }_{25} \cdot e^{\left(\frac{1}{298}-\frac{1}{273+T_{\mathrm{L}}}\right) \frac{E}{R}}
$$

where $R$ is the universal gas constant $\left(8.314 \mathrm{~J} \mathrm{~K}^{-1} \mathrm{~mol}^{-1}\right)$. Eqn (S5.7) applies to $R_{\mathrm{d}}, \Gamma_{*}, V_{\mathrm{cmax}}, K_{\mathrm{mC}}, K_{\mathrm{mo}}$, $T_{\mathrm{p}}$, and $b_{1}$. The temperature response of $J_{\max }$ is described by the modified Arrhenius equation:

$$
\text { Parameter }=\text { Parameter }_{25} \cdot e^{\left(\frac{1}{298}-\frac{1}{273+T_{1}}\right) \frac{E}{R}} \cdot \frac{1+e^{(S-D / 298) / R}}{1+e^{\left[S-D /\left(273+T_{1}\right)\right] / R}}
$$

The values at $25^{\circ} \mathrm{C}$ of parameters $R_{\mathrm{d}}, V_{\mathrm{cmax}}, J_{\max }$, and $T_{\mathrm{p}}$ can be further quantified as a linear function of specific leaf nitrogen $(S L N)$ above a certain base value $\left(n_{\mathrm{b}}\right)$, at or below which leaf photosynthesis is zero:

$$
\operatorname{Parameter}_{25}=\chi\left(S L N-n_{\mathrm{b}}\right)
$$

where $\chi$ have different values for different parameters.

All these parameter values were based on our previous estimate for hemp (Chapter 4) or based on the literature for those conservative parameter values in $C_{3}$ species (see Supplementary Material Table S5.1).

Leaf transpiration model When there is no water stress, photosynthesis rate largely determines the transpiration rate. The basic equation to estimate potential leaf transpiration, $E_{\mathrm{p}}$, is the Penman-Monteith equation (Monteith 1973):

$$
E_{\mathrm{p}}=\frac{s R_{\mathrm{n}}+\rho c_{\mathrm{p}} D_{\mathrm{a}} / r_{\mathrm{bh}}}{\lambda\left\{s+\gamma\left[\left(r_{\mathrm{bw}}+r_{\mathrm{sw}, \mathrm{p}}\right) / r_{\mathrm{bh}}\right]\right\}}
$$

where $R_{\mathrm{n}}$ is net absorbed radiation, $r_{\mathrm{bh}}$ and $r_{\mathrm{bw}}$ are the boundary layer resistance to heat and water transfer, respectively, $r_{\mathrm{sw}, \mathrm{p}}$ is the stomatal resistance to water transfer if there is no water stress, $D_{\mathrm{a}}$ is saturation vapour pressure deficit of the external air, $\rho c_{\mathrm{p}}$ is volumetric heat capacity of air, $\lambda$ is the latent heat of vapourisation of water, $\gamma$ is the psychrometric constant. Calculation of $r_{\mathrm{bw}}, r_{\mathrm{bh}}$, and $R_{\mathrm{n}}$ was the same as used in the GECROS model (Yin \& Struik 2017).

In the presence of water limitation, actual transpiration is assumed to be the amount of actual available water. Then, the change of actual stomatal resistance to water vapour $\left(r_{\mathrm{sw}, \mathrm{a}}\right)$ due to stomatal closure was obtained (see Eqn 5.7 in the main text), and this actual $r_{\mathrm{sw}, \mathrm{a}}$ was then used to calculate actual photosynthesis using an analytical, quadratic solution as presented by Yin \& Struik 2017). 


\section{Chapter 5}

Scaling up to canopy The sun/shade model (de Pury \& Farquhar 1997) is adopted, in which the canopy is divided into sunlit and shaded fractions and each fraction is modelled separately with a single-layer leaf model (described above).

Radiation absorbed by a canopy, $I_{\mathrm{c}}$, was determined as:

$$
I_{\mathrm{c}}=\left(1-\rho_{\mathrm{cb}}\right) I_{\mathrm{b} 0}\left(1-e^{-k_{\mathrm{b}}^{\prime} L}\right)+\left(1-\rho_{\mathrm{cd}}\right) I_{\mathrm{d} 0}\left(1-e^{-k_{\mathrm{d}}^{\prime} L}\right)
$$

where $I_{\mathrm{b} 0}$ and $I_{\mathrm{d} 0}$ are incident direct-beam and diffuse radiation above the canopy, $\rho_{\mathrm{cb}}$ and $\rho_{\mathrm{cd}}$ are canopy reflection coefficient for direct-beam and diffuse light, respectively, $k_{\mathrm{b}}^{\prime}$ and $k_{\mathrm{d}}^{\prime}$ are extinction coefficients for beam and scattered beam, diffuse and scattered diffuse lights, respectively.

Radiation absorbed by the sunlit fraction of the canopy, $I_{\mathrm{c}, \mathrm{su}}$, is given as the sum of direct-beam, diffuse, and scattered beam components (de Pury \& Farquhar 1997):

$$
\begin{aligned}
I_{\mathrm{c}, \mathrm{su}} & =(1-\sigma) I_{\mathrm{b} 0}\left(1-e^{-k_{\mathrm{b}} L}\right)+\left(1-\rho_{\mathrm{cd}}\right) I_{\mathrm{d} 0} \frac{k_{\mathrm{d}}^{\prime}\left[1-e^{-\left(k_{\mathrm{d}}^{\prime}+k_{\mathrm{b}}\right) L}\right]}{k_{\mathrm{d}}^{\prime}+k_{\mathrm{b}}} \\
& +I_{\mathrm{b} 0}\left\{\left(1-\rho_{\mathrm{cb}}\right) \frac{k_{\mathrm{b}}^{\prime}\left[1-e^{-\left(k_{\mathrm{b}}^{\prime}+k_{\mathrm{b}}\right) L}\right]}{k_{\mathrm{b}}^{\prime}+k_{\mathrm{b}}}-(1-\sigma) \frac{1-e^{-2 k_{\mathrm{b}} L}}{2}\right\}
\end{aligned}
$$

where $\sigma$ is leaf scattering coefficient.

Radiation absorbed by the shaded fraction of the canopy, $I_{\mathrm{c}, \mathrm{sh}}$, is calculated as the difference between the total radiation absorbed by the canopy, $I_{\mathrm{c}}$, and the radiation absorbed by the sunlit fraction, $I_{\mathrm{c}, \mathrm{su}}(\mathrm{de}$ Pury \& Farquhar 1997):

$$
I_{\mathrm{c}, \mathrm{sh}}=I_{\mathrm{c}}-I_{\mathrm{c}, \mathrm{su}}
$$

Eqns (S5.11-S5.13) were applied separately to visible or photosynthetically active radiation (PAR) and near-infrared radiation (NIR), because they have different values for $\sigma, \rho_{\mathrm{cb}}, \rho_{\mathrm{cd}}, k_{\mathrm{b}}, k_{\mathrm{b}}^{\prime}$ and $k_{\mathrm{d}}^{\prime}$. The model assumes that half of the incident solar radiation is in the visible and other half is in the NIR waveband. All these coefficients are described as in GECROS (Yin \& Struik 2017).

Many photosynthetic parameters are related to $S L N$, and $r_{\mathrm{bh}}$ and $r_{\mathrm{bw}}$ are related to wind speed $u$. Both $S L N$ and $u$ change with the depth of the canopy. To estimate these parameters for the entire canopy, and for the sunlit and shaded fractions of the canopy, photosynthetically active leaf nitrogen has to be scaled up. Assuming an exponential profile for the vertical decline of SLN in the canopy (Supplementary Material Figure S5.1), photosynthetically active nitrogen for the entire canopy $\left(N_{\mathrm{cp}}\right)$, for the sunlit 
fraction of the canopy $\left(N_{\mathrm{cp}, \mathrm{su}}\right)$ and for the shaded fraction of the canopy $\left(N_{\mathrm{cp}, \mathrm{sh}}\right)$, can be estimated by (Yin \& van Laar 2005):

$$
\begin{gathered}
N_{\mathrm{cp}}=S L N_{0}\left(1-e^{-k_{\mathrm{n}} L}\right) / k_{\mathrm{n}}-n_{\mathrm{b}} L \\
N_{\mathrm{cp}, \mathrm{su}}=S L N_{0}\left[1-e^{-\left(k_{\mathrm{n}}+k_{\mathrm{b}}\right) L}\right] /\left(k_{\mathrm{n}}+k_{\mathrm{b}}\right)-n_{\mathrm{b}}\left(1-e^{-k_{\mathrm{b}} L}\right) / k_{\mathrm{b}} \\
N_{\mathrm{cp}, \mathrm{sh}}=N_{\mathrm{cp}}-N_{\mathrm{cp}, \mathrm{su}}
\end{gathered}
$$

where $S L N_{0}$ is the SLN for uppermost leaves, $k_{\mathrm{n}}$ is the leaf nitrogen extinction coefficient in the canopy (see the main text). With a similar logic, boundary-layer conductance can be scaled up to the canopy level.

\section{References used in Text S5.1 and Table S1 not already cited in main text}

Bernacchi, C.J., Portis, A.R., Nakano, H. et al. (2002) Temperature response of mesophyll conductance. Implications for the determination of Rubisco enzyme kinetics and for limitations to photosynthesis in vivo. Plant Physiology, 130, 1992-1998.

de Pury, D. and Farquhar, G. (1997) Simple scaling of photosynthesis from leaves to canopies without the errors of big-leaf models. Plant, Cell \& Environment, 20, 537-557.

Farquhar, G.D., von Caemmerer, S. and Berry, J.A. (1980) A biochemical model of photosynthetic $\mathrm{CO}_{2}$ assimilation in leaves of $\mathrm{C}_{3}$ species. Planta, 149, 78-90.

Flexas, J., Niinemets, Ü., Gallé, A. et al. (2013) Diffusional conductances to $\mathrm{CO}_{2}$ as a target for increasing photosynthesis and photosynthetic water-use efficiency. Photosynthesis research, 117, $45-59$.

Monteith, J.L. (1973) Principles of environmental physics. Edward Arnold, London, UK.

Ögren, E. and Evans, J. (1993) Photosynthetic light-response curves. Planta, 189, 182-190. 

Chapter 6

General discussion 


\title{
Chapter 6
}

\begin{abstract}
This chapter first provides a brief summary of the main findings presented in the previous chapters. Subsequently, in view of these findings and information from the literature, the potential of hemp for the sustainable development of the agricultural bio-economy is discussed. In the final section, implications for future research are discussed, focusing on the need for crop modelling to develop strategies to optimise cultivation and breeding in hemp.
\end{abstract}




\subsection{Introduction}

The multiple societal challenges such as climate change, natural resource scarcity and environmental pollution have fuelled interests in sustainable development of the agricultural bio-economy. In Chapter 1 of this thesis I argued that hemp may be a multi-purpose crop that fits well in the context of sustainable bio-economy. However, hemp remains poorly developed because hemp production declined in the last century and was displaced largely by cotton and synthetic fibres. Therefore, the EC funded project Multihemp (www.multihemp.eu) was launched in 2012 with the aim to have significant impacts from both scientific and economic aspects, by building on fundamental scientific understanding from the development of hemp raw materials through to providing the basis for innovations in the areas of crop breeding, agronomy and harvesting, and biorefinery. Within the framework of Multihemp, this thesis reports key research findings on the agronomy of hemp production and the photosynthesis physiology of hemp's resource-use efficiencies (RUE). This chapter broadens the discussion of preceding chapters to the overall achievements and to critical issues for bio-economically sustainable hemp production. Specifically, the following sections are presented: (1) advances made in agronomic aspects; (2) insights into photosynthesis physiology of hemp; (3) hemp production for the development of a sustainable bio-economy; and (4) implications for future research: crop modelling to develop strategies for optimisation of cultivation and breeding in hemp.

\subsection{Advances made in agronomic aspects}

Driven by the shift of a rapidly expanding market for hemp seeds coupled with lower-quality fibre requirements for innovative biomaterials, harvesting hemp for both stems and seeds is now a common practice in Europe while crop management strategies for the dual-purpose hemp cultivation have not been properly addressed so far. To support the dual-purpose cultivation of hemp, this thesis brought new information on the agronomy of hemp production, paying attention to cultivar choice (Chapter 2) and management of planting density and nitrogen fertilization (Chapter 3).

The number of available hemp cultivars has risen rapidly since the 1990s, when hemp cultivation was progressively authorized throughout the EU. Currently, there are more than 60 hemp cultivars registered in the common catalogue of varieties of agricultural plant species (https://ec.europa.eu/). Given that these cultivars differ in many traits related either to quantity or to quality of their products, and that large environmental effects on the yields of stems and 


\section{Chapter 6}

seeds have been widely reported (Cosentino et al., 2013; Faux et al., 2013; Höppner \& MengeHartmann, 2007; Struik et al., 2000), to choose a cultivar that is suitable for a particular environment is of paramount importance to the success of hemp cultivation. In Chapter 2, productivity of 14 commercial cultivars was investigated under contrasting European environments. The results showed that hemp stem yield was strictly related to the duration of the vegetative phase while seed yield was low in the late flowering cultivars (Figures 2.4, 2.6). Thus, for dual-purpose hemp production, a cultivar that gives a long vegetative phase while leaves enough time for seed growth is preferable. In addition, the results also suggested that genotype-specific characteristics, such as sex type and stem fibre content, are important to maximize economic return of hemp cultivation. A monoecious cultivar with a high bark fibre content is preferable because bark fibre is considered more valuable than wood core and the male plants of dioecious cultivar senesce soon after flowering that causes biomass loss and heterogeneous quality.

The duration of the vegetative phase of a hemp crop is mainly affected by genotype and environment (Figure 2.2). Hemp development rate increases with increasing temperature between a base and a cut-off temperature, and as a short-day plant, hemp development rate also increases with decreasing day-length during the photoperiod-sensitive phase (Amaducci et al., 2008a). Thus, a few studies have aimed at predicting hemp flowering time using genotypespecific parameters, temperature and photoperiod (Cosentino et al., 2012; Amaducci et al., 2008a; Lisson et al., 2000d). Results of this thesis showed that the phenological model proposed by Amaducci et al. (2008a) renders a good estimation of hemp flowering time under contrasting environments (Figure 2.3). Such a model could, therefore, facilitate cultivar choice basing on historical meteorological information and genotype-specific parameter values.

Planting density is an important factor for growing hemp as it relates to the quantity of seed input and may affect the quantity and quality of stem and seed yields (see review by Amaducci et al., 2015). In Chapter 3, a series of planting densities ranging from 30 plants $\mathrm{m}^{-2}$ to 240 plants $\mathrm{m}^{-2}$ were tested for their effects on stem and seed yields under contrasting environments. The results showed that increasing planting density resulted in thin and short stems (Figure 3.5) while it had limited effect on the yields of stem and seed (Figures 3.1, 3.2). Slender stems contain a higher percentage of long fibre (Westerhuis et al., 2009) and require less energy for their mechanical processing (Khan et al., 2010) that is desirable for fibre targeted production (Westerhuis et al., 2009). But the pursuit of stem slenderness through a very dense crop is not encouraged because it not only increases the risk of lodging but also results in high fibre loss 
during processing (Amaducci et al., 2008b; Amaducci et al., 2005). On the other hand, planting at extremely low density could result in reduction in biomass yield due to delayed canopy closure and weed competition (authors' experience). The optimum planting density for dualpurpose hemp cultivation could be set at 90-150 plants $\mathrm{m}^{-2}$.

Optimization of crop nitrogen fertilization is a key issue for sustainable development of the agricultural bio-economy. The responses of hemp crops to nitrogen fertilization under contrasting environments were tested in Chapter 3. While the yields of stem and seed were limited by insufficient nitrogen supply (Figures 3.1, 3.2), this effect varied considerably, depending on soil fertility. In line with previous studies (Amaducci et al., 2002; Struik et al., 2000), the effect of nitrogen fertilization on hemp stem and seed yields did not interact with planting density.

There were a number of studies that addressed the effect of nitrogen fertilization on hemp productivity (Campiglia et al., 2017; Finnan \& Burke, 2013). However, none of them has quantified the nitrogen demand of this crop. Chapter 3 filled this knowledge gap up by analysing the dynamics of hemp nitrogen uptake and then determining a critical nitrogen $\left(N_{\text {critical }}\right)$ dilution curve for hemp crop (Figure 3.7). The $N_{\text {critical }}$ of hemp is comparable with that of linseed but indicates a lower nitrogen requirement than found for other $\mathrm{C}_{3}$ crops for producing the same biomass, such as rice (ssp. japonica; Ata-Ul-Karim et al., 2013) and cotton (Xiaoping et al., 2007). This result confirms the widely reported low fertilization requirement of the hemp crop (Finnan \& Burke, 2013; Struik et al., 2000). Moreover, the presented $N_{\text {critical }}$ dilution curve is a useful tool to quantify crop nitrogen status (Lemaire et al., 2008). Based on this curve a nitrogen nutrition index $(N N I)$ can be calculated as the ratio of $N: N_{\text {critical, where }} N$ is actual nitrogen concentration in aboveground biomass. $N N I<1$ indicates nitrogen is limiting while $N N I>1$ indicates nitrogen is sufficient (Lemaire et al., 2008).

\subsection{Insights into photosynthesis physiology of hemp}

This section focuses on hemp's RUE at leaf and canopy levels, basing on the assessments of its photosynthetic capacity conducted in Chapters 4 and 5. It is argued that photosynthesis is central for interpreting biomass production in response to genotype, environment, management interactions and hemp's high RUE.

While the mechanisms of leaf photosynthesis have been studied in detail for major crops, those of hemp have rarely been investigated. In Chapter 4, based on the $\mathrm{C}_{3}$ leaf photosynthesis 


\section{Chapter 6}

model of Farquhar et al. (1980), the responses of hemp photosynthesis to leaf nitrogen status and environmental factors were analysed following the procedures described in Yin et al. (2009), and a complete set of photosynthetic parameters were made available for hemp (Figure 4.6). These parameters provide fundamental information for the understandings of hemp's RUE at leaf level (Figure 4.7), and for the modelling of hemp growth. However, caution is needed when modelling photosynthesis rate using the value of parameters derived from different environments. In this thesis, it was found that the effects of leaf nitrogen and temperature on almost all photosynthesis parameters were consistent at different leaf positions and among different growth environments. The exception is the effect on the efficiency of converting incident irradiance into linear electron transport under limiting light $\left(\kappa_{2} \mathrm{LL}\right)$, and the value of $\kappa_{2} \mathrm{LL}$ was higher for plants grown in the glasshouse than for those grown outdoors (Figure 4.6).

Based on the results obtained in Chapter 4, the leaf photosynthesis of hemp was scaled up to canopy level in Chapter 5 with the aim to assess water-use efficiency (WUE) and nitrogen-use efficiency $(N U E)$ in relation to levels of water and nitrogen supply. The results showed that the $W U E_{\mathrm{c}}$ (defined as the ratio of gross canopy photosynthesis to canopy transpiration) and the $N U E_{\mathrm{c}}$ (the ratio of the gross canopy photosynthesis to canopy leaf-N content) decreased with an increase in nitrogen-input levels; these effects were largely determined by the nitrogen effect on $L A I$ (Figure 5.10). Water stress resulted in an increase in $W U E_{\mathrm{c}}$ but a decrease in $N U E_{\mathrm{c}}$. The effect of short-term water stress was reflected by stomatal regulation, whereas the long-term stress increased leaf senescence, decreased $L A I$ but retained total canopy nitrogen content. The lost $L A I$ coupled with the increased average leaf-nitrogen content resulted in a further increase in $W U E_{\mathrm{c}}$ (Figure 5.10). These results not only imply that hemp's final biomass yield and nitrogen use efficiency may be restricted by water limitation during growth (Cosentino et al., 2013), but also suggest that crop models should take stress-induced senescence into account in addition to stomatal effects if crops experience a prolonged water stress during growth.

An innovative aspect in Chapter 5 of this thesis is that a multi-chamber system (Poni et al., 2014) was used to determine hemp canopy gas exchange. To date, the canopy gas exchange rate is mainly assessed by micro-meteorological methods or by means of canopy-enclosure chamber systems. The micro-meteorological techniques such as the eddy covariance or Bowen ratio methods enable gas flux measurements without disturbing canopy micro-environment, and they are often applied to large homogeneous areas but do not suit for plot/pot-sized experiments (Jones, 2013). In contrast, the canopy chamber technique enables to determine precisely canopy gas exchange at a relatively small scale (Müller et al., 2009; Müller et al., 2005) that is a useful 
tool to assess crop responses to nitrogen deficiency and water shortage at canopy scale. However, in line with previous studies (Müller et al., 2009; Poni et al., 1997), the presence of the chamber wall had a significant effect on the micro-environment within the chambers (Figure 5.3) due to photosynthetic $\mathrm{CO}_{2}$ uptake, the greenhouse effect and transpiration. Results of model analysis showed that the micro-environment conditions within the chamber had large effects on canopy gas exchange and this effect were larger in the chambers with higher fertilization rate and lower water supply (Table 5.4). Therefore, a model based approach was applied to normalize measurements within different chambers to avoid any confounding effect due to the differences in chamber in micro-environmental factors (Chapter 5).

\subsection{Hemp production for the development of a sustainable bio-economy}

Hemp can be considered an exemplary crop to develop and promote the concept of bioeconomy (Fike, 2016; Amaducci et al., 2015; Finnan \& Styles, 2013) as it produces a high and valuable biomass yield while requiring low inputs. This section assesses the productivity of hemp crops and its environmental effects.

\subsubsection{The productivity of hemp}

The high productivity of hemp is confirmed in this thesis (Table 2.8). The maximum stem yield measured in this study was $22.7 \mathrm{Mg} \mathrm{ha}^{-1}$. This yield was slightly higher than the maximum stem yield reported in a previous work that compared hemp yield potential across Europe (Struik et al., 2000). Results of the comprehensive field experiments conducted in the present study and that in the literature suggested that typical hemp stem yield were in the broad range of about 5$15 \mathrm{Mg} \mathrm{ha}^{-1}$ (Aubin et al., 2016; Finnan \& Burke, 2013; Höppner \& Menge-Hartmann, 2007; Struik et al., 2000). The observed hemp stem yields were likely limited, to some extent, by the production of seeds in many studies. Mostly cultivated for harvesting stem and seeds simultaneously, Carus et al. (2013) and Carus \& Sarmento (2016) reported that the industrial yield of hemp stem across Europe is on average $7 \mathrm{Mg} \mathrm{ha}^{-1}$. In Canada, where cultivation of hemp is mainly for harvesting seeds, Vera et al. (2010) and Aubin et al. (2016) reported the stem yields of 4-7 $\mathrm{Mg} \mathrm{ha}^{-1}$.

Earlier studies had revealed that light-use efficiency (LUE) of hemp was low after flowering (De Meijer et al., 1995). Struik et al. (2000) reported that hemp crop had LUE at 2.2-2.3 $\mathrm{g} \mathrm{MJ}^{-}$

${ }^{1}$ (on the basis of intercepted photosynthetically active radiation) during vegetative phase while this value decreased to $1.0-1.1 \mathrm{~g} \mathrm{MJ}^{-1}$ after flowering. Van der Werf et al. (1994) analysed the 
effect of flowering on hemp LUE and pointed out that a minor part of the post-flowering decline in the LUE of hemp can be accounted for by larger losses of shed leaves and increased growth respiration due to the synthesis of fat and protein in the seed. The results of this thesis suggested that a major part of the decline of LUE after flowering is likely caused by reduction of crop gross photosynthesis due to senescence of the leaves (Figure 4.2).

The yields of hemp seed ranged from none up to $2.3 \mathrm{Mg} \mathrm{ha}^{-1}$ in this thesis. Cherney \& Small (2016) pointed out that the present productivity of hemp seeds, about $1.0 \mathrm{Mg} \mathrm{ha}^{-1}$ under good conditions, occasionally $1.5-2.0 \mathrm{Mg} \mathrm{ha}^{-1}$, is not yet sufficient for the crop to be competitive with major oilseeds. However, the reported yields of hemp seed were, to some extent, underestimated due to shattering prior to and during harvesting as a result of heterogeneity in inflorescence maturity (Figure 6.1), particularly if harvested outside the optimal harvest time windows, ranging between $50 \%$ and $70 \%$ maturity. Another important reason for the underestimation of the hemp seed yield was bird predation. Bird predation can cause a significant loss of seed but measures of prevention such as using nets or bird scarers are hardly economically successful. At present, losses up to $30 \%$ of the hemp seed yields are not uncommon (Cherney \& Small, 2016). Therefore, great improvement of hemp seed yield may be achieved through reducing loss due to shattering. To this end, breeder could select for shattering resistant cultivars while technical engineering could improve harvesting machines.
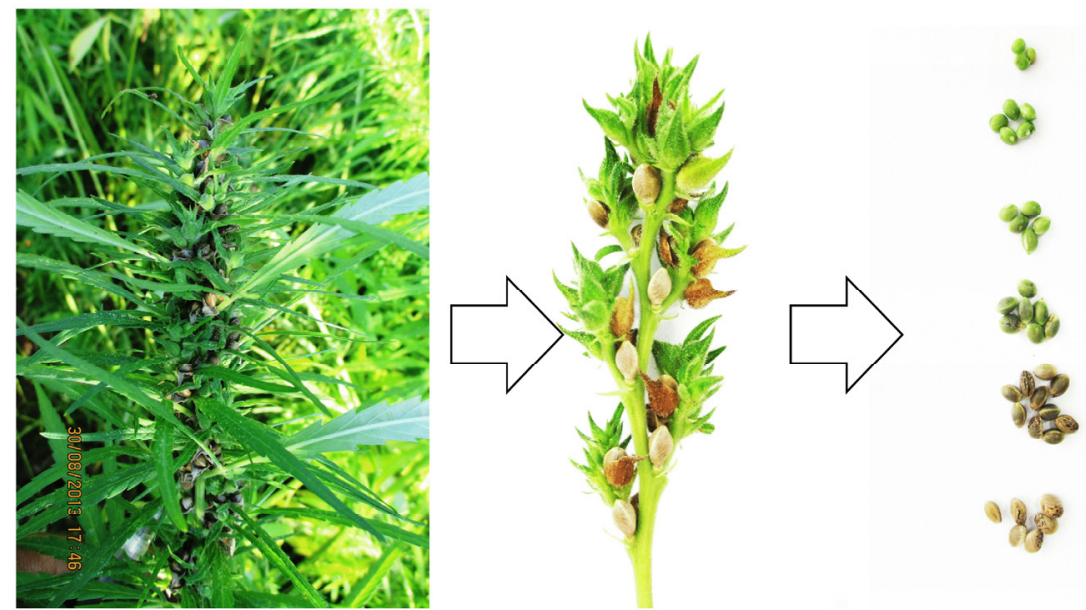

Figure 6.1 Heterogeneity inflorescence maturity of hemp. From left to right: inflorescence of individual plant, a branch on the inflorescence (small leaves have been removed), seeds in the same branch. 


\subsubsection{The environmental effects of hemp cultivation}

Hemp is advantageous over other annual crops in terms of their impact on environment. Firstly, as discussed previously, hemp has a high nitrogen-use efficiency and requires low nitrogen inputs (Chapters 3, 4). In addition, hemp was generously fertilized with manure in the past, and is naturally adapted to employing mammalian manure as fertilizer. It, therefore, has the potential of efficiently employing stocks of livestock manure. A study carried out within the framework of Multihemp to compare the carbon footprint of flax, hemp, jute and kenaf for the natural fibres consumed in Europe (Barth \& Carus, 2015) suggested that use of organic fertilizer for hemp cultivation could minimize greenhouse gas emissions that puts hemp ahead of the other crops.

Secondly, hemp cultivation is virtually free of herbicides and pesticides, which may reduce biodiversity. Hemp generally has few problems of weed due to its ability to outcompete most weed species under favourable conditions. However, several weeds may occur in hemp field when canopy closure is limited by insufficient nutrition supply, low planting density, preflowering, drought, etc. The species of weeds differ among environments. Legros et al. (2013) identified six main weed species in a French field, including weeds from the Sinapis and Chenopodium genera. In Northern Italy, Echinochloa crus-galli occurred dominantly and it caused significant yield loss in our study in the field trials carried out in 2014 (Chapter 3). Hemp can also be affected by parasitic and climbing weeds. Parasitic plants, such as broomrape (Orobanche L.) and dodder (Cuscuta L.), can cause hemp plants to die before maturity and reduce productivity. Although some form of weed control may be needed to prevent economic losses, no herbicide is currently registered for use on hemp. Different trials carried out in France (Legros et al., 2013) showed that hemp crops are sensitive to herbicides, especially when they are applied before sowing or immediately after emergence. It is common to see several bugs on the inflorescence of hemp plants and some diseases have been identified (Van der Werf et al., 1995). A list of management practices and biological control agents for hemp pests and diseases have been made available (McPartland et al., 2000) while some do not consider the pests and diseases a problem of economic consequence (Desanlis et al., 2013).

Thirdly, hemp has potential to improve soil quality. Hemp has a deep root system (Amaducci et al., 2008c) that decays rapidly to provide both soil aeration and fertilization for the subsequent crops. Gorchs et al. (2017) reported that, after growing hemp, the yield of subsequent wheat increased by $1368 \mathrm{~kg} \mathrm{ha}^{-1}$ and $155 \mathrm{~kg} \mathrm{ha}^{-1}$ in the subsequent first and second years, respectively, to the wheat monoculture. Moreover, several studies suggested that hemp 
has the capability to decontaminate soils that are polluted with heavy metals (Angelova et al., 2004; Linger et al., 2002).

\subsection{Implication on future research: crop modelling to develop strategies for optimisation of cultivation and breeding in hemp}

In order to favour the need of high-quality hemp raw materials, field trials have undoubtedly been considered the most direct ways in understanding the effects of genotype-by-environmentby-management interactions $(\mathrm{G} \times \mathrm{E} \times \mathrm{M})$ on hemp production. However, except being costly and labour intensive, field trials are easily affected by many undesirable factors due to the complicated field conditions (Amaducci et al., 2000). Since the pioneering work on crop modelling by De Wit (1959), crop growth models have been applied extensively in support of the theoretical research, yield prediction, and decision making in agriculture (Yin \& Struik, 2010) and examples have been reported widely (Keating et al., 2003). As exemplified by the successful applications for staple crops (Bouman et al., 2007; Aggarwal et al., 1997), crop growth models that are based on physiological mechanisms, capture crop growth and development processes in response to management, genotypic, soil and climate factors, have a potential to design strategies for improving hemp production. Furthermore, recent studies successfully integrated the genetic information into advanced crop models (Gu et al., 2014; Prudent et al., 2011), showing the possibility of using crop growth models to assist breeding. For these reasons, developing a heuristic hemp growth model that is based on fundamental understanding of the effects of $\mathrm{G} \times \mathrm{E} \times \mathrm{M}$ on hemp biomass production is necessary to develop strategies for optimization of cultivation and breeding in hemp.

Several attempts have been made for modelling hemp production. For estimating the potential of hemp as a crop for sustainable farming systems in temperate regions, based on experimental results, Van der Werf et al. (1996) described the first hemp growth model (LINTUL-hemp) on the basis of "light interception and utilization" concept. The LINTULhemp focused on the assessment of hemp potential production, ignored the larger variation of hemp growth due to the changing environmental variables and different genotypes, and therefore has a limited value for analysing hemp production in response to $\mathrm{G} \times \mathrm{E} \times \mathrm{M}$ under field conditions. Inspired by the criteria of Carberry et al. (1992) for kenaf (Hybiscus cannabinus L.), a short-day plant similar to hemp, Lisson et al. (2000a-d) quantified hemp phenology and LAI in response to environmental variables and plant density and developed a model called APSIM-Hemp for simulating the growth, development and yield of hemp in response to 
climatic, soil and management. These studies, to some extent, explored the hemp model development. However, they were developed on the basis of limited, largely agronomic perspectives and observations. Many summary concepts (e.g. LUE) were used in the description of complicated physiological mechanisms. Important yield relevant factors were ignored (e.g., nitrogen application). Therefore, these models may not play a heuristic role or correctly predict each process or crop growth over a wide range of conditions. A common view (e.g., Boote et al., 2013) is that accurate modelling of $\mathrm{G} \times \mathrm{E} \times \mathrm{M}$ would require more mechanistic approaches.

In this thesis, advances have been made in understanding the physiology of growth and development processes of hemp. Some of the processes were quantified at the biochemical level, e.g., leaf photosynthesis (Chapter 4). Corresponding simulation models were used to integrate physiological information from leaf to canopy scales (Chapter 5). These results provide an excellent opportunity to parameterise a generic crop growth model (i.e., Genotype-byEnvironment interaction on CROp growth Simulator, GECROS) (Yin \& van Laar, 2005; Yin $\&$ Struik 2017) for hemp, as analyses described in Chapters 4 and 5 followed exactly the model methodology as used in the GECROS model. In addition, GECROS simulates the growth and development of the crop, and generates phenotypes for a multitude of traits, based on concepts of the interaction and feedback mechanisms among various contrasting components of crop growth, carbon-nitrogen interaction in particular (Yin \& Struik, 2010). If successful, such a growth modelling could facilitate the development strategies for optimisation of cultivation and breeding in hemp, as exemplified by the successful applications in major crops (Gu et al., 2014, Khan et al., 2014; Biernath et al., 2011).

\subsection{Concluding remarks}

With the aim of providing novel information to support cultivation of hemp, particularly dualpurpose (stems + seeds) cultivation in Europe, in this thesis, comprehensive studies have been conducted on the agronomy of hemp production and photosynthesis physiology of hemp's RUE. Hemp has a great potential for dual-purpose production. The cultivation of dual-purpose hemp is not difficult. A monoecious cultivar that has high content of bark fibre in stem and gives a long vegetative phase while leaves enough time for seed growth should be chosen. The planting density should be set at 90-150 plants $\mathrm{m}^{-2}$. Nitrogen fertilization depends on soil fertility but generally $60 \mathrm{~N} \mathrm{ha}^{-1}$ is sufficient across most European conditions.

Hemp is one of the very few crops that have the capacity to be cultivated on non-organic farms with few or no agrochemicals and have positive effects on soil conditions. Therefore, it 
can be concluded that hemp has the right profile to fit in the concept of sustainable development of the agricultural bio-economy. Advances have been made in understanding the physiology of hemp growth and development processes. These understandings provide essential knowledge for developing a generic hemp growth model that can facilitate to develop strategies for optimisation of cultivation and breeding in hemp.

\section{References}

Aggarwal, P., Kropff, M., Cassman, K. et al. (1997) Simulating genotypic strategies for increasing rice yield potential in irrigated, tropical environments. Field Crops Research, 51, 5-17.

Amaducci, S., Amaducci, M.T., Benati, R. et al. (2000) Crop yield and quality parameters of four annual fibre crops (hemp, kenaf, maize and sorghum) in the North of Italy. Industrial Crops and Products, 11, 179-186.

Amaducci, S., Colauzzi,, M. and Bellocchi G. (2008a) Modelling post-emergent hemp phenology (Cannabis sativa L.): Theory and evaluation. European Journal of Agronomy, 28, 90-102.

Amaducci, S., Errani, M. and Venturi, G. (2002) Response of hemp to plant population and nitrogen fertilisation. Italian Journal of Agronomy, 6, 103-111.

Amaducci, S., Pelatti, F. and Bonatti, P.M. (2005) Fibre development in hemp, (Cannabis sativa L.) as affected by agrotechnique: preliminary results of a microscopic study. Journal of Industrial Hemp, 10, 31-48.

Amaducci, S., Scordia, D., Liu, F. et al. (2015) Key cultivation techniques for hemp in Europe and China. Industrial Crops and Products, 68, 2-16

Amaducci, S., Zatta, A., Pelatti, F. et al. (2008b) Influence of agronomic factors on yield and quality of hemp (Cannabis sativa L.) fibre and implication for an innovative production system. Field Crops Research, 107, 161-169.

Amaducci, S., Zatta, A., Raffanini, M. et al. (2008c) Characterisation of hemp (Cannabis sativa L.) roots under different growing conditions. Plant and Soil, 313, 227-235.

Angelova, V., Ivanova, R., Delibaltova, V. et al. (2004) Bio-accumulation and distribution of heavy metals in fibre crops (flax, cotton and hemp). Industrial Crops and Products, 19, 197-205.

Ata-Ul-Karim, S.T., Yao, X., Liu, X. et al. (2013) Development of critical nitrogen dilution curve of Japonica rice in Yangtze River Reaches. Field Crops Research, 149, 149-158.

Aubin, M.P., Seguin, P., Vanasse, A. et al. (2016) Evaluation of eleven industrial hemp cultivars grown in eastern Canada. Agronomy Journal, 108, 1972-1980.

Barth, M. and Carus, M. (2015) Carbon Footprint and Sustainability of Different Natural Fibres for Biocomposites and Insulation Material. Nova-Institute, Hürth, Germany. Available at (2017, November 6): http://eiha.org/media/2017/01/15-04-CarbonFootprint-of-Natural-Fibres-nova1.pdf 
Biernath, C., Gayler, S., Bittner, S. et al. (2011) Evaluating the ability of four crop models to predict different environmental impacts on spring wheat grown in open-top chambers. European Journal of Agronomy, 35, 71-82.

Boote, K.J., Jones, J.W., White, J.W. et al. (2013) Putting mechanisms into crop production models. Plant, Cell \& Environment, 36, 1658-1672.

Bouman, B.M., Feng, L., Tuong, T.P. et al. (2007) Exploring options to grow rice using less water in northern China using a modelling approach: II. Quantifying yield, water balance components, and water productivity. Agricultural Water Management, 88, 2333.

Campiglia, E., Radicetti, E. and Mancinelli, R. (2017) Plant density and nitrogen fertilization affect agronomic performance of industrial hemp (Cannabis sativa L.) in Mediterranean environment. Industrial Crops and Products, 100, 246-254.

Carberry, P., Muchow, R., Williams, R. et al. (1992) A simulation model of kenaf for assisting fibre industry planning in northern Australia. I. General introduction and phenological model. Australian Journal of Agricultural Research, 43, 1501-1513.

Carus, M., Karst, S., Kauffmann, A. et al. (2013) The European hemp industry: Cultivation, processing and applications for fibres, shivs and seeds. European hemp Industry Association. Available at (2017, November 29): http://eiha.org/media/2014/10/13-06European-Hemp-Industry.pdf

Carus, M. and Sarmento, L. (2016) The European hemp industry: cultivation, processing and applications for fibres, shivs and seeds. Industrial Hemp Association (EIHA), Hürth, Germany, European. Available at (2017, November 29): http://eiha.org/media/2016/05/16-05-17-European-Hemp-Industry-2013.pdf

Cherney, J. and Small, E. (2016) Industrial hemp in North America: production, politics and potential. Agronomy, 6, 58-82.

Cosentino, S.L., Riggi, E., Testa, G. et al. (2013) Evaluation of European developed fibre hemp genotypes (Cannabis sativa L.) in semi-arid Mediterranean environment. Industrial Crops and Products, 50, 312-324.

Cosentino, S.L., Testa, G. and Scordia, D. (2012) Sowing time and prediction of flowering of different hemp (Cannabis sativa L.) genotypes in southern Europe. Industrial Crops and Products, 37, 20-33.

De Meijer, W.J.M., Van der Werf, H.M.G., Mathijssen E.W.J.M. et al. (1995) Constraints to dry matter production in fibre hemp (Cannabis sativa L.). European Journal of Agronomy, 4, 109-117.

De Wit, C.T. (1959) Potential photosynthesis of crop surfaces. Netherlands Journal of Agricultural Science, 7, 141-149.

Desanlis, F., Cerruti, N., Warner, P. et al. (2013) Hemp agronomics and cultivation. In Hemp: industrial production and uses (eds Allegret, S., Bouloc, P. and Arnaud, L.), pp. 98-124. CPi Group Ltd, Croydon, UK.

Farquhar, G.D., Von Caemmerer, S. and Berry, J.A. (1980) A biochemical model of photosynthetic $\mathrm{CO}_{2}$ assimilation in leaves of $\mathrm{C}_{3}$ species. Planta, 149, 78-90. 
Faux, A.M., Draye, X. and Lambert, R. (2013) The relationship of stem and seed yields to flowering phenology and sex expression in monoecious hemp (Cannabis sativa L.). European Journal of Agronomy, 47, 11-22.

Fike, J (2016) Industrial hemp: renewed opportunities for an ancient crop. Critical Reviews in Plant Sciences, 35, 406-424.

Finnan, J. and Burke, B. (2013) Nitrogen fertilization to optimize the greenhouse gas balance of hemp crops grown for biomass. GCB Bioenergy, 5, 701-712.

Finnan, J. and Styles, D. (2013) Hemp: A more sustainable annual energy crop for climate and energy policy. Energy Policy, 58, 152-162.

Gorchs, G., Lloveras, J., Serrano, L. et al. (2017) Hemp yields and its rotation effects on wheat under rainfed mediterranean conditions. Agronomy Journal, 109, 1551-1560.

Gu, J., Yin, X., Stomph, T.J. et al. (2014) Can exploiting natural genetic variation in leaf photosynthesis contribute to increasing rice productivity? A simulation analysis. Plant Cell \& Environment, 37, 22-34.

Hikosaka, K., Kumagai, T.O. and Ito, A. (2016) Modeling canopy photosynthesis. In: Canopy Photosynthesis: From Basics to Applications. (eds Hikosaka, K., Niinemets, Ü. and Anten, N.P.R.), pp. 239-268. Springer, Dordrecht, Netherlands.

Höppner, F. and Menge-Hartmann, U. (2007) Yield and quality of fibre and oil of fourteen hemp cultivars in Northern Germany at two harvest dates. Landbauforschung Volkenrode, 57, 219-232.

Jones, H.G., 2013. Heat, mass and momentum transfer. In: Plants and microclimate: $a$ quantitative approach to environmental plant physiology (ed, Jones, H.G.), pp. 47-67. Cambridge university press, UK.

Keating, B.A., Carberry, P.S., Hammer, G.L. et al. (2003) An overview of APSIM, a model designed for farming systems simulation. European Journal of Agronomy, 18, 267-288.

Khan, M.M.R., Chen, Y., Laguë, C. et al. (2010) Compressive properties of hemp (Cannabis sativa L.) stalks. Biosystems Engineering, 106, 315-323.

Khan, M.S., Yin, X., Van der Putten, P.E.L. et al. (2014) An ecophysiological model analysis of yield differences within a set of contrasting cultivars and an F1 segregating population of potato (Solanum tuberosum L.) grown under diverse environments. Ecological Modelling, 290, 146-154.

Legros, S., Picault, S. and Cerruti, N. (2013) Factors affecting the yield of industrial hemp experimental results from France. In: Hemp: industrial production and uses (eds Allegret, S., Bouloc, P. and Arnaud, L.), pp. 72-97. CPi Group Ltd, Croydon, UK.

Lemaire, G., Jeuffroy, M.H. and Gastal, F. (2008) Diagnosis tool for plant and crop N status in vegetative stage: Theory and practices for crop N management. European Journal of Agronomy, 28, 614-624.

Linger, P., Müssig, J., Fischer, H. et al. (2002) Industrial hemp (Cannabis sativa L.) growing on heavy metal contaminated soil: fibre quality and phytoremediation potential. Industrial Crops and Products, 16, 33-42. 
Lisson, S.N., Mendham, N.J. and Carberry, P.S. (2000a) Development of a hemp (Cannabis sativa L.) simulation model 1 . General introduction and the effect of temperature on the pre-emergent development of hemp. Australian Journal of Experimental Agriculture, 40, 405-411.

Lisson, S.N., Mendham, N.J. and Carberry, P.S. (2000b) Development of a hemp (Cannabis sativa L.) simulation model 2. The flowering response of two hemp cultivars to photoperiod. Australian Journal of Experimental Agriculture, 40, 413-417.

Lisson, S.N., Mendham, N.J. and Carberry, P.S. (2000c) Development of a hemp (Cannabis sativa $L$.) simulation model 3. The effect of plant density on leaf appearance, expansion and senescence. Australian Journal of Experimental Agriculture, 40, 419-423.

Lisson, S.N., Mendham, N.J. and Carberry, P.S. (2000d) Development of a hemp, (Cannabis sativa L.) simulation model 4. Model description and validation. Australian Journal of Experimental Agriculture, 40, 425-432.

Mcpartland, J.M., Clarke, R.C. and Watson, D.P. (2000) Hemp diseases and pests: management and biological control: an advanced treatise, CABI Publishing, Wallingford, UK.

Müller, J., Behrens, T. and Diepenbrock, W. (2005) Measurement and modelling of canopy gas exchange of oilseed rape. Agricultural and Forest Meteorology, 132, 181-200.

Müller, J., Eschenröder, A. and Diepenbrock W. (2009) Through-flow chamber $\mathrm{CO}_{2} / \mathrm{H}_{2} \mathrm{O}$ canopy gas exchange system - Construction, microclimate, errors, and measurements in a barley (Hordeum vulgare L.) field. Agricultural and Forest Meteorology, 149, 214229.

Poni, S., Magnanini, E. and Rebucci B. (1997) An automated chamber system for measurements of whole-vine gas exchange. HortScience, 32, 64-67.

Poni, S., Merli, M.C., Magnanini, E. et al. (2014) An improved multichamber gas exchange system for determining whole canopy water use efficiency in the grapevine. American Journal of Enology and Viticulture, 65, 268-276.

Prudent, M., Lecomte, A., Bouchet, J.P. et al. (2010) Combining ecophysiological modelling and quantitative trait locus analysis to identify key elementary processes underlying tomato fruit sugar concentration, Journal of Experimental Botany, 62, 907-919.

Struik, P.C., Amaducci, S., Bullard, M.J. et al. (2000) Agronomy of fibre hemp (Cannabis sativa L.) in Europe. Industrial Crops and Products, 11, 107-118.

Van der Werf, H.M.G., Van Geel and W., Wijlhuizen, M. (1995) Agronomic research on hemp (Cannabis sativa L.) in the Netherlands, 1987-1993. Journal of the International Hemp Association, 2, 14-17.

Van der Werf, H.M.G., Haasken, H.J. and Wijlhuizen, M. (1994) The effect of daylength on yield and quality of fibre hemp (Cannabis sativa L.). European Journal of Agronomy, $3,117-123$.

Van der Werf, H.M.G., Mathijssen, E.W.J.M. and Haverkort, A.J. (1996) The potential of hemp (Cannabis sativa L.) for sustainable fibre production: A crop physiological appraisal. Annals of Applied Biology, 129, 109-123.

Vera, C.L., Malhi, S.S., Phelps, S.M. et al. (2010) N, P, and S fertilization effects on industrial 
hemp in Saskatchewan. Canadian Journal of Plant Science, 90, 179-184.

Westerhuis, W., Amaducci, S., Struik, P.C. et al. (2009) Sowing density and harvest time affect fibre content in hemp (Cannabis sativa L.) through their effects on stem weight. Annals of Applied Biology, 155, 225-244.

Xiaoping, X., Jianguo, W., Zhiwei, W et al. (2007) Determination of a critical dilution curve for nitrogen concentration in cotton. Journal of Plant Nutrition and Soil Science, 170, 811-817.

Yin, X. and Van Laar, H.H. (2005) Crop systems dynamics: an ecophysiological simulation model for genotype-by-environment interactions, Wageningen, Wageningen Academic, the Netherlands.

Yin, X. and Struik, P.C. (2010) Modelling the crop: From system dynamics to systems biology. Journal of Experimental Botany, 61, 2171-2183.

Yin, X. and Struik, P.C., 2017. Can increased leaf photosynthesis be converted into higher crop mass production? A simulation study for rice using the crop model GECROS. Journal of Experimental Botany, 68, 2345-2360.

Yin X., Struik P.C., Romero P. et al. (2009) Using combined measurements of gas exchange and chlorophyll fluorescence to estimate parameters of a biochemical $\mathrm{C}_{3}$ photosynthesis model: a critical appraisal and a new integrated approach applied to leaves in a wheat (Triticum aestivum) canopy. Plant Cell \& Environment, 32, 448-464. 


\section{Summary}

Hemp (Cannabis sativa L.) is a sustainable high-yielding crop that delivers valuable fibres, seeds and psychoactive substances. Traditionally cultivated mainly for the production of textiles and ropes, hemp is now considered as an ideal crop to produce innovative biomaterials. In recent years, the innovative uses of hemp materials and the increasing concern on sustainable development of the agricultural bio-economy have encouraged and sustained the development of the hemp industry that supports the cultivation, processing and use of hemp and its products, particularly in Europe. However, there is a lack of novel information to support this industry as hemp production declined in the last century and was displaced largely by cotton and synthetic fibres; consequently, hemp has not been subject to the intensive research that has driven great improvements in major crops in the last 50 years. With the aim to support the resurging hemp production, in this thesis, comprehensive studies were defined to assess the effects of genotype, environment and management on the performance of hemp crops, and to elucidate the physiological basis of hemp's high resource-use efficiencies (RUE).

Chapter 1 provides a brief introduction to the hemp plant and the state of knowledge on hemp agronomy and photosynthesis physiology. Knowledge gaps on the effects of genotype, environment, and management on hemp production and on hemp's RUE are identified thereof.

In the following four chapters (Chapters 2-5) research results gained in the experimental studies are presented. Chapters 2 and 3 present investigations to improve our understanding of hemp agronomy for dual-purpose cultivation (fibre + seeds) that is a common practice in Europe, driven by the shift of a rapidly expanding market for hemp seeds coupled with lower quality fibre requirements for innovative biomaterials. Chapters 4 and 5 present experimental research, combined with modelling analyses, to improve our understanding of hemp photosynthesis physiology. In the final chapter (Chapter 6) the overall achievement of this study is discussed.

Chapter 2 presents the production of stems and seeds of hemp in relation to genotype and environment. The variation of stem and seed yield among cultivars was mainly determined by the difference in flowering time. In the later flowering cultivars stem yield was high but seed yield was constrained. Thus, a cultivar that gives a long vegetative phase while leaving enough time for seed growth is preferable for dual-purpose hemp production. The flowering time of hemp is under control of the genotype $\times$ environment interactions that can be accurately simulated using mathematical models, with genotype-specific parameters, temperature and 
photoperiod as inputs. Such a model could, therefore, facilitate cultivar choice based on historical meteorological information and genotype-specific parameter values. In addition to the time of flowering, considerable variation among cultivars in sex morphology and stem fibre content were observed. A monoecious cultivar with a high bark fibre content is preferable for dual-purpose production because bark fibre is considered more valuable than wood core and the male plants of dioecious cultivar senesce soon after flowering resulting in biomass loss and heterogeneous quality.

Chapter 3 presents the stem and seed productivities of hemp in response to two important management practices: planting density and nitrogen fertilization. The effects of these two factors on hemp stem and seed yields neither interacted with each other nor with the cultivar effect. Changing planting density over a wide range had limited effect on both stem and seed yields while plant height and stem diameter decreased with increasing population density. The optimum planting density for dual-purpose hemp cultivation could be set at 90-150 plants $\mathrm{m}^{-2}$. Nitrogen demand of hemp crop during growth was analysed and a critical nitrogen ( $\left.N_{\text {critical }}\right)$ dilution curve was determined thereof. The $N_{\text {critical }}$ of hemp is comparable with that of linseed but indicates a lower nitrogen requirement than found for other $\mathrm{C}_{3}$ crops, such as rice and cotton, for producing the same amount of biomass. Nitrogen fertilization rate at $60 \mathrm{~kg} \mathrm{~N} \mathrm{ha}^{-1}$ is generally sufficient in the European conditions whereas further optimization of nitrogen fertilization requires accurate assessment of the crop nitrogen status.

The responses of hemp leaf photosynthesis to nitrogen content and environmental factors were quantified in Chapter 4. Based on such data, a biochemical model for $\mathrm{C}_{3}$ leaf photosynthesis was parameterized and validated for hemp. It was shown that the effect of leaf nitrogen and temperature on all the photosynthetic parameters of hemp were consistent at different development stages and growth environments, except for the effect on the efficiency of converting incident irradiance into linear electron transport under limiting light $\left(\kappa_{2} \mathrm{LL}\right)$. The value of $\kappa_{2} \mathrm{LL}$ was higher for plants grown in the glasshouse than for those grown outdoors. Model analysis with the photosynthetic parameters obtained in this study and those in literature showed that hemp has higher leaf photosynthesis rate than cotton and kenaf at a low nitrogen (i.e. at a specific nitrogen content of less than $2.0 \mathrm{~g} \mathrm{~N} \mathrm{~m}^{-2}$ ).

Chapter 5 investigates the effect of nitrogen and water supply on the use efficiencies of these resources at canopy level. Canopy photosynthesis and transpiration were assessed using a multichamber canopy gas exchange system. Canopy chambers differed significantly in microclimate 
and therefore observations were corrected for such differences using a validated physiological canopy model. After correcting for the differences in microclimate, the $W U E_{\mathrm{c}}$ (defined as the ratio of gross canopy photosynthesis to canopy transpiration) and the $N U E_{\mathrm{c}}$ (the ratio of the gross canopy photosynthesis to canopy leaf-N content) depended on the levels of water and nitrogen supply. Water stress resulted in an increase in $W U E_{\mathrm{c}}$ but a decrase in $N U E_{\mathrm{c}}$. The $W U E_{\mathrm{c}}$ and the $N U E_{\mathrm{c}}$ were lower at higher nitrogen level; this effect was strictly related to the effect of nitrogen supply on canopy size or leaf area index ( $L A I)$. The effect of short-term water stress was reflected in the stomatal regulation, whereas the effect of long-term water stress was complicated. In addition to the stomatal effect, long-term water stress enhanced leaf senescence, reduced $L A I$ but retained total canopy nitrogen content, and therefore, resulted in a further increase in $W U E_{\mathrm{c}}$.

Chapter 6 broadens the discussion of the preceding chapters to the overall achievements of this thesis. I highlight the advances made in hemp agronomy and in photosynthesis physiology, and critically assess the environmental effects of hemp cultivation. Hemp has a high-yielding potential while its cultivation is environmentally friendly. Therefore, it can be concluded that hemp can be grown as a sustainable crop over a wide range of climatic and agronomic conditions. 



\section{Acknowledgements}

I would like to thank all the people who inspired, encouraged and helped me during this memorable PhD journey. Without them, I would never have finished this thesis.

I would like to express my deepest gratitude to the excellent multidisciplinary supervisory team consisting of Prof. Paul C. Struik [Centre for Crop Systems Analysis, Wageningen University \& Research, Wageningen, the Netherlands (CSA)], Dr Xinyou Yin (CSA) and Dr Stefano Amaducci [(Università Cattolica del Sacro Cuore, Piacenza, Italy (UCSC)]. The team supported me in all the aspects allowing me to complete this challenging work. Paul, thank you for your excellence guidance during my PhD study and your energetic and efficient support of my work. Working with you, I learned that I must look after every single detail; to be precise and concrete. Xinyou, thank you for your unconditional help throughout the whole academic training process: literature review - hypothesis formulation - experimental design - data collection - data analysis and interpreting - writing and publishing. You are very patient, and your office was always open to me for discussion. I could not have wished for a better daily supervisor. Stefano, thank you for bringing me to the unforgettable $\mathrm{PhD}$ journey. I am very grateful for your patience in spending many hours in guiding me to articulate clear definitions and questions.

I would like to express my gratitude to Prof. Weihong Luo [Nanjing Agricultural University, Nanjing, China (NAU)], Dr Tjeerd Jan Stomph (CSA) and Dr Francesca O'Kane although they were not directly included in my supervisory team. Weihong, my supervisor during my master study at NAU, thank you for encouraging and supporting me to pursue a $\mathrm{PhD}$ abroad. Tjeerd Jan, thank you for your constructive contributions to the proposal development, and for your valuable comments on my manuscripts. Francesca, thank you for your kind help whenever I needed it. Without you, I would never have passed my English exam and would not have had a smooth stay in Italy and in the Netherlands.

I am very grateful to those people whom provided me great help in arranging the experimental equipment, field management and data collection. Prof. Adriano Marocco (UCSC), Prof. Vincenzo Tabaglio (UCSC) and Mr. Remigio Calligaro (UCSC), your kind help made it possible for me to run the field experiments smoothly. Dr Gianpaolo Grassi, Mr. Gianmaria Magagnini, Ms. Claire Thouminot, Ms. Marie Bjelková, Mr. Tālis Laizāns and Mr. Eibert Tigchelaar, thanks for your excellent co-operation within the framework of Multihemp. 
Mr. Andrea Maffini, Mr. Leonardo Poni, Mr. Stefano Pinna, Ms. Rebecca Sudati, Mr. Francesco Saraconi and Ms. Raffaella Santagata, thanks for doing your master studies associated with my project. Working with you, I learnt to change my position from a student to a supervisor and to change the way of behaviour and thinking. Most importantly, I learnt from you so much on Italian language and culture.

I would like to thank all the people whom made me have an enjoyable time in Italy. Alessandra Fracasso, Andrea Ferrarini, Paolo Serra, Salvatore Musio, Davide Calzolari, Carlo Chimento, Murjal Chiazzese, Andrea Fiorini, Alessia Perego, Maria Almagro, Luca Poletti, thanks for making me feel at home in Italy. It's great to have you around. I wish you a lot of success.

I will not forget to thank all my friends and colleagues in Wageningen. My special thanks to the excellent secretaries and financial officer in CSA: Ms. Sjanie van Wetten, Ms. Nicole Wolffensperger and Mr. Alex-Jan de Leeuw. You are very professional and efficient. Thank for your assistance whenever I asked for it. I would also like to express my appreciation to all other CSA colleagues, especially to Prof. Niels Anten, Dr Steven Driever, Dr Alejandro Morales Sierra, Dr Jochem Evers, Dr Lammert Bastiaans, Dr Bob Douma, and Dr Wopke van der Werf. Thank you all for your nice tips during coffee time and great comments and suggestions during lunch seminars. I would also like to thank many friends and $\mathrm{PhD}$ fellows in Wageningen: Li Huayi, Zhang Ningyi, Wang Zhaojun, Li Guohua, Wang Jingmeng, Zhang Peiyu, Wu Liansun, Zhang Hao, Zou Yi, Cong Wenfeng, Chen Bin, Zhu Junqi, Yu Yang, Gou Fang, Herman Berghuijs, Ouyang Wenjing, Luuk van Dijk, Gu Shenghao, Marcelo Labra Fernandez, Martin Sikma, Giovani Theisen, Dennis Tippe, Ioannis Baltzakis, Niteen Kadam, Shi Wanju, Ali Elhakeem, Uta Priegnitz, Jorad de Vries, Franca Bongers, Ambra Tosto, Cai Chuang, Tan Meixiu, Wei Huanghe, Meng Tianyao, Wang Yuyun, Yan Zenzen and everyone that I shamefully forgot to mention. I enjoyed a lot the time with you during the scientific seminars, $\mathrm{PhD}$ meetings, lunch/dinner discussions, Thursday drinks, outdoor activities, etc. Wenjing and Luuk, thank you very much for your willingness to be my paranymphs and your great help in preparing my public defence.

Last but by no means least, I would like to express my deepest gratitude to my family. Thank you for encouraging and supporting me to pursue my career abroad. My special thanks to my wife, Wang Ting, whom gave me lots of mental support to get me out of hardship. 


\section{PE\&RC Training and Education \\ Statement}

With the training and education activities listed below the $\mathrm{PhD}$ candidate has complied with the requirements set by the C.T. de Wit Graduate School for Production Ecology and Resource Conservation (PE\&RC) which

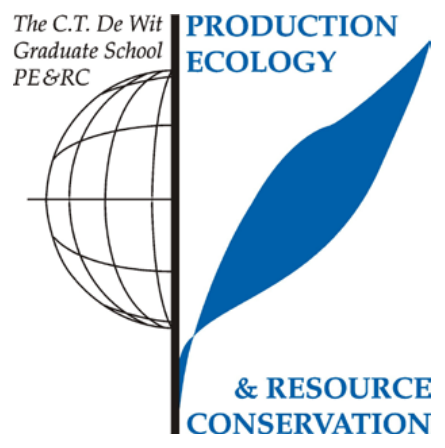
comprises of a minimum total of 32 ECTS (= 22 weeks of activities)

\section{Review of literature (6 ECTS)}

- Modelling the effect of agronomic practices on hemp production

\section{Writing of project proposal (4.5 ECTS)}

- Experimentation and crop modelling to develop strategies for optimisation of cultivation and breeding in hemp

\section{Post-graduate courses (3 ECTS)}

- Measuring the photosynthetic phenome; PE\&RC (2014)

- Lignocellulosic crops as feedstock for value added bioproducts and bioenergy; IBFC, China (2015)

- Fibre quality workshop for young researchers; Université de Lille, France (2016)

- Long fibre technical meeting; Linificio, Italy (2017)

\section{Laboratory training and working visits (3.1 ECTS)}

- Assessment of hemp biomass yields; CREA, Italy (2013)

- Hemp breeding; YAAS, China (2015)

\section{Deficiency, refresh, brush-up courses (1.5 ECTS)}

- Basic statistics; PE\&RC (2014)

\section{Competence strengthening / skills courses (2.1 ECTS)}

- Information literacy including EndNote introduction (ILP); WGS (2013) 
- Data management; WGS (2014)

- The essentials of writing and presenting a scientific paper (WPRP); WGS (2016)

\section{PE\&RC Annual meetings, seminars and the PE\&RC weekend (1.5 ECTS)}

- First year's weekend; PE\&RC (2013)

- Last year's weekend; PE\&RC (2017)

\section{Discussion groups / local seminars / other scientific meetings (5.9 ECTS)}

- Twinning event of Fibra project; Wageningen (2013)

- First annual meeting of multipurpose crops for industrial bio-products and biomass; Wageningen (2013)

- CSA Photosynthesis meetings (2013-2017)

- Second annual meeting of multipurpose crops for industrial bio-products and biomass; oral presentation; UK (2015)

- Third annual meeting of multipurpose crops for industrial bio-products and biomass; oral presentation; France (2016)

\section{International symposia, workshops and conferences (3.5 ECTS)}

- Final annual meeting of multipurpose crops for industrial bio-products and biomass; oral presentation; Italy (2017)

- $2^{\text {nd }}$ Agriculture and climate change conference; oral presentation; Spain (2017)

\section{Supervision of MSc students (12 ECTS)}

- Comparing hemp cultivars for dual-purpose production

- The effect of planting density and nitrogen fertilisation on hemp yield and yield components

- The effect of planting density and nitrogen fertilisation on hemp canopy development

- Analysis of hemp nitrogen demand 


\section{Curriculum vitae}

Kailei Tang was born in Yunnan province, China, on 18 August 1987. From 2006 to 2010, he studied Agronomy at Nanjing Agricultural University, China (NAU), for a BSc degree. After his Bachelor studies, he continued his study on Agronomy at NAU and obtained a MSc degree in 2013. In the same year, he was granted a four-year scholarship from Università Cattolica del Sacro Cuore, Italy, and enrolled to the $\mathrm{PhD}$ programme of Wageningen University in the Centre for Crop Systems Analysis. During his PhD study, he worked on "Experimentation and crop modelling to develop strategies for optimisation of cultivation and breeding in hemp". 


\section{Funding}

The research described in this thesis was funded by MultiHemp (http://multihemp.eu), a programme within the European Union's Seventh Framework Programme for research, technological development and demonstration under Grant agreement $n^{\circ} 311849$. 



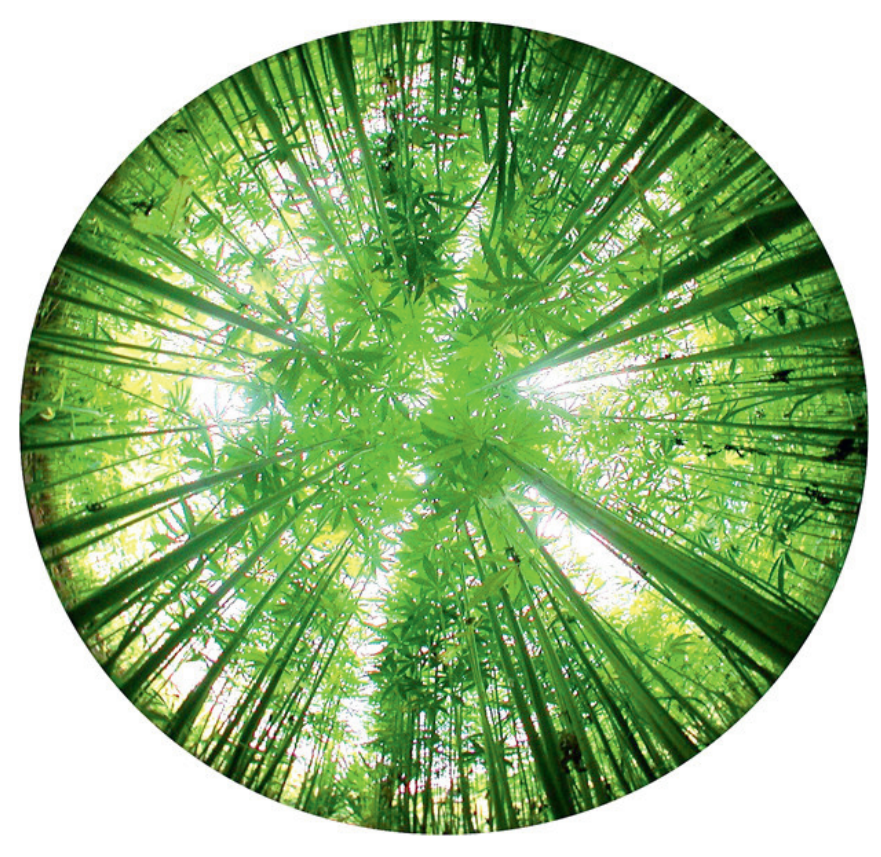

